Murilo da Silva

\title{
IMPLEMENTAÇÃO DE UM LOCALIZADOR DE FALTAS HÍBRIDO PARA LINHAS DE TRANSMISSÃO COM TRÊS TERMINAIS BASEADO NA TRANSFORMADA WAVELET
}

Tese de doutorado apresentada à Escola de Engenharia de São Carlos, Universidade de São Paulo, como parte dos requisitos para obtenção do Título de Doutor em Engenharia Elétrica.

Orientador: Prof. Tit. Denis Vinicius Coury Co-orientador: Prof. Dr. Mário Oleskovicz

São Carlos

2008 
Candidato: Engenheiro MURILO DA SILVA

Tese defendida e julgada em 15/02/2008 perante a Comissão Julgadora:

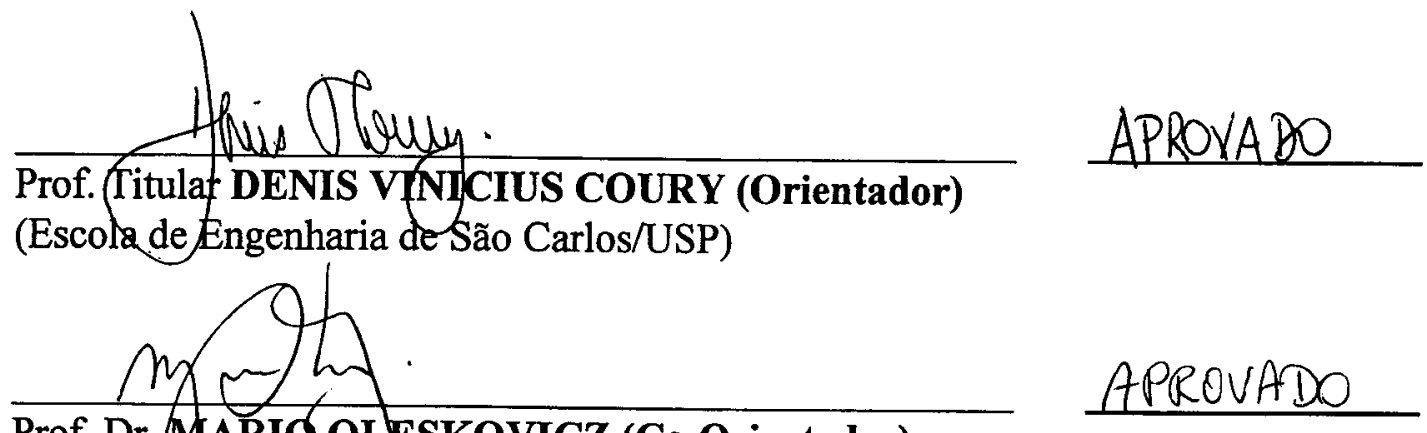

Prof. Dr.MARId OLESKOVICZ (Co-Orientador)

(Escola de/Engenhariatie São Carlos/USP)<smiles>CC1CC1C(=O)C(C)C1CCC1</smiles>

Prof. Dr. LUIZ CARLOS PEREIRA DA SILVA

(Universidade Estadual de Campinas/UNICAMP)

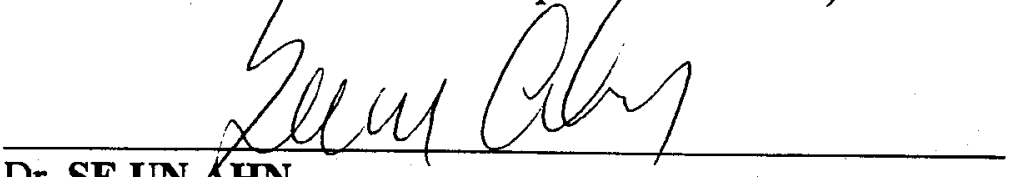

Dr. SE UN AHN

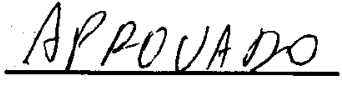

(Companhia Paulista de Força e Luz/CPFL)

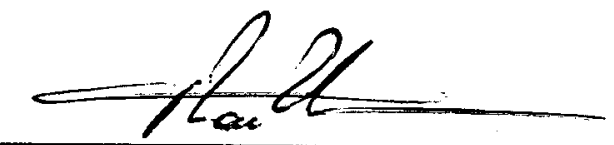

ArRouAX

Prof. Dr. THAIR IBRAHIM ABDEL HAMID MUSTAFA

(Fundação Universidade Regional de Blumenau/FURB)

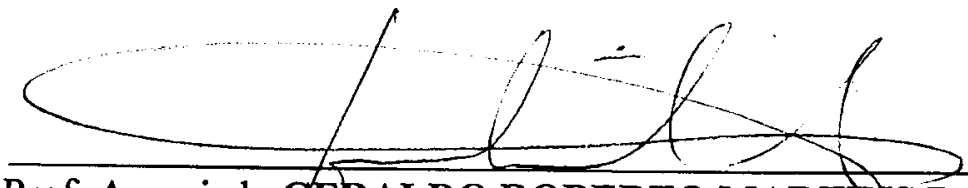

Prof. Associado GERALDO ROBERTO MARTIXs DA COSTA

Coordenador do Plograma de Pós-Graduação em Engenharia Elétrica e Presidente da Comissão de Pós-Graduação 

Aos meus pais, Dorival e Maria e, minha irmã Patrícia por sempre acreditarem e investirem em mim. 



\section{AGRADECIMENTOS}

Em primeiro lugar a DEUS, pelo ontem, pelo hoje e pelo amanhã, pois sem ELE nada seria possível realizar.

À minha família, meu pai Dorival, minha mãe Maria, minha irmã Patrícia, meu cunhado André, minhas sobrinhas Thais e Isabela pelo amor, pelo carinho, por sempre acreditarem em mim e nunca deixarem de me incentivar. Aos meus familiares, em especial a minha tia Magda e meu primo Julio Cezar pelo apoio e incentivo.

Em especial ao Prof. ${ }^{o}$ Titular Denis Vinicius Coury, pela oportunidade, pelo apoio, confiança, amizade, conselhos, momentos de descontração e por sua sábia e segura orientação no desenvolvimento deste trabalho.

Ao Prof..$^{\circ}$ Doutor Mário Oleskovicz, pela amizade, pela paciência, atenção, prontidão, conselhos e por seu imprescindível auxílio no desenvolvimento deste trabalho.

A Karla, pela amizade, apoio, paciência e conselhos nos momentos difíceis.

A todos os meus amigos e amigas que tive a honra de conhecer durante a minha caminhada pela EESC-UP, em especial aos integrantes do LSEE, pela ajuda nos momentos de trabalho sério, assim como pelos momentos de descontração e alegria.

Aos amigos que estimo demais, Odilon e Silvio, com os quais compartilhei morada, momentos alegres, tristes, dificuldades e vitórias durante esta jornada, assim como, aos meus amigos(as), Daniel, Marco Aurélio, Julia e Eugenia pelo apoio e ajuda.

Aos meus amigos de Barretos que acompanharam toda minha trajetória e aos meus amigos da CPFL, em especial ao Alexandre, Reginaldo e Walter, como também ao André Maschetto e Ricardo Torrezan pelo incentivo e apoio para o término desta.

Ao Departamento de Engenharia Elétrica e, aos professores e funcionários que sempre estiveram dispostos a colaborar, em especial a Marisa, Denise, Jussara e ao Zé.

A todos aqueles que direta ou indiretamente contribuíram para realização deste trabalho.

À CAPES - Coordenação de Aperfeiçoamento de Pessoal de Nível Superior, pelo auxílio financeiro fornecido durante um certo período da realização deste trabalho, sem o qual o mesmo não seria possível. 
Você obtém o melhor esforço dos outros não por acender uma fogueira so6 seus pés, mas por atear um incêndio dentro deles.

Bo6 $\mathcal{N}$ elson. 


\section{RESUMO}

SILVA, M. Implementação de um localizador de faltas híbrido para linhas de transmissão com três terminais baseado na Transformada Wavelet. 2008. 236p. Tese (Doutorado) - Escola de Engenharia de São Carlos, Universidade de São Paulo, São Carlos, 2008.

Este trabalho apresenta o estudo e o desenvolvimento de um algoritmo híbrido para detecção, classificação e localização de faltas em sistemas com três terminais utilizando como principal ferramenta a Transformada Wavelet (TW) em suas versões Discreta (TWD) e Estacionária (TWE). O algoritmo é dito híbrido, pois alia duas metodologias para localizar a falta. A primeira baseada na análise de componentes de alta freqüência (ondas viajantes) e a segunda, baseada na extração dos componentes fundamentais para o cálculo da impedância aparente. A metodologia proposta foi concebida de maneira a trabalhar com dados sincronizados dos três terminais ou apenas dados locais para estimar a localização da falta. O localizador híbrido escolhe automaticamente qual a melhor técnica de localização ser utilizada para alcançar uma localização confiável e precisa. Deste modo, um método pode suprir as dificuldades do outro, ou, no mínimo, fornecer mais informações para que, junto ao conhecimento do operador, uma localização próxima da ótima possa ser alcançada. Com o objetivo de testar e validar a aplicabilidade do algoritmo de localização de faltas híbrido para linhas com três terminais, utilizou-se de dados de sinais faltosos obtidos através de simulações do software ATP (Altenative Transients Program), levando-se em conta a variação de diversos parâmetros que poderiam influenciar o desempenho do algoritmo proposto. Os resultados alcançados pelo algoritmo frente às situações avaliadas são bastante animadores, apontando a uma promissora aplicabilidade do mesmo.

Palavras chave: Localizador de faltas híbrido, ondas viajantes, componentes fundamentais, Transformada Wavelet, Transformada Wavelet Discreta, Transformada Wavelet Estacionária, linhas de transmissão com três terminais. 



\begin{abstract}
SILVA, M. Implementation of a hybrid fault location for tree-terminals transmission lines based in Wavelet Transform. 2008. 236p. Ph.D Thesis. School of Engineering of São Carlos, University of São Paulo, São Carlos, 2008.
\end{abstract}

This work presents a study and development of a hybrid algorithm for fault detection, classification and location in tree terminal lines based on Wavelet Transform (WT). It will be presented in two versions: Discrete Wavelet Transform (DWT) and Stationary Wavelet Transform (SWT). The algorithm is called hybrid because it uses two fault location methodologies: one based on fundamental components and other based on traveling waves. The proposed methodology works either with synchronized tree terminal data or only local data. The hybrid fault locator chooses automatically which location technique to be used in order to reach a reliable and accurate fault location. In this manner, this technique can avoid some difficulties present in other techniques, aiming to reach an optimized fault location. The proposed hybrid fault location was evaluated by simulated fault signals obtained by Alternative Transient Program (ATP). In the tests, several parameters, which would influence the performance of the hybrid algorithm, were varied, such as: fault inception angle, fault resistance, fault type, etc. The results obtained by the proposed methodology are very encouraging and it points out to a very promising application.

Key-works: Hybrid fault location, traveling waves, fundamental component, Wavelet Transform, Discrete Wavelet Transform, Stationary Wavelet Transform and Treeterminals transmission lines. 



\section{LISTA DE FIGURAS}

FIGURA 1 - Distribuição de faltas em um sistema de $500 \mathrm{kV}$, para um periodo de dez anos, com a ocorrência de noventa e nove faltas. ............................ 1

FIGURA 2 - Exemplo de linha com parâmetros distribuídos...................................... 34

FIGURA 3 - Diagrama Lattice representando as sucessivas reflexões de um sinal

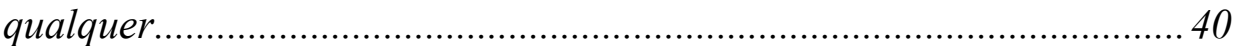

FIGURA 4 - Escalamento de uma função Wavelet ........................................................ 45

FIGURA 5 - Translação aplicada a uma Wavelet ....................................................... 45

FIGURA 6 - Processo de filtragem de um sinal no primeiro nível................................. 47

FIGURA 7 - Processo de diminuição do número de amostras do sinal

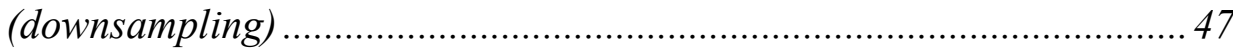

FIGURA 8 - Exemplo de filtragem com downsampling de um sinal senoidal ruidoso. 48

FIGURA 9 - Processo de decomposição de um sinal. 49

FIGURA 10 - Exemplo da AMR: sinal original. A1 e A2 - primeira e segunda aproximação; D1 e D2 - primeiro e segundo detalhe.

FIGURA 11 - Processo de reconstrução de um sinal filtrado. 50

FIGURA 12 - Processo de aumento do número de amostras para reconstrução de um sinal

FIGURA 13 - Processos de decomposição e reconstrução de um sinal.

FIGURA 14 - Reconstrução de um sinal a partir de seus coeficientes de aproximação

FIGURA 15 - Reconstrução do primeiro nivel de detalhe do sinal. 52

FIGURA 16 - Diferentes formas para se reconstruir o sinal a partir de seus coeficientes 53

FIGURA 17 - Processo de decomposição em nível 1 via TWE. 57

FIGURA 18 - Processo de decomposição em nível j via TWE. 58

FIGURA 19 - Sinais de detalhe em nível 5 obtidos utilizando a TWD e TWE. 59

FIGURA 20 - Áreas de aplicação da TW em sistemas elétricos de potência. 60

FIGURA 21 - Representação do sistema elétrico analisado 61

FIGURA 22 - Situações de faltas sobre o sistema 62 


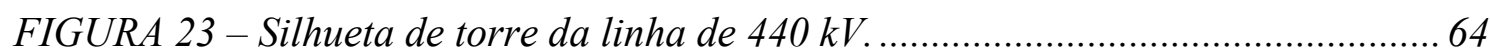

FIGURA 24 - Transposição de uma linha de transmissão ............................................ 65

FIGURA 25 - Representação de um comprimento $\Delta x$ de uma linha de transmissão por parâmetros distribuídos............................................................. 65

FIGURA 26-Rotina Line Constant para o sistema simples horizontal tipo VVV ......... 66

FIGURA 27 - Rotina JMarti para o sistema simples horizontal tipo VVV ..................... 68

FIGURA 28 - Modelo do TPC inicialmente empregado ................................................... 69

FIGURA 29 - Modelo completo do TPC ........................................................................ 70

FIGURA 30 - Formas de onda da tensão primária para uma falta fase-fase-terra aplicada a $75 \mathrm{~km}$ da barra A.......................................................... 70

FIGURA 31 - Formas de onda da tensão de saída do TPC para uma falta fasefase-terra aplicada a $75 \mathrm{~km}$ da barra A............................................. 71

FIGURA 32 - Modelo do transformador monofásico empregado - ATP....................... 72

FIGURA 33 - Detalhe das conexões dos enrolamentos................................................. 72

FIGURA 34 - Curva de Saturação (VxI) de um TC 10B400 - 3000:5A - 460 kV ......... 73

FIGURA 35 - Característica do filtro passa baixa ideal. ............................................... 74

FIGURA 36 - Resposta em freqüencia de um filtro passa-baixa Butterworth............... 75

FIGURA 37 - Parâmetro para o projeto de filtros passa baixa. .................................... 75

FIGURA 38 - Sinais de tensão e corrente, originais e filtrados pelo filtro passabaixa Butterworth de $2^{a}$ ordem............................................................ 76

FIGURA 39 - Configuração do sistema com circuito duplo vertical ............................. 80

FIGURA 40 - Silhueta da torre de um circuito de transmissão duplo vertical de $440 \mathrm{kV}$.

FIGURA 41 - Arquivo de entrada para a rotina Line Constant referente ao circuito duplo.....

FIGURA 42 - Sinais de tensão e corrente em operação normal, medidos nos terminais do circuito duplo de transmissão proposto.

FIGURA 43 - Sistema Elétrico com três barras e diagrama Lattice. 87

FIGURA 44 - Fluxograma do algoritmo de localização de faltas híbrido (LFHTW 1.01)

FIGURA 45 - Resultados alcançados pelo algoritmo de ondas viajantes utilizando dados locais frente à variação do número de bits do CAD. 
FIGURA 46 - Resultados alcançados pelo algoritmo de ondas viajantes utilizando dados dos três terminais frente à variação do número de bits do $C A D$

FIGURA 47 - Resultados alcançados pelo algoritmo baseando em freqüência fundamental utilizando dados dos três terminais frente à variação do número de bits do CAD.

FIGURA 48 - Resultados utilizando o nível de ruído para definição do método de localização - Faltas fase-terra sobre o ramo 1 com ângulo de $90^{\circ} e$ resistência de 0 ohm.

FIGURA 49 - Resultados utilizando o nível de ruído para definição do método de localização - Faltas fase-terra sobre o ramo 2 com ângulo de $0^{\circ} \mathrm{e}$ resistência de $100 \mathrm{ohm}$.

FIGURA 50 - Janelamento do processo de detecção. 99

FIGURA 51 - Processo de detecção - sinais de detalhe 2 (D2) e 7 (D7) referentes às suas respectivas janelas de detecção (Figura 50) 99

FIGURA 52 - Sub-rotina para classificação do tipo da falta 101

FIGURA 53 - Classificação dos diversos tipos de faltas. 102

FIGURA 54 - Identificação da chegada da primeira onda via diagrama Lattice. 104

FIGURA 55 - Exemplo de detecção dos picos iniciais . 105

FIGURA 56 - Exemplo preliminar do relatório de eventos 108

FIGURA 57 - Fluxograma referente às etapas para determinação dos tempos $t_{1} e$ $t_{2}$.

FIGURA 58 - Diagrama de reflexão para falta fase-terra: (a) falta na primeira metade do ramo AP e (b) falta na segunda metade do ramo AP

FIGURA 59 - Modelo do sistema sob falta no ramo 1 (AP).....

FIGURA 60 - Sinais de detalhe 2 do modo 1 das correntes nos três terminais para uma falta fase A-terra a $70 \mathrm{~km}$ da barra A, com resistência de falta de 100 ohms e ângulo de incidência de $0^{\circ}$.

FIGURA 61 - Sinais de detalhe 2 do modo 1 das tensões nos três terminais para uma falta fase A-terra a $70 \mathrm{~km}$ da barra A, com resistência de falta de 100 ohms e ângulo de incidência de $0^{\circ}$.

FIGURA 62 - Resultados referentes à aplicação de faltas AT em diferentes localizações do ramo 1, com resistência de falta de 0 ohm e ângulo de incidência de $90^{\circ}$ - Dados 3 terminais. 
FIGURA 63 - Resultados referentes à aplicação de faltas ABT em diferentes localizações do ramo 1, com resistência de falta de $0 \mathrm{ohm}$ e ângulo de incidência de $90^{\circ}$ - Dados 3 terminais.

FIGURA 64 - Resultados referentes à aplicação de faltas AB em diferentes localizações do ramo 1, com ângulo de incidência de $90^{\circ}$ - Dados 3 terminais.

FIGURA 65 - Resultados referentes à aplicação de faltas trifásicas em diferentes localizações do ramo 1, com ângulo de incidência de $90^{\circ}$ - Dados 3 terminais.

FIGURA 66 - Resultados referentes à aplicação de faltas AT em diferentes localizações do ramo 1, com resistência de falta de $0 \mathrm{ohm}$ e ângulo de incidência de $90^{\circ}$ - Dados Locais.

FIGURA 67 - Resultados referentes à aplicação de faltas ABT em diferentes localizações do ramo 1, com resistência de falta de 0 ohm e ângulo de incidência de $90^{\circ}$ - Dados locais.

FIGURA 68 - Resultados referentes à aplicação de faltas AB em diferentes localizações do ramo 1, com ângulo de incidência de $90^{\circ}$ - Dados locais.

FIGURA 69 - Resultados referentes à aplicação de faltas trifásicas em diferentes localizações do ramo 1, com ângulo de incidência de $90^{\circ}$ - Dados locais.

FIGURA 70 - Resultados obtidos com referência ao terminal A em relação ao terminal B, para faltas fase-fase aplicadas no ramo 1 -dados sincronizados. 128

FIGURA 71 - Resultados obtidos com referência ao terminal B em relação ao terminal A, para faltas fase-fase aplicadas no ramo 2 - dados sincronizados.

FIGURA 72 - Resultados obtidos com referência ao terminal C em relação ao terminal A, para faltas fase-fase aplicadas no ramo 3 - dados sincronizados.

FIGURA 73 - Resultados obtidos com referência ao terminal A, para faltas fasefase aplicadas no ramo 1 - dados locais.

FIGURA 74 - Resultados obtidos com referência ao terminal B, para faltas fasefase aplicadas no ramo 2 - dados locais. 
FIGURA 75 - Resultados obtidos com referência ao terminal C, para faltas fasefase aplicadas no ramo 3 - dados locais.

FIGURA 76 - Influência do ângulo incidência da falta sobre os sinais de corrente frente situações de faltas fase-fase (AB) aplicadas sobre o ramo 1 dados sincronizados.

FIGURA 77 - Influência do ângulo incidência da falta sobre os sinais de tensão frente situações de faltas fase-fase (AB) aplicadas sobre o ramo 1 dados sincronizados.

FIGURA 78 - Influência do ângulo incidência da falta sobre os sinais de corrente frente situações de faltas fase-fase (AB) aplicadas sobre o ramo 1 dados locais.

FIGURA 79 - Influência do ângulo incidência da falta sobre os sinais de tensão frente situações de faltas fase-fase (AB) aplicadas sobre o ramo 1 dados locais.

FIGURA 80 - Resultados médios referentes às situações de faltas fase-terra aplicadas sobre o ramo 3, com ângulo de incidência de $0^{\circ} e$ variação da resistência de falta em 0, 17, 30, 50 e $100 \mathrm{ohms}$

FIGURA 81 - Resultados médios referentes a situações de faltas fase-terra aplicadas sobre o ramo 3 com ângulo de incidência de $30^{\circ} e$ variação resistência de falta em 0, 17, 30, 50 e $100 \mathrm{ohms}$

FIGURA 82 - Resultados médios referentes a situações de faltas fase-terra aplicadas sobre o ramo 3 com ângulo de incidência de $90^{\circ} \mathrm{e}$ variação da resistência de falta em 0, 17, 30, 50 e 100 ohms.

FIGURA 83 - Resultados médios referentes a situações de faltas fase-terra aplicadas sobre o ramo 3, com ângulo de incidência de $0^{\circ} e$ variação da resistência de falta em 200, 400 e 800 ohms. 135

FIGURA 84 - Resultados médios referentes a situações de faltas fase-terra aplicadas sobre o ramo 3, com ângulo de incidência de $30^{\circ} \mathrm{e}$ variação da resistência de falta em 200, 400 e 800 ohms.

FIGURA 85 - Resultados médios referentes a situações de faltas fase-terra aplicadas sobre o ramo 3, com ângulo de incidência de $90^{\circ} e$ variação da resistência de falta em 200, 400 e 800 ohms..... 136 
FIGURA 86 - Resultados médios referentes a situações de faltas fase-fase-terra aplicadas sobre o ramo 3, com ângulo de incidência de $0^{\circ} e$ variação da resistência de falta em 200, 400 e 800 ohms.

FIGURA 87 - Resultados médios referentes à utilização dos sinais de tensão para situações de faltas fase-terra aplicadas sobre o ramo 3, com ângulo de incidência de $0^{\circ}$ e variação da resistência de falta em 0, 17, 30, 50 e 100 ohms.

FIGURA 88 - Resultados médios referentes à utilização dos sinais de tensão para situações de faltas fase-terra aplicadas sobre o ramo 3, com ângulo de incidência de $30^{\circ}$ e variação da resistência de falta em 0, 17, 30, 50 e 100 ohms.

FIGURA 89 - Resultados médios referentes à utilização dos sinais de tensão para situações de faltas fase-terra aplicadas sobre o ramo 3, com ângulo de incidência de $90^{\circ}$ e variação da resistência de falta em 0, 17, 30, 50 e 100 ohms.

FIGURA 90 - Resultados médios referentes à utilização dos sinais de tensão para situações de faltas fase-terra aplicadas sobre o ramo 3, com ângulo de incidência de $0^{\circ}$ e variação da resistência de falta em 200, 400 e 800 ohms.

FIGURA 91 - Resultados médios referentes à utilização dos sinais de tensão para situações de faltas fase-terra aplicadas sobre o ramo 3, com ângulo de incidência de $30^{\circ}$ e variação da resistência de falta em 200, 400 e 800 ohms.

FIGURA 92 - Resultados médios referentes à utilização dos sinais de tensão para situações de faltas fase-terra aplicadas sobre o ramo 3, com ângulo de incidência de $90^{\circ}$ e variação da resistência de falta em 200, 400 e 800 ohms.

FIGURA 93 - Resultados médios referentes à utilização dos sinais de tensão para situações de faltas fase-fase-terra aplicadas sobre o ramo 3, com ângulo de incidência de $0^{\circ}$ e variação da resistência de falta em 200, 400 e 800 ohms.

FIGURA 94 - Resultados médios referentes a situações de faltas fase-terra aplicadas sobre o ramo 3 com ângulo de incidência de $0^{\circ}$ e variação da resistência de falta em 0, 17, 30, 50 e 100 ohms-dados locais...... 140 
FIGURA 95 - Resultados médios referentes a situações de faltas fase-terra aplicadas sobre o ramo 3 com ângulo de incidência de $30^{\circ} e$ variação da resistência de falta em 0, 17, 30, 50 e 100 ohms-dados locais.

FIGURA 96 - Resultados médios referentes a situações de faltas fase-terra aplicadas sobre o ramo 3 com ângulo de incidência de $90^{\circ} e$ variação da resistência de falta em 0, 17, 30, 50 e 100 ohms-dados locais.

FIGURA 97 - Resultados médios referentes à utilização dos sinais de tensão para situações de faltas fase-terra aplicadas sobre o ramo 3, com ângulo de incidência de $0^{\circ}$ e variação da resistência de falta em 0, 17, 30, 50 e 100 ohms - dados locais.

FIGURA 98 - Resultados médios referentes à utilização dos sinais de tensão para situações de faltas fase-terra aplicadas sobre o ramo 3, com ângulo de incidência de $30^{\circ}$ e variação da resistência de falta em $0,17,30$, 50 e 100 ohms - dados locais.

FIGURA 99 - Resultados médios referentes à utilização dos sinais de tensão para situações de faltas fase-terra aplicadas sobre o ramo 3, com ângulo de incidência de $90^{\circ}$ e variação da resistência de falta em 0, 17, 30, 50 e 100 ohms - dados locais.

FIGURA 100 - Resultados médios referentes a situações de faltas fase-fase-terra aplicadas sobre o ramo 3 com ângulo de incidência de $0^{\circ}$ e variação da resistência de falta em 0, 17, 30, 50 e 100 ohms-dados locais...... 142

FIGURA 101 - Resultados médios referentes a situações de faltas fase-fase-terra aplicadas sobre o ramo 3 com ângulo de incidência de $30^{\circ} e$ variação da resistência de falta em 0, 17, 30, 50 e 100 ohms-dados locais.

FIGURA 102 - Resultados médios referentes a situações de faltas fase-fase-terra aplicadas sobre o ramo 3 com ângulo de incidência de $90^{\circ} e$ variação da resistência de falta em 0, 17, 30, 50 e 100 ohms -dados locais.

FIGURA 103 - Sinais de tensão e corrente em regime permanente com adição de diferentes niveis de ruído branco gaussiano. 
FIGURA 104 - Resultados médios obtidos utilizando sinais de corrente dado situações de faltas fase-terra aplicada sobre o ramo 3, com ângulo de incidência de $0^{\circ}$, resistência de falta de $0 \mathrm{ohm}$ e presença de ruido branco. 145

FIGURA 105 - Resultados médios obtidos utilizando sinais de corrente dado situações de faltas fase-terra aplicada sobre o ramo 3, com ângulo de incidência de $90^{\circ}$, resistência de falta de $50 \mathrm{ohm}$ e presença de ruído branco.

FIGURA 106 - Resultados médios obtidos utilizando sinais de corrente dado situações de faltas fase-fase aplicadas sobre o ramo 1, com ângulo de incidência de $90^{\circ}$ e presença de ruído branco.

FIGURA 107 - Resultados médios obtidos utilizando sinais de tensão dado situações de faltas fase-terra aplicadas sobre o ramo 3, com ângulo de incidência de $0^{\circ}$ resistência de falta de $0 \mathrm{ohm}$ e presença de ruído branco.

FIGURA 108 - Resultados médios obtidos utilizando sinais de tensão dado situações de faltas fase-terra aplicadas sobre o ramo 3 com ângulo de incidência de $90^{\circ}$, resistência de falta de $50 \mathrm{ohm}$ e presença de ruído branco 146

FIGURA 109 - Resultados médios obtidos utilizando sinais de tensão dado situações de faltas fase-fase aplicadas sobre o ramo 1, com ângulo de incidência de $90^{\circ}$ e presença de ruído branco

FIGURA 110 - Resultados médios obtidos utilizando sinais de corrente dado situações de faltas fase-fase aplicadas sobre o ramo 2, com ângulo de incidência de $0^{\circ}$ e presença de ruído branco - dados locais.

FIGURA 111 - Resultados médios obtidos utilizando sinais de corrente dado situações de faltas fase-fase aplicadas sobre o ramo 2, com ângulo de incidência de $30^{\circ}$ e presença de ruído branco-dados locais.

FIGURA 112 - Resultados médios obtidos utilizando sinais de corrente dado situações de faltas fase-fase aplicadas sobre o ramo 2, com ângulo de incidência de $90^{\circ}$ e presença de ruído branco - dados locais.

FIGURA 113 - Resultados médios obtidos utilizando sinais de tensão dado situações de faltas fase-fase aplicadas sobre o ramo 2, com ângulo de incidência de $0^{\circ}$ e presença de ruído branco-dados locais. 148 
FIGURA 114 - Resultados médios obtidos utilizando sinais de tensão dado situações de faltas fase-fase aplicadas sobre o ramo 2, com ângulo de incidência de $30^{\circ}$ e presença de ruído branco - dados locais

FIGURA 115 - Resultados médios obtidos utilizando sinais de tensão dado situações de faltas fase-fase aplicadas sobre o ramo 2, com ângulo de incidência de $90^{\circ}$ e presença de ruído branco - dados locais.

FIGURA 116 - Resultados médios obtidos utilizando sinais de corrente, dado situações de faltas fase-terra aplicadas sobre o ramo 1 de um circuito duplo vertical com ângulo de incidência de $30^{\circ}$.

FIGURA 117 - Resultados médios obtidos utilizando sinais de corrente, dado situações de faltas fase-terra aplicadas sobre o ramo 2 de um circuito duplo com ângulo de incidência de $0^{\circ}$.

FIGURA 118 - Resultados médios obtidos utilizando sinais de corrente, dado situações de faltas fase-terra aplicadas sobre o ramo 3 de um circuito duplo vertical com ângulo de incidência de $90^{\circ}$.

FIGURA 119 - Resultados médios obtidos utilizando sinais de corrente, dado situações de faltas fase-terra aplicadas sobre o ramo 1 de um circuito duplo vertical com ângulo de incidência de $30^{\circ}$ - dados locais.

FIGURA 120 - Resultados médios obtidos utilizando sinais de corrente, dado situações de faltas fase-terra aplicadas sobre o ramo 2 de um circuito duplos com ângulo de incidência de $0^{\circ}$ - dados locais.

FIGURA 121 - Resultados obtidos utilizando sinais de corrente, dado situações de faltas fase-terra aplicadas sobre o ramo 1 com ângulo de incidência de $0^{\circ}$ e linhas com parâmetros variando com a freqüência.

FIGURA 122 - Resultados obtidos utilizando sinais de corrente, dado situações de faltas fase-terra aplicadas sobre o ramo 3 com ângulo de incidência de $90^{\circ}$ e linhas com parâmetros variando com a freqüência.

FIGURA 123 - Resultados obtidos utilizando sinais de tensão, dado situações de faltas fase-terra aplicadas sobre o ramo 1 com ângulo de incidência de $0^{\circ}$ e linhas com parâmetros variando com a freqüência.

FIGURA 124 - Resultados obtidos utilizando sinais de corrente, dado situações de faltas fase-terra aplicadas sobre o ramo 1 com ângulo de incidência 
de $0^{\circ}$ e linhas com parâmetros variando com a freqüência - Dados locais.

FIGURA 125 - Resultados obtidos utilizando sinais de corrente, dado situações de faltas fase-terra aplicadas sobre o ramo 3 com ângulo de incidência de $90^{\circ}$ e linhas com parâmetros variando com a freqüência - dados locais.

FIGURA 126 - Resultados obtidos utilizando sinais de tensão, dado situações de faltas fase-terra aplicadas sobre o ramo 1 com ângulo de incidência de $0^{\circ}$ e linhas com parâmetros variando com a freqüência - dados locais.

FIGURA 127 - Resultados obtidos utilizando sinais de tensão, dado situações de faltas fase-terra aplicadas sobre o ramo 3 com ângulo de incidência de $90^{\circ}$ e linhas com parâmetros variando com a freqüencia - dados locais.

FIGURA 128 - Forma e características da descarga atmosférica gerada.

FIGURA 129 - Formas de ondas da tensão e corrente, medidas nos três terminais para uma situação de falta fase-terra com duração de $1 / 4$ de ciclo aplicada a $75 \mathrm{~km}$ da barra $A$.

FIGURA 130 - Correntes provenientes da saturação dos TC's (barra A) no caso de uma falta trifásica aplicada a $20 \mathrm{~km}$ com relação à mesma barra. . 160

FIGURA 131 - Sensibilidade do módulo de ondas viajante utilizando dados de três terminais em situações de faltas fase-fase com ângulo de incidência de $0^{\circ}$ e com variação da velocidade de propagação.

FIGURA 132 - Sensibilidade do módulo de ondas viajante utilizando dados de três terminais em situações de faltas fase-fase com ângulo de incidência de $90^{\circ}$ e com variação da velocidade de propagação.

FIGURA 133 - Sensibilidade do módulo de ondas viajante utilizando dados locais em situações de faltas fase-fase com ângulo de incidência de $0^{\circ} e$ com variação da velocidade de propagação.

FIGURA 134 - Sensibilidade do módulo de ondas viajante utilizando dados locais em situações de faltas fase-fase com ângulo de incidência de $0^{\circ} \mathrm{e}$ com variação da velocidade de propagação. 
FIGURA 135 - Sinais de tensão e corrente não filtrados e de detalhe 5 dado uma falta fase-terra a $70 \mathrm{~km}$ da barra A, com ângulo de incidência de $0^{\circ}$ e resistência de 100 ohms.

FIGURA 136 - Sinais de tensão e corrente não filtrados e de Aproximação 3 dado uma falta fase-terra a $70 \mathrm{~km}$ da barra A com ângulo de incidência de $0^{\circ}$ e resistência de 100 ohms.

FIGURA 137 - Influência do tipo de falta sobre o módulo de localização baseado em componentes fundamental quando analisado os sinais de detalhe.

FIGURA 138 - Influência do tipo de falta sobre o módulo de localização baseado em componentes fundamental quando analisado os sinais de aproximação.

FIGURA 139 - Influência do ângulo de incidência sob o módulo de localização por componente fundamental utilizando dos sinais de detalhe para casos de falta fase-fase aplicadas no ramo 1 .

FIGURA 140 - Influência do ângulo de incidência sob o módulo de localização por componente fundamental utilizando dos sinais de detalhe para casos de falta fase-fase aplicadas no ramo 3.

FIGURA 141 - Influência do ângulo de incidência sob o módulo de localização por componente fundamental utilizando dos sinais de aproximação para casos de falta fase-fase aplicadas no ramo 1.

FIGURA 142 - Influência do ângulo de incidência sob o módulo de localização por componente fundamental utilizando dos sinais de aproximação para casos de falta fase-fase aplicadas no ramo 3.

FIGURA 143 - Influência da resistência da falta sob o módulo de localização por componente fundamental utilizando dos sinais de detalhe para casos de falta fase-terra aplicadas no ramo 1.

FIGURA 144 - Influência de elevadas resistências da falta sob o módulo de localização por componente fundamental utilizando dos sinais de detalhe para casos de falta fase-terra aplicadas no ramo 1.

FIGURA 145 - Influência da resistência da falta sob o módulo de localização por componente fundamental utilizando dos sinais de aproximação para casos de falta fase-terra aplicadas no ramo 3. 
FIGURA 146 - Influência de elevadas resistências da falta sob o módulo de localização por componente fundamental utilizando dos sinais de aproximação para casos de falta fase-terra aplicadas no ramo 3. 169

FIGURA 147 - Influência do ruído associado aos sinais no módulo de localização por componente fundamental utilizando dos sinais de detalhe para casos de falta fase-fase aplicadas no ramo 2.

FIGURA 148 - Influência do ruído associado aos sinais no módulo de localização por componente fundamental utilizando dos sinais de aproximação para casos de falta fase-fase aplicadas no ramo 2.

FIGURA 149 - Influência do acoplamento mútuo sobre o módulo de localização por componente fundamental utilizando dos sinais de detalhe para casos de falta fase-terra aplicadas no ramo 1.

FIGURA 150 - Influência do acoplamento mútuo sobre o módulo de localização por componente fundamental utilizando dos sinais de aproximação para casos de falta fase-terra aplicadas no ramo 1.

FIGURA 151 - Influência do acoplamento mútuo sobre o módulo de localização por componente fundamental tradicional via TF para casos de falta fase-terra aplicadas no ramo 1.

FIGURA 152 - Influência da variação dos parâmetros da linha com a freqüência para falta fase-terra aplicadas sobre o ramo 1 ao analisar os sinais de detalhe.

FIGURA 153 - Influência da variação dos parâmetros da linha com a freqüência para falta fase-terra aplicadas sobre o ramo 3 ao analisar os sinais de detalhe.

FIGURA 154 - Influência da variação dos parâmetros da linha com a freqüência para falta fase-terra aplicadas sobre o ramo 1 ao analisar os sinais de aproximação.

FIGURA 155 - Influência da variação dos parâmetros da linha com a freqüência para falta fase-terra aplicadas sobre o ramo 3 ao analisar os sinais de aproximação.

FIGURA 156 - Sensibilidade do módulo por componente fundamental utilizando os sinais de detalhe para variações da impedância de onda e da constante de propagação - ramo 1 . 
FIGURA 157 - Sensibilidade do módulo por componente fundamental utilizando os sinais de detalhe para variações da impedância de onda e da constante de propagação - ramo 3.

FIGURA 158 - Sensibilidade do módulo por componente fundamental utilizando os sinais de aproximação para variações da impedância de onda e da constante de propagação - ramo 1.

FIGURA 159 - Sensibilidade do módulo por componente fundamental utilizando os sinais de aproximação para variações da impedância de onda e da constante de propagação - ramo 3. 


\section{LISTA DE TABELAS}

TABELA 1- Taxas de falta em linhas - Anos 1999-2001............................................... 2

TABELA 2 - Custo médio de interrupção para as categorias de consumo do Estado

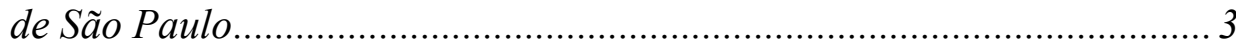

TABELA 3 - Parâmetros da linha de transmissão de $440 \mathrm{kV}$........................................ 66

TABELA 4 - Parâmetros dos equivalentes de geração das barras $A, B$ e $C$................... 67

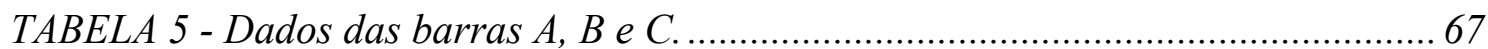

TABELA 6 - Parâmetros da linha de transmissão em circuito duplo vertical. .............. 81

TABELA 7 - Niveis de decomposição utilizados no algoritmo proposto......................... 94

TABELA 8 - Decisão da técnica de localização de faltas ............................................. 95

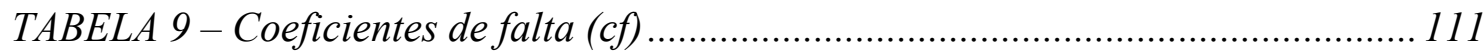

TABELA 10 - Resultados referentes à aplicação de faltas transitórias e descarga atmosférica, utilizando sinais de corrente ou tensão. .......................... 158

TABELA 11 - Resultados referentes à aplicação de faltas transitórias e descarga atmosférica, utilizando sinais de corrente ou tensa-dados locais...... 159

TABELA 12 - Resultados obtidos pelo módulo de localização por componente fundamental frente à faltas transitórias. .............................................. 176

TABELA 13 - Aplicabilidade geral do LFHTW 1.01 .................................................... 184 


\section{LISTA DE SIGLAS E ABREVIATURAS}

\begin{tabular}{|c|c|}
\hline SEP & Sistemas Elétricos de Potência \\
\hline $\mathrm{LT}$ & Linha de Transmissão \\
\hline CAD & Conversor Analógico/Digital \\
\hline PDS & Processadores Digitais de Sinais \\
\hline RNA & Rede Neural Artificial \\
\hline TW & Transformada Wavelet \\
\hline ATP & Alternative Transients Program \\
\hline TDF & Transformada Discreta de Fourier \\
\hline $\mathrm{CC}$ & Corrente Contínua \\
\hline FDC & Fator de Distribuição de Corrente \\
\hline MLP & MultiLayer Perceptron \\
\hline EAT & Extra Alta Tensão \\
\hline GPS & Global Positioning System \\
\hline $\mathrm{RBF}$ & Radial Basis Function \\
\hline TPs & Transformadores de Potencial \\
\hline TPCs & Transformadores de Potencial Capacitivo \\
\hline TCs & Transformadores de Corrente \\
\hline TWC & Transformada Wavelet Contínua \\
\hline TWD & Transformada Wavelet Discreta \\
\hline TWE & Transformada Wavelet Estacionária \\
\hline $\mathrm{TF}$ & Transformada de Fourier \\
\hline STFT & Short-Time Fourier Transform \\
\hline TFJ & Transformada de Fourier Janelada \\
\hline TWDI & Transformada Wavelet Discreta Inversa \\
\hline CTEEP & Companhia de Transmissão de Energia Elétrica Paulista \\
\hline CESP & Companhia Energética de São Paulo \\
\hline CEPEL & Centro de Pesquisa de Engenharia Elétrica \\
\hline SINAPE & Sistema Integrado de Apoio à Análise de Perturbações \\
\hline LFHTW 1.0 & Localizador de Faltas Híbrido via Transformada Wavelet, versão 1.01 \\
\hline FPGA & Field-Programmable Gate Array \\
\hline
\end{tabular}




$\begin{array}{ll}\text { AT } & \text { Falta-fase(A)-terra } \\ \text { BT } & \text { Falta-fase(B)-terra } \\ \text { CT } & \text { Falta-fase(C)-terra } \\ \text { ABT } & \text { Falta-fase(A)-fase(B)-terra } \\ \text { ACT } & \text { Falta-fase(A)-fase(C)-terra } \\ \text { BCT } & \text { Falta-fase(B)-fase(C)-terra } \\ \text { AB } & \text { Falta-fase(A)-fase(B) } \\ \text { AC } & \text { Falta-fase(A)-fase(C) } \\ \text { BC } & \text { Falta-fase(B)-fase(C) } \\ \text { ABC } & \text { Falta-fase(A)-fase(B)-fase(C) }\end{array}$




\title{
LISTA DE SÍMBOLOS
}

\author{
$\mathrm{V}_{\mathrm{F}}, \mathrm{I}_{\mathrm{F}} \quad$ tensão e corrente no ponto de falta \\ $\mathrm{V}_{\mathrm{S}}{ }^{\prime}, \mathrm{I}_{\mathrm{S}}{ }^{\prime} \quad$ tensão e corrente pós-falta no terminal $\mathrm{S}$ \\ $\mathrm{V}_{\mathrm{S}}, \mathrm{I}_{\mathrm{S}} \quad$ tensão e corrente pré-falta no terminal $\mathrm{S}$ \\ $\mathrm{V}_{\mathrm{S}}$ ", IIS $\quad$ componentes superpostos de tensão e corrente em S \\ $\mathrm{I}_{\mathrm{SF}} \quad$ componente superposto da corrente de falta do terminal $\mathrm{S}$ ao ponto $\mathrm{F}$ \\ $V_{R}^{\prime}, I_{R}^{\prime} \quad$ tensão e corrente pós-falta no terminal R \\ $V_{R}, I_{R} \quad$ tensão e corrente pré-falta no terminal $\mathrm{R}$ \\ $V_{R}^{\prime \prime}, I_{R}^{\prime \prime} \quad$ componentes superpostos de tensão e corrente em $\mathrm{R}$ \\ $\mathrm{R}_{\mathrm{F}} \quad$ resistência de falta \\ $\mathrm{Z}_{\mathrm{F}} \quad$ impedância de falta \\ p distância da falta em porcentagem da extensão da linha \\ $\mathrm{Z}_{\mathrm{L}} \quad$ impedância da linha de transmissão por unidade de comprimento \\ $\mathrm{Z}_{\mathrm{LS}} \quad$ impedância da linha entre a falta e o terminal $\mathrm{S}$ \\ $1 \quad$ comprimento da linha \\ $\mathrm{Z}_{0} \quad$ impedância característica \\ $\mathrm{Z}_{\mathrm{S}}, \mathrm{Z}_{\mathrm{R}} \quad$ impedância das fontes dos terminais local e remoto \\ $\mathrm{Z}_{\text {th }} \quad$ impedância de Thévenin vista no ponto de falta \\ $\mathrm{V}_{\mathrm{Fd}} \quad$ componente de tensão superposta de seqüência positiva no ponto de falta \\ $\mathrm{I}_{\mathrm{Fd}} \quad$ componente de corrente superposta de seqüência positiva no ponto de \\ falta \\ $\left[\mathrm{V}_{\mathrm{F}}\right] \quad$ vetor de tensões trifásicas no ponto de falta \\ $\left[\mathrm{V}_{\mathrm{L}}\right] \quad$ vetor de tensões trifásicas no terminal local \\ $\left[\mathrm{V}_{\mathrm{R}}\right] \quad$ vetor de tensões trifásicas no terminal remoto \\ $\left[\mathrm{I}_{\mathrm{L}}\right] \quad$ vetor de correntes trifásicas no terminal local \\ $\left[\mathrm{I}_{\mathrm{R}}\right] \quad$ vetor de correntes trifásicas no terminal remoto \\ $\left[\mathrm{Z}_{\mathrm{a}, \mathrm{b}, \mathrm{c}}\right] \quad$ matriz trifásica de impedâncias série da linha \\ $\mathrm{K}_{\mathrm{p}} \quad$ fator de distribuição de corrente \\ $\lambda \quad$ constante de propagação da linha \\ $v_{0}, v_{1} \quad$ velocidade de propagação do modo terra e aéreo 1
}


$v_{m 0}, v_{m 1} \quad$ velocidades de propagação do modo terra (modo 0) e aéreo 1 (modo 1)

d distância ao ponto de falta

A, B, C e D parâmetros do quadripólo representativo da linha

T matriz de transformação modal de Clarke

$\mathrm{X}_{\mathrm{S}} \quad$ reatância no terminal S

$\mathrm{Z}_{\mathrm{abc}} \quad$ matriz de impedância série

$\mathrm{D}_{\mathrm{x}} \quad$ distância entre dois pontos consecutivos da linha de transmissão.

a fator de escala para a Transformada Wavelet Contínua

A versão aproximada de um sinal

b fator de translação para a Transformada Wavelet Contínua

$\mathrm{cA}$

versão aproximada de um sinal com operador downsampling

$\mathrm{cD}$

versão de detalhes de um sinal com operador downsampling

D versão de detalhes de um sinal

$\mathrm{h}_{0} \quad$ filtro passa baixa

$\mathrm{h}_{1} \quad$ filtro passa alta

k fator de translação relacionado à Análise Multiresolução

m parâmetro de escala para a Transformada Wavelet Discreta

n parâmetro de translação para a Transformada Wavelet Discreta

t variável tempo

x variável correspondente a tempo ou espaço

$\varphi \quad$ função escala

$\psi \quad$ função Wavelet

a,b,c fases da linha

$0, \alpha, \beta \quad$ índices modais 


\section{SUMÁRIO}

1 INTRODUÇÃO ................................................................................................1

1.1 Localizadores de faltas para linhas de transmissão.................................................. 3

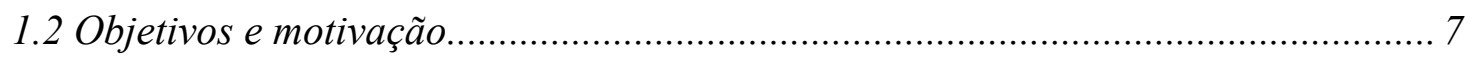

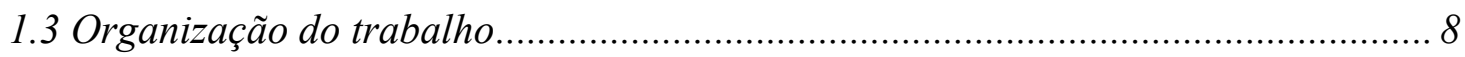

2 REVISÃO BIBLIOGRÁFICA.........................................................................9

2.1 Métodos baseados nos componentes de freqüência fundamental ............................ 9

2.1.1 Algoritmos que utilizam dados somente do terminal local da linha ................ 10

2.1.2 Algoritmos que utilizam dados de mais de um terminal da linha ..................... 18

2.2 Métodos baseados nos componentes de alta freqüência gerados por uma falta ... 24

2.2.1 Algoritmos que utilizam dados somente do terminal local da linha ................. 25

2.2.2 Algoritmos que utilizam dados de múltiplos terminais da linha ....................... 30

\section{FUNDAMENTOS SOBRE ONDAS VIAJANTES E TRANSFORMADA}

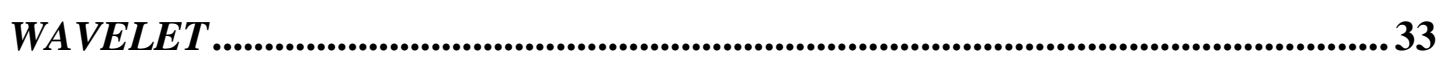

3.1 Ondas viajantes em sistemas de transmissão .................................................... 33

3.1.1 Equacionamento fundamental de propagação das ondas................................ 34

3.1.2 Reflexões e refrações de ondas viajantes .......................................................... 39

3.1.3 Reflexões sucessivas e diagrama Lattice ......................................................... 40

3.1.4 Atenuação e distorção das ondas viajantes .................................................... 41

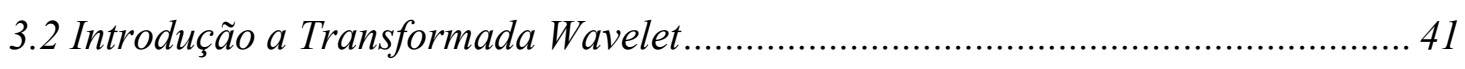

3.2.1 A Transformada Wavelet Contínua ................................................................. 44

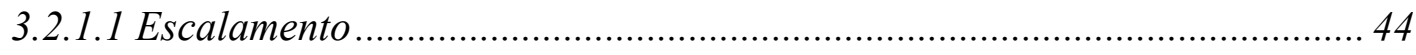

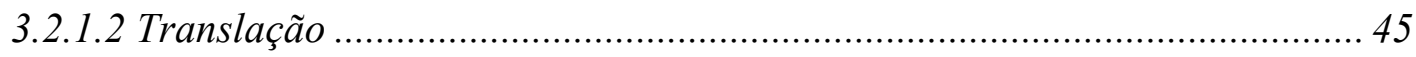

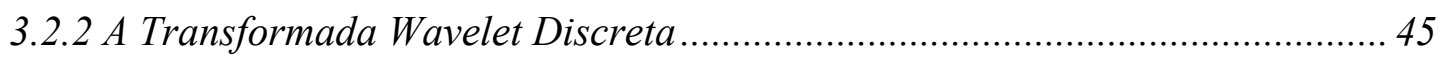

3.2.3 Filtragem e Análise Multiresolução .............................................................. 46

3.2.3.1 Decomposição em múltiplos níveis ou análise multiresolução ................... 48

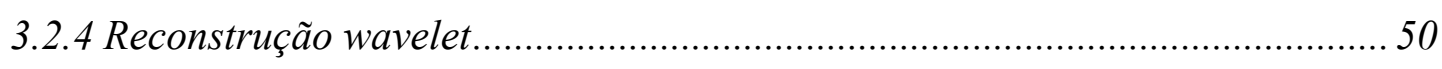

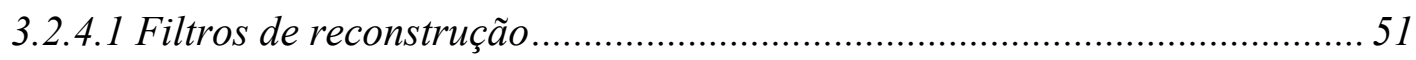

3.2.4.2 Aproximações e detalhes na reconstrução.............................................. 51 
3.2.5 Decomposição e Reconstrução Wavelet via método matricial

3.2.6 Transformada Wavelet Estacionária ou Transformada Wavelet Discreta não dizimada 57

3.2.7 Aplicações da Transformada Wavelet em Sistemas Elétricos de Potência ...... 59

\section{SISTEMA ELÉTRICO ANALISADO} 61

4.1 Configuração do sistema de potência 61

4.2 Modelagem da linha de transmissão 62

4.2.1 Parâmetros do sistema elétrico. 63

4.2.2 Rotina Line Constant e arquivo de entrada para o software ATP 65

4.3 Condicionamento analógico e digital dos sinais.................................................... 68

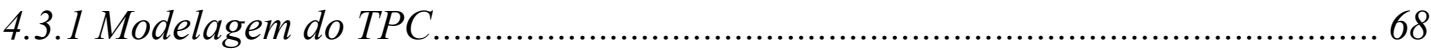

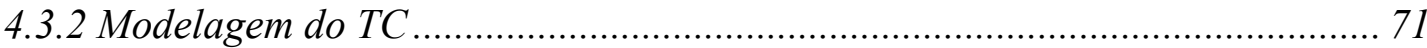

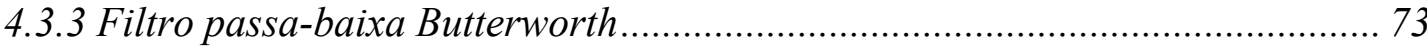

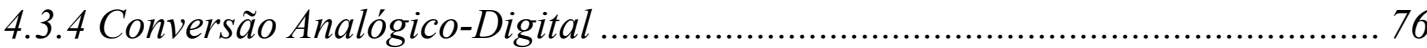

4.4 Variações nas simulações das condições de faltas aplicadas ao circuito de transmissão simples horizontal ............................................................................ 77

4.5 Modelagem e dados referentes ao circuito duplo vertical ................................... 79

4.5.1 Variações nas simulações das condições de faltas aplicadas ao circuito de transmissão duplo

\section{LOCALIZAÇÃO DE FALTAS UTILIZANDO A TRANSFORMADA}

WAVELET - ABORDAGEM TEÓRICA .................................................................. 85

5.1 Princípio básico do método de localização de faltas híbrido ................................. 85

5.2 O Algoritmo do Localizador de Faltas Hibrido ...................................................... 87

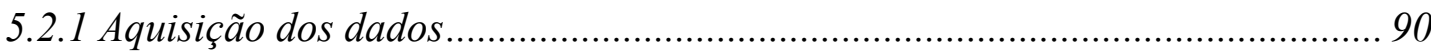

5.2.2 Condicionamento Analógico e Digital dos sinais ............................................ 91

5.2.3 Decomposição Wavelet Discreta ................................................................. 93

5.2.4 Decisão 1: Utilizar método com ou sem comunicação entre terminais............ 94

5.2.5 Decisão 2: Há presença de ruído no sinal de entrada? ................................... 95

5.2.6 Metodologia de localização de faltas por ondas viajantes e Transformada

Wavelet utilizando dados dos três terminais .................................................. 97

5.2.6.1 Detecção por ondas viajantes (detecção preliminar)................................ 98

5.2.6.2 Classificação da falta ................................................................................... 100 
5.2.6.3 Transformação modal. 102

5.2.6.4 Determinação dos tempos de reflexão (Detecção Fina)... 104

5.2.6.5 Identificação do Ramo faltoso 105

5.2.6.6 Cálculo da distância da falta envolvendo dados dos três terminais..... 106

5.2.6.7 Relatório do evento. 107

5.2.7 Metodologia de localização de faltas por ondas viajantes e Transformada

Wavelet utilizando dados locais (terminal local) 108

5.2.7.1 Determinação dos tempos de reflexão da primeira e segunda onda no terminal local 109

5.2.7.2 Pré-Localização para faltas fase-terra...... 111

5.2.7.3 Cálculo da distância para faltas fase-fase-terra, fase-fase e trifásica ..... 114

5.2.7.4 Cálculo da distância para faltas fase-terra. 115

5.2.8 Metodologia de localização de faltas por componentes fundamentais via

Transformada Wavelet Estacionária para dados de Três terminais. 115

5.2.8.1 Decomposição dos sinais via TWE. 116

5.2.8.2 Detecção do distúrbio via componentes fundamentais...... 116

5.2.8.3 Classificação da falta 116

5.2.8.4 Componentes Superpostos 116

5.2.8.5 Transformação Modal. 117

5.2.8.6 Equacionamento para Localização da falta e identificação do ramo faltoso via componentes fundamentais extraídos via TWE. 117

\section{TESTES E RESULTADOS UTILIZANDO O LFHTW 1.01}

6.1 Resultados preliminares utilizando-se do algoritmo baseado em ondas viajantes......

6.1.1 Influência dos diferentes tipos de faltas. 124

6.1.2 Influência do terminal de referência 127

6.1.3 Influência do ângulo de incidência da falta. 130

6.1.4 Influência da resistência de falta 133

6.1.5 Influência do ruído correlacionado ao sinal..... 143

6.1.6 Influência do acoplamento mútuo dado um circuito duplo de transmissão.... 149

6.1.7 Comportamento do algoritmo de ondas viajantes sobre linhas com parâmetros variando com a freqüência. 
6.1.9 Influência da saturação dos TC's na localização por ondas viajantes .....

6.1.10 Análise de sensibilidade dos módulos baseados em ondas viajantes 160

6.2 Resultados alcançados pelo módulo de localização baseado em componentes

fundamentais extraídos via TWE. 162

6.2.1 Influência dos diferentes tipos de falta 165

6.2.2 Influência da variação do ângulo de incidência da falta..... 166

6.2.3 Influência da variação da resistência de falta..... 167

6.2.4 Influência da distância da falta. 170

6.2.5 Influência do ruído correlacionado aos sinais analisados 170

6.2.6 Comportamento da técnica frente ao acoplamento mútuo entre circuitos de uma linha de transmissão dupla

6.2.7 Comportamento do módulo de localização quando utilizado linhas com parâmetros variantes com a freqüência

6.2.8 Localização de distúrbios transitórios 175

6.2.9 Influência da saturação dos TC's na localização por componentes fundamentais. 176

6.2.10 Análise de sensibilidade do módulo por componente fundamental 176

7 CONCLUSÕES 179

7.1 Considerações sobre a metodologia baseada em ondas viajantes. 179

7.2 Considerações sobre a metodologia baseada na extração do componente fundamental via TWE 181

7.3 Considerações gerais sobre o algoritmo de localização de faltas híbrido. 183

7.4 Continuidade da pesquisa 184 


\section{INTRODUÇÃO}

A energia elétrica é um dos recursos fundamentais para o desenvolvimento econômico de um país, bem como, para promover a satisfação e o bem-estar da sociedade. Dessa forma, os Sistemas Elétricos de Potência (SEP) devem garantir um alto grau de confiabilidade na continuidade do fornecimento da energia elétrica. Contudo, interrupções no fornecimento da energia elétrica podem ser provocadas pela ocorrência de diferentes tipos de fenômenos eletromagnéticos no sistema elétrico que podem afetar distintas classes de consumidores. Dentre os diversos componentes de um SEP, podem-se destacar as Linhas de Transmissão (LTs) como o elemento mais susceptível, especialmente se considerarmos suas dimensões físicas, complexidade funcional e o ambiente que se encontram, apresentando assim, maior dificuldade para manutenção e monitoramento. A Figura 1 ilustra a predominância de faltas em linhas de transmissão, conforme VAN ZEE apud COURY [1], que mostra o registro da distribuição de faltas em um sistema de $500 \mathrm{kV}$, para um período de dez anos. Salientase que dado o período de amostragem dos dados para constituição da Figura 1, alterações podem ser encontradas em dados atualizados.

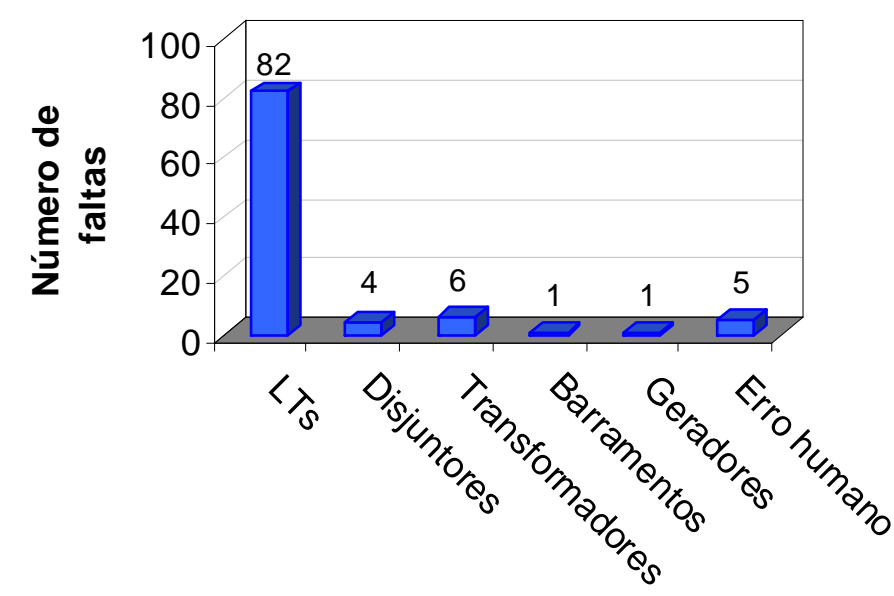

FIGURA 1 - Distribuição de faltas em um sistema de $500 \mathrm{kV}$, para um período de dez anos, com a ocorrência de noventa e nove faltas. 
Observações práticas também mostram que entre $70 \%$ a $80 \%$ das faltas nas linhas de transmissão ocorrem entre um só condutor e a terra (STEVENSON) [2]. Um menor número de faltas refere-se às que envolvem todas as fases, em torno de $5 \%$. Porém, tal estatística pode variar conforme o nível de tensão do sistema de transmissão. A Tabela 1 ilustra as estatísticas de situações de falta registradas sobre linhas de transmissão de uma importante concessionária do sistema brasileiro, obtidas no período de 1999 a 2001, reportada em Filhos et al. [3].

TABELA 1- Taxas de falta em linhas - Anos 1999-2001

\begin{tabular}{lcccc}
\hline $\begin{array}{c}\text { Nível de } \\
\text { Tensão }\end{array}$ & $\begin{array}{c}\text { Taxa de } \\
\text { Falta* }\end{array}$ & $\begin{array}{c}\text { Fase-Terra } \\
(\mathbf{( \% )}\end{array}$ & $\begin{array}{c}\text { Fase-Fase } \\
\mathbf{( \% )}\end{array}$ & $\begin{array}{c}\text { Trifásica } \\
\mathbf{( \% )}\end{array}$ \\
\hline $\mathbf{5 0 0} \mathbf{~ k V}$ & 2,09 & 94,24 & 5,04 & 0,72 \\
\hline $\mathbf{3 4 5} \mathbf{~ k V}$ & 1,10 & 92,65 & 7,35 & 0,00 \\
\hline $\mathbf{2 3 0} \mathbf{~ k V}$ & 1,90 & 79,65 & 18,18 & 2,27 \\
\hline * número de faltas/100km/ano.
\end{tabular}

$\mathrm{O}$ crescente aumento em complexidade dos SEP, devido à demanda de energia elétrica e a interligação dos sistemas existentes, tem exigido uma considerável melhora dos equipamentos de controle e proteção, bem como dos localizadores de faltas. Desta melhora nos dispositivos empregados, busca-se possibilitar uma redução do período de interrupção do fornecimento da energia, em caso de falhas, e garantir uma operação confiável e econômica do sistema de potência, seja em condições normais de operação ou em contingência. Destaca-se também, a crescente competitividade no mercado de energia nacional devido ao processo de desestatização e regulação pelo qual passou o setor elétrico. Tais fatos têm levado as empresas de energia elétrica a investirem em modernos sistemas de gerenciamento e proteção, a fim de assegurar uma fatia significativa do mercado, através da oferta de energia a um menor custo e com alto padrão de qualidade.

Como se não fosse suficiente, é importante lembrar que a interrupção no fornecimento da energia, por menor que seja, gera perdas de faturamento, pois as empresas de energia além de deixarem de vender o produto, podem levar pesadas multas por parte da agência de regulação do setor elétrico (ANEEL). Essa mesma interrupção pode também gerar prejuízos decorrentes de processos judiciais por perdas e danos causados a grandes e pequenos consumidores, e a insatisfações, seja por parte dos consumidores residenciais, comerciais e ou industriais. Como exemplo, tem-se na Tabela 2 os valores típicos para o custo do $\mathrm{kWh}$ interrompido, ponderados pelo universo 
de consumidores das categorias pesquisadas, para o Estado de São Paulo no ano de 2000, conforme Magalhães et al. [4].

TABELA 2 - Custo médio de interrupção para as categorias de consumo do Estado de São Paulo

\begin{tabular}{cc}
$\begin{array}{c}\text { Categorias utilizadas } \\
\text { na pesquisa }\end{array}$ & $\begin{array}{c}\text { Custo de Interrupção Médio } \\
\text { (US\$/kWh interrompido) }\end{array}$ \\
\hline Residencial & 0,9 \\
\hline Comercial & 1,7 \\
\hline Industrial & 5,3 \\
\hline
\end{tabular}

Dado o contexto acima, nas últimas duas décadas, utilizar dispositivos baseados em microprocessadores para as soluções de problemas relacionados aos sistemas elétricos de potência, tem sido assunto de grande interesse por parte de engenheiros e pesquisadores. Esse interesse se deve ao rápido avanço da tecnologia, aliado ao desenvolvimento na área de software destinado às aplicações em sistemas elétricos de potência, especialmente quando se faz necessário grande precisão, como é a situação da localização de faltas, assunto este a ser abordado no que segue.

\subsection{Localizadores de faltas para linhas de transmissão}

Um localizador digital de faltas, como o próprio nome induz, tem por objetivo determinar, o mais precisamente possível, o ponto de ocorrência de uma falta em uma linha de transmissão, o que é de suma importância para uma operação confiável e econômica do sistema de potência como um todo. Além da segurança do sistema, conhecendo-se a localização da falta, um menor tempo é despendido nos serviços de manutenção e reparo, o que permite uma rápida restauração da operação às condições normais desejadas. Sendo assim, além de prover a localização de faltas sustentadas, um localizador pode vir a estimar faltas transitórias, como por exemplo, as decorrentes de descargas atmosféricas, toque de galhos de árvores, etc. Tal estimação poderá alimentar um banco de dados contendo o local dos distúrbios o que permitiria a identificação de pontos fracos nos sistemas de transmissão, possibilitando que medidas preventivas e adequadas a cada caso sejam tomadas, tais como instalação de pára-raios e corte de árvores, visando evitar problemas futuros de maior grandeza.

Um localizador de faltas pode ser implementado de três maneiras distintas (GIRGIS et al.) [5], sendo essas: 
1) como um dispositivo stand-alone: o localizador de faltas possui um hardware, similar ao de um relé digital (o localizador de faltas seria apresentado como único produto);

2) como parte de um relé digital de proteção: neste caso, o algoritmo de um localizador de faltas é incluído juntamente com o algoritmo do relé de proteção (a localização de faltas seria mais uma das funções de um relé digital);

3) como um algoritmo independente: dispondo de dados obtidos através de registradores digitais de faltas. Neste caso, o software do localizador poderia estar instalado, por exemplo, em um notebook e com base nas oscilografias o mesmo poderia analisar os dados e localizar a falta.

Cabe comentar que os localizadores de faltas processam dados registrados digitalmente de modo off-line e, por essa razão, não estão sujeitos às restrições de processamento impostas aos relés de proteção, que devem operar em modo on-line. Isso permite um aumento na sofisticação dos algoritmos e, portanto, na precisão relacionada à localização de faltas, o que é particularmente desejável para linhas longas ou localizadas em terrenos acidentados, onde poucos quilômetros de imprecisão podem comprometer a continuidade do fornecimento da energia (GAUTIER) [5].

O projeto dos localizadores de faltas microprocessados inclui a escolha de um hardware e de um método de localização para implementação do algoritmo de localização (software).

O hardware de um localizador deve ser adequado para cada algoritmo de localização, respeitando assim, os requisitos de aquisição, armazenamento e condicionamento dos dados, bem como todo o processamento e variáveis de saída pertinentes à lógica de localização adotada.

Em se tratando dos métodos ou algoritmos de localização de faltas, estes têm sido classificados em três diferentes categorias (LIAN e SALAMA) [7], como segue:

1) métodos baseados em componentes de freqüência fundamental;

2) métodos baseados nos componentes de alta freqüência, também conhecidos na literatura como métodos de ondas viajantes e

3) métodos baseados na solução de equações diferenciais do sistema elétrico.

Dentre as metodologias citadas, as duas primeiras são as mais usuais e apontadas na literatura e serão, por esta justificativa, as abordadas no escopo deste trabalho, não diminuindo, é claro, a importância da terceira metodologia. 
Em contrapartida, as duas primeiras metodologias citadas, podem ser classificadas de acordo com o modo de obtenção dos dados em técnicas: (i) dispondo de dados provenientes de um único terminal e (ii) de dados provenientes de múltiplos terminais da linha de transmissão.

Os algoritmos de localização de faltas que utilizam dados provenientes de um terminal da linha, os quais consideram as componentes de freqüência fundamental, são em sua maioria, baseados na determinação da impedância aparente da linha de transmissão observada do local ao ponto físico da falta. Esta impedância é obtida em função dos parâmetros da LT e dos fasores de freqüência fundamental de tensão e corrente extraídos via algum método de filtragem, como por exemplo, Fourier, Mínimos Quadrados, Kalman, etc [7]. Cabe comentar que as estimativas para essas localizações de faltas, dependendo do algoritmo utilizado, podem estar sujeitas a erros, em maior ou menor grau, devido ao efeito combinado da corrente de carga e da resistência de falta, do infeed ou outfeed remoto de corrente, acoplamento mútuo, etc. Melhorias em tais métodos são alcançadas utilizando-se de medições sincronizadas nos diferentes terminais da linha. Os métodos de localização de dois terminais são basicamente similares aos de um terminal, porém, são mais precisos e capazes de atenuar ou eliminar os efeitos da resistência de falta, carregamento e outros efeitos nocivos aos algoritmos de um terminal (SCHWEITZER III)[8] e (IEEE STANDARDS C37.114)[9]. Todavia, deve ser mencionado que quando da utilização de dois ou mais terminais, faz-se necessário um meio de comunicação entre os terminais para transmissão dos dados de falta registrados para um terminal de referência, onde será realizado o processamento para a localização da falta. Contudo, ao contrário da detecção da falta, que opera em modo on-line e, por essa razão exige alta velocidade e canais de comunicação contínuos, os requisitos de comunicação para os localizadores são bastante simples, uma vez que o algoritmo opera em modo off-line (COURY)[10].

Os métodos que utilizam às componentes de alta freqüência dos sinais transitórios gerados por uma falta estão fundamentados na teoria de ondas viajantes. Estes algoritmos são baseados na determinação do tempo de viagem da onda de tensão ou corrente do ponto de falta ao terminal de monitoramento e na velocidade de propagação da onda viajante na linha, a qual é função dos parâmetros da mesma. Tal método tipicamente apresenta excelente precisão, além de ser pouco sensível aos efeitos das variáveis citadas anteriormente. 
A principal limitação encontrada na implementação dos algoritmos que consideram o emprego da teoria de ondas viajantes decorre da necessidade da utilização de elevadas taxas de freqüência de amostragem e um acurado dispositivo de sincronização ou selagem de tempo (time stamping) dos dados. Todavia, com o progresso atual da tecnologia dos dispositivos de aquisição e condicionamento de dados, da sincronização do tempo por GPS (Global Positioning System) e dos sistemas de comunicação de dados, tem-se viabilizado e aumentado o interresse por esta metodologia (IEEE STANDARDS C37.114)[9].

Vale ainda frisar que os recentes estudos relacionados ao problema de localização de faltas, apontam a utilização de PMU (Phasor Mesurement Unit)(SHENGFANG et al.)[11], o emprego de ferramentas inteligentes e algoritmos evolutivos como Redes Neurais Artificiais (RNAs) (AMORIM e HUAIS)[12] e Algoritmos Genéticos (GAs) (EL-NAGGAR)[13], bem como, aplicações de novas ferramentas matemáticas, como por exemplo, a Transformada Wavelet (SILVEIRA)[14].

Pelos apontamentos encontrados, no que dizem respeito à TW, observa-se um ótimo compromisso entre os domínios do tempo e da freqüência, propício à localização de faltas caracterizadas tanto em altas como em baixas freqüências, devido a sua característica de escalamento. Esta característica permite que a TW seja utilizada em um algoritmo de localização de faltas, tanto nos métodos baseados nos componentes de alta freqüência quanto nos métodos baseados em componentes de freqüência fundamental.

Como característica inerente, a análise wavelet é capaz de localizar com precisão os instantes de tempo de ocorrência de eventos, pontos de descontinuidades, etc, o que a torna muito adequada para a aplicação na localização de faltas, quando da utilização dos métodos baseados em ondas viajantes.

Neste contexto, este trabalho propõe a aplicação da TW para analisar os transitórios de alta e baixa freqüência, provenientes de uma situação de falta com o intuito de determinar o ponto ocorrência da mesma, bem como os terminais associados, utilizando-se de dados dos três terminais ou apenas de dados locais. Em função das variáveis caracterizadas, pretende-se então estimar o ramo faltoso e indicar com precisão a distância de ocorrência da falta com relação ao terminal do ramo faltoso. 


\subsection{Objetivos e motivação}

A tarefa de localização precisa de uma situação de falta fica bem mais complexa com a utilização de linhas de transmissão com três terminais. Este tipo de linha, onde um novo terminal alimentador é conectado a uma linha de transmissão já existente, oferece consideráveis vantagens econômicas e benefícios ambientais sobre sistemas de transmissão de Extra Alta Tensão (EAT) com dois terminais. Tais vantagens e benefícios tornam-se desejáveis, tendo em vista a crescente demanda por energia e a grande dificuldade em se construir novas linhas de EAT e subestações. Nesse sentido, um circuito com três terminais oferece uma alternativa bastante atrativa e de baixo custo. Em contrapartida, é de conhecimento geral que tais sistemas são de difícil proteção e localização de faltas dispondo-se de filosofias convencionais e, por esta razão, exigem atenção especial. Destes fatos, busca-se então, a proposição de um novo modelo de localizador de faltas híbrido para linhas de três terminais, que venha a transpor os desafios impostos pela configuração do sistema, assim como as limitações dos métodos empregados, apresentando precisão, confiabilidade e aplicabilidade.

A metodologia a ser explanada visa alcançar um localizador de faltas baseado na teoria: das ondas viajantes, de maneira que se possa acusar o intervalo de tempo de viagem da onda do ponto de falta ao terminal ou terminais da linha em questão (um, dois ou três terminais) e pelo cálculo da impedância aparente via componentes fundamentais. Cabe frisar que tanto a estimação dos tempos de viagem das ondas até os terminais das linhas, como a extração dos componentes fundamentais, deverá ser apontada pelo emprego da TW. Conforme será apresentado, o algoritmo proposto foi desenvolvido de maneira a possibilitar a localização da falta independentemente de haver ou não meios de comunicação, podendo para isto, utilizar dados registrados em todos os terminais disponíveis da linha simultaneamente ou utilizar apenas dados locais. Portanto, quando da falha ou inexistência do canal de comunicação, a lógica privilegia a utilização de dados registrados localmente, de forma independente em cada terminal. Destas opções, com ou sem o canal de comunicação, possibilita-se uma maior flexibilidade ao usuário, podendo o mesmo escolher a técnica de localização a ser utilizada, de acordo com suas necessidades, configuração do sistema e recursos disponíveis, além disso, o algoritmo foi automatizado permitindo a escolha do método de localização (por onda viajante ou por componente fundamental) que melhor se adapte aos sinais de entrada. 
Tal motivação advém de uma melhor exploração no processamento dos sinais caracterizados usufruindo de todas as particularidades disponibilizadas e ressaltadas pelas teorias envolvidas, bem como, pela busca em minimizar os erros na localização do ponto da falta devido a problemas inerentes a cada metodologia, com base na utilização ótima das mesmas.

\subsection{Organização do trabalho}

O capítulo 1, como já descrito, apresenta uma breve introdução sobre localização de faltas, seguindo-se dos objetivos e a motivação do trabalho.

No capítulo 2 é apresentada uma revisão bibliográfica referente às diferentes metodologias aplicadas à localização de faltas em linhas de transmissão. Essas metodologias estarão alocadas a duas categorias principais: (i) métodos que fazem uso das componentes de freqüência fundamental e (ii) métodos que fazem uso das componentes de alta freqüência. Por sua vez, esses métodos são subdivididos em duas técnicas conforme a obtenção dos dados que podem ser provenientes de um ou de múltiplos terminais da linha.

No capítulo 3 são abordados os fundamentos básicos da teoria sobre ondas viajantes, Transformada Wavelet e suas aplicações no sistema elétrico de potência.

A modelagem do sistema elétrico de potência a ser analisado, bem como as considerações referentes às variações nas simulações das faltas aplicadas sobre o sistema proposto, é apresentada no capítulo 4.

O capítulo 5 aborda detalhadamente todos os aspectos teóricos e funcionais referentes ao algoritmo de localização de faltas híbrido utilizando a Transformada Wavelet.

$\mathrm{Na}$ seqüência, no capítulo 6, são apresentados e discutidos os resultados dos testes obtidos até então, quando da aplicação do algoritmo de localização de faltas proposto.

Finalizando, para o capítulo 7, reservam-se as conclusões e propostas para continuidade do trabalho delineado. 


\section{REVISÃO BIBLIOGRÁFICA}

Como fato, tem-se que o desenvolvimento de novos métodos de localização digital de faltas para linhas de transmissão (LT), utilizando dispositivos baseados em microprocessadores, é questão de interesse de pesquisadores e engenheiros de potência nos últimos anos. Sobre um considerável número de propostas, estas buscam novas metodologias e o aperfeiçoamento das já existentes, visando melhorar a precisão das localizações de faltas em LTs. Portanto, faz-se necessário num primeiro momento, apresentar uma revisão bibliográfica dos principais algoritmos de localização de faltas encontrados na literatura.

A revisão bibliográfica descrita a seguir, focará os algoritmos de localização mais relevantes referentes apenas aos métodos baseados em componentes de freqüência fundamental e ondas viajantes, por fazerem estes, parte do escopo principal desta pesquisa.

As referências serão citadas de modo ordenado conforme o método, a obtenção e a utilização dos dados observados.

\subsection{Métodos baseados nos componentes de freqüência fundamental}

Como comentado anteriormente, a maioria dos métodos de localização que consideram as componentes de freqüência fundamental, são baseados na determinação da impedância aparente da linha de transmissão durante a falta. Esta impedância é obtida em função dos parâmetros da LT e dos fasores fundamentais (60 ou $50 \mathrm{~Hz}$ ) de tensão e corrente, extraídos dos sinais registrados em um, ou em múltiplos terminais da LT, via alguma técnica de filtragem. 


\subsubsection{Algoritmos que utilizam dados somente do terminal local da linha}

Os algoritmos baseados nos componentes de freqüência fundamental registrados em um único terminal, geralmente fazem uso da impedância aparente calculada em relação ao ponto de falta e das correntes de pré-falta para calcular a localização da falta. Entretanto, os mesmos estão sujeitos a erros devido à contribuição de correntes provenientes dos alimentadores remotos e também devido à resistência de falta. Nesses métodos, em geral, faz-se necessário primeiro a identificação do tipo de falta ocorrida, pois o equacionamento para cada tipo de falta é diferente dos demais.

Saint e Paithankar apud Gautier [6] propuseram uma técnica de localização de faltas baseada no cálculo da razão entre a reatância de falta da linha $\left(\mathrm{X}_{\mathrm{LS}}\right)$ (a partir do terminal onde se encontra o localizador de falta até o ponto da falta), e a reatância total da $\operatorname{LT}\left(X_{n}\right)$, ou seja, $X_{L S} / X_{n}$. Como $X_{n}$ é um valor conhecido, a razão $X_{L S} / X_{n}$ determina a posição da falta. Do cálculo dessa razão pode ser derivada a seguinte expressão:

$$
\frac{X_{L S}}{X_{n}}=\frac{\operatorname{sen} \theta_{3} \operatorname{sen} \theta_{1}}{\operatorname{sen} \theta_{2}}
$$

Onde:

$$
\begin{aligned}
& \theta_{1}=\operatorname{arctg}\left(\frac{I_{R}^{\prime} X_{n}}{V_{S}^{\prime}}\right) \\
& \theta_{2}=-\frac{V_{S}^{\prime}}{I_{R}^{\prime} X_{n}-V_{S}^{\prime}} \\
& \theta_{3}=180^{\circ}-\left(\theta_{1}+\theta_{2}\right)
\end{aligned}
$$

Sendo que $I_{R}^{\prime}$ é a corrente pós-falta no terminal $R$ e $V_{S}^{\prime}$ a tensão de pós-falta no terminal local.

A eq.(2.1) denota que a posição da falta pode ser determinada pela medida de dois quaisquer dos três ângulos $\theta_{1}, \theta_{2}$ e $\theta_{3}$. A técnica proposta é baseada na medição destes ângulos por dois contadores digitais. O localizador de faltas é analisado somente sob condições de fonte conectada em um único terminal. Conforme relatado, as estimativas da localização de falta não são precisas caso exista uma contribuição à corrente de falta por fontes conectadas em ambos os terminais da linha e se for levada em conta a resistência de falta. 
Takagi et al. [15] apresentaram um algoritmo de localização baseado no uso de sinais de tensão e corrente apenas de um terminal, os quais são posteriormente filtrados através da técnica da Transformada Discreta de Fourier (TDF), a fim de se obter uma medida dos fasores de tensão e corrente em regime permanente. $\mathrm{O}$ algoritmo utiliza componentes superpostos e modais de tensão e corrente, ao invés dos valores totais para o cálculo da distância. Isso permite que um sistema trifásico seja tratado como um sistema com três circuitos monofásicos independentes, simplificando consideravelmente os cálculos necessários. O equacionamento deste algoritmo faz uso da teoria de quadripólos, do método de Newtow-Raphson e necessita da classificação da falta.

Para uma linha monofásica, aplicando-se a teoria da superposição em redes lineares, isto é, separando a rede faltosa em duas redes derivadas (uma rede de pré-falta e uma rede em que a falta foi isolada) obteremos o vetor $V_{F}$ no ponto de falta:

$$
V_{F}=R_{F} I_{F}=-R_{F}\left(I_{S F}^{\prime \prime}+I_{R F}^{\prime \prime}\right)
$$

Onde $\mathrm{V}_{\mathrm{F}}$ e $I_{S F}^{\prime \prime}$ são estimados por vetores medidos no terminal local da linha:

$$
\begin{aligned}
& V_{F}=A(d) V_{S}-B(d) I_{S} \\
& I_{S F}^{\prime \prime}=C(d) V_{S}^{\prime \prime}-D(d) I_{S}^{\prime \prime}
\end{aligned}
$$

A, B, C e D são as constantes do quadripólo representativo da linha de transmissão, expressas por:

$$
\begin{aligned}
& A(d)=D(d)=\cosh (\lambda d) \\
& B(d)=Z_{0} \cdot \sinh (\lambda d) \\
& C(d)=\sinh (\lambda d)
\end{aligned}
$$

Onde $\lambda$ é a constante de propagação da onda e $d$ a distância da falta.

A partir de uma série de manipulações algébricas envolvendo as eq.(2.3, 2.4 e a 2.5), chega-se a:

$$
R_{F}[1+K(d)]=-\frac{A(d) V_{S}-B(d) I_{S}}{C(d) V_{S}^{\prime \prime}-D(d) I_{S}^{\prime \prime}}
$$

Dadas as equações acima, temos que $V_{F}$ e $I_{F}$ são respectivamente a tensão e a corrente no ponto de falta, $V_{S}$ e $I_{S}$ representam a tensão e a corrente de pré-falta no terminal local, $R_{F}$ a resistência de falta, $I_{S F}^{\prime \prime}$ é o componente superposto da corrente de 
falta do terminal local ao ponto de falta, $I_{R F}^{\prime \prime}$ é o componente superposto da corrente de falta do terminal remoto ao ponto de falta, $Z_{0}$ a impedância característica da linha e $K(d)$ é a relação entre $I_{R F}^{\prime \prime}$ e $I_{S F}^{\prime \prime}$ considerando-se as seguintes hipóteses:

- $R_{F}$ é puramente resistiva e

- Relação $K(d)$ é um número real.

Entretanto, a segunda hipótese só é válida se os equivalentes nos terminais da linha de transmissão forem puramente indutivos e a linha sem perdas, o que em determinados casos pode ser uma boa aproximação.

A equação básica do localizador é definida como:

$$
I_{m}\left[\frac{A(d) V_{S}-B(d) I_{S}}{C(d) V_{S}^{\prime \prime}-D(d) I_{S}^{\prime \prime}}\right]=0
$$

Onde $I_{m}[$.$] representa a parte imaginária de uma variável complexa. A solução \boldsymbol{d}$ da eq.(2.8) corresponde à distância do ponto de falta ao terminal local. A eq.(2.8) é uma equação não linear, sendo necessária uma técnica iterativa, como a de Newton-Raphson, para resolvê-la.

Em Takagi et al. [16], uma continuação de [15], é apresentado uma possível solução para o problema de localização da falta baseado na Transformada de Laplace. Este método considera o modelo de linhas com parâmetros distribuídos e utiliza o princípio da superposição aplicado a análise do estado transitório de uma rede faltosa. A equação fundamental do localizador é não linear. Portanto, se faz novamente necessário o uso de uma técnica de solução iterativa, como a citada anteriormente.

Takagi et al. [17] desenvolveram uma técnica aproximada de localização de faltas, na qual se calcula a reatância da linha faltosa, usando a representação dos fasores de tensão e corrente no terminal local da LT, juntamente com a teoria de quadripólos. Erros causados por vários fatores como: fluxo de carga, resistência de falta e disposição não simétrica da linha de transmissão foram amenizados por esta abordagem. Segundo os autores, a técnica é aplicável para linhas curtas, sendo estas, transpostas ou não.

Este método parte do mesmo equacionamento apresentado anteriormente em [15], mas é direcionado de forma a chegar à seguinte equação: 


$$
V_{S}-I_{S} \cdot Z_{0} \cdot \tanh (\lambda d)=R_{F} \cdot K\left(\frac{V_{S}^{\prime \prime} \cdot \tanh (\lambda d)}{Z_{0}}-I_{S}^{\prime \prime}\right)
$$

Nesse caso as aproximações consideradas são:

- $\tanh (\lambda d)=\lambda d$

- $\frac{V_{S}^{\prime \prime} \cdot \tanh (\lambda d)}{Z_{0}}<<I_{S}^{\prime \prime}$

Considerando essas hipóteses, admitindo que a resistência de falta seja puramente resistiva e que não haja diferença entre as fases das correntes de falta isoladas na linha (em falta menos pré-falta), os valores de $R_{F}$ e $K$ são números reais.

Dessa forma é possível chegar a uma expressão em que a distância da falta pode ser obtida de maneira direta, sem a necessidade de cálculos iterativos por.

$$
d=\frac{I_{m}\left(V_{S}^{\prime} I_{S}^{\prime *}\right)}{I_{m}\left(Z_{L} I_{S}^{\prime} I_{S}^{\prime *}\right)}
$$

Onde o símbolo * indica o conjugado complexo e $d$ a distância do ponto de falta ao terminal local.

Eriksson et al. [18] descreveram uma técnica de localização de faltas usando o Fator de Distribuição de Corrente (FDC), na qual determinam-se o ângulo da tensão no ponto de falta e a distância de falta. Esta técnica apresenta maiores benefícios se comparada ao método proposto por Takagi et al. [17], uma vez que considera a influência introduzida pelo terminal remoto da linha, usando para isso, o modelo completo da rede. Além disso, valores representativos para a impedância da fonte são também armazenados, para compensar as variações nos ângulos das impedâncias e determinar uma correta descrição da rede. O valor de $R_{F}$ desconhecido não é necessário, sendo usado somente o ângulo de $R_{F} I_{F}$ e a tensão no ponto de falta.

O cálculo da localização determina a impedância aparente da falta com uma compensação para a queda de tensão na resistência de falta, eliminando erros na medição convencional do tipo à reatância. Como a impedância de seqüência positiva não depende da resistência do pé de torre e nem da resistência do solo, as componentes da corrente de seqüência zero foram eliminadas e somente as componentes da corrente de seqüência positiva e negativa foram usadas. A partir de todo um equacionamento foi obtida a eq.(2.11), na qual foi introduzido o $\operatorname{FDC}\left(K_{p}\right)$ : 


$$
V_{S}=I_{S} p Z_{l}+\left(\frac{I_{S F}}{K_{P}}\right) R_{F}
$$

Onde $I_{S F}$ varia conforme o tipo de falta e representa a mudança na corrente produzida pela falta, que é igual a atual corrente menos a corrente de pré-falta. O FDC $\left(K_{p}\right)$ é definido pela eq.(2.12) como função da localização da falta, dos parâmetros de seqüência positiva da linha e da impedância das fontes $\left(Z_{S}\right.$ e $\left.Z_{R}\right)$ :

$$
K_{P}=\frac{(1-p) Z_{L}+Z_{S}}{Z_{R}+Z_{L}+Z_{R}}
$$

Onde $Z_{L}$ é a impedância da linha, $p$ a distância da falta em percentagem e $K p$ o fator de distribuição de corrente.

Substituindo a eq.(2.12) na eq.(2.11) foi obtida a expressão complexa (2.13) que contém as variáveis $p$ e $R_{F}$ desconhecidas:

$$
p^{2}-p K_{1}+K_{2}-K_{3} R_{F}
$$

Onde:

$$
\begin{aligned}
& K_{1}=\frac{V_{S}}{I_{S} Z_{L}}+1+\frac{Z_{R}}{Z_{L}} \\
& K_{2}=\frac{V_{S}}{I_{S} Z_{L}} \cdot\left(\frac{Z_{R}}{Z_{L}}+1\right) \\
& K_{3}=\frac{I_{S F}}{I_{S} Z_{L}} \cdot\left(\frac{Z_{S}+Z_{R}}{Z_{L}}+1\right)
\end{aligned}
$$

Separando a equação complexa (2.13), em uma parte real e outra imaginária, são obtidas duas equações simultâneas. Eliminando a resistência de falta $R_{F}$, que é desconhecida, resulta uma expressão em função de uma única variável desconhecida - $p$. Esta é resolvida através de um algoritmo que emprega os valores de pico e posições de fase, obtidos por uma rotina baseada na análise de Fourier.

Ranjbar et al. [19] apresentaram um técnica baseada em modelos de linha de transmissão por parâmetros distribuídos que leva em consideração o efeito da capacitância da linha. A abordagem utilizada baseia-se no cálculo da tensão ao longo da linha de transmissão. No ponto de falta, a tensão assume seu valor mínimo e, assim, 
uma comparação dos valores das tensões em diferentes pontos da linha fornece uma base para a localização da falta. Para isso os autores desenvolveram uma função G(x), proporcional à integral do valor absoluto da tensão sobre um intervalo de tempo limitado. Esta função, por sua vez, faz uso das ondas de tensão ao longo da linha calculadas por meio de equações telegráficas. $\mathrm{G}(\mathrm{x})$ é calculada para diversos pontos sobre a linha e possui seu valor mínimo no local de ocorrência da falta.

O método determina a localização mesmo para uma falta com ângulo de incidência igual à zero. $\mathrm{O}$ erro máximo atingido foi menor que $D_{x} / 2$. Onde $D_{x}$ é a distância entre dois pontos consecutivos da linha de transmissão, sobre os quais são calculados valores para a função $G(x)$. O método faz uso da teoria modal para transformação das equações aplicadas às faltas não simétricas.

Girgis e Fallow [20] desenvolveram duas técnicas de localização de faltas baseadas no conceito de impedância aparente e uso dos fasores trifásicos de tensão e corrente. O primeiro método utiliza dados de apenas um terminal da linha e o segundo método, utiliza dados de dois terminais, sendo estes obtidos por registradores digitais de faltas. Ambos os métodos foram testados utilizando-se de registros de faltas sobre linhas de 69 e de $115 \mathrm{kV}$. Tais técnicas apresentaram alto grau de precisão nos testes avaliados. Segundo os autores, as imprecisões constatadas nas técnicas são devidas à imprecisão dos parâmetros da linha, carga do sistema e comprimento da linha.

Johns et al. [21] apresentaram uma nova proposta para o cálculo da distância de falta dispondo somente dos dados do terminal local. O método utiliza componentes superpostos de tensão e corrente, sendo a equação básica utilizada, expressa por:

$$
Z_{F}=\frac{\left(E_{F}-V_{S}+I_{S} \cdot d \cdot Z_{L}\right) \cdot\left((1-d) \cdot Z_{L}+Z_{R}\right)}{V_{S}-I_{S} \cdot\left(Z_{L}+Z_{R}\right)}
$$

Tal que:

$$
E_{F}=-\left(V_{S}-d \cdot Z_{L} \cdot I_{L}\right)
$$

Onde $Z_{F}$ representa a impedância de falta e $E_{F}$ a tensão no ponto da falta.

Um dos objetivos do método é apresentar insensibilidade às condições de operação da rede. Para os testes realizados, considerando-se uma linha de $400 \mathrm{kV}$ com $100 \mathrm{~km}$ de comprimento, a precisão obtida foi bastante satisfatória. 
Purushothama et al. [22] propuseram a aplicação de Redes Neurais Artificiais (RNAs) ao problema de localização de faltas, usando dados registrados em um, ou em ambos os terminais da linha. Os autores desenvolveram duas RNAs, uma utilizando a rede Multilayer Perceptron (MLP) convencional e outra, baseada na técnica de correlação em cascata de Fahlman, para localização da falta em LTs de Extra Alta Tensão (EAT). Na primeira aplicação (rede MLP), as entradas para a rede caracterizam dados de pré e pós-falta das correntes e de pós-falta das tensões trifásicas, medidas no terminal local, assim como o tipo da falta. A saída do modelo artificial é a localização e a resistência da falta associada. Na segunda aplicação (cascata de Fahlman's) são usadas como entrada, valores de seqüência positiva, negativa e zero da tensão, medidos em ambos os terminais. Esta também apresenta como saída a distância e a resistência da falta. Pelo relato, ambas as aplicações foram comparadas a três convencionais métodos, apresentando resultados promissores.

Saha et al. [23] apresentaram um algoritmo de localização de faltas para linhas paralelas utilizando sinais de tensão e corrente provenientes do terminal local. O algoritmo faz uso de componentes simétricos. As correntes e tensões de fase em ambas as linhas, com falta e sem falta, são utilizadas pelo localizador. O algoritmo é capaz de localizar faltas quando da operação de ambas as linhas, não requerendo o conhecimento das impedâncias das fontes e o uso de sinais de pré-falta. As incertezas com respeito a impedância de seqüência zero da linha é parcialmente limitada, pois a queda de tensão gerada pela falta ao longo da linha é determinada excluindo-se a componente de seqüência zero.

Yibin et al. [24] propuseram uma nova técnica de localização de faltas usando a Transformada Wavelet. Este método faz uso das componentes de freqüência fundamental do sistema, extraídas com o auxílio da TW, para promover a localização da falta. Com base na Análise Multiresolução (AMR) usando wavelets, sendo os sinais amostrados à freqüência de $5 \mathrm{kHz}$, os autores afirmam que as componentes fundamentais estão inclusas na sexta escala de decomposição, a qual compreende a faixa de freqüência de 39,06 à $78,13 \mathrm{~Hz}$. Porém, nesta escala, os sinais são representados por menos de duas amostras por ciclo, o que pode ser considerado insuficiente para representar o sinal. Portanto, considera-se o emprego do algoritmo de codificação por sub-bandas de tempo invariante, o qual mantém o mesmo número de 
amostras em todas as escalas. O algoritmo proposto apresentou melhores resultados quando comparado a um algoritmo baseado na extração dos fasores fundamentais por meio da Transformada de Fourier.

Soares et al. [25] descrevem uma outra aplicação da teoria wavelet ao problema de localização de faltas em linhas de transmissão seguindo o princípio apresentado em [24]. O método faz uso das componentes de freqüência fundamental dos sinais de tensão e corrente para promover a localização da falta. A partir dos sinais de tensão e corrente, suas versões aproximadas e detalhadas são obtidas através da implementação do algoritmo de codificação por sub-bandas, baseado na AMR. Porém, neste método, são consideradas as aproximações de terceira escala dos sinais de tensão e corrente para se obter as componentes na faixa de freqüência de 0 a $480 \mathrm{~Hz}$. Para a implementação deste método, considera-se que as componentes fundamentais dos sinais de tensão e corrente são obtidas ao extrair as componentes dos sinais de terceira escala, sendo a distância estimada considerando o método da impedância aparente.

Senger et al. [26] também apresentam o desenvolvimento e implementação de um algoritmo para localização de faltas em linhas de transmissão. $\mathrm{O}$ algoritmo de faltas proposto baseia-se na referência [15]. Porém, leva em consideração algumas modificações com o objetivo de melhorar a resposta do algoritmo quando aplicado a circuitos duplos e a diminuir o esforço computacional. O algoritmo modificado é baseado no modelo de linha curta, isto é, as capacitâncias são desprezadas e não são utilizadas funções hiperbólicas. O método utiliza um modelo de filtro digital tipo FIR (Finite Impulse Response) desenvolvido para filtrar os sinais de tensão e corrente, de forma a eliminar a componente exponencial amortecida eventualmente presente nas formas de onda e, dessa forma, reduzir o erro na estimativa dos fasores de pré e pósfalta calculados pela TDF. O cálculo da distância é realizado de forma direta, sem nenhum processo iterativo. Segundo os autores, a função de localização proposta é robusta e apresenta um nível de precisão satisfatória.

Em Pereira e Zanetta Jr. [27] é apresentado um algoritmo de localização de faltas baseado nos fasores fundamentais dos sinais de pré-falta da corrente e pós-falta de tensão medidos no terminal local. O algoritmo não usa hipóteses simplificadoras no seu equacionamento, mas requer a impedância equivalente das fontes de ambos os lados da 
linha e a classificação do tipo da falta. A principal vantagem do algoritmo reside no fato do mesmo ser insensível à saturação dos transformadores de corrente (TCs), uma vez que o mesmo não utiliza sinais de pós-falta da corrente.

\subsubsection{Algoritmos que utilizam dados de mais de um terminal da linha}

Com a finalidade de melhorar a precisão dos algoritmos de localização de faltas em linhas de transmissão, muitos autores propõem o uso de dados observados em ambos os terminais da linha. Essas técnicas, geralmente, são independentes da impedância de falta e de mudanças na configuração das fontes dos sistemas de potência. Por outro lado, torna-se necessário um meio de comunicação entre os terminais, bem como um método para determinação dos ângulos de fase das tensões e correntes, em relação a um eixo de referência comum.

Schweitzer e Jachinowshi [28] propuseram uma técnica usando corrente e tensão em regime permanente, provenientes dos dois terminais da linha. Uma primeira abordagem é usada para um modelo de linha curta. A tensão no ponto da falta (ponto $F$ ), usando dados de ambos os barramentos, como por exemplo, barramentos $S$ e $R$, são dadas pelas eq.(2.16 e 2.17):

$$
\begin{aligned}
& V_{F}^{\prime}=V_{S}^{\prime}-p Z_{L} I_{S}^{\prime} \\
& V_{F}^{\prime}=V_{R}^{\prime}-(1-p) Z_{L} I_{R}^{\prime}
\end{aligned}
$$

Equacionando-as de modo a eliminar $V_{F}^{\prime}$, obtêm-se o resultado:

$$
p=\frac{\left(V_{S}^{\prime}-V_{R}^{\prime}\right)+Z_{L} I_{R}^{\prime}}{Z_{L}\left(I_{S}^{\prime}+I_{R}^{\prime}\right)}
$$

A eq.(2.18) fornece o valor de $p$, usando valores em regime permanente para correntes e tensões, e representa a distância fracionada ao ponto de falta.

Considerando um sistema com linhas curtas e assumindo que as correntes em ambos os terminais da linha são as mesmas sob condições normais (sem a ocorrência de faltas). Portanto, pode-se deduzir que na condição de pré-falta:

$$
I_{R}^{\prime}=-I_{S}^{\prime}
$$


Dado a observação anterior, pode-se pela corrente de pré-falta estabelecer uma relação de fase entre os clocks nas duas subestações, tornando possível a sincronização dos dados para a obtenção da precisão máxima.

Todavia, para linhas longas a aproximação para linhas curta não é justificada, sendo necessário a dedução usando-se equações com parâmetros distribuídos. Portanto, as eqs. (2.16 e 2.17) são substituídas por:

$$
\begin{aligned}
& V_{F}^{\prime}=V_{S}^{\prime} \cosh (\lambda p L)-Z_{0} I_{S}^{\prime} \cosh (\lambda p L) \\
& V_{F}^{\prime}=V_{R}^{\prime} \cosh [\lambda(1-p) L]-Z_{0} I_{R}^{\prime} \cosh [\lambda(1-p) L]
\end{aligned}
$$

A solução obtida para a localização, usando as equações acima definidas e as aproximações de primeira ordem para as exponenciais das funções hiperbólicas, fica:

$$
p=\frac{\left(V_{S}^{\prime}-V_{R}^{\prime}\right)-Z_{0} \lambda L I_{R}^{\prime}}{Z_{0} \lambda L\left(I_{S}^{\prime}+I_{R}^{\prime}\right)-\left(V_{S}^{\prime}-V_{R}^{\prime}\right)(\lambda L)-\left(V_{R}^{\prime}+Z_{0} I_{R}^{\prime}\right)(\lambda L)^{2}}
$$

Onde: $Z_{0} \lambda L=Z_{L}$.

Uma estimativa da corrente de pré-falta $\left(I_{R}^{\prime}\right)$ no barramento local é necessária para a sincronização dos clocks. Usando as mesmas aproximações, a estimativa é:

$$
I_{R S}^{\prime}=V_{S}^{\prime}\left[\lambda L / Z_{0}\right]-I_{S}^{\prime}
$$

Onde $I_{R S}^{\prime}$ denota uma estimativa para a corrente do barramento $R$ no barramento $S$.

Conforme apontado, este método não requer valores para os parâmetros do sistema externo à linha de transmissão monitorada. Contudo, não são apresentados resultados com referência a nenhuma das técnicas mencionadas acima. Na realidade, a precisão pode ser limitada por alguns fatores, como por exemplo, grau de fidelidade do modelo da linha usado na implementação, precisão com que os parâmetros da linha são determinados e pelos hardwares e softwares empregados, o que inclui eficiência do método de filtragem para obtenção dos valores em regime permanente.

Sachedev e Agarwal [29] propuseram uma técnica de localização de faltas não iterativa que é adequada às situações envolvendo o terra. O método faz uso da impedância aparente local da linha, da corrente de seqüência positiva medida localmente por relés, e também de dados correspondentes ao terminal remoto. A partir dessas informações, diferentes tipos de faltas foram analisados e testados usando a 
teoria de componentes simétricos, a fim de se obter a distância da falta para cada caso. Impedâncias das fontes, fatores de distribuição e correntes de pré-falta não foram usados no processo de NI.

A técnica foi testada para dados simulados envolvendo situações de faltas faseterra e fase-fase-terra. Os resultados indicaram que os erros de estimação são menores que $5 \%$ do comprimento da linha, exceto para uma porção da linha próxima do seu ponto médio, onde as contribuições das correntes de faltas dos dois terminais da linha são iguais. Conforme relatado, as medidas realizadas nos dois terminais não necessitam ser sincronizadas e o efeito da capacitância em paralelo é desprezado.

Jeyasurya e Rahman [30] tomaram por base a eq.(2.18) para estimar a localização de faltas em linhas de transmissão. Os autores também fizeram uso de um método para determinar o ângulo de fase entre as correntes dos relés relativos a um eixo de referência comum.

Cabe comentar que a eq.(2.18) despreza a capacitância em paralelo nas linhas de transmissão. Para linhas de EAT longas, onde as correntes de carga são substanciais, os autores afirmam que o método apresentará uma estimação altamente precisa para a localização da falta, visto que os transitórios de alta freqüência, originados pela capacitância em paralelo, são eliminados através de filtros adequados.

Uma estimativa precisa da posição da falta é obtida com um ciclo de dados pósfalta, quando a capacitância da linha é desprezada. Levando-se em conta essa capacitância, foi observado que quase dois ciclos de dados pós-falta são necessários para obter a mesma estimativa.

Johns e Jamali [31] descreveram uma técnica precisa de localização de faltas para linhas de transmissão, a qual envolve o monitoramento e a filtragem das ondas de tensões e correntes medidas em ambos os terminais da linha, de maneira a produzir uma medida dos fasores fundamentais em regime permanente. Eles usaram as eq.(2.20 e 2.21) para uma avaliação exata da distância à falta, calculando-a pela teoria dos modos naturais e função matricial. A expressão final para o cálculo da distância da falta para o modelo em uma única etapa é dada pela eq.(2.24):

$$
d=\frac{\arctan h(-B / A)}{\lambda}
$$


Onde:

$$
\begin{aligned}
& A=I_{R}^{\prime} \cosh (\lambda L) Z_{0}-V_{R}^{\prime} \sinh (\lambda L)+Z_{0} I_{S}^{\prime} \\
& B=V_{R}^{\prime} \cosh (\lambda L)-Z_{0} V_{R}^{\prime} \sinh (\lambda L)+V_{S}^{\prime}
\end{aligned}
$$

A localização da falta independe da resistência de falta e não exige qualquer conhecimento da impedância da fonte. $\mathrm{O}$ método mantém um alto grau de precisão para linhas não transpostas e nenhuma identificação do tipo da falta é exigida. Para todos os casos avaliados, o erro produzido pelo algoritmo foi satisfatório.

Kalam e Johns [32] descrevem um novo método de localização de faltas para linhas de transmissão com três terminais, fundamentado nas idéias de Johns e Jamali [31]. Entretanto, a aplicação é estendida para os dados de tensão e corrente, medidos nos três terminais, os quais são filtrados de maneira a produzir uma medida dos fasores fundamentais em regime permanente. $\mathrm{O}$ algoritmo é independente da resistência da falta e não exige qualquer conhecimento da impedância da fonte e do tipo da falta. $O$ algoritmo também não requer um pré-conhecimento da seção na qual a falta ocorreu.

Em Girgis et al. [5] a distância da falta é obtida a partir do equacionamento dos vetores trifásicos de tensão e corrente com o uso da matriz trifásica de impedâncias série da linha, sendo desprezado o efeito da capacitância, o que é uma boa aproximação apenas para linhas curtas.

O método considera linhas de dois ou três terminais, e pode ser aplicado mesmo no caso de não haver sincronização dos dados entre os terminais. Para o caso de linhas de dois terminais com dados sincronizados, tem-se:

$$
\begin{aligned}
& {\left[V_{F}\right]=\left[V_{S}\right]-d \cdot\left\lfloor Z_{a, b, c}\right\rfloor \cdot\left[I_{S}\right]} \\
& {\left[V_{F}\right]=\left[V_{R}\right]-(l-d) \cdot\left\lfloor Z_{a, b, c}\right\rfloor \cdot\left[I_{R}\right]}
\end{aligned}
$$

Das duas equações acima:

$$
\left[V_{L}\right]-\left[V_{R}\right]+l \cdot\left\lfloor Z_{a, b, c}\right\rfloor \cdot\left[I_{R}\right]=d \cdot\left[Z_{a . b . c}\right] \cdot\left(\left[I_{L}\right]+\left[I_{R}\right]\right)
$$

A eq.(2.29) pode ser rescrita como:

$$
Y=M \cdot d
$$


Onde:

$$
\begin{aligned}
& Y=\left[V_{L}\right]-\left[V_{R}\right]+\left\lfloor Z_{a, b, c}\right\rfloor \cdot\left[I_{R}\right] \cdot l \\
& M=\left[Z_{a, b, c}\right] \cdot\left(\left[I_{L}\right]+\left[I_{R}\right]\right)
\end{aligned}
$$

O valor da incógnita $d$ na expressão (2.30) é obtido com o uso do método dos mínimos quadrados:

$$
d=\left(\bar{M}^{T} \cdot M\right)^{-1} \cdot \bar{M}^{T} \cdot Y
$$

Onde $\bar{M}^{T}$ é a matriz $M$ transposta com os elementos conjugados, $\left[\mathrm{V}_{\mathrm{L}}\right]$ e $\left[\mathrm{I}_{\mathrm{L}}\right]$ são os vetores de tensão e corrente trifásicos no terminal local, $\left[\mathrm{V}_{R}\right]$ e $\left[\mathrm{I}_{\mathrm{R}}\right]$ são os vetores de tensão e corrente trifásicos no terminal remoto, $\left[Z_{\mathrm{a}, \mathrm{b}, \mathrm{c}}\right]$ é a matriz trifásica de impedância série da linha, $l$ é o comprimento da linha e $d$ a distância da falta.

A metodologia apresentada estende-se para linhas de três terminais e permite a utilização de dados não sincronizados. A mesma independe do tipo e da resistência de falta.

Coury et al. [33] apresentaram um método para computar a localização das faltas nas linhas de transmissão de três terminais, desenvolvido a partir do método para linha de dois terminais reportado por Johns e Jamali [31]. A técnica é baseada na utilização das formas de ondas de tensão e corrente em todos os terminais de uma típica linha de três terminais de EAT, sendo as formas de ondas filtradas, usando-se a técnica da TDF a fim de se obter uma medida dos fasores de tensão e corrente em regime permanente. Essa técnica faz uso da teoria da superposição e de componentes modais, ao invés dos valores de fase para calcular a distância da falta. Alguns artifícios são também desenvolvidos para efetivamente sincronizar os dados provenientes dos três terminais e identificar exatamente o ramo faltoso. Artifícios estes, necessários para se obter um alto grau de exatidão. A técnica é também virtualmente independente da resistência de falta e insensível às variações na impedância da fonte e configurações de linha, incluindo a sua não transposta. O método em questão apresenta uma boa precisão para as condições analisadas.

Novosel et al. [34] apresentam um método baseado no equacionamento com matrizes trifásicas da linha. Por ser um método off-line, não requer sincronização dos 
dados nos terminais e permite a comunicação por um simples canal, como é o caso do modem.

Em Zamora et al. [35] a obtenção da distância de falta é feita utilizando apenas os componentes fundamentais dos sinais de tensão de falta e pré-falta registrados em ambos os terminais da linha e um novo conceito denominado fator de distância $\left(K_{v}\right)$. São considerados no equacionamento componentes superpostos e componentes simétricos de tensão e corrente para a melhoria da precisão do algoritmo, que parte da seguinte equação:

$$
V_{F d}=-Z_{t h} \cdot I_{F d}
$$

Onde $Z_{\text {th }}$ representa a impedância equivalente de Thévenin de seqüência positiva do sistema modelado como um circuito PI, $V_{F d}$ é a componente de tensão superposta de seqüência positiva e $I_{F d}$ a corrente superposta de seqüência positiva, ambas no ponto de falta.

No que segue, os autores fizeram uso de um fator de distância $\left(K_{v}\right)$, que representa a razão entre os componentes de tensão superpostos de seqüência positiva de ambos os terminais, que por sua vez é função da distância. A partir do fator de distância é obtida a distância de falta, através da consulta a uma curva $K_{v}$ versus $p$, sendo $p$ igual a distância da falta em p.u.. A curva referenciada está definida como uma função de $K_{v}$ e determinada em particular para a linha em análise. Para os testes apresentados, o erro máximo obtido foi de $2,25 \%$ do comprimento da linha, mesmo considerando a entrada de dados com erros em amplitude e em ângulo. O algoritmo é independente do sincronismo de dados, do tipo e resistência de falta e condições de pré-falta.

Gong et al. [36] apresentam um algoritmo de localização de faltas que faz uso de sinais de tensão e corrente provenientes de dois ou três terminais. O algoritmo utiliza um modelo matemático expresso por equações diferenciais, onde o efeito da resistência de falta é eliminado completamente. Os autores propõem o uso de GPS para uma ideal sincronização dos dados e o uso de modem e linha telefônica para transferência dos mesmos.

Tziouvaras et al. [37] apresentam um novo sistema de localização de faltas para linhas com múltiplos terminais. O algoritmo proposto utiliza componentes de seqüência 
negativa, não requer sincronização dos dados ou a identificação do tipo da falta. O mesmo não é afetado pelo fluxo de carga de pré-falta, acoplamento mútuo, resistência de falta, assimetria do sistema e infeeds de corrente.

Sollero et al. [38] descrevem um novo método de localização de faltas em linhas de transmissão a ser incorporado ao Sistema Integrado de Apoio à Análise de Perturbações (SINAPE - CEPEL). Este módulo faz uso dos fasores de tensão e corrente de falta de ambas as extremidades da linha, obtidos pelo processamento, via SINAPE, das amostras armazenadas por oscilógrafos digitais. O algoritmo implementado é fundamentado em [31]. O SINAPE é uma ferramenta que integra uma ampla variedade de funções para análise de eventos oscilográficos. Para utilização do novo algoritmo proposto no SINAPE é necessária uma estrutura de comunicação para transferência dos dados. Os resultados obtidos indicam que o módulo de localização de falta apresentado resolve, simultaneamente, vários problemas, não triviais, para se chegar ao ponto de ocorrência da falta, além de apresentar resultados mais consistentes e precisos.

Sousa et al. [39] apresentam a concepção, implementação e validação prática de uma metodologia para localização de faltas em linhas de transmissão utilizando informações dos dois terminais, baseada no método proposto por Johns e Jamali [31] em 1990, adaptada para linhas de transmissão do sistema brasileiro, e implementada no software de análise de perturbações da CEMIG (Companhia Energética de Minas Gerais). O método foi modificado de modo a informar a provável faixa de localização da falta via processo estatístico e distribuição de Gauss, assim como, estimar o ponto exato da falta.

\subsection{Métodos baseados nos componentes de alta freqüência gerados por uma falta}

Os algoritmos baseados nas componentes de alta freqüência dos sinais transitórios gerados por uma situação de falta são fundamentados na teoria de ondas viajantes em um sistemas de transmissão, (BEWLEY) [40]. Estes algoritmos se baseiam, geralmente, na determinação do tempo de viagem da onda do ponto de falta ao terminal de monitoramento e na velocidade de propagação da onda viajante na linha em questão, 
para estimar, o mais precisamente quanto possível, o ponto de ocorrência de uma falta (JOHNS e SALMAN) [41] e (CHRISTOPOULOS e WRIGHT) [42].

Os algoritmos fundamentados na teoria de ondas viajantes podem ser classificados em duas categorias quanto à aquisição de dados, a saber: em um ou em múltiplos terminais. A seguir serão apresentados alguns dos trabalhos referentes aos métodos comentados.

\subsubsection{Algoritmos que utilizam dados somente do terminal local da linha}

Gale et al. [43] descrevem diversos e distintos tipos de equipamentos que foram desenvolvidos na década de 50, para a localização de faltas em linhas de transmissão, baseados em ondas viajantes. Estes foram classificados de acordo com o seu modo de operação em tipos: A, B, C e D. Apesar da eficácia apresentada pelos resultados obtidos por essas técnicas ser encorajadora, o custo de instalação, operação e manutenção era alto, limitando as suas aplicações. Todavia, em meados dos anos 60, diversas linhas de 275 e $400 \mathrm{kV}$ do Reino Unido foram equipadas com o localizador do Tipo C, que ainda hoje pode ser encontrado comercialmente.

Cabe comentar que os localizadores do Tipo A e D não incluem circuitos geradores de pulso, utilizando-se apenas dos transitórios viajantes produzidos pela falta para poder determinar a localização da falta. Os Tipos B e C necessitam de um circuito gerador de pulsos para efetuarem a localização.

- Localizador de falta Tipo A: utiliza dados de um terminal e mede o tempo de viagem dos transitórios gerados por uma falta entre o ponto de falta e o terminal local.

- Localizador de falta Tipo D: utiliza dados dos dois terminais e detecta o tempo de chegada da primeira onda viajante gerada por uma falta para o cálculo da distância da mesma. Esse método necessita de sincronização dos dados.

- Localizador de falta Tipo B: este utiliza dados provenientes de ambos os terminais e, o envio de um sinal de sincronização no tempo aos detectores de onda em cada terminal da linha. Há três variações do Tipo B, sendo elas:

> Tipo B1: utiliza um pulso de rádio enviado por um canal de microondas;

Tipo B2: faz uso de um sistema carrier de linha de potência e

Tipo B3: usa a injeção de um pulso CC sobre a linha. 
Os três tipos detectam a chegada dos transitórios em seus terminais. Quando a primeira onda gerada por uma situação faltosa atinge o terminal mais próximo, esta dispara um contador eletrônico que será parado por um sinal enviado pelo terminal remoto, assim que o transitório inicial da falta alcançá-lo. Conhecendo-se o tempo de propagação para todo o comprimento da linha e o valor contado, determina-se a distância como no Tipo D.

- Localizador de faltas do Tipo C: utiliza dados de um terminal e opera usando o princípio do radar. Um pulso é aplicado na linha e o tempo de viagem ao ponto de falta, e deste ao terminal local, é determinada e usada para calcular a distância de ocorrência.

Os autores apresentam também resultados observados por um localizador de faltas baseado nos modos de operação do Tipo A, D e B3, implementados utilizando-se da tecnologia atual (microprocessadores, GPS, etc). Os autores chamam a atenção para técnicas inviáveis quando das suas apresentações, mas promissoras e tecnicamente viáveis nos dias atuais.

Vitins [44] apresenta um método de proteção de distância para linhas de transmissão baseado nas equações de onda da linha. Neste método, a localização da falta é considerada como um problema de determinação do tempo de viagem das ondas entre o terminal local e o ponto de falta. O tempo de viagem é extraído das formas de ondas fundamentais de tensão e corrente na presença de transitórios superpostos, por meio de uma técnica de correlação. O método foi testado por simulações numéricas e dados experimentais apresentando resultados satisfatórios.

Crossley e Maclaren [45] apresentam uma técnica para uma rápida medida da distância da falta usando o princípio das ondas viajantes. A localização da falta é determinada pelo intervalo de tempo entre a primeira onda incidente ao relé e a correspondente onda refletida do ponto de falta, também observada sobre o relé. A onda refletida é reconhecida através da correlação cruzada do sinal refletido contra o sinal inicialmente incidente e armazenado. A máxima saída da função de correlação cruzada ocorre quando o atraso da seção do sinal inicial corresponde a duas vezes a distância para a falta. A precisão da localização da falta depende do local da falta, do tipo da falta e do ângulo de incidência da falta. 
Rajendra e Maclaren [46] partem do mesmo princípio apresentado em [45], estendendo a aplicação a circuitos com derivação ou de três terminais. O método utiliza a correlação cruzada entre uma seção da primeira onda viajante direta, detectada e armazenada, e a segunda onda viajante reversa que reflete do ponto de falta e retorna ao ponto do relé. Pelos autores, consegue-se então estimar o intervalo de viagem dos transitórios, determinando-se assim a distância da falta.

Shehab-Elkin e Maclaren [47] examinam alguns problemas e sugerem novas técnicas para melhorar a proteção de distância baseada em ondas viajantes propostas em [45]. Os autores usam uma correlação composta, consistindo na correlação de uma janela de dados pequena e uma janela de dados longa, para reconhecer as reflexões do ponto de falta e distingui-las de outras reflexões provenientes do terminal remoto, assim como, para aumentar a amplitude da correlação cruzada. Um fator de correção é usado para compensar a queda na amplitude dos sinais devido aos efeitos do ângulo de incidência da falta, mantendo a amplitude de saída da correlação dependente da distância da falta. Conforme apresentado, observa-se que a resistência da falta não afeta a precisão do localizador de faltas.

Ancell e Pahalawaththa [48] descrevem uma aplicação para o problema de localização de faltas baseado na estimação da máxima verossimilhança dos tempos de chegada das ondas refletidas. O método da máxima verossimilhança, na maioria dos testes realizados, apresentou resultados melhores que dos métodos de correlação convencional. Já para ângulos de incidência de falta próximos a zero, nenhum dos esquemas apresenta bons resultados.

Bo et al. [49] descrevem uma nova técnica para uma precisa localização de faltas. Um equipamento projetado especialmente para o registro dos transitórios de falta é usado para extrair os sinais de tensão transitórios gerados por uma falta em um sistema de transmissão ou distribuição. O tempo de viagem dos sinais de alta freqüência é usado para determinar a posição da falta. O algoritmo é insensível ao tipo de falta, resistência e ângulo de incidência da falta, bem como as configurações das fontes. A precisão da localização da falta é proporcional a taxa de amostragem.

Magnago e Abur [50] descrevem o uso da Transformada Wavelet na análise dos transitórios de faltas em sistemas elétricos de potência, a fim de determinar a 
localização da falta. Usando a teoria das ondas viajantes, os sinais registrados são primeiramente decompostos em seus componentes modais, que por sua vez, são transformados do domínio do tempo para o domínio tempo-freqüência através da TW. Esta informação relata o tempo de viajem dos sinais transitórios para localizar a falta. Os coeficientes wavelets nas duas menores escalas (detalhe um e dois) dos sinais do modo aéreo 1 e do modo terra são usados pelo algoritmo. Os coeficientes wavelets do modo aéreo na escala 1 são utilizados para o cálculo da distância da falta, enquanto os coeficientes wavelets do modo terra, em ambas as escalas somente são utilizados para determinar a presença de conexão a terra e a metade da linha em que uma falta aterrada se encontra. O método proposto é independente da resistência de falta e se mostra também adequado para aplicação em linhas com compensação série. O método pode ser usado tanto para dados provenientes de um terminal, quanto para dados dos dois terminais. A precisão do algoritmo é proporcional a taxa de amostragem utilizada para o registro dos sinais transitórios de falta.

Liang et al. [51] analisam um algoritmo de proteção baseado na função de correlação convencional usando ondas viajantes e propõem uma lógica baseada em uma função de correlação wavelet. O algoritmo utiliza a Transformada Wavelet spline multiescala para detectar o sinal das ondas viajantes, e então, uma função de correlação wavelet para completar a operação de correlação no domínio wavelet ao invés do domínio do tempo e determinar a localização da falta. O algoritmo apresentou melhor precisão e rejeição a ruídos quando comparado a um método de correlação tradicional.

Chen et al. [52] tomam por base o método proposto por Bo e companheiros [49], aliando este ao uso da Transformada Wavelet. A TW é usada para decompor os sinais transitórios de falta e desta maneira revelar o tempo de viagem destes sinais, necessários para localizar a falta em cabos de distribuição. O método proposto é insensível ao tipo da falta, resistência e ângulo de incidência da falta, bem como da configuração das fontes do sistema.

Abur e Magnago [53] apresentam um aperfeiçoamento do método de localização de faltas baseado na teoria de ondas viajantes e uso da TW, proposto pelos mesmos autores em [50]. O novo método requer o registro dos transitórios de falta em apenas um terminal da LT. Os sinais são desacoplados em seus componentes modais e então 
transformados no domínio tempo-freqüência usando a TW, fornecendo desta maneira, o tempo entre as reflexões de onda para a estimação da distância da falta. O novo método faz uso da diferença entre os tempos dos modos terra e aéreo para determinar a localização de faltas aterradas na primeira ou segunda metade da linha de transmissão. São apresentados dois diferentes algoritmos para linhas com e sem acoplamento mútuo. Neste método, a precisão da localização da falta não é afetada pela impedância da falta, acoplamento mútuo, compensação série e transitórios produzidos por eventos que não caracterizem uma falta. O erro na estimação do local da falta é função da taxa de amostragem utilizada.

Silveira et al. [14] descrevem uma metodologia aplicada ao problema de localização de faltas utilizando a TW. Neste método, os sinais normalizados de tensão e corrente são decompostos através da TW, fornecendo os coeficientes wavelet de mais alta resolução no tempo. Esses coeficientes são desacoplados, utilizando-se uma matriz de pesos modais modificada, descrita em Silveira et al. [54] e [55], obtendo-se por meio desta, sete saídas. A primeira relacionada ao modo terra e as demais, aos modos aéreos. Estas saídas são comparadas a limiares apropriados, detectando-se, em caso de falta, a primeira e segunda frente de ondas viajantes com seus respectivos instantes de ocorrência. Pelo intervalo de onda entre duas frentes de ondas, estima-se a distância da falta.

Os maiores erros encontrados, em relação à localização real da falta, foram de $2,8 \%$ para ocorrências próximas aos terminais da linha.

Mustafa e co-autores [56] apresentam um esquema de análise de dados gráfica e localização de faltas por ondas viajantes, o qual é validado por meio de simulações e dados reais medidos em determinadas barras do sistema ScottishPower 440kV. O algoritmo de localização testado utiliza os sinais modais de corrente, a impedância de onda e correlação cruzada para distinguir dentre ondas incidentes e ondas refletidas para posterior localização da falta.

Em Silva et al. [57] é apresentado um esquema completo de localização de faltas baseado nas teorias das ondas viajantes e TW. O algoritmo foi concebido para utilizar dados do terminal local e/ou dados de ambos os terminais, conforme a necessidade do usuário e a disponibilidade dos recursos necessários no sistema. Conforme os testes 
apresentados, o algoritmo mostra-se praticamente insensível à forma de aquisição de dados, ao tipo, resistência e ângulo de incidência da falta e acoplamento mútuo. Porém sua precisão é sensível à variação da taxa amostral.

Jiang et al. [58] utilizam uma nova ferramenta de processamento de sinais denominada Análise via Segunda Geração Wavelet aplicada ao problema de localização de faltas em linhas de transmissão. O propósito desta nova análise é de extrair, de maneira mais eficiente, características das ondas viajantes (amplitude e polaridade) geradas por uma situação de falta para posteriormente usá-las para a estimação da distância da falta. Segundo os autores, os resultados obtidos decorrentes das simulações utilizando o novo esquema de análise mostraram-se mais eficientes no tocante a esforço computacional e precisão.

\subsubsection{Algoritmos que utilizam dados de múltiplos terminais da linha}

A técnica proposta por Ibe e Cory [59]-[60], para linhas de dois terminais, baseada nos princípios das ondas viajantes, também é empregada para determinar a localização de faltas em linha de três terminais. Para linhas de dois terminais, dados amostrados somente no terminal local são suficientes para localizar a falta. No entanto, para as linhas de três terminais, um registro adicional em qualquer um dos terminais remotos pode ser necessário para confirmar o ramo faltoso. Uma localização precisa entre 0,07 e $3,2 \%$ é encontrada para um sistema de $33 \mathrm{kV}$.

Em Gale et al. [43] também são apresentadas duas técnicas de localização por ondas viajantes, que fazem uso de dois terminais. Essas técnicas são classificadas de acordo com o seu modo de operação em tipos D e B, os quais já foram comentados anteriormente. Os autores demonstram que tais técnicas podem ser implementadas dispondo da tecnologia atual dos microprocessadores e GPS, alcançando bons resultados.

Lee e Mousa [61] descrevem a aplicação e operação prática de um novo sistema de localização de faltas baseado em ondas viajantes utilizado no sistema de $500 \mathrm{kV}$ da Bristish Columbia Hydro (Burnaby, Bristish Columbia, Canadá). Este sistema mede o tempo de chegada da onda viajante gerada por uma falta nos terminais do sistema, 
sincronizados por meio de GPS. A experiência com este localizador de faltas, tanto em caso de faltas permanentes como frente às descargas atmosféricas, indica uma alta precisão na maioria dos casos. Somente para alguns casos decorrentes de descargas atmosféricas o sistema apresentou medidas equivocadas.

Os autores Jian et al. [62] apresentam um novo método de localização, com dados registrados em ambos os terminais, utilizando a Transformada Wavelet Contínua (TWC). São descritas duas técnicas para o cálculo da distância, levando-se em consideração o comprimento da linha. O novo método apresentou uma melhor precisão, em relação ao método convencional, além de ser independente da resistência de falta, posição da falta e características geográficas. A taxa de amostragem utilizada foi de 1 $\mathrm{MHz}$.

Gale et al. [63] relatam o uso e a experiência da aplicação prática de um localizador de faltas baseado em ondas viajantes no sistema de transmissão de Eskom, localizado na África do Sul. Segundo os autores, o sistema de localização de faltas por ondas viajantes (TWS, do inglês Traveling Wave Fault Location System) foi extensivamente testado e apresentou resultados promissores para localização de faltas em linhas de transmissão de corrente alternada, compensadas ou não, considerando também nos testes, sistemas de corrente contínua. Este localizador é agora utilizado em toda a rede de transmissão de Eskom e fornece níveis de precisão melhores do que os convencionais baseados no cálculo da impedância da linha.

Kim et al. [64] descrevem um método de localização de faltas usando como ferramenta a TW para analisar os transitórios de falta e, por conseguinte, determinar a localização da falta. Os dados amostrados em ambos os terminais são sincronizados via GPS, e posteriormente, analisados usando a TW. Os sinais provenientes da análise wavelet são transmitidos a um servidor principal, onde é feito o cálculo da localização da falta. Os autores apresentam também a estrutura de um possível sistema de monitoração para localização de faltas. A viabilidade do sistema proposto é mostrada através de alguns resultados experimentais.

Chanda et al. [65] propuseram um método de localização baseado na análise multiresolução wavelet combinada com uma técnica de interpolação cúbica. Este 
método utiliza sinais de correntes obtidos em ambos os terminais da linha. Os resultados obtidos por meio de extensivas simulações demonstram que o método proposto apresenta uma elevada precisão, além de ser independente dos efeitos do ângulo de incidência, distância e resistência da falta.

Pereira et al. [66] apresentam os primeiros resultados de um protótipo de um localizador de faltas para linhas de transmissão baseado em ondas viajantes e aquisição de dados em dois terminais. O trabalho discorre sobre toda concepção utilizada, evidenciando-se o processo de detecção da chegada dos transitórios aos terminais da linha e o esquema de correlação dos arquivos de registros temporais de forma a se localizar a falta. O protótipo é testado por simulações e dados reais, apresentando resultados adequados. O método das ondas viajantes implementado mostrou-se robusto e insensível aos fatores que influenciam os métodos baseado em componentes de freqüência fundamental.

Mais recentemente, Silva e co-autores [67] apresentaram o desenvolvimento inicial de um algoritmo de localização de faltas para linhas de transmissão com três terminais, dispondo da TW. Neste trabalho a TW é utilizada para analisar os transitórios de alta freqüência dos sinais de corrente, gerados por uma situação de falta em um sistema de transmissão com três terminais. O objetivo de tal análise é detectar o instante de chegada da primeira onda em ambos os terminais do sistema, para com isso, estimar com precisão o ponto de ocorrência da falta e o ramo faltoso. Este trabalho considera que haja um meio de comunicação entre os terminais da linha de transmissão e que os dados sejam sincronizados por meio de GPS. Os resultados alcançados até o momento, referentes às diversas situações de faltas aplicadas sobre o sistema teste, mostram-se altamente satisfatórios e promissores. 


\section{FUNDAMENTOS SOBRE ONDAS VIAJANTES E TRANSFORMADA WAVELET}

\subsection{Ondas viajantes em sistemas de transmissão}

Quando se fala em ondas viajantes, refere-se à propagação da energia sobre um sistema, aqui em especial, a propagação da energia elétrica sobre uma linha de transmissão. Se uma variação qualquer de corrente ou de tensão ocorre em um terminal de uma linha de transmissão, o outro terminal só irá sentir tal variação quando a onda referente ao sinal elétrico percorrer todo o comprimento da linha. Sendo assim, o terminal remoto da linha de transmissão, não pode influenciar nas decisões sobre o sistema, até que a onda tenha viajado da fonte do terminal local ao terminal remoto, onde, através da interação deste com a linha de transmissão, seja produzida uma resposta que viaja de volta para a fonte local. Desta maneira, os sinais elétricos tendem a se propagar para frente e para trás, como ondas viajantes, normalmente dissipando energia com perdas no material (HEDMAN) [68].

Do exposto acima, tem-se que qualquer distúrbio em uma linha de transmissão (tal como os provocados por descargas atmosféricas, curtos-circuitos, ou uma súbita alteração da condição de regime permanente) dá origem a ondas viajantes. Estas por sua vez, deslocam-se do ponto de inserção às extremidades da linha de acordo com a velocidade de propagação caracterizada. Quando do encontro de descontinuidades físicas no sistema, tem-se a reflexão e refração das ondas manifestadas. Este sucessivo processo continua até que as ondas sejam extintas, devido às atenuações causadas por perdas na linha, alcançando o regime permanente do distúrbio.

Salienta-se que o objetivo desta seção é apenas o de apresentar, de forma simples, clara e objetiva a teoria fundamental sobre ondas viajantes. Toda teoria descrita a seguir, assim como, informações complementares sobre o assunto, podem ser 
encontradas nas seguintes referências: Bewley [40], Hedman [68], Greenwood [69], Naidu [70] e Zanetta Jr. [71].

\subsubsection{Equacionamento fundamental de propagação das ondas}

Para se determinar as equações que governam as linhas monofásicas, consideremos um caso simples de uma linha de transmissão com parâmetros distribuídos dados por R, L e C (Figura 2), onde:

$\mathrm{R}$ - resistência (ohm/m);
$\mathrm{L}$ - indutância (Henry/m);
$\mathrm{C}$ - capacitância $($ Farad $/ \mathrm{m})$.

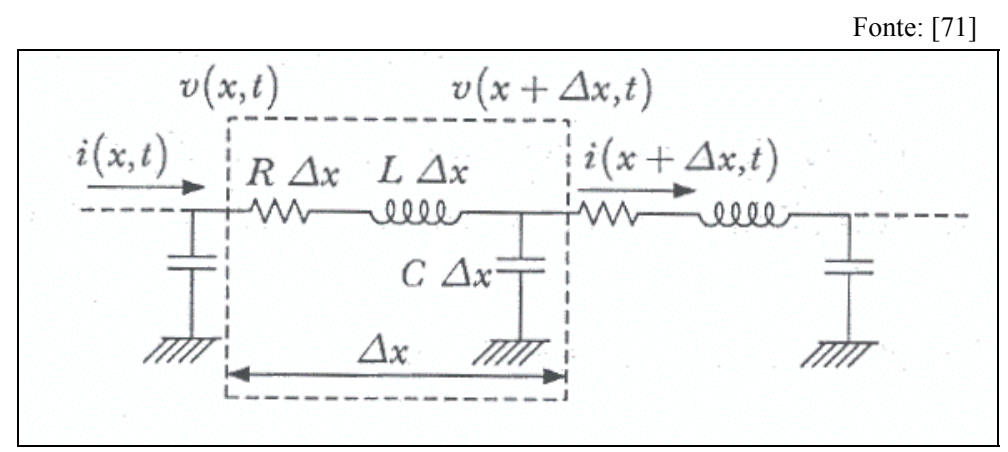

FIGURA 2 - Exemplo de linha com parâmetros distribuidos.

Considerando um trecho $\Delta \mathrm{x}$ da linha, podemos escrever as equações para as variações de tensão $v(x, t)$ e corrente $i(x, t)$ como segue:

$$
\begin{aligned}
& v(x, t)-v(x+\Delta x, t)=R \Delta x i(x, t)+L \Delta x \frac{\partial i}{\partial t}(x, t) \\
& i(x, t)-i(x+\Delta x, t)=C \Delta x \frac{\partial v(x+\Delta x, t)}{\partial t}
\end{aligned}
$$

Aplicando a transformada de Laplace nas equações acima, temos:

$$
\begin{aligned}
& V(x, s)-V(x+\Delta x, s)=R \Delta x i(x, s)+s L \Delta x I(x, s) \\
& I(x, s)-I(x+\Delta x, s)=s C \Delta x V(x+\Delta x, s) \\
& \frac{V(x+\Delta x, s)-V(x, s)}{\Delta x}=-(R+s L \Delta x) I(x, s)
\end{aligned}
$$




$$
\frac{I(x+\Delta x, s)-I(x, s)}{\Delta x}=-s C V(x+\Delta x, s)
$$

Passando ao limite, obtemos as derivadas em relação à variável $x$ :

$$
\begin{aligned}
& \frac{\partial V(x, s)}{\partial x}=-(R+s L) I(x, s) \\
& \frac{\partial I(x, s)}{\partial x}=-s C V(x, s)
\end{aligned}
$$

Derivando novamente a eq. (3.7) em relação à x:

$$
\frac{\partial^{2} V(x, s)}{\partial x^{2}}=-(R+s L) \frac{\partial I(x, s)}{\partial x}
$$

Dispondo da eq. (3.8), temos:

$$
\frac{\partial^{2} V(x, s)}{\partial x^{2}}=(R+s L) s C V(x, s)
$$

De forma análoga, temos:

$$
\frac{\partial^{2} I(x, s)}{\partial x^{2}}=(R+s L) s C I(x, s)
$$

Supondo que $\mathrm{R}=0$ (linhas sem perdas) temos:

$$
\begin{aligned}
& \frac{\partial^{2} V(x, s)}{\partial x^{2}}=s^{2} \operatorname{LCV}(x, s) \\
& \frac{\partial^{2} I(x, s)}{\partial x^{2}}=s^{2} L C I(x, s)
\end{aligned}
$$

A solução geral das eqs. (3.12) e (3.13) podem ser escrita da seguinte forma:

$$
\begin{aligned}
& V(x, s)=V^{+}(0, s) e^{-\gamma(s) x}+V^{-}(0, s) e^{\gamma(s) x} \\
& I(x, s)=I^{+}(0, s) e^{-\gamma(s) x}+I^{-}(0, s) e^{\gamma(s) x}
\end{aligned}
$$

Sendo:

$$
\gamma=\sqrt{s^{2} L C}=s \sqrt{L C}
$$


Caracterizando a velocidade de propagação como:

$$
v=\frac{1}{\sqrt{L C}}
$$

Temos:

$$
\gamma=\frac{s}{v}
$$

Aplicando a transformada inversa de Laplace nas eqs. (3.14) e (3.15) temos:

$$
\begin{aligned}
& v(x, t)=v^{+}\left(0, t-\frac{x}{v}\right)+v^{-}\left(0, t+\frac{x}{v}\right) \\
& i(x, t)=i^{+}\left(0, t-\frac{x}{v}\right)+i^{-}\left(0, t+\frac{x}{v}\right)
\end{aligned}
$$

Onde $v^{+}$é uma onda que se propaga no sentido positivo de $x$ ( $x$ crescente, onda progressiva) e $v^{-}$é uma onda que se propaga no sentido negativo de $x$ ( $x$ decrescente, onda regressiva). A tensão ou corrente total pode ser obtida pela superposição das duas componentes.

Por este raciocínio, da eq. 3.7 para uma linha sem perdas, obtemos:

$$
\frac{\partial V(x, s)}{\partial x}=-s L I(x, s)
$$

Substituindo a eq. (3.14) na eq. (3.21), obtemos:

$$
I(x, s)=\frac{1}{s L}\left[-\gamma(s) V^{+}(0, s) e^{-\gamma(s) x}+\gamma(s) V^{-}(0, s) e^{\gamma(s) x}\right]
$$

$\mathrm{Ou}:$

$$
I(x, s)=\frac{\gamma(s)}{s L}\left[V^{+}(0, s) e^{-\gamma(s) x}-V^{-}(0, s) e^{\gamma(s) x}\right]
$$

Substituindo a eq. (3.16) na eq. (3.23):

$$
I(x, s)=\frac{1}{Z}\left[V^{+}(0, s) e^{-\gamma(s) x}-V^{-}(0, s) e^{\gamma(s) x}\right]
$$

Onde $\mathrm{Z}$ é a impedância característica, também conhecida como impedância de surto. Neste caso particular: 


$$
Z=\sqrt{\frac{L}{C}}
$$

Relacionando as eqs. (3.24) e (3.15) obtemos as tensões e correntes que se deslocam em ambos os sentidos do eixo $\mathrm{x}$, definidas por:

$$
\begin{aligned}
& V^{+}(0, s) e^{-\gamma(s) x}=Z I^{+}(0, s) e^{-\gamma(s) x} \\
& V^{-}(0, s) e^{\gamma(s) x}=-Z I^{-}(0, s) e^{\gamma(s) x}
\end{aligned}
$$

Ou, utilizando uma notação mais simplificada:

$$
\begin{aligned}
& V^{+}=Z I^{+} \\
& V^{-}=-Z I^{-}
\end{aligned}
$$

Portanto, $Z$ é denominado impedância característica da linha. Para o caso de uma linha sem perdas (velocidade de propagação da onda igual a velocidade da luz), $Z$ tem o comportamento de uma resistência, e nesse caso é também conhecida como impedância de surto.

O equacionamento para uma linha monofásica descrito acima, pode ser ampliado para um sistema trifásico, representando o mesmo via equações diferenciais na forma matricial como segue:

Considerando que:

$$
\begin{aligned}
& Z_{f}(s)=R_{f}+s L_{f} \\
& Y_{f}(s)=s C_{f}
\end{aligned}
$$

Temos:

$$
\begin{gathered}
-\frac{\partial \widetilde{V}(x, s)}{\partial x}=Z_{f}(s) \tilde{I}(x, s) \\
-\frac{\partial \widetilde{I}(x, s)}{\partial x}=Y_{f}(s) \widetilde{V}(x, s)
\end{gathered}
$$

Onde:

$R_{f}, L_{f}, C_{f}$ : matrizes de parâmetros da linha por unidade de comprimento;

$Z_{f}$ : matriz impedância série de fase e

$Y_{f}$ : matriz admitância de fase. 
Derivando a eq. (3.32) em relação à x e usando a eq. (3.33), temos:

$$
\begin{aligned}
& \frac{\partial^{2} \widetilde{V}(x, s)}{\partial x^{2}}=Z_{f}(s) Y_{f}(s) \widetilde{V}(x, s) \\
& \frac{\partial^{2} \widetilde{I}(x, s)}{\partial x^{2}}=Y_{f}(s) Z_{f}(s) \widetilde{I}(x, s)
\end{aligned}
$$

A solução geral para o par de equações de onda na forma de matrizes exponenciais é dada por:

$$
\begin{aligned}
& \widetilde{V}(x, s)=e^{-\left[\gamma_{v}(s)\right] x} \widetilde{V}^{+}(0, s)+e^{\left[\gamma_{v}(s)\right] x} \widetilde{V}^{-}(0, s) \\
& \widetilde{I}(x, s)=e^{-\left[\gamma_{i}(s)\right] x} \widetilde{I}^{+}(0, s)+e^{\left[\gamma_{i}(s)\right] x} \widetilde{I}^{-}(0, s)
\end{aligned}
$$

sendo $\widetilde{V}(0, s)$ e $\widetilde{I}(0, s)$ definidos pelas condições de contorno no ponto $\mathrm{x}=0$ (origem).

Logo temos que:

$$
\begin{aligned}
& {\left[\gamma_{v}\right]=\left(Z_{f} Y_{f}\right)^{1 / 2}} \\
& {\left[\gamma_{i}\right]=\left(Y_{f} Z_{f}\right)^{1 / 2}}
\end{aligned}
$$

Pode-se perceber que o uso destas equações é um tanto complexo. Portanto, ao invés de trabalharmos com os valores de fase, pode ser introduzida a transformação modal que diagonaliza o sistema de equações e oferece uma importante simplificação no equacionamento. Os vetores das tensões e correntes de fase são transformados de acordo com a seguinte relação:

$$
\begin{aligned}
& \widetilde{V}(x, s)=P \overline{\widetilde{V}}(x, s) \\
& \widetilde{I}(x, s)=Q \overline{\widetilde{I}}(x, s)
\end{aligned}
$$

Onde:

$P, Q$ : matrizes de transformação modal para tensões e corrente, respectivamente.

$\overline{\widetilde{V}}, \overline{\widetilde{I}}$ : vetores de tensão e corrente em componentes modais.

Substituindo a eq. (3.40), em (3.34), obtemos para a tensão:

$$
\frac{\partial^{2}}{\partial x^{2}} P \overline{\widetilde{V}}(x, s)=\left(Z_{f} Y_{f}\right) P \overline{\widetilde{V}}(x, s)
$$


Multiplicando a eq. (3.42) por $P^{-1}$ e chamando $A=Z_{f} Y_{f}$, temos:

$$
\begin{aligned}
& \bar{A}=P^{-1}\left(Z_{f} Y_{f}\right) P \\
& \frac{\partial^{2}}{\partial x^{2}} \overline{\widetilde{V}}(x, s)=\bar{A} \overline{\widetilde{V}}(x, s)
\end{aligned}
$$

Analogamente para corrente, chamando $B=Y_{f} Z_{f}$, temos:

$$
\begin{aligned}
& \bar{B}=Q^{-1}\left(Y_{f} Z_{f}\right) Q \\
& \frac{\partial^{2}}{\partial x^{2}} \overline{\widetilde{I}}(x, s)=\bar{B} \overline{\widetilde{I}}(x, s)
\end{aligned}
$$

Portanto, a solução geral para as equações em componentes modais pode ser dada por:

$$
\begin{aligned}
& \overline{\widetilde{V}}(x, s)=e^{-[\bar{\gamma}(s)] x} \overline{\widetilde{V}}^{+}(0, s)+e^{[\bar{\gamma}(s)] x} \overline{\widetilde{V}}^{-}(0, s) \\
& \overline{\widetilde{I}}(x, s)=e^{-[\bar{\gamma}(s)] x} \overline{\widetilde{I}}^{+}(0, s)+e^{[\bar{\gamma}(s)] x} \overline{\widetilde{I}}^{-}(0, s)
\end{aligned}
$$

Para um determinado modo $k$ de propagação, temos:

$$
\begin{aligned}
& V_{k}(x, s)=e^{-\left[\gamma_{k}(s)\right] x} V_{k}^{+}(0, s)+e^{\left[\gamma_{k}(s)\right] x} V_{k}^{-}(0, s) \\
& I_{k}(x, s)=e^{-\left[\gamma_{k}(s)\right] x} I_{k}^{+}(0, s)+e^{\left[\gamma_{k}(s)\right] x} I_{k}^{-}(0, s)
\end{aligned}
$$

\subsubsection{Reflexões e refrações de ondas viajantes}

Quando uma onda viajante atinge uma descontinuidade, caracterizada, por exemplo, por um ponto de transição no qual há uma súbita mudança nos parâmetros do circuito, uma parte da onda é refletida de volta, e uma parte da onda é transmitida para a outra sessão do circuito. A onda que chega à descontinuidade é chamada de onda $\underline{\text { incidente e as duas ondas oriundas da descontinuidade são chamadas de ondas refletidas }}$ e refratadas (transmitida), respectivamente. Tais ondas formadas no ponto de transição seguem as leis de Kirchhoff. Elas satisfazem as equações diferenciais das linhas de transmissão, e são condizentes com os princípios de conservação de energia (BEWLEY)[40]. 


\subsubsection{Reflexões sucessivas e diagrama Lattice}

Em muitos problemas (tais como os referentes aos cabos guardas, o efeito de cabos com pouca extensão, processo de carga e descarga em linhas e de redes extensas com muitas conexões e uma variedade de terminações) é necessário considerar as reflexões sucessivas das ondas viajantes. Para simplificar o que seria um problema complexo, Bewley [40], optou por utilizar uma técnica gráfica, de suma importância na análise de problemas relacionados a ondas viajantes em linhas de transmissão, denominada diagrama Lattice ou diagrama espaço-tempo. Tal diagrama mostra a posição e direção de cada onda viajante (incidente, refletida e refratada) em cada instante de tempo. Além disso, o diagrama Lattice facilita o cálculo da forma de todas as ondas refletidas e refratadas. O diagrama Lattice também mostra uma visão ampla do histórico de cada onda. Conhecendo-se as funções de atenuação e distorção, tais efeitos podem ser incluídos no diagrama (NAIDU) [70].

A finalidade do diagrama Lattice é propiciar um meio gráfico simples que denote as relações tempo-espaço dos sinais em análise sobre redes de transmissão com múltiplas descontinuidades. Por exemplo, no cálculo de surtos de descargas atmosféricas em linhas de transmissão com muitos pontos de aterramento, torna-se difícil o conhecimento de todas as ondas refletidas e refratadas ao longo da linha, especialmente após um intervalo de tempo relativamente longo. Isto é devido ao fato de que, à medida que cada onda atinge uma descontinuidade, uma nova onda refletida e refratada é gerada naquele ponto. A Figura 3 ilustra um diagrama Lattice onde temos três junções de linhas com diferentes comprimentos.

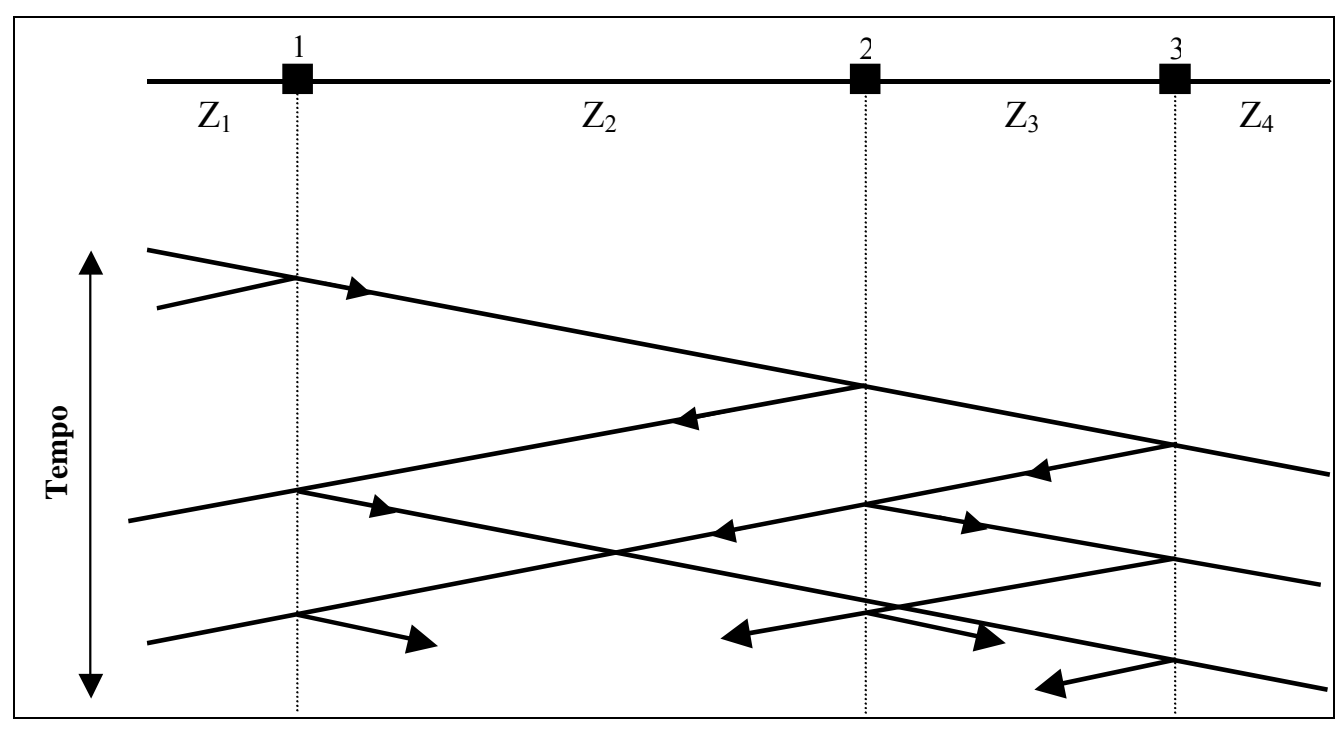

FIGURA 3 - Diagrama Lattice representando as sucessivas reflexões de um sinal qualquer 
Quando há linhas em conexão a pequenos trechos de cabos, como por exemplo, na entrada de subestações, a influência destes deve ser considerada. Geralmente, um cabo tem uma impedância de surto de aproximadamente um décimo da impedância de surto de uma linha aérea e a metade da velocidade de propagação da onda sobre a mesma referência (NAIDU) [70]. Para simplificar o diagrama Lattice, emprega-se uma escala de distância diferente em cada seção, uma para a linha e outra para o cabo.

\subsubsection{Atenuação e distorção das ondas viajantes}

As ondas viajantes em uma linha de transmissão são passíveis de sofrerem três diferentes alterações: (i) o valor de crista da onda decresce em amplitude, ou seja, é atenuado; (ii) as ondas mudam de forma, tornam-se mais alongadas, suas irregularidades são alisadas, e sua inclinação é reduzida e (iii) os términos das ondas de tensão e corrente tornam-se similares. Estas duas últimas mudanças ocorrem juntas e são chamadas de distorções. As distorções e atenuações das ondas ao longo da linha são causadas por perdas de energia, e estas estão ligadas a resistência da linha, ao efeito skin (pelicular), à dispersão sobre isoladores, às perdas dielétricas, e, principalmente, ao efeito corona (BEWLEY)[40].

\subsection{Introdução a Transformada Wavelet}

O tema wavelets, muito empregado nos últimos 20 anos, é formado pela união de idéias de áreas como da matemática pura e aplicada, física, ciência da computação e engenharias, sendo que a sua aplicabilidade e características continuam a despertar grande interesse por parte de cientistas e pesquisadores de diversos segmentos. A “Wavelet" é descrita como uma 'pequena' onda no sentido de ser de curta duração com energia finita.

A primeira menção a wavelets apareceu no apêndice de A. Haar, em 1909, como descrito por HAAR apud (LIMA) [72]. Uma propriedade das wavelets de Haar é de possuírem suportes compactos; contudo, não são continuamente diferenciáveis, o que de certa forma limita a aplicabilidade a elas relacionadas.

As wavelets de Haar ficaram no anonimato por muitos anos, até que na década de 30, vários grupos trabalhando de forma independente, pesquisaram a representação de funções usando uma base com escala variável. Naquela ocasião, usando a base de 
Haar, Paul Levy mostrou que estas funções como bases, ofereciam melhores resultados quando comparados com os resultados obtidos com a utilização das funções bases de Fourier no estudo dos pequenos e complicados detalhes do movimento Browniano (GRAPS) [73]. Por um período muito longo, as wavelets de Haar continuaram a ser a única base ortonormal de funções wavelets conhecida, até que, em 1980, o termo "wavelet" foi originariamente introduzido pelo engenheiro J. Morlet, sendo a base matemática de suas idéias formalizada pelo físico teórico Alex Grossmann. Os dados sísmicos estudados por Morlet exibiam conteúdos de freqüência que mudavam rapidamente ao longo do tempo, para os quais a Transformada de Fourier não era adequada como ferramenta de análise (SCHIMIDT) [74].

Como é de conhecimento, a série de Fourier requer periodicidade de todas as funções envolvidas no tempo. Isto efetivamente significa que as funções base (isto é, ondas de seno e coseno) usadas na análise de Fourier estão precisamente situadas na freqüência, mas existem para todo o tempo. Vale comentar que, a informação em freqüência de um sinal calculado pela transformada clássica de Fourier é a média durante todo o tempo do sinal. Assim, se existe um sinal transitório local durante algum intervalo de tempo pequeno, o transitório contribuirá para a TF (embora de modo um pouco ineficiente), mas a sua localização no eixo do tempo será perdida. A análise tradicional de Fourier não considera freqüências que variam com o tempo, ou seja, sinais não estacionários.

Com o objetivo de corrigir a deficiência mencionada da TF, Dennis Gabor adaptou-a para analisar apenas uma pequena porção do sinal, originando a chamada Short-Time Fourier Transform (STFT), também conhecida como Transformada de Fourier Janelada (TFJ). Esta faz o mapeamento de um sinal unidimensional em duas dimensões: tempo e freqüência. No entanto, a precisão das informações obtidas por esta forma de transformação é limitada, uma vez que esta utiliza uma "janela" de dados fixa. Isto é, o conteúdo de informações do sinal, amostrado seqüencialmente, é analisado em um intervalo fixo no domínio do tempo. Com uma janela larga, por exemplo, obtêm-se uma boa resolução em freqüência, mas uma pobre resolução no tempo. Por outro lado, com uma janela estreita, será obtida uma boa resolução no tempo, mas uma pobre resolução em freqüência. Contudo, deve ser mencionado que a técnica da TFJ pode ser aplicada com uma seqüência de janelas de diferentes larguras para conseguir mais detalhes na localização dos transitórios associados. No entanto, esta última opção é complexa e de grande esforço computacional (KIM e AGGARWAL) [75]. 
Em 1985, Stephane Mallat proporcionou às Wavelets um grande impulso através de seu trabalho em processamento digital de imagens e, inspirado nos resultados deste, Y. Meyer construiu a primeira Wavelets não-trivial (suave) (DAUBECHIES) [76]. Ao contrário das Wavelets de Haar, as Wavelets de Meyer são continuamente diferenciáveis; não possuindo, contudo, suportes compactos. Poucos anos mais tarde, Ingrid Daubechies usou os trabalhos de Mallat para construir um conjunto de bases ortonormais de Wavelets suaves, com suportes compactos (LIMA) [72].

A Transformada Wavelet representa o próximo passo lógico: uma técnica de “janelamento" variável, permitindo o uso de uma janela de tempo maior para analisar informações de baixa freqüência de forma mais precisa, e de uma pequena janela para informações de alta freqüência (MISITI et al.) [77].

De uma forma geral, uma família de funções pode ser definida como na eq. 3.51:

$$
\psi_{a, b}(x)=|a|^{-\frac{1}{2}} \psi\left(\frac{x-b}{a}\right) \quad a, b \in \mathfrak{R}, \quad a \neq 0,
$$

Onde a variável $x$ pode corresponder ao tempo ou espaço. Estas funções podem ser geradas a partir de operações de dilatação (fator de escala $a$ ) e de translação (fator $b$ ) da mesma função $\psi$ (Wavelets mãe) (DAUBECHIES)[78].

Como será visto, devem-se distinguir duas versões diferentes da TW, a contínua e a discreta:

- a Transformada Wavelet Contínua (TWC) faz o mapeamento de uma função de uma variável contínua em uma função de duas variáveis contínuas e

- a Transformada Wavelet Discreta (TWD) decompõe um sinal discretizado em diferentes níveis de resolução. Esta faz o mapeamento de uma seqüência de números em outra seqüência de números (KIM e AGGARWAL) [75].

Cabe mencionar que neste trabalho será exposto somente o equacionamento matemático básico e necessário para o entendimento da teoria da Transformada Wavelet. Para maiores informações e um estudo mais aprofundado sobre o assunto, algumas bibliografias são recomendadas, entre as quais temos: Daubechies [78], Meyer [79], Chui [80] e ou Strang e Nguuen [81], as quais trazem uma introdução matemática. Burrus et al. [82] e Addison [83] apresentam uma excelente introdução do ponto de vista de engenharia e, Burke Hubbard [84], para uma introdução não matemática. Além destas, encontram-se inúmeras publicações nacionais e internacionais sobre a teoria e implementação da TW, aplicadas a específicos problemas. 


\subsubsection{A Transformada Wavelet Contínua}

A análise Wavelet emprega um protótipo de função chamado Wavelet mãe. Esta função tem média zero e parte central oscilante, a qual decai para zero em ambos os lados de sua trajetória. Matematicamente, a TWC de um dado sinal $x(t)$, com respeito à Wavelet mãe $\psi(t)$, é genericamente definida como:

$$
T W C(a, b)=\frac{1}{\sqrt{a}} \int_{-\infty}^{\infty} x(t) \psi\left(\frac{t-b}{a}\right) d t
$$

Onde $a$ é a dilatação ou fator de escala e $b$ é o fator de translação, e ambas as variáveis são contínuas. É claro da eq. (3.52) que o sinal original no domínio do tempo $x(t)$, com uma dimensão, é mapeado para uma nova função no espaço, de dimensão dois, através dos coeficientes de escala e de translação pela TW. Os coeficientes da TW, em uma particular escala e translação - $T W C(a, b)$, representam quão bem o sinal original $x(t)$ e a Wavelet mãe escalada e transladada se combinam. Então, o conjunto de todos os coeficientes $T W C(a, b)$ associados a um particular sinal é a representação do sinal original $x(t)$ com respeito a Wavelet mãe $\psi(t)($ KIM e AGGARWAL)[75].

Podemos visualizar a wavelet mãe como uma função janela. $\mathrm{O}$ fator de escala $a$ e o tamanho da janela são interdependentes, onde menores escalas implicam em menores janelas. Conseqüentemente, podemos analisar componentes de bandas estreitas em freqüência de um sinal com um pequeno fator de escala e, componentes de bandas largas em freqüência, com fatores de escala maiores, o que permite captar todas as características de um sinal particular.

\subsubsection{Escalamento}

Escalar uma Wavelet significa simplesmente dilatá-la ou contraí-la (MISITI et al.) [77]. O fator de escala é usualmente denotado pela letra $a$. Em se tratando de wavelets, o efeito do fator de escala é facilmente observado, como ilustrado na Figura 4: 


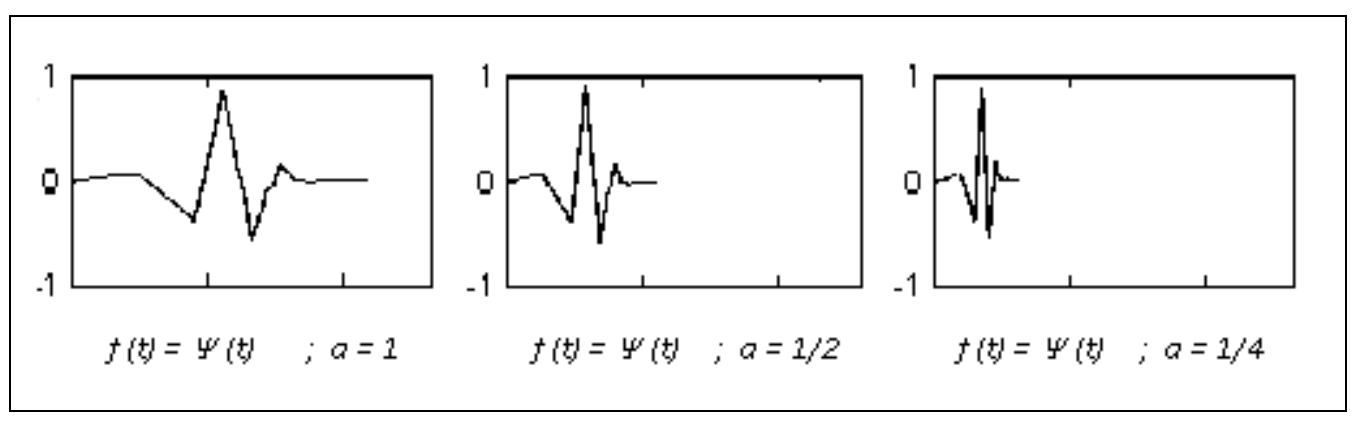

FIGURA 4 - Escalamento de uma função Wavelet

Fica claro através da Figura 4 que, quanto menor o fator de escala, mais "contraída" será a Wavelet. Na análise Wavelet, a escala é relacionada com a freqüência do sinal. O que corresponde a:

- Baixa escala $a \rightarrow$ Wavelet contraída $\rightarrow$ detalhes que mudam rapidamente $\rightarrow$ alta freqüência $w$.

- Alta escala $a \rightarrow$ Wavelet dilatada $\rightarrow$ detalhes que mudam vagarosamente $\rightarrow$ baixa freqüência $w$.

\subsubsection{Translação}

Transladar uma Wavelet significa atrasá-la ou adiantá-la em relação ao eixo das abscissas, que é o que fazemos matematicamente quando escrevemos $f(x-k)$, como um atraso na função $f$ por um fator k, como pode ser visto na Figura 5.

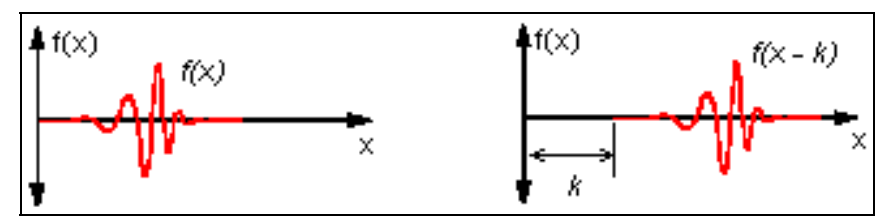

FIGURA 5 - Translação aplicada a uma Wavelet

\subsubsection{A Transformada Wavelet Discreta}

Análoga à relação existente entre a transformada contínua de Fourier e a Transformada Discreta de Fourier (TDF), a TWC tem uma versão digitalmente implementável, denotada como Transformada Wavelet Discreta (TWD) que é definida como segue:

$$
T W D(m, k)=\frac{1}{\sqrt{a_{0}^{m}}} \sum_{n} x(n) \psi\left(\frac{k-n b_{0} a_{0}^{m}}{a_{0}^{m}}\right)
$$


Onde $\psi($. (.) é a Wavelet mãe e os parâmetros de escala e de translação $a$ e $b$ são funções de um parâmetro inteiro $m$. Isto é, $a=a_{o}^{m}$ e $b=n b_{o} a_{o}^{m}$, que permite uma expansão da família originada pela Wavelet mãe, gerando as Wavelets filhas. Nesta equação, $k$ é uma variável inteira que se refere a um número particular de amostra de um determinado sinal de entrada. O parâmetro de escala permite o aumento geométrico da escala, isto é, $1,1 / \mathrm{a}_{0}, 1 / \mathrm{a}_{\mathrm{o}}{ }^{2}$, e assim por diante. A saída da TWD pode ser representada em duas dimensões de maneira similar a TDF, mas com divisões muito diferentes no tempo e na freqüência. Associado com a análise Wavelet, ambas as principais características em alta e baixa freqüência nos diferentes níveis de detalhes são claramente evidenciadas. Isto é obtido aplicando-se a TWD a um determinado número de ciclos do sinal transitório (KIM e AGGARWAL) [75].

\subsubsection{Filtragem e Análise Multiresolução}

Filtrar um sinal implica em eliminar determinadas freqüências, ou uma banda de freqüência do mesmo. Na teoria de processamento de sinais, isto implica em realizar uma convolução do sinal para a resposta impulso do filtro, ou, simplesmente, convolução.

O processo de filtragem considerado dispõe do uso da técnica de Análise Multiresolução. Este processo baseia-se na filtragem de um sinal a ser analisado através de bancos de filtros passa alta e passa baixa, fornecendo versões do sinal original relativas aos coeficientes de funções Wavelets e funções escalas respectivamente.

Considerando-se a TW em suas formas contínua e discreta, fala-se usualmente em aproximações e detalhes. As aproximações são as altas escalas, isto é, as componentes de baixa freqüência do sinal. Os detalhes são as baixas escalas ou seja, as componentes de alta freqüência. O processo de filtragem é ilustrado na Figura 6 em uma forma simplificada, considerando-se somente o primeiro nível de filtragem.

O sinal original $S$, passa através de dois filtros complementares que fornecem como saída dois sinais. Infelizmente, caso esse processo seja utilizado sobre um sinal digital real, haveria na saída duas vezes mais amostras em relação às iniciais. Suponha que o sinal original S consista de 1000 amostras. Sendo assim, as versões aproximadas (A) e detalhadas (D) do sinal original terão 1000 amostras cada uma, totalizando 2000 amostras, ao final de uma fase do processo. 


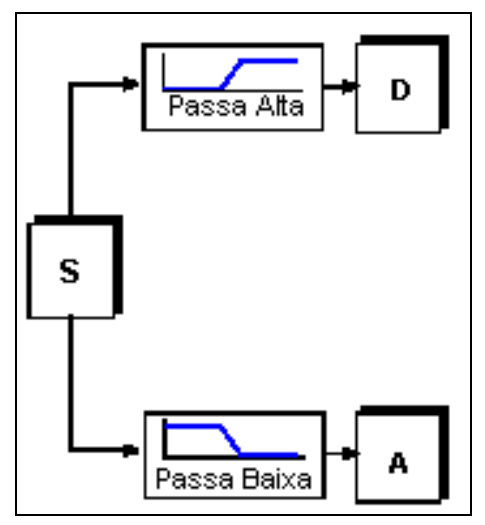

FIGURA 6 - Processo de filtragem de um sinal no primeiro nível

Para sobrepor este problema, foi introduzido um operador que diminui o número de amostras, o operador downsampling (BURRUS et al.) [82] e (MISITI et al.) [77], o qual considera uma intercalação entre os dados. Ou seja, considera o primeiro dado, rejeita o segundo, aceita novamente o terceiro, e assim por diante. A Figura 7 ilustra a operação do operador downsampling representado pelo símbolo $($ ).

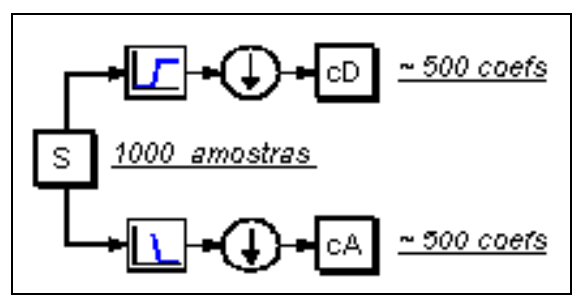

FIGURA 7 - Processo de diminuição do número de amostras do sinal (downsampling)

Com o intuito de se obter uma melhor visualização do processo de filtragem com a diminuição do número de amostras do sinal, apresenta-se na Figura 8, um exemplo do desenvolvimento da TWD de um determinado sinal. Neste caso, o sinal é uma senóide pura com um sinal de ruído de alta freqüência sobreposto ao mesmo.

Observe na Figura 8 que o coeficiente de detalhe $c D$ consiste principalmente do ruído em alta freqüência, enquanto que os coeficientes $c A$, contém muito menos ruído que o sinal original. 


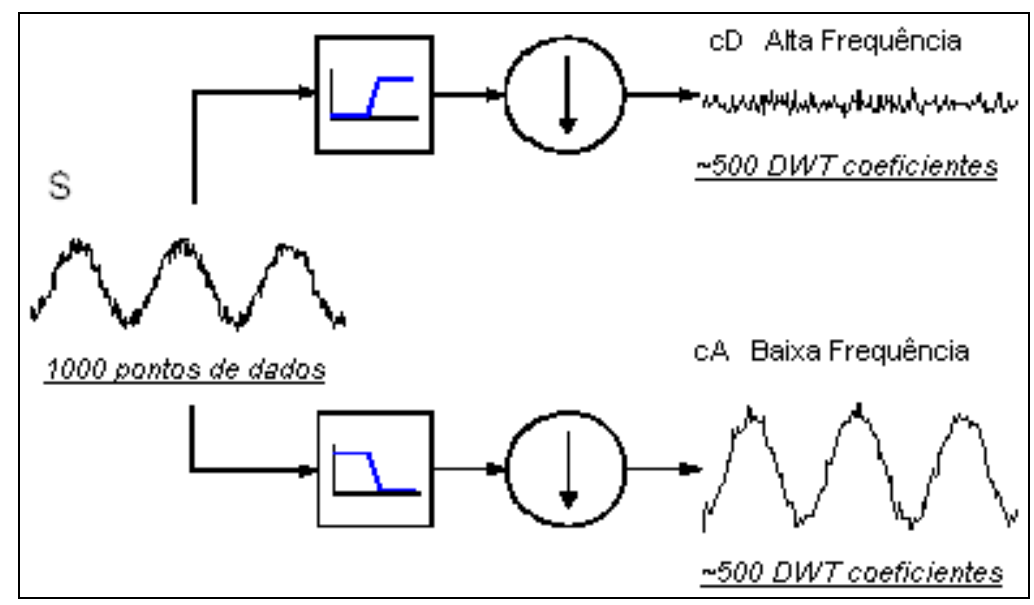

FIGURA 8 - Exemplo de filtragem com downsampling de um sinal senoidal ruidoso.

\subsubsection{Decomposição em múltiplos níveis ou análise multiresolução}

A análise multiresolução refere-se ao procedimento para obter aproximações dos filtros passa baixa e de detalhes dos filtros passa alta do sinal original. Desta maneira, uma aproximação é a representação em baixa resolução de um sinal, enquanto que um detalhe é a diferença entre duas sucessivas representações em baixa resolução do sinal original. A aproximação compreende as baixas freqüências do sinal original, enquanto um detalhe engloba o conteúdo de alta freqüência do sinal original. Aproximações e detalhes são obtidos através de um processo sucessivo de convolução. O sinal original é dividido em diferentes escalas de resolução, particularmente em diferentes freqüências, como no caso da análise de Fourier.

O processo de decomposição de um sinal em análise multiresolução é ilustrado na Figura 9, o qual apresenta três níveis de decomposição. Os detalhes e aproximações do sinal original S são obtidos por meio de bancos de filtros, os quais são formados por filtros passa baixa $\left(h_{0}\right)$ e passa alta $\left(h_{1}\right)$. Um filtro passa baixa remove os componentes de altas freqüências, enquanto o filtro passa alta separa o conteúdo de alta freqüência no sinal sendo analisado (KIM e AGGARWAL)[85].

Resumindo, a idéia básica da decomposição em múltiplos níveis, também conhecida como Análise Multiresolução (AMR), é dividir o espectro de um sinal em sub-bandas e então tratar individualmente cada uma das sub-bandas, considerando o propósito desejado. 


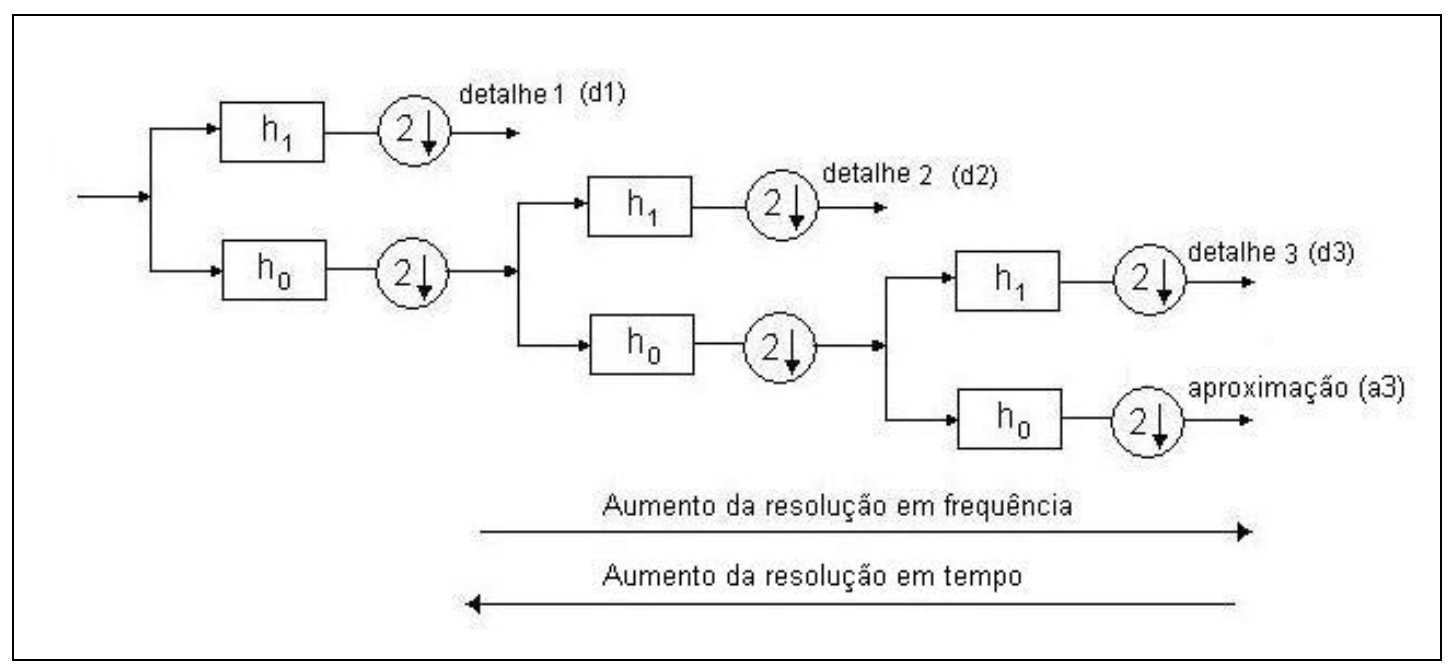

FIGURA 9 - Processo de decomposição de um sinal

A fim de se conseguir uma representação não redundante e a reconstrução perfeita do sinal original, são requeridos bancos de filtros ortogonais e, conseqüentemente, o uso de wavelets ortogonais.

O número máximo de níveis de decomposição wavelet é determinado pelo comprimento do sinal, pela wavelet mãe selecionada e, pelo nível de detalhe exigido. $\mathrm{Na}$ prática, selecionamos um número satisfatório de níveis baseado na natureza do sinal (KIM e AGGARWAL) [85]. A Figura 10 ilustra um exemplo de aplicação de AMR sobre dois ciclos de um sinal senoidal, sendo, um ciclo puro e um ciclo com adição de ruído branco gaussiano.

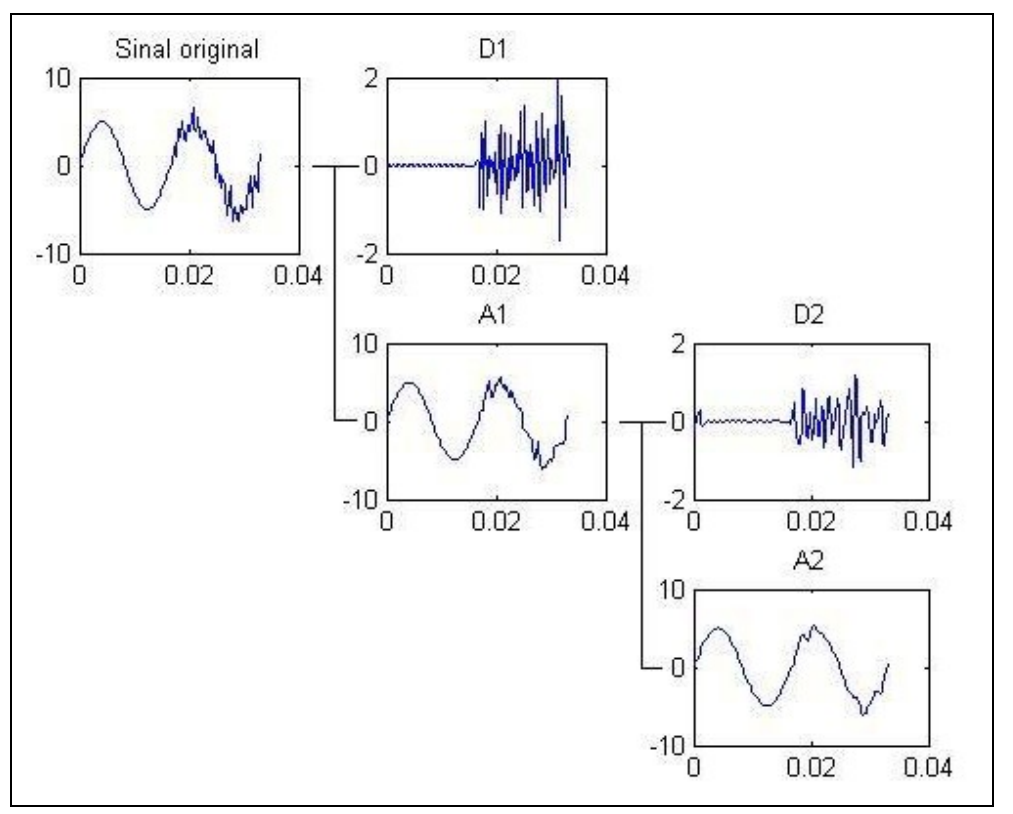

FIGURA 10 - Exemplo da AMR: sinal original. A1 e A2 - primeira e segunda aproximação; D1 e D2 primeiro e segundo detalhe. 
As famílias wavelets freqüentemente mais usadas para o processamento de sinais são as wavelets Daubechies (db), Morlets, Coiflets (coif) e Symlets (sym). Estas wavelets exibem diferentes atributos e critérios de desempenho quando utilizadas em aplicações específicas, tais como: detecção de transitórios, compressão de sinais e filtragem de ruído. Apesar de não existir um critério definido para a escolha das wavelets, a melhor escolha é uma wavelet que caracterize por completo o fenômeno ou o problema a ser estudado (KIM e AGGARWAL)[85].

\subsubsection{Reconstrução wavelet}

Anteriormente foi descrito como a TWD pode ser usada para analisar, ou decompor, sinais ou imagens. Outra etapa é saber como as componentes podem ser reagrupadas para reconstruir o sinal original, sem perder importantes informações. Este processo é chamado de reconstrução, ou de síntese, e é reconhecido como o cálculo da Transformada Wavelet Discreta Inversa (TWDI).

A reconstrução de um sinal é feita a partir dos coeficientes Wavelets, como ilustrado na Figura 11:

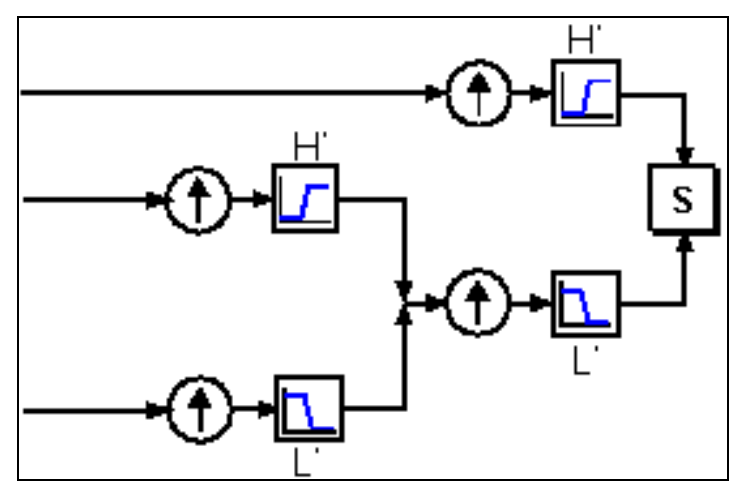

FIGURA 11 - Processo de reconstrução de um sinal filtrado

Como a análise Wavelet envolve filtragem e diminuição do número de amostras, a reconstrução Wavelet consiste em aumentar o número de amostras na filtragem. Aumentar o número de amostras é o processo de elevar o número de componentes do sinal pela inserção de zeros entre as amostras, o que está ilustrado na Figura 12. 


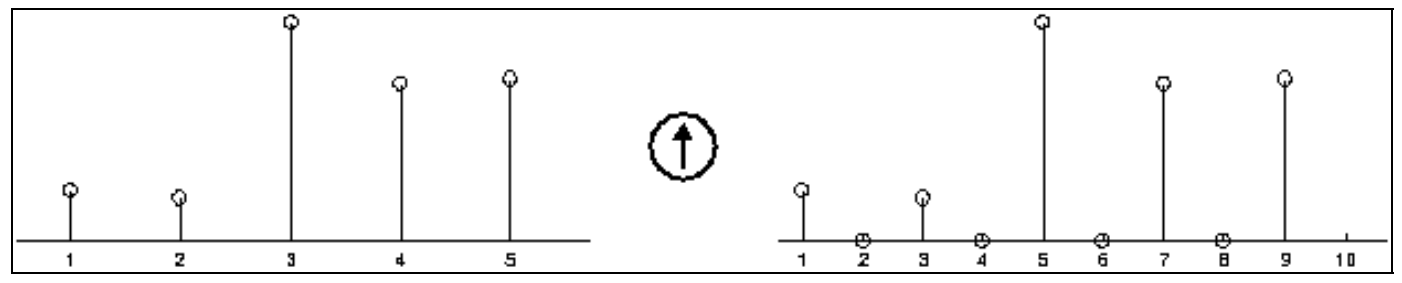

FIGURA 12 - Processo de aumento do número de amostras para reconstrução de um sinal

\subsubsection{Filtros de reconstrução}

A parte de filtragem para a reconstrução (Figura 13) do sinal também merece algumas considerações, devido ao fato de a escolha do filtro ser crucial para uma perfeita reconstrução do mesmo.

O processo de diminuição do número de amostras do sinal introduz neste, distorções de aliasing, que podem ser canceladas pela correta escolha do filtro de reconstrução, também conhecidos na literatura como filtros de síntese. Esta foi uma das grandes descobertas de Ingrid Daubechies e reportada como descrito em [78].

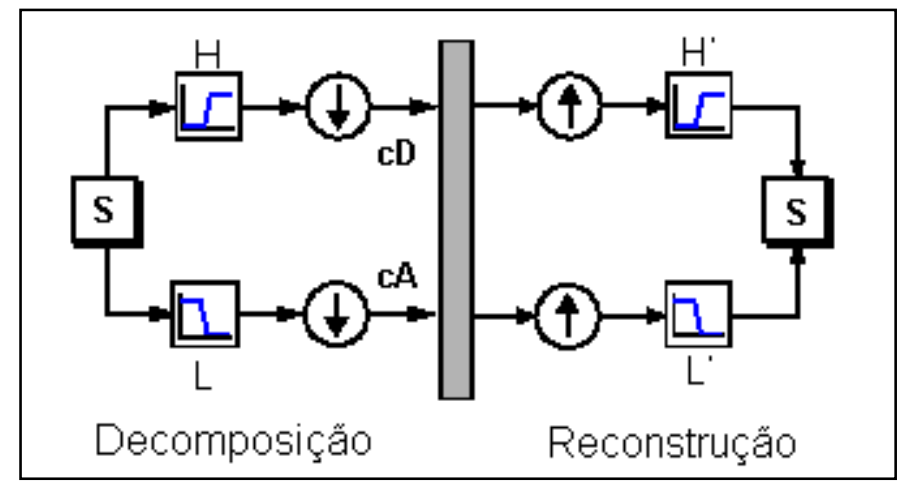

FIGURA 13 - Processos de decomposição e reconstrução de um sinal

\subsubsection{Aproximações e detalhes na reconstrução}

Também é possível reconstruir as aproximações e detalhes em si, a partir dos vetores de coeficientes. Como exemplo, veremos como reconstruir o primeiro nível de aproximação A1, do vetor de coeficientes cA1.

$\mathrm{O}$ vetor dos coeficientes cA1 passa pelo mesmo processo usado para reconstruir o sinal original. No entanto, ao invés de combiná-los com o nível um (1) de detalhes cD1, alimenta-se com um vetor de zeros no lugar dos detalhes, como indicado na Figura 14. 


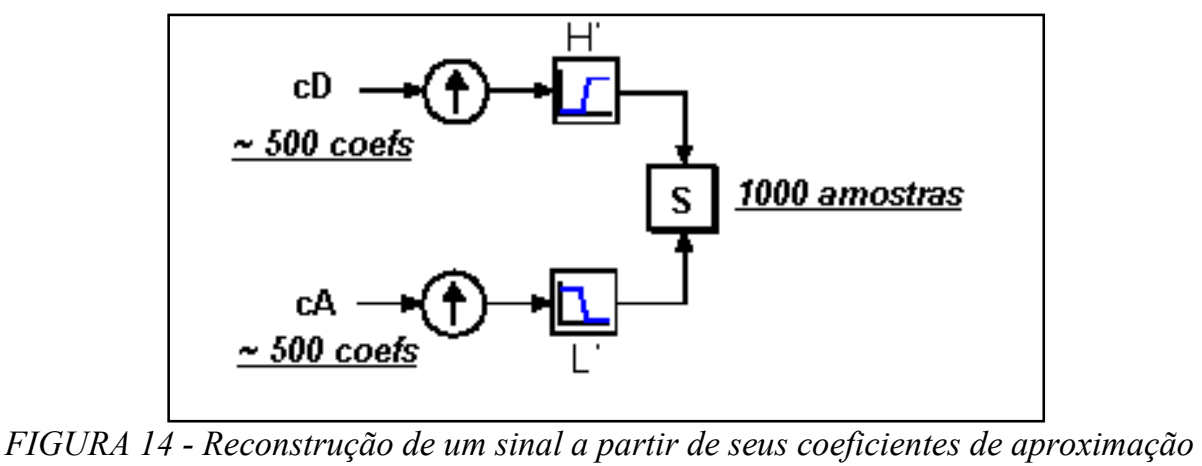

Este processo produz a reconstrução do sinal de aproximação A1, que possui o mesmo tamanho que o sinal original S, sendo uma aproximação real.

Similarmente, podemos reconstruir o primeiro nível de detalhe D1, usando o processo análogo, como na Figura 15.

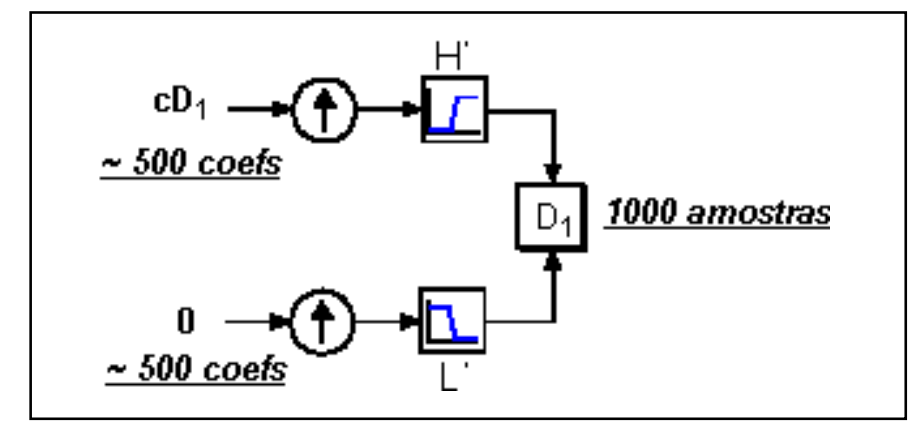

FIGURA 15 - Reconstrução do primeiro nível de detalhe do sinal

Os detalhes e aproximações reconstruídos são verdadeiramente constituintes dos sinais originais. De fato, encontramos isto quando combinamos $A_{1}+D_{1}=S$.

Note que os vetores de coeficientes cA1 e cD1, por serem produzidos pela diminuição do número de amostras, contêm distorção aliasing, e suas dimensões são somente a metade da dimensão do sinal original. Assim, não podem ser combinados diretamente para reproduzir o sinal original. É necessário reconstruir as aproximações e detalhes antes de combiná-los.

Estendendo esta técnica para os componentes associados aos demais níveis, encontramos relações similares, como mostrado na Figura 16, para todo o sinal reconstruído. Deve ser observado que existem vários caminhos para reconstruir o sinal original. 


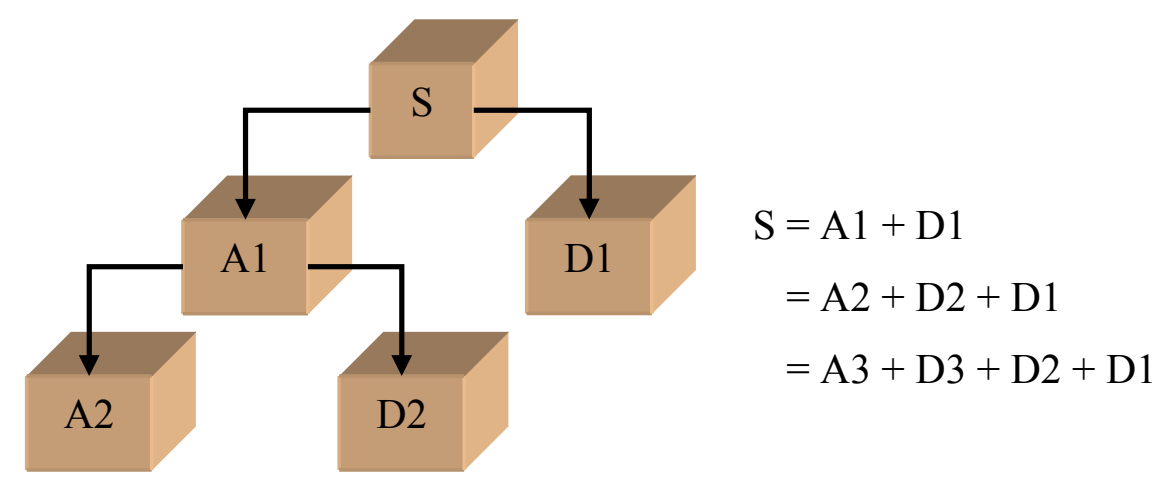

FIGURA 16 - Diferentes formas para se reconstruir o sinal a partir de seus coeficientes

\subsubsection{Decomposição e Reconstrução Wavelet via método matricial}

A decomposição e reconstrução wavelet pode ser facilmente implementada via cálculos matriciais relacionando o sinal de entrada com os filtros de decomposição (filtros de análise) ou com os filtros de reconstrução (filtros de síntese). Para um melhor entendimento do cálculo matricial, nada melhor do que utilizar um exemplo numérico.

Vamos calcular a TWD nível máximo do sinal discreto $f[]=\{1,2,3,4,4,3,2$, 1 ) pelo método matricial utilizando a wavelet $d b 4$ e mostrar como fica a árvore de decomposição. A seguir, vamos inverter o processo, para obter o sinal f[], ou seja, vamos reconstruir o sinal a partir do último nível de decomposição.

- Decomposição

Primeiramente vamos calcular o nível máximo de decomposição conforme a Eq. (3.54):

$$
\text { nivel } \max =\frac{\log (n)}{\log (2)}
$$

Onde: $\mathrm{n}$ é o número de pontos do sinal a ser decomposto, em nosso caso f[] que tem 8 elementos. Portanto, temos:

nivel $\max =\frac{\log (8)}{\log (2)}=3$

Os filtros passa-baixa e passa-alta de análise e síntese que representam a db4 são dados por: 
$h[]=\left\{\begin{array}{llll}h_{0} & h_{1} & h_{2} & h_{3}\end{array}\right\}$

$g[]=\left\{\begin{array}{llll}g_{0} & g_{1} & g_{2} & g_{3}\end{array}\right\}$

$\bar{h}[]=\left\{\begin{array}{llll}\bar{h}_{0} & \bar{h}_{1} & \bar{h}_{2} & \bar{h}_{3}\end{array}\right\}$

$\vec{g}[]=\left\{\begin{array}{llll}\bar{g}_{0} & \bar{g}_{1} & \bar{g}_{2} & \bar{g}_{3}\end{array}\right\}$

onde:

$h[]=\left\{\begin{array}{lllll}0,4829629131446 & 0,83651630373747 & 0,22414386804186 & -0,129409522550\end{array}\right\}$

$g[]=\left\{\begin{array}{lllll}-0,12940952255 & -0,2241438680418 & 0,83651630373747 & -0,482962913144\}\end{array}\right.$

$\bar{h}[]=\left\{\begin{array}{lllll}-0,129409522550 & 0,22414386804186 & 0,8365163037374 & 0,4829629131446\end{array}\right\}$

$\vec{g}[]=\left\{\begin{array}{lllll}-0,482962913144 & 0,83651630373747 & -0,224143868041 & -0,129409522550\end{array}\right\}$

O primeiro nível de decomposição é obtido pelo produto da matriz dos filtros com o sinal de entrada:

$\left[\begin{array}{llllllll}h_{0} & h_{1} & h_{2} & h_{3} & 0 & 0 & 0 & 0 \\ g_{0} & g_{1} & g_{2} & g_{3} & 0 & 0 & 0 & 0 \\ 0 & 0 & h_{0} & h_{1} & h_{2} & h_{3} & 0 & 0 \\ 0 & 0 & g_{0} & g_{1} & g_{2} & g_{3} & 0 & 0 \\ 0 & 0 & 0 & 0 & h_{0} & h_{1} & h_{2} & h_{3} \\ 0 & 0 & 0 & 0 & g_{0} & g_{1} & g_{2} & g_{3} \\ h_{2} & h_{3} & 0 & 0 & 0 & 0 & h_{0} & h_{1} \\ g_{2} & g_{3} & 0 & 0 & 0 & 0 & g_{0} & g_{1}\end{array}\right] *\left[\begin{array}{l}1 \\ 2 \\ 3 \\ 4 \\ 4 \\ 3 \\ 2 \\ 1\end{array}\right]=\left[\begin{array}{c}2,31078903454151 \\ 0 \\ 5,303300858889861 \\ 0,61237243569561 \\ 4,76027877732396 \\ 0 \\ 1,76776695296686 \\ -0,61237243569561\end{array}\right]$

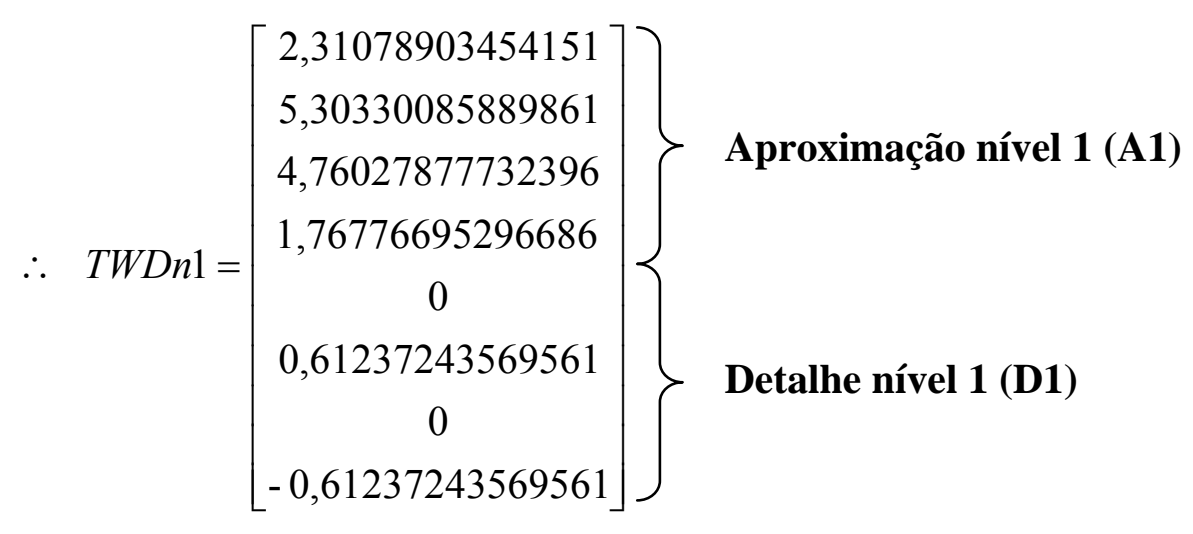

O segundo nível de decomposição é obtido de forma análoga ao primeiro, porém o sinal f[] passa ser agora o primeiro nível de aproximação (D1), com segue: 


$$
\begin{aligned}
& {\left[\begin{array}{llll}
h_{0} & h_{1} & h_{2} & h_{3} \\
g_{0} & g_{1} & g_{2} & g_{3} \\
h_{2} & h_{3} & h_{0} & h_{1} \\
g_{2} & g_{3} & g_{0} & g_{1}
\end{array}\right] *\left[\begin{array}{c}
2,31078903454151 \\
5,30330085889861 \\
4,76027877732396 \\
1,76776695296686
\end{array}\right]=\left[\begin{array}{c}
6,39054445662080 \\
1,64054445662201 \\
3,60945554337920 \\
-1,64054445662201
\end{array}\right]} \\
& \left.\therefore \quad T W D n 2=\left[\begin{array}{c}
6,39054445662080 \\
3,60945554337920 \\
1,64054445662201 \\
-1,64054445662201
\end{array}\right]\right\} \quad \begin{array}{l}
\text { Aproximação nível 2 (A2) } \\
\text { Detalhe nível 2 (D2) }
\end{array}
\end{aligned}
$$

Seguindo o mesmo raciocínio, o terceiro e último nível de decomposição pode ser calculado, lembrando que o sinal f[] passa a ser a aproximação nível 2 (A2), como segue:

$$
\begin{aligned}
& {\left[\begin{array}{llll}
h_{0} & h_{1} & h_{2} & h_{3} \\
g_{0} & g_{1} & g_{2} & g_{3}
\end{array}\right] *\left[\begin{array}{l}
6,39054445662080 \\
3,60945554337920 \\
6,39054445662080 \\
3,60945554337920
\end{array}\right]=\left[\begin{array}{l}
7,07106781186548 \\
1,96652682963587
\end{array}\right]} \\
& \therefore \quad T W D n 3=\left[\begin{array}{l}
7,07106781186548 \\
1,96652682963587
\end{array}\right] \rightarrow \text { Aproximação nível 3 (A3) }
\end{aligned}
$$

\section{- Reconstrução}

A reconstrução do sinal é semelhante à decomposição. Entretanto, segue o sentido contrário da decomposição e utiliza os filtros de reconstrução ou síntese. Para ilustrar o processo de reconstrução utilizaremos o exemplo anterior, partindo do terceiro nível de decomposição até alcançar o sinal original f[].

$$
\left[\begin{array}{l}
7,07106781186548 \\
1,96652682963587 \\
7,07106781186548 \\
1,96652682963587
\end{array}\right]^{T} *\left[\begin{array}{ll}
\bar{h}_{3} & \bar{g}_{3} \\
\bar{h}_{2} & \bar{g}_{2} \\
\bar{h}_{1} & \bar{g}_{1} \\
\bar{h}_{0} & \bar{g}_{0}
\end{array}\right]=[6,39054445662080 \quad 3,60945554337920]=A 2
$$


$\therefore \quad$ TWDn $2=\left[\begin{array}{c}6,39054445662080 \\ 3,60945554337920 \\ 1,64054445662201 \\ -1,64054445662201\end{array}\right]$

De maneira análoga reconstruímos a TWDn1 a partir da TWDn2, como segue:

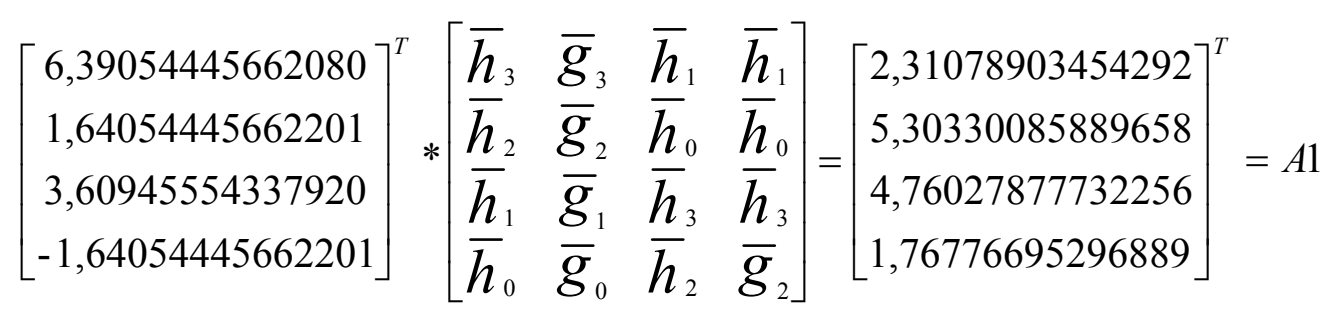

Finalmente podemos reconstruir o sinal original a partir da TWDn1:

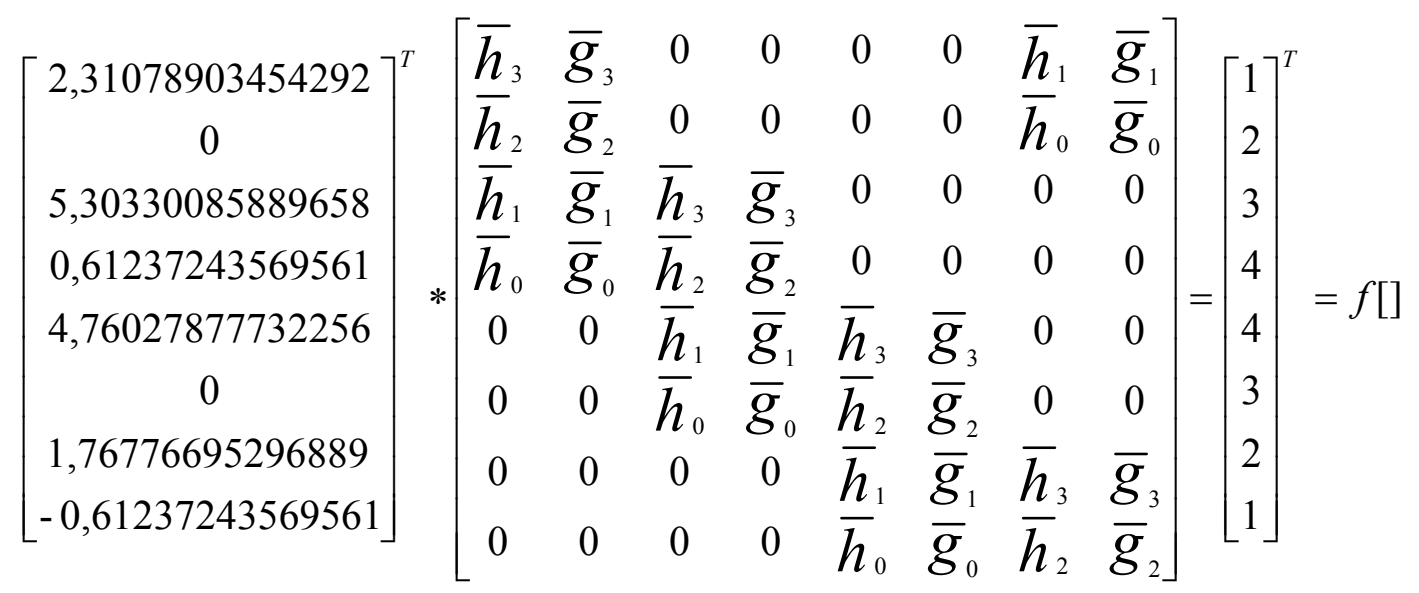

A árvore de decomposição para o exemplo anterior seria:

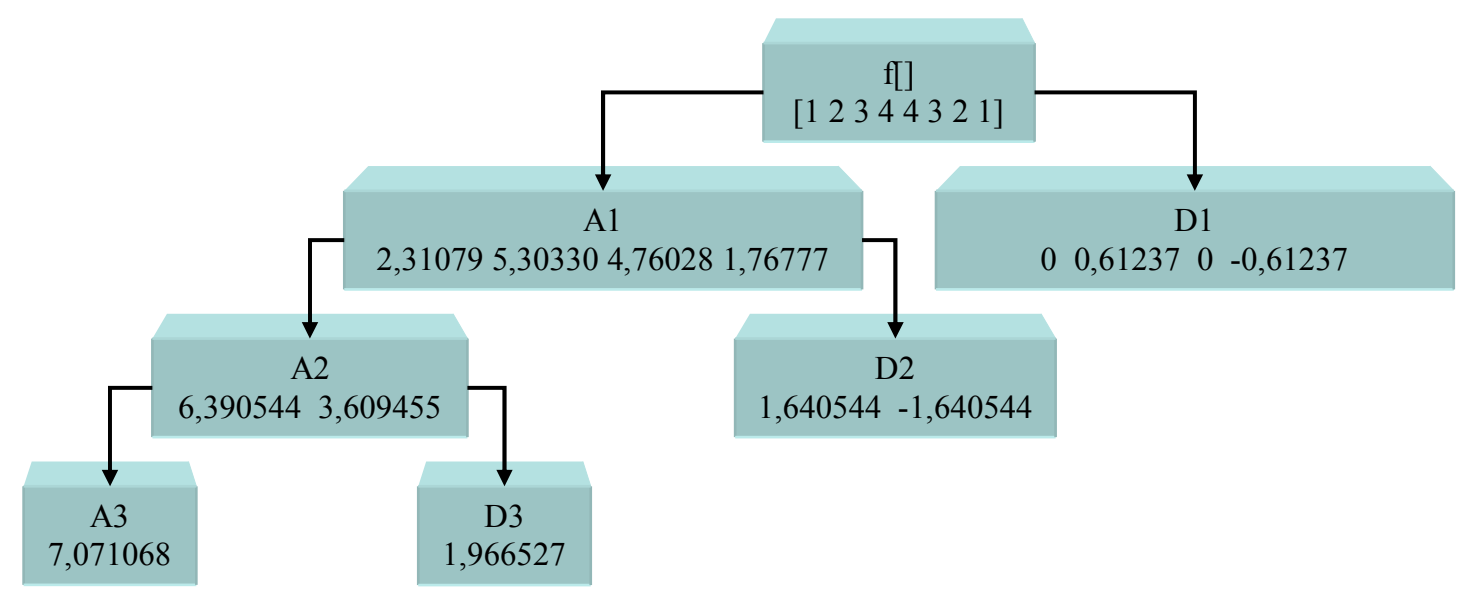




\subsubsection{Transformada Wavelet Estacionária ou Transformada Wavelet Discreta não dizimada}

A operação de dizimação (downsampling) por um fator de 2, representada pelo símbolo (21) nas saídas dos filtros $h_{1}$ e $h_{0}$ do processo da AMR, ilustrado na Figura 9, como foi comentado anteriormente, realiza um escalamento no sinal para o processamento do próximo nível de decomposição. Deste modo, o sinal de um dado nível de decomposição tem sempre a metade do número de amostras do sinal de um nível subseqüente a este nível, o que nem sempre pode trazer uma adequada representação do sinal (PESQUET et al.) [86]. Para resolver este problema e outros, como a não invariância no tempo da TWD, foi proposta a utilização da Transformada Wavelet Estacionária (TWE) ou TWD sem dizimação.

O algoritmo da TWE é simples e muito semelhante ao processo da TWD. O primeiro nível da TWE de um dado sinal pode ser obtido por um processo de filtragem do sinal através de filtros passa baixa e passa alto apropriados como no caso da análise multiresolução. Porém, sem a etapa de dizimação, de modo a fornecer os coeficientes de aproximação e de detalhe com o mesmo número de amostras do sinal original (Figura 17). Para se obter os coeficientes de detalhe e de aproximação em um nível $j$ de decomposição, devem-se utilizar filtros com escalamento $h_{1}^{j}(n)$ e $h_{0}^{j}(n)$. Esses filtros são obtidos de $h_{1}(n)$ e $h_{0}(n)$, intercalando-se $\left(2^{\mathrm{j}-1}-1\right)$ zeros entre cada um dos coeficientes desses filtros (Figura 18). Deve-se observar que a resposta em freqüência destes filtros fornece, obviamente, as mesmas bandas de freqüência obtidas no caso da utilização do dizimador na saída dos filtros (SILVEIRA) [87].

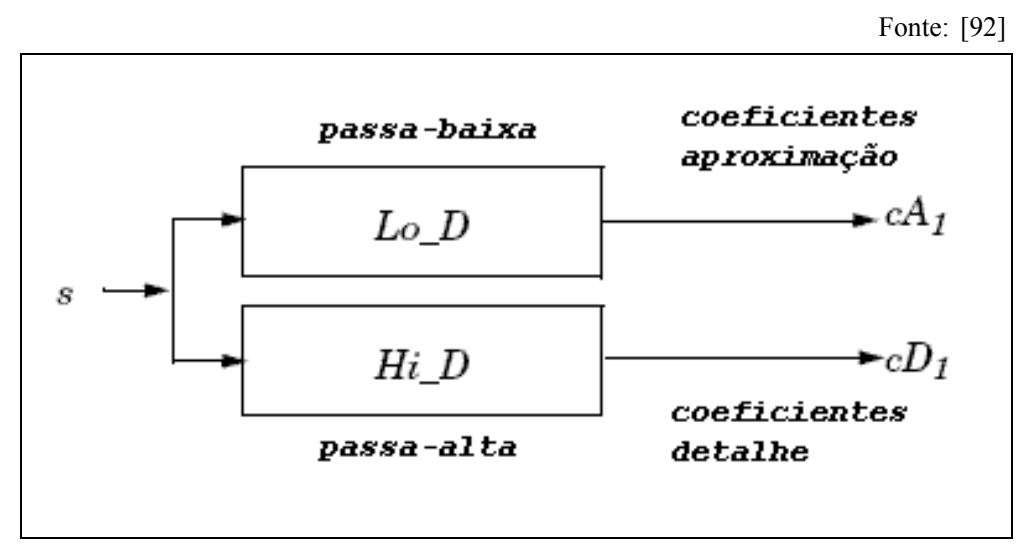

FIGURA 17 - Processo de decomposição em nivel 1 via TWE 
Decomposição

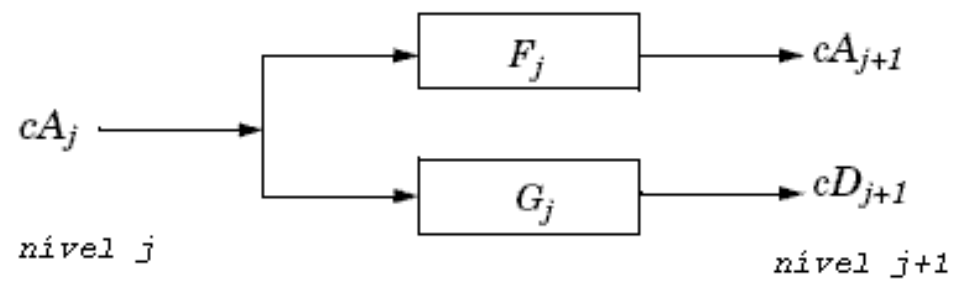

Escalamento do filtro e Upsample

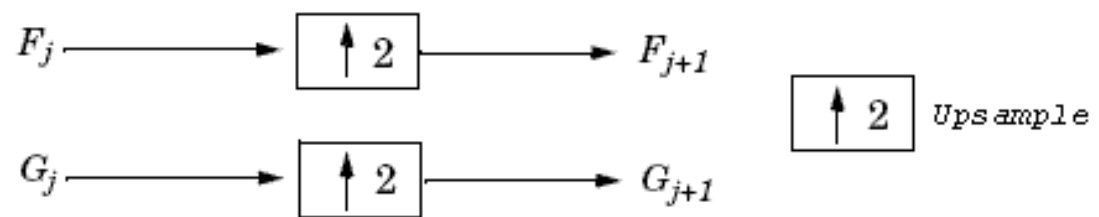

Inicialização

$$
c A_{0}=s \quad F_{0}=L o_{-} D \quad G_{0}=H i_{-} D
$$

FIGURA 18 - Processo de decomposição em nível j via TWE

Ressalta-se que a utilização da TWE implica em um maior esforço computacional, bem como na introdução de redundância nos sinais de saída. Porém, dependendo do nível de decomposição requerido, o número de amostras para a reconstrução do sinal pode ser insuficiente para uma boa representação quando da utilização da análise multiresolução com dizimação. Fato este que pode ser atenuado utilizando a TWE, uma vez que sempre teremos o mesmo número de amostras do sinal original, conforme ilustra a Figura 19. 


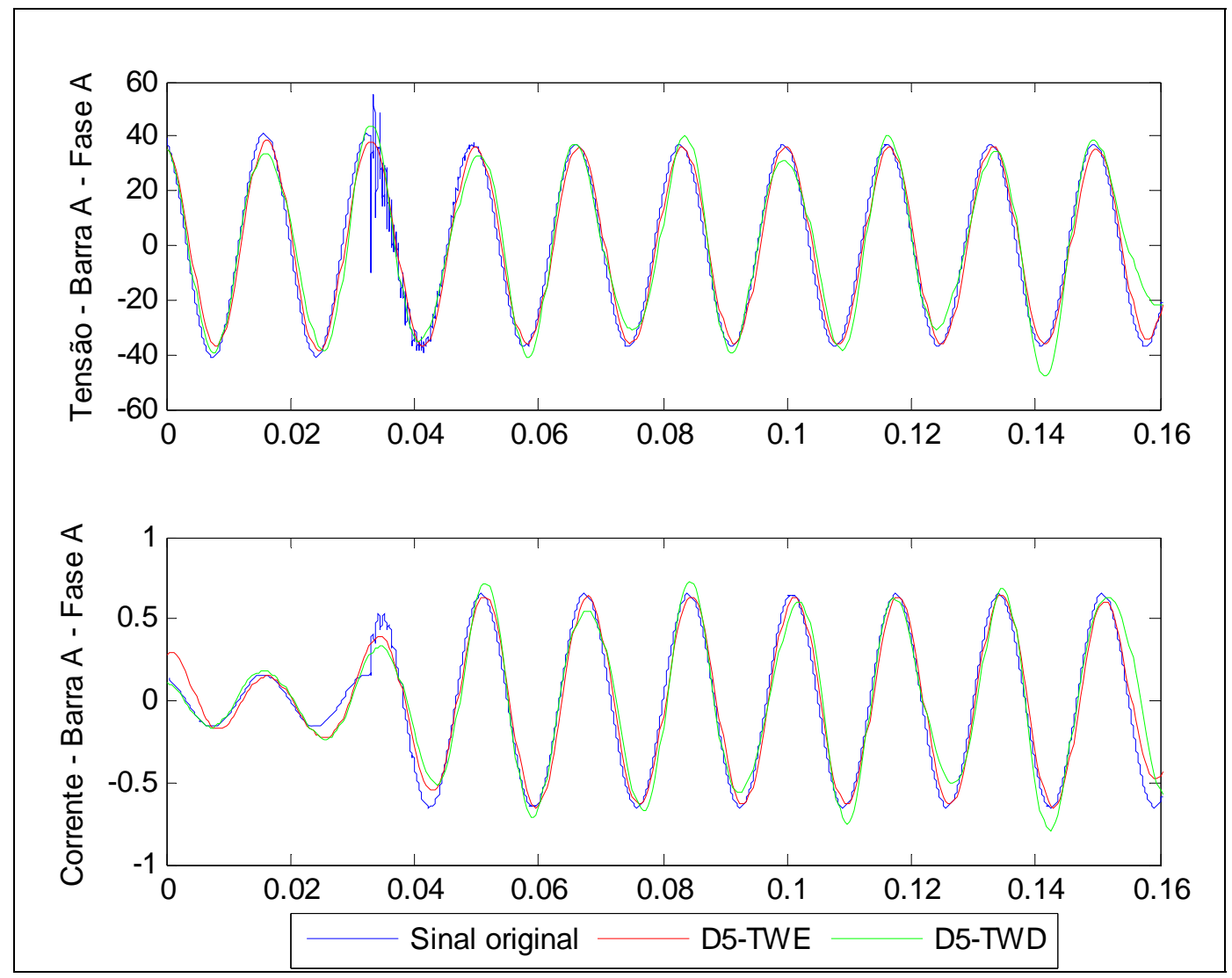

FIGURA 19 - Sinais de detalhe em nível 5 obtidos utilizando a TWD e TWE.

Maiores informações sobre a TWE podem ser encontradas nas seguintes referências: Nason e Silverman [88], Coifman e Donoho [89], Pesquet et al. [86], Simoncelli et al. [90], Lang et al. [91] e Misiti et al. [92].

\subsubsection{Aplicações da Transformada Wavelet em Sistemas Elétricos de Potência}

Na última década, houve um maior número de publicações sobre a aplicação da TW em sistemas elétricos de potência. Diferentes propostas de aplicações foram introduzidas, principalmente no tocante a qualidade da energia, destacando neste contexto o trabalho de Santoso et al. [93]. A Figura 20 ilustra as áreas de aplicação da TW em sistemas elétricos de potência (KIM e AGGARWAL) [85].

Relacionado à área de proteção e supervisão de SEPs, diversas contribuições foram apresentadas até o momento, como por exemplo, o emprego da TW na detecção, classificação e localização de faltas (SILVEIRA) [87].

Quando aplicada, a TW pode ser implementa através do uso de uma linguagem de programação, como por exemplo, C, C++ e mais recentemente, Java. Ou ainda 
através da utilização de pacotes computacionais, como é o caso do "Toolbox" incluído no software Matlab ${ }^{\circledR}$ [92].

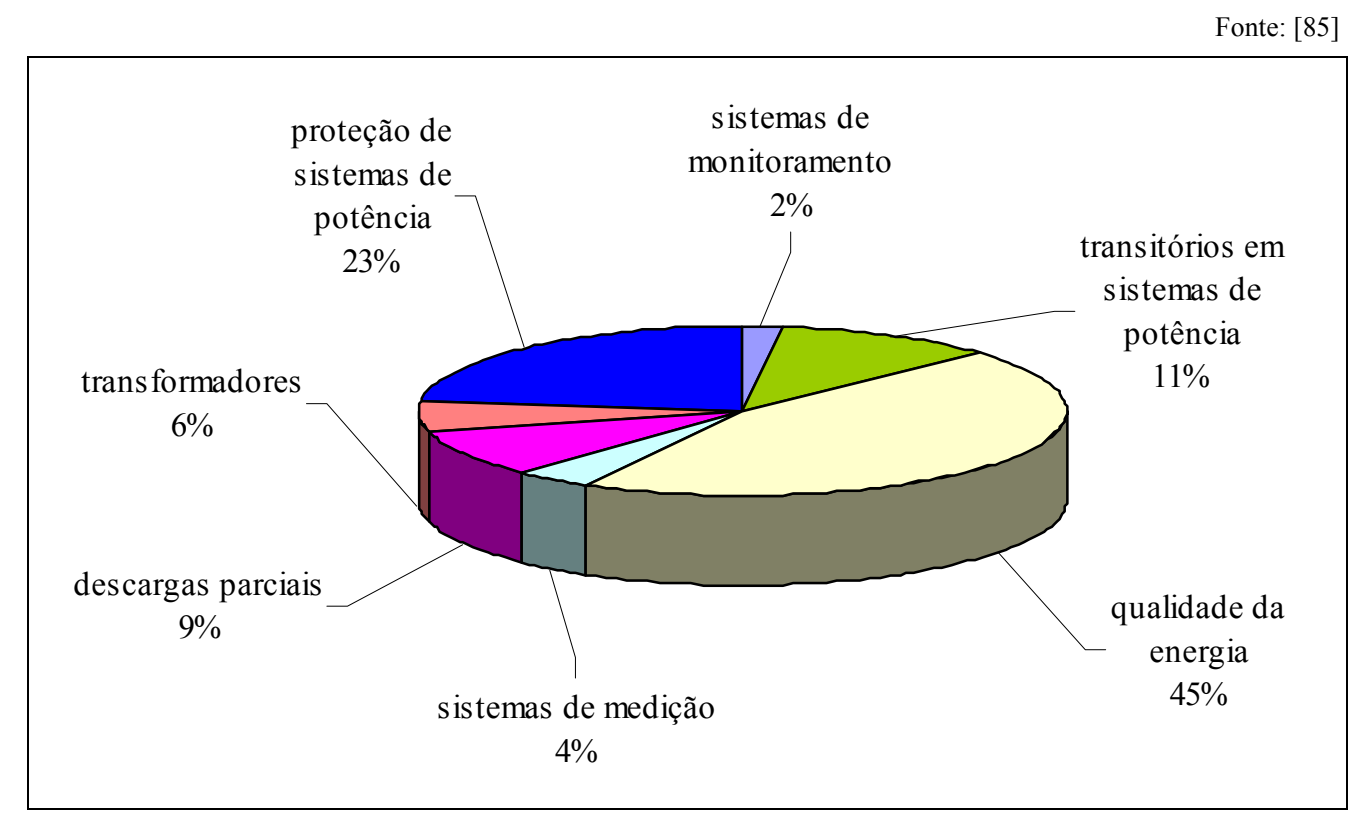

FIGURA 20 - Áreas de aplicação da TW em sistemas elétricos de potência. 


\section{SISTEMA ELÉTRICO ANALISADO}

Com o objetivo de testar e validar a aplicabilidade do algoritmo de localização de faltas proposto, utilizou-se da simulação de um sistema de transmissão em condição faltosa. Para tal, o software ATP (Alternative Transient Program) [94], [95] foi empregado. Deve ser mencionado que a técnica descrita é baseada em simulações computacionais e que considerações práticas tais como o efeito dos transdutores (TPC's e TC's), filtros anti-aliasing e conversores Análogico/Digital, foram também incluídas na simulação, fazendo com que os dados obtidos se aproximassem ao máximo dos reais observados na prática. Foram também consideradas as características dos condutores e suas respectivas disposições geométricas nas torres de transmissão.

\subsection{Configuração do sistema de potência}

Observa-se na Figura 21 a representação do sistema elétrico estudado, o qual é semelhante ao encontrado em Oleskovicz [96], com a especificação dos equivalentes de barra e comprimentos das linhas de transmissão.

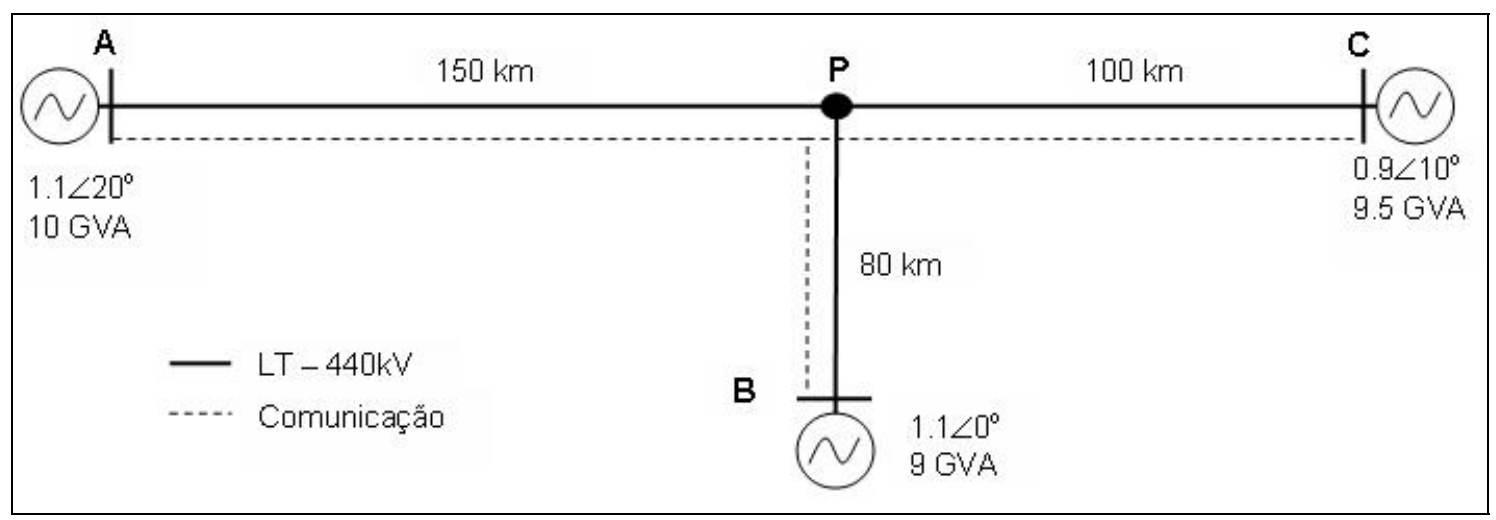

FIGURA 21 - Representação do sistema elétrico analisado 
Considerando-se os diferentes tipos de faltas que podem ocorrer sobre as linhas de transmissão AP, BP e CP do sistema proposto, as simulações foram geradas tomando-se as faltas entre:

- algum condutor a terra (falta fase-terra);

- dois condutores a terra (falta fase-fase-terra);

- dois condutores (falta fase-fase) ou

- todos os condutores (falta trifásica).

Tais situações de faltas foram implementadas dispondo do software ATP conforme as combinações apresentadas na Figura $22^{*}$.

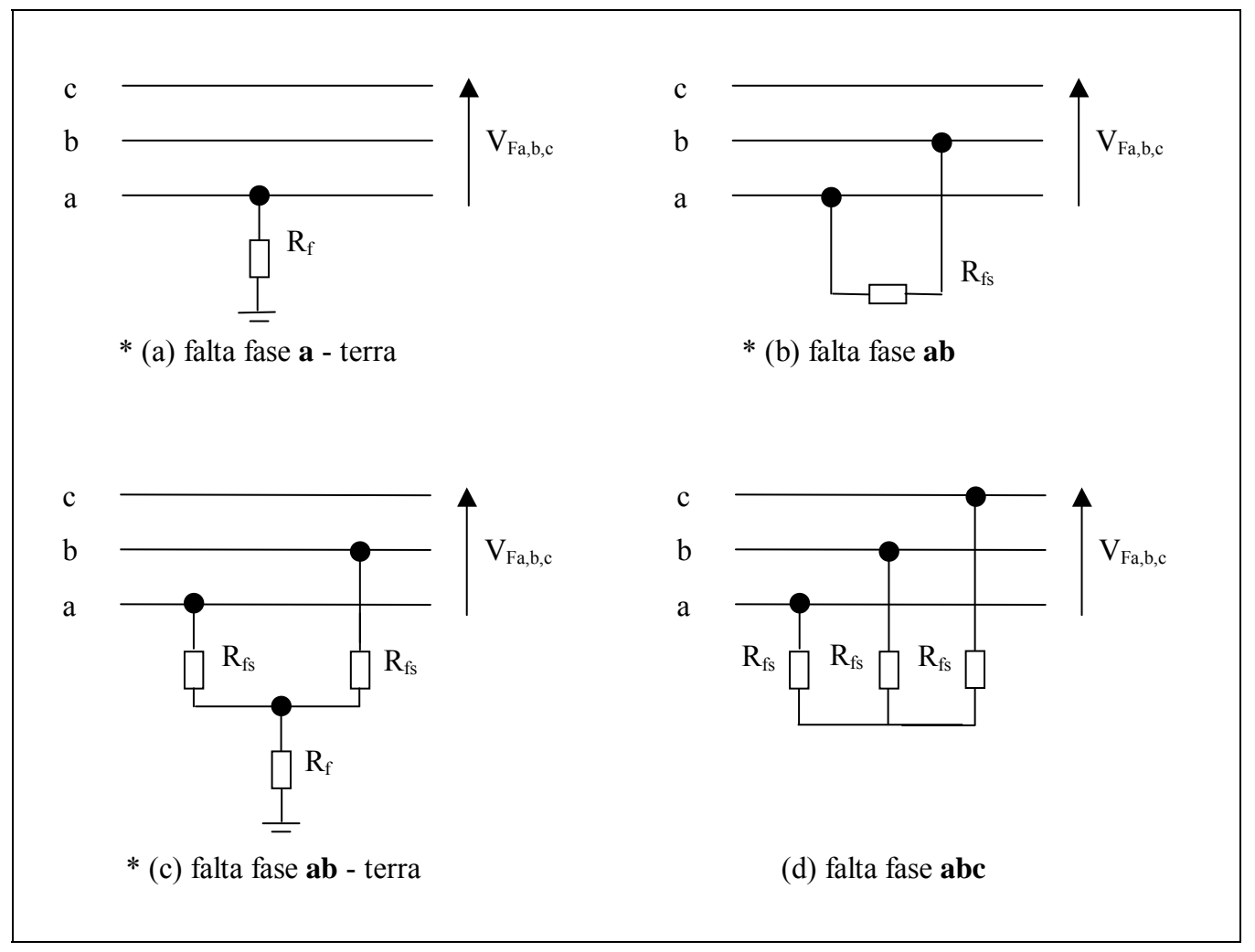

FIGURA 22 - Situações de faltas sobre o sistema

* Combinações obtidas da tese de doutorado "A practical approach to accurate fault location on extra high voltage teed feeders", Denis Vinicius Coury, Tese C858p Biblioteca Central da Escola de Engenharia de São Carlos - Figura B.5.

\subsection{Modelagem da linha de transmissão}

A estrutura da linha de transmissão de $440 \mathrm{kV}$ (Figura 23) corresponde a uma linha típica da CTEEP (Companhia de Transmissão de Energia Elétrica Paulista), 
empregada entre as cidades de Araraquara - Bauru e Jupiá - Ilha Solteira. Apresentamse, no que segue as especificações referentes aos condutores, denotando-se as suas principais características, bem como a resistividade do solo considerada.

Condutor de fase: cabo Grosbeak
a) raio externo do condutor: $12,57 \mathrm{~mm}$;
b) raio interno do condutor: $4,635 \mathrm{~mm}$;
c) resistência em corrente contínua: $0,08998 \Omega / \mathrm{km}$.
d) quatro cabos por fase.

\section{Cabos Pára-raios: EHS 3/8"}
a) raio externo do condutor: $4,572 \mathrm{~mm}$;
b) resistência em corrente contínua: $4,188 \Omega / \mathrm{km}$.

$\underline{\text { Resistividade do solo: }}$

$\mathrm{R}_{\text {solo }}: 250 \Omega . \mathrm{km}$

\section{Flecha a meio vão:}

das fases: $13,43 \mathrm{~m}$

dos pára-raios: $6,4 \mathrm{~m}$

\subsubsection{Parâmetros do sistema elétrico}

Para se efetuar as devidas simulações do sistema elétrico proposto, utilizando-se do software ATP, adotaram-se considerações necessárias para os cálculos dos parâmetros da linha de transmissão, considerando-se as características dos condutores e suas respectivas disposições geométricas nas torres de transmissão, como mostrado na Figura 23. Esta representa uma torre de transmissão de um circuito simples horizontal tipo VVV. Dentre as considerações, optou-se por linhas transpostas, já que a transposição compensa os desequilíbrios dos campos magnéticos entre fases, cabo guarda, ferragens e solo sob a linha de transmissão. O resultado esperado da transposição, segundo Stevenson [2], será a mesma indutância média para cada condutor. Uma observação prática feita por Christopoulos e Wright [42] nos diz que raramente as linhas são transpostas em intervalos regulares, sendo a transposição 
executada onde for fisicamente conveniente, como por exemplo, em subestações. Um exemplo de transposição de uma linha de transmissão qualquer é ilustrado na Figura 24.

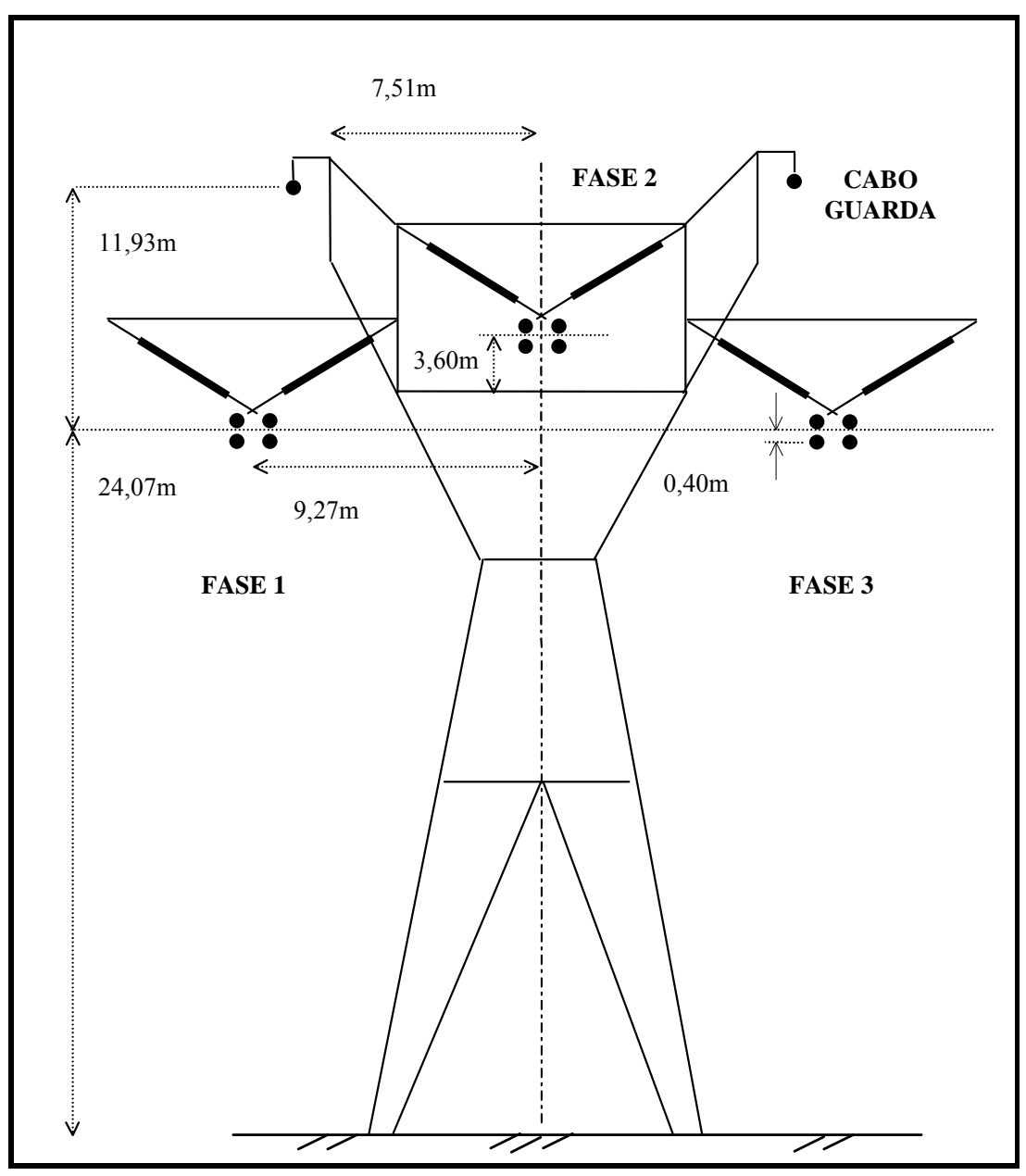

FIGURA 23 - Silhueta de torre da linha de $440 \mathrm{kV}$.

A linha de transmissão foi modelada com parâmetros distribuídos e constantes em relação à freqüência, utilizando-se para isso, a rotina Line Constants [94], [95] decorrente do software ATP, a qual será abordada posteriormente.

Para se obter uma solução exata para os parâmetros de qualquer linha de transmissão, bem como um alto grau de precisão, deve-se considerar o fato de que os parâmetros de uma linha não estão concentrados em um ponto, e sim, uniformemente distribuídos ao longo de todo o seu comprimento. Na Figura 25 mostra-se um esquema monofásico representando um comprimento $\Delta \mathrm{x}$ de uma linha de transmissão, sendo os parâmetros (R, L e C), distribuídos e constantes, determinados pela rotina Line Constants do software ATP. Nesta, L é a indutância da linha por unidade de comprimento, $\mathbf{R}$ é a resistência por unidade de comprimento em corrente alternada e $\mathbf{C}$ é a capacitância da linha por unidade de comprimento. 


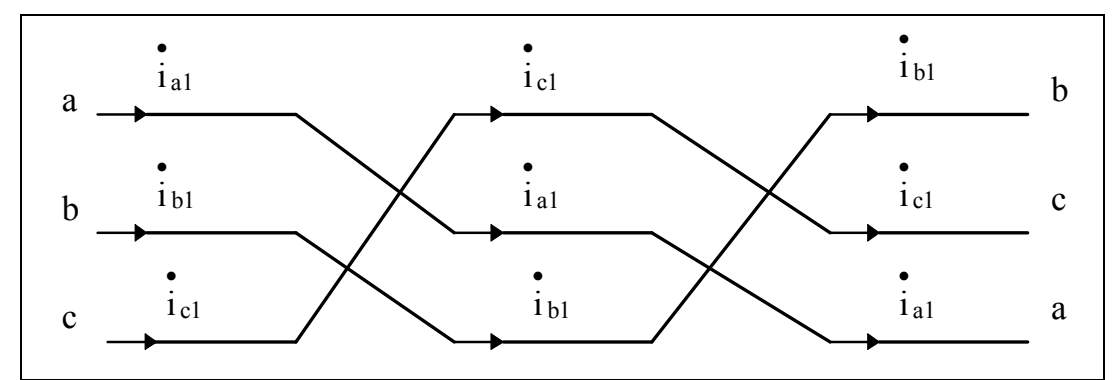

FIGURA 24 - Transposição de uma linha de transmissão

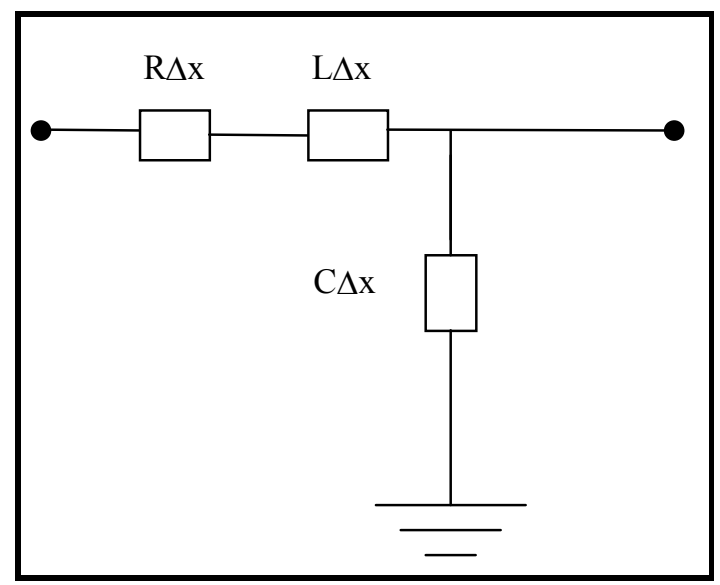

FIGURA 25 - Representação de um comprimento $\Delta x$ de uma linha de transmissão por parâmetros distribuídos.

\subsubsection{Rotina Line Constant e arquivo de entrada para o software ATP}

Após a caracterização da topologia das linhas de transmissão desejadas, passa-se ao início dos cálculos dos parâmetros das mesmas, através da rotina Line Constant, presente no software ATP. Para isto, é considerada toda a geometria e características do sistema, como os espaçamentos e alturas relativas entre condutores, número de condutores por fase, resistividade do solo, freqüência em que os parâmetros foram calculados, condições da linha (com ou sem transposição), etc. Ressalta-se que os parâmetros do modelo de linha em circuito simples foram calculados para uma freqüência de $600 \mathrm{~Hz}$, com o objetivo de simular ou atenuar o efeito da variação da freqüência em caso de faltas. $\mathrm{O}$ arquivo de entrada da rotina Line Constant para o sistema apresentado anteriormente (linha de transmissão tipo simples horizontal - VVV) é dado na Figura 26. 


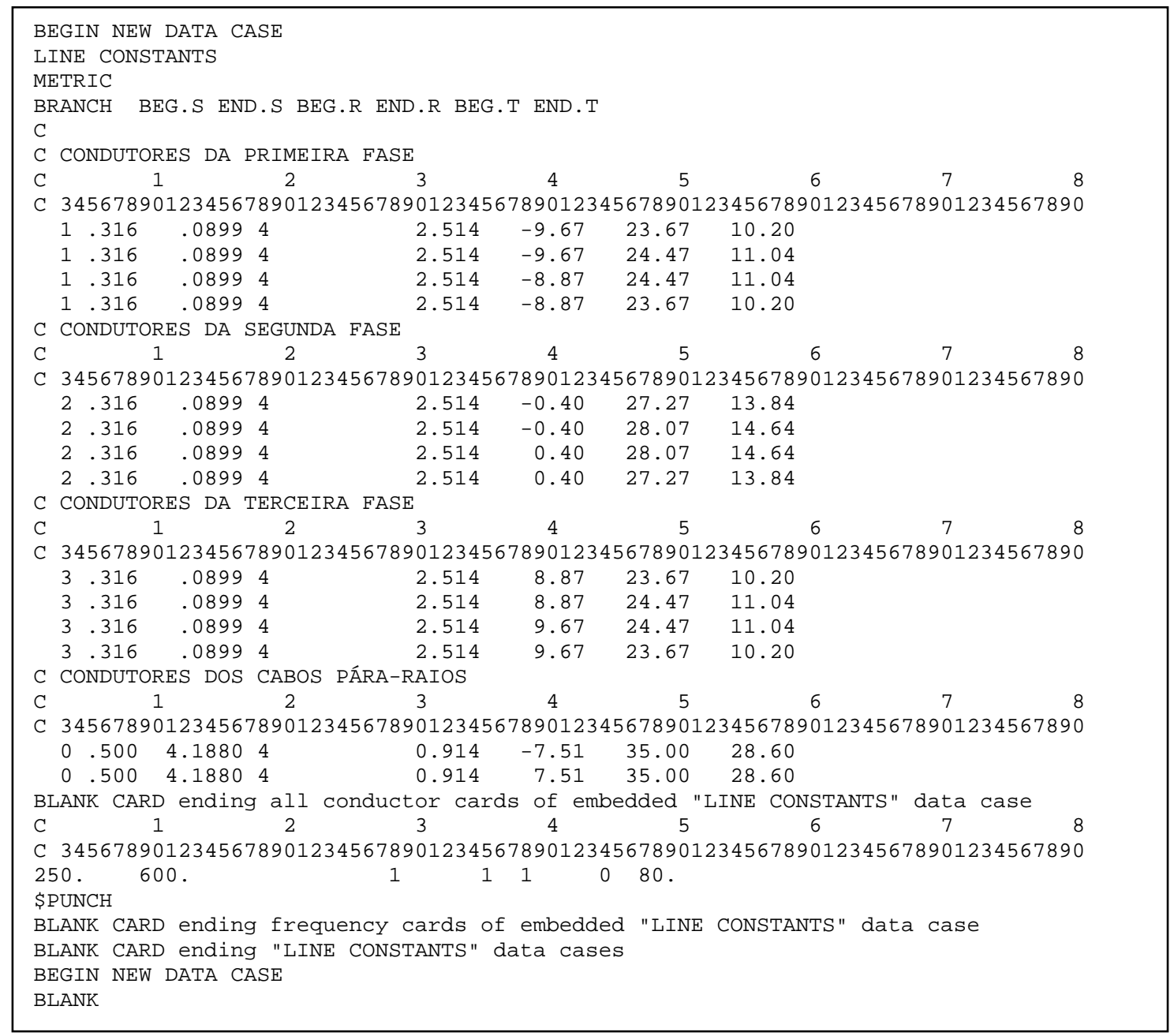

FIGURA 26-Rotina Line Constant para o sistema simples horizontal tipo VVV

Da execução da rotina Line Constant interessa-nos, dentre as inúmeras informações, a impedância série reduzida do sistema e os valores de seqüência zero e positiva das grandezas referentes às resistências, reatâncias e susceptâncias da linha de transmissão. Os valores de reatância e susceptância são convertidos para valores de indutância (L) e capacitância (C), os quais alimentarão o arquivo principal de simulação. Os valores obtidos pela rotina Line Constants referente ao sistema simples, são mostrados na Tabela 3. Uma vez que foi considerado o mesmo tipo de estrutura e cabos para os três segmentos de linha do sistema proposto, os valores dos parâmetros das três linhas serão idênticos.

TABELA 3 - Parâmetros da linha de transmissão de $440 \mathrm{kV}$

\begin{tabular}{ccc|ccc}
\hline \multicolumn{3}{c|}{ Sequência Positiva } & \multicolumn{3}{c}{ Sequência Zero } \\
$\mathbf{R}$ (ohms/km) & $\mathbf{L}(\mathbf{m H} / \mathbf{k m})$ & $\mathbf{C}(\mathbf{u F} / \mathbf{k m})$ & $\mathbf{R}(\mathbf{o h m s} / \mathbf{k m})$ & $\mathbf{L}(\mathbf{m H} / \mathbf{k m})$ & $\mathbf{C}(\mathbf{u F} / \mathbf{k m})$ \\
\hline $3,853 \mathrm{E}-02$ & $7,410 \mathrm{E}-01$ & $1,570 \mathrm{E}-02$ & $1,861 \mathrm{E}+00$ & $2,230 \mathrm{E}+00$ & $9,034 \mathrm{E}-03$ \\
\hline
\end{tabular}


Na Tabela 4 e na Tabela 5, são apresentados os parâmetros e dados de barra para os equivalentes nos terminais da linha de $440 \mathrm{kV}$, necessários para a elaboração do arquivo principal de simulação do ATP.

TABELA 4 - Parâmetros dos equivalentes de geração das barras $A, B$ e $C$.

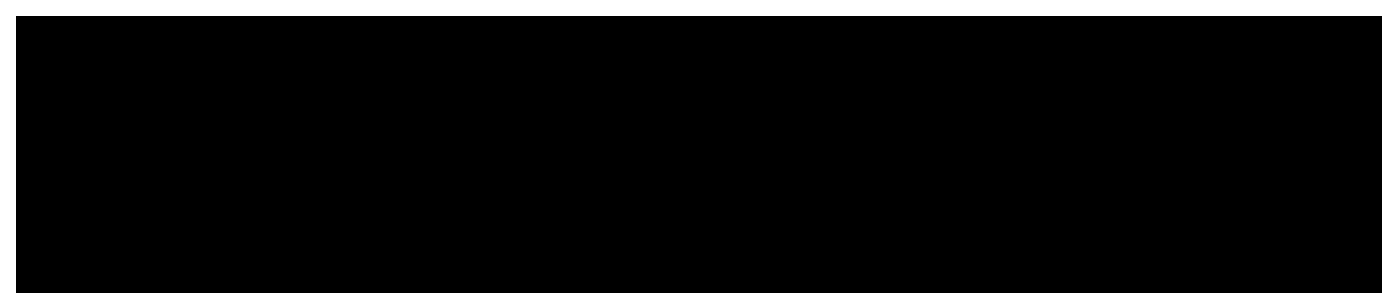

TABELA 5 - Dados das barras A, B e C.

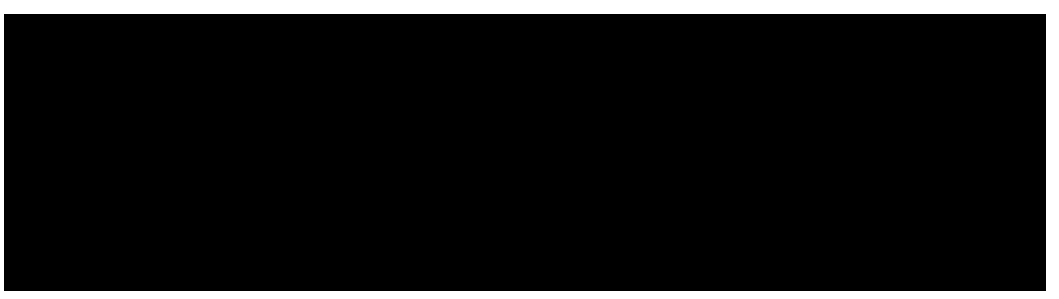

Com os resultados obtidos através da rotina Line Constant, considerando as linhas de transmissão com transposição e parâmetros distribuídos, foi possível a modelagem do sistema elétrico em todos os detalhes por meio do software ATPDRAW [95] o qual pode ser visualizado por meio da figura apresentada no Apêndice. A partir do modelo do ATPDRAW extraí-se o arquivo de entrada expresso em linhas de comando ou cartões de entrada, o qual também compõe o Apêndice A. Neste arquivo de entrada, todas as conexões do sistema estão representadas, bem como as condições referentes ao tipo de falta aplicada (localização, resistência e ângulo de incidência da falta, fluxo de energia no sistema) e demais considerações adotadas.

Visto que na prática os parâmetros das LTs variam com freqüência, utilizou-se também neste trabalho linhas com parâmetros variando na freqüência. Para tal, as linhas foram modeladas conforme parâmetros fornecidos pela rotina JMarti do ATP [94]-[95], a qual fornece os parâmetros variantes na freqüência. $O$ cartão de entrada da rotina JMarti, considerando a configuração geométrica da rede apresentada anteriormente na Figura 23, é ilustrado na Figura 27. 
Com respeito aos Transformadores de Corrente (TC's) e de Potencial Capacitivo (TPC's), estes também foram considerados na modelagem do sistema e são descritos a seguir.

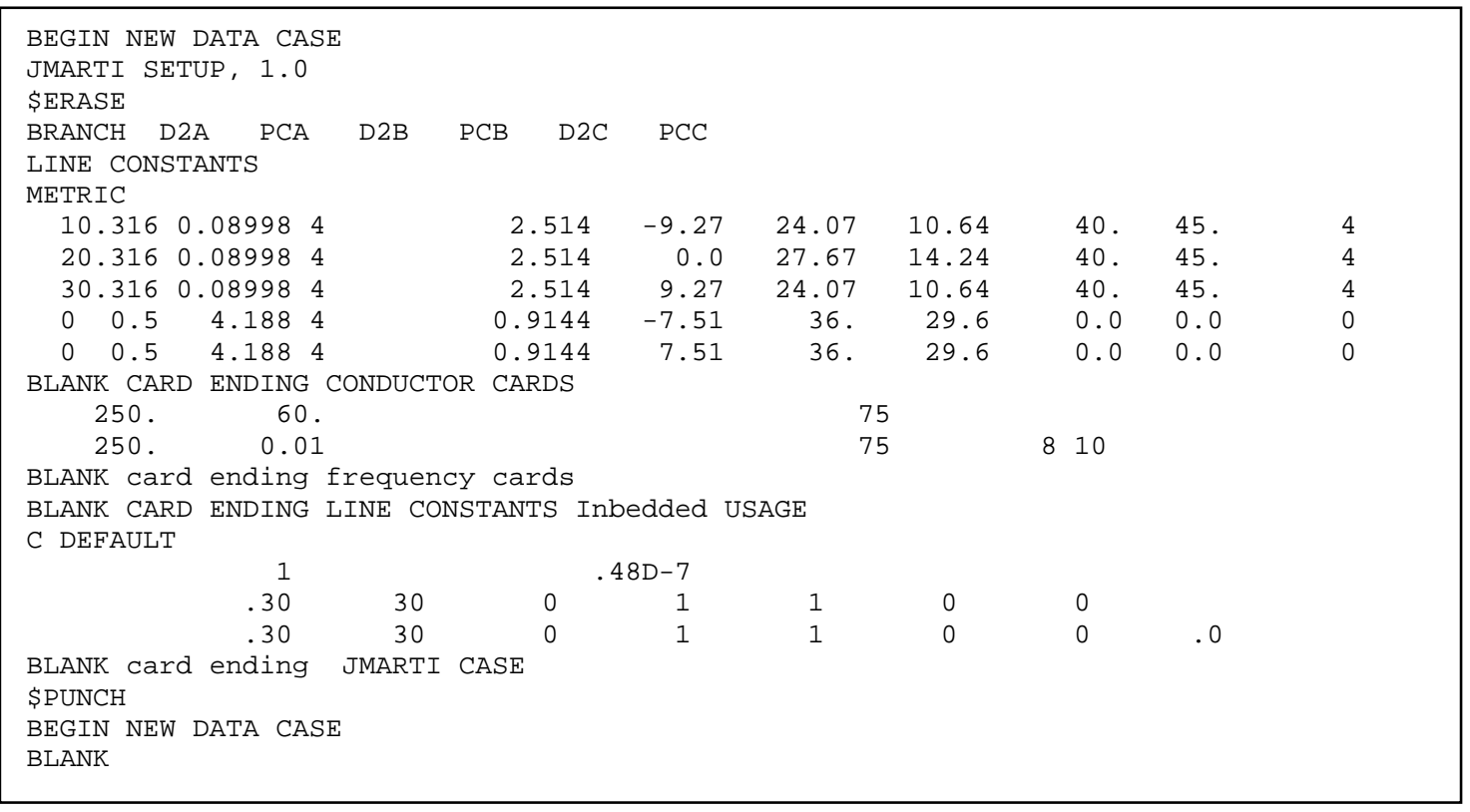

FIGURA 27 - Rotina JMarti para o sistema simples horizontal tipo VVV

\subsection{Condicionamento analógico e digital dos sinais}

Sempre pensando na representação, simulação e aquisição de dados o mais próximo do real, foram consideradas no desenvolvimento deste trabalho as etapas de aquisição e condicionamento dos sinais de corrente e de tensão a serem processados pelo algoritmo de localização de faltas. Portanto, considerou-se no modelo do sistema o uso de TPC's e de TC's, com o intuito de se adequar os níveis dos sinais observados, assim como, considerar os efeitos introduzidos por tais equipamentos frente às situações faltosas. Além dos TPC's e TC's, considerou-se também o uso de filtros passa baixa Butterworth (quando necessários) e a digitalização dos sinais de corrente e tensão via linguagem de programação. Os detalhes sobre estas etapas serão descritas no que segue.

\subsubsection{Modelagem do TPC}

Adotou-se neste trabalho o uso de TPC's por serem estes os mais usados em sistemas de extra alta tensão (EAT), visto que o uso de transformadores de potencial eletromagnético não é adequado. Inicialmente o modelo utilizado neste trabalho foi 
baseado em um simples divisor capacitivo, como o ilustrado na Figura 28. Nesta $C_{1}$ e $C_{2}$ representam a capacitância do divisor de tensão, $V_{p}$ e $V_{s}$ são respectivamente as tensões de fase e intermediária (secundária) do sistema. Na prática, utiliza-se um valor de $\mathrm{C}_{1}$ tão grande quanto possível (usualmente $2000 \mathrm{pF}$ ). O valor de $\mathrm{C}_{2}$ é estabelecido conforme a tensão de saída desejada [42]. Neste trabalho, o cálculo de $C_{2}$ foi baseado na eq.(4.1), considerando-se $\mathrm{C}_{1}=2000 \mathrm{pF}$ e $\mathrm{V}_{\mathrm{s}}=12 \mathrm{kV}$ (fase-terra).

$$
V_{p}=\frac{C_{1}}{C_{1}+C_{2}} V_{S}
$$

Na saída dos TPC's não foi considerado nenhum modelo de transformação de potencial auxiliar, sendo os dados secundários apenas divididos por uma dada relação de transformação para serem posteriormente processados pelo localizador.

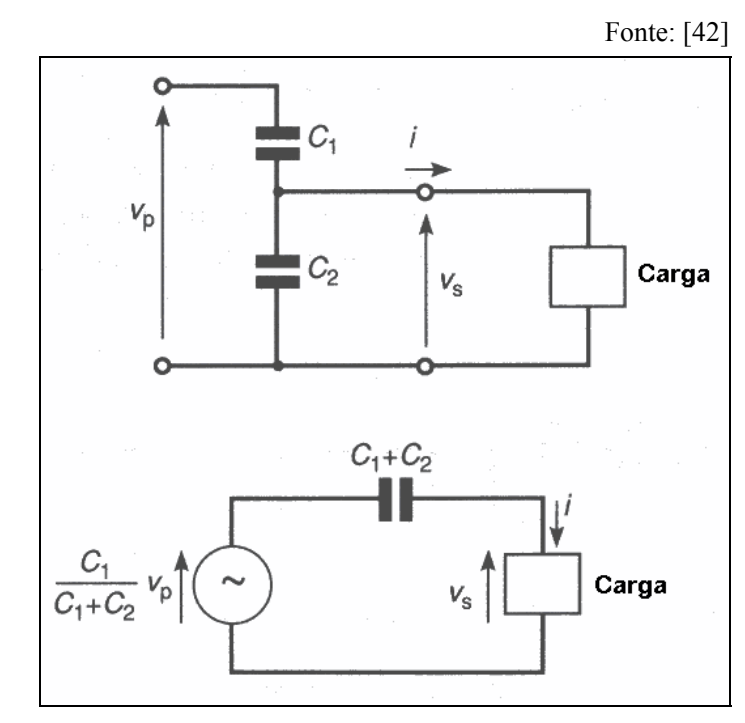

FIGURA 28 - Modelo do TPC inicialmente empregado

Em uma segunda etapa, uma modelagem mais completa para o TPC foi implementada via ATPDRAW, baseado em (TSIOUVARAS et al.) [97], (KOJOVIC et al.) [98] e (USHIKUBO e ROMEIRO FILHO) [99]. Na Figura 29 é representado o circuito completo do TPC baseado em modelo real. Os valores dos parâmetros que compõem o modelo foram extraídos e adequados ao sistema deste trabalho com base em [99]. Tal representação permite simular condições e respostas do TPC próximas as reais obtidas em campo. 


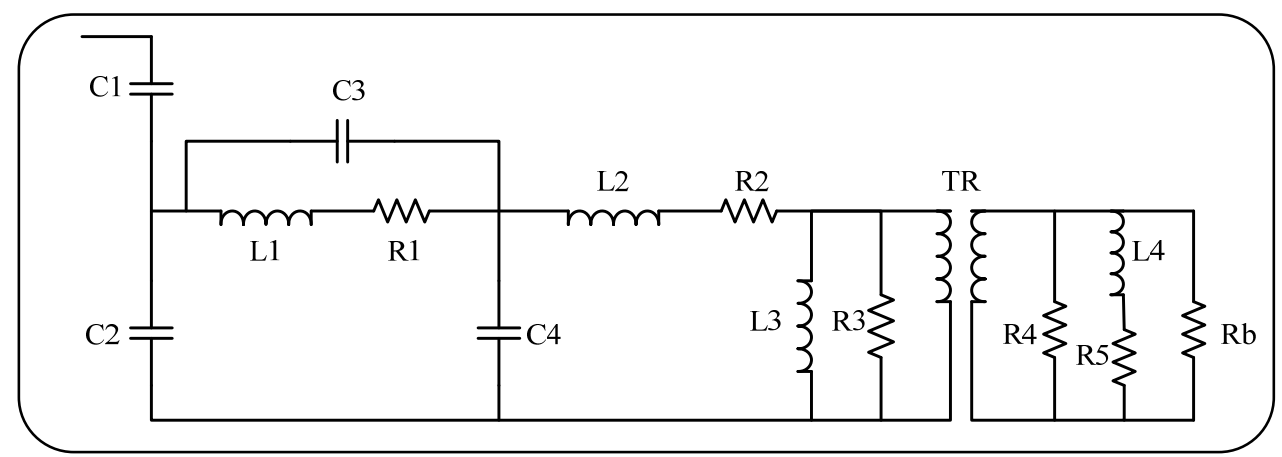

FIGURA 29-Modelo completo do TPC

Executando o arquivo de entrada do ATP similar ao apresentado no Apêndice A, relativo a uma falta fase-fase-terra, com ângulo de incidência de $90^{\circ}$ e aplicada a $75 \mathrm{~km}$ da barra A, obtemos respectivamente as seguintes formas de ondas de tensão referentes ao primário (entrada de $C 1)$ e ao secundário $(R b)$ do TPC modelado (Figuras 30 e 31).

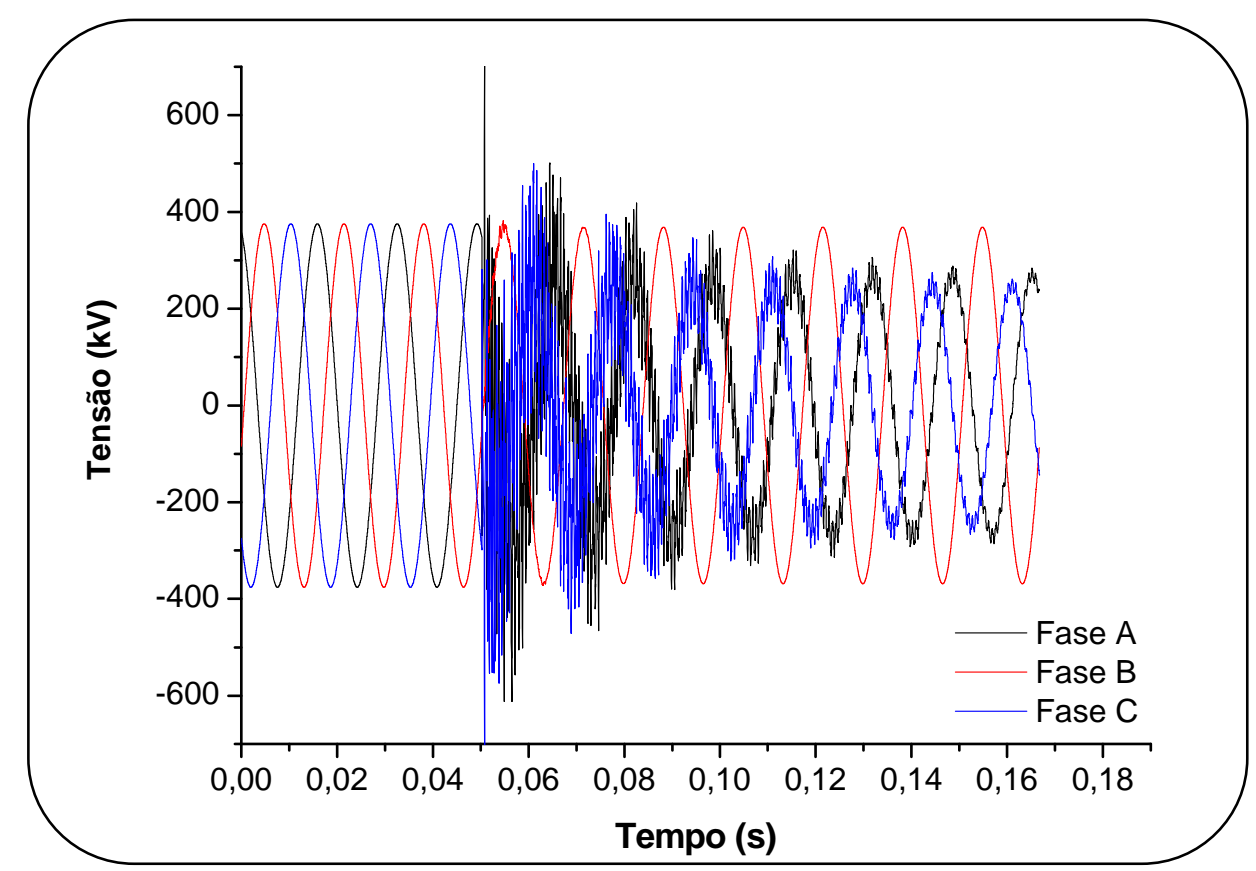

FIGURA 30 - Formas de onda da tensão primária para uma falta fase-fase-terra aplicada a $75 \mathrm{~km} \mathrm{da}$ barra $A$. 


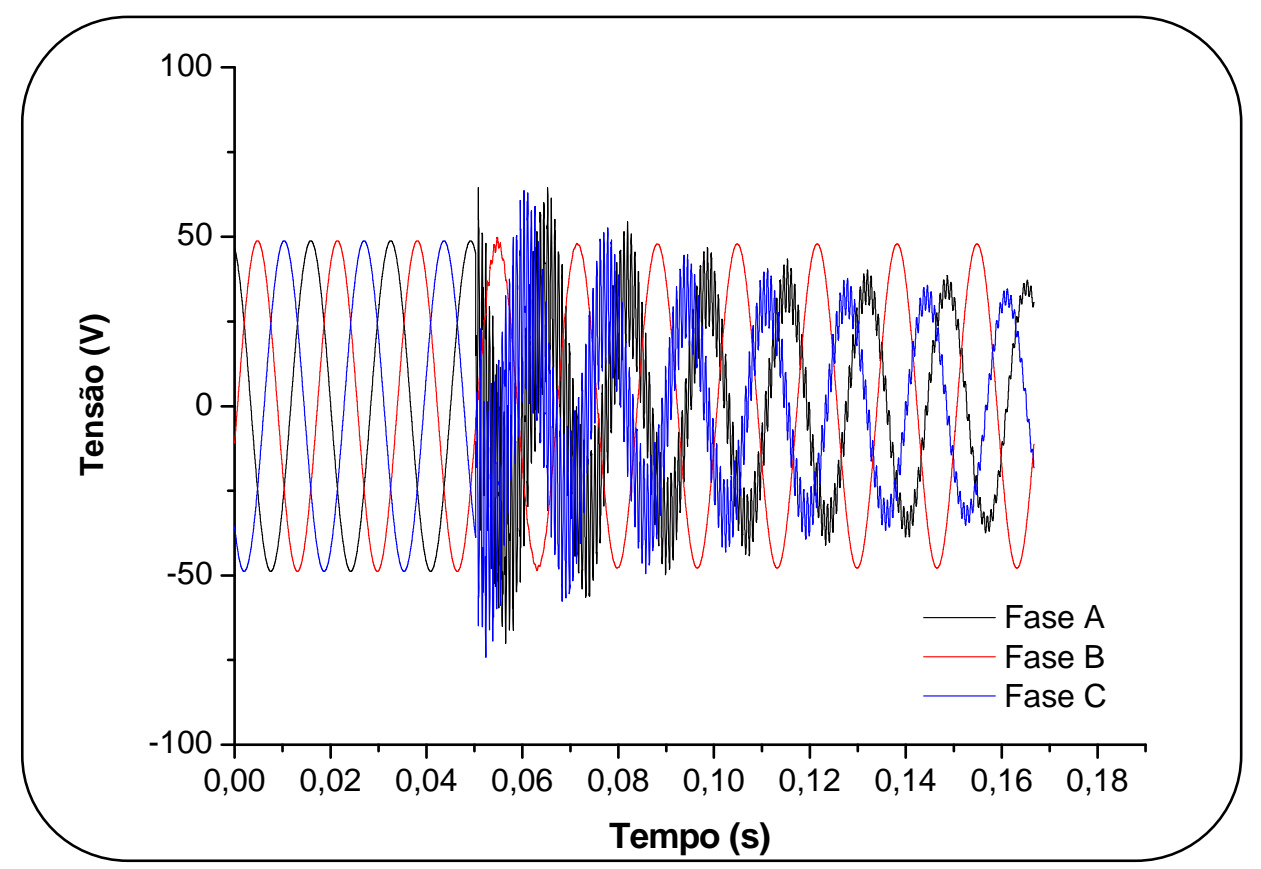

FIGURA 31 - Formas de onda da tensão de saída do TPC para uma falta fase-fase-terra aplicada a 75 km da barra A.

\subsubsection{Modelagem do TC}

De modo análogo aos TPC's, os TC's destinam-se a evitar a conexão direta de medidores e relés ao circuito de corrente alternada de alta tensão, reproduzindo com certa fidelidade os sinais de correntes observados.

A representação dos TC's sobre o sistema estudado foi feita com base no modelo de transformador incorporado ao software ATP [94]. As Figuras 32 e 33 apresentam respectivamente o modelo do transformador empregado e o detalhe das conexões dos enrolamentos. Para caracterizar um TC, os enrolamentos primários (alta tensão) foram ligados em série, enquanto o secundário, ligado em estrela, foi conectado a carga (terminal do relé), conforme Oleskovicz [100] e Kezunovic [101].

O modelo do TC foi implementado levando em conta características reais de um TC 10B400 com relação 3000:5A (460 kV), fornecidos pela CTEEP (Companhia de Transmissão de Energia Elétrica Paulista), incluindo sua respectiva curva de saturação.

Dentre os diversos parâmetros podemos destacar:

- Indutância de dispersão do primário (L1): $1,0 * 10^{-4} \mathrm{H}$

- Resistência de dispersão do primário (R1): $1,0 * 10^{-3} \Omega$

- Indutância de dispersão do secundário (L2): $1,0 * 10^{-6} \mathrm{H}$

- Resistência de dispersão do secundário (R2): 1,2 $\Omega$ 
- Relação de transformação: 3000:5A.

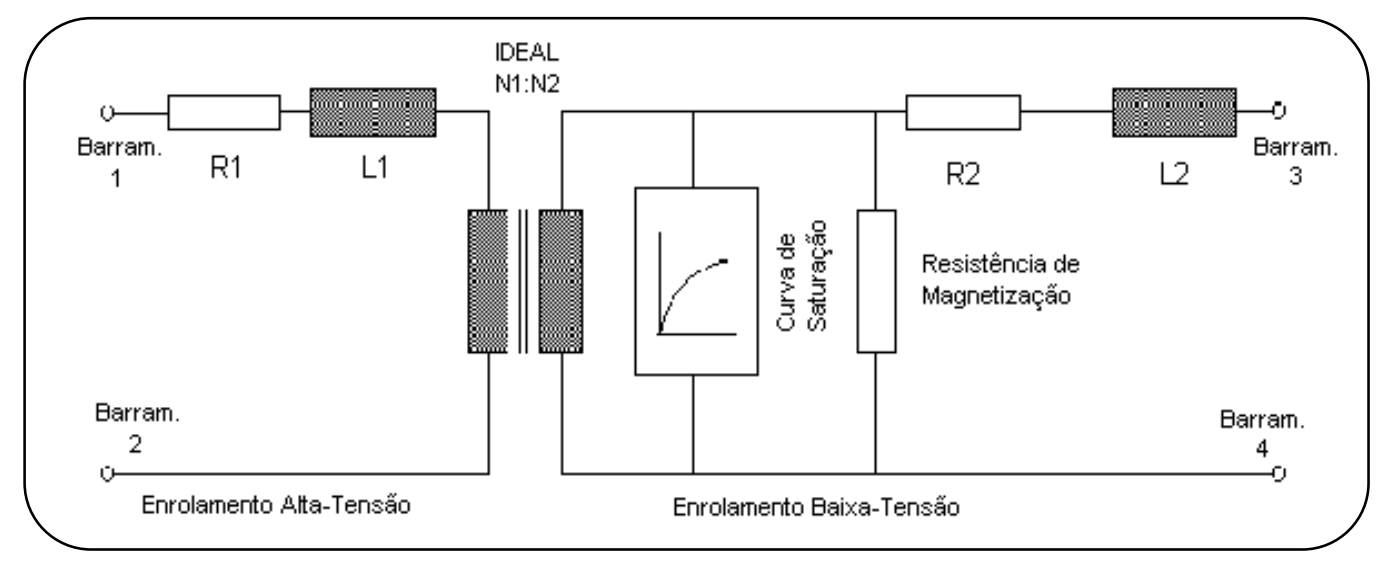

FIGURA 32 - Modelo do transformador monofásico empregado - ATP

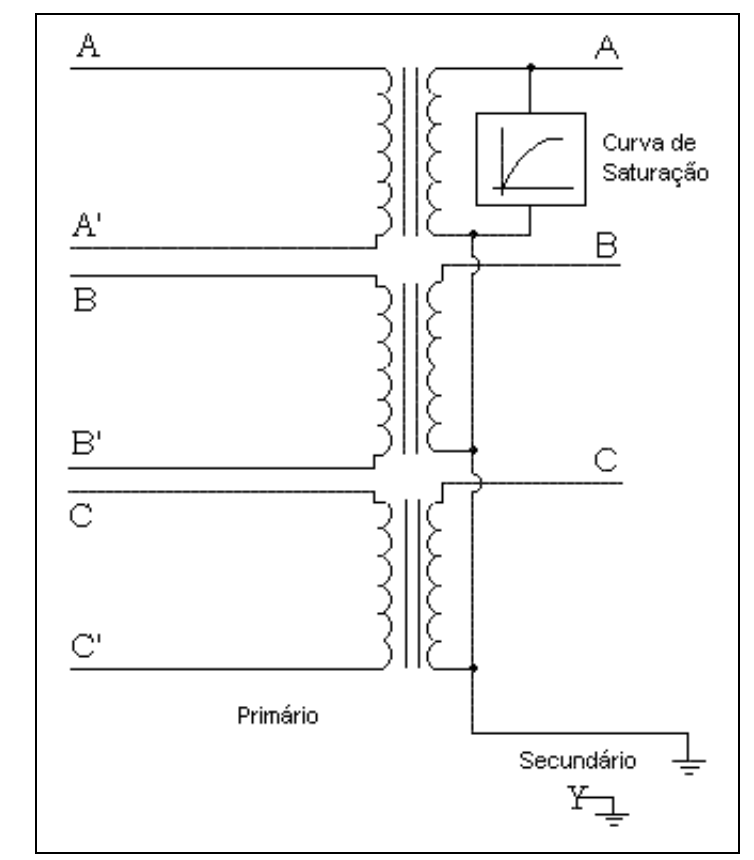

FIGURA 33 - Detalhe das conexões dos enrolamentos

Com base na curva de saturação do referido TC dada pela Figura 34, foi possível utilizar-se de uma sub-rotina do ATP, denominada SATURATION, para levantar a curva característica (fluxo versus corrente) e assim alimentar o modelo do TC conforme configurado pelo ATP. O modelo dos TC's pode ser encontrado no arquivo de entrada do sistema em estudo, conforme disposto no Apêndice A. 


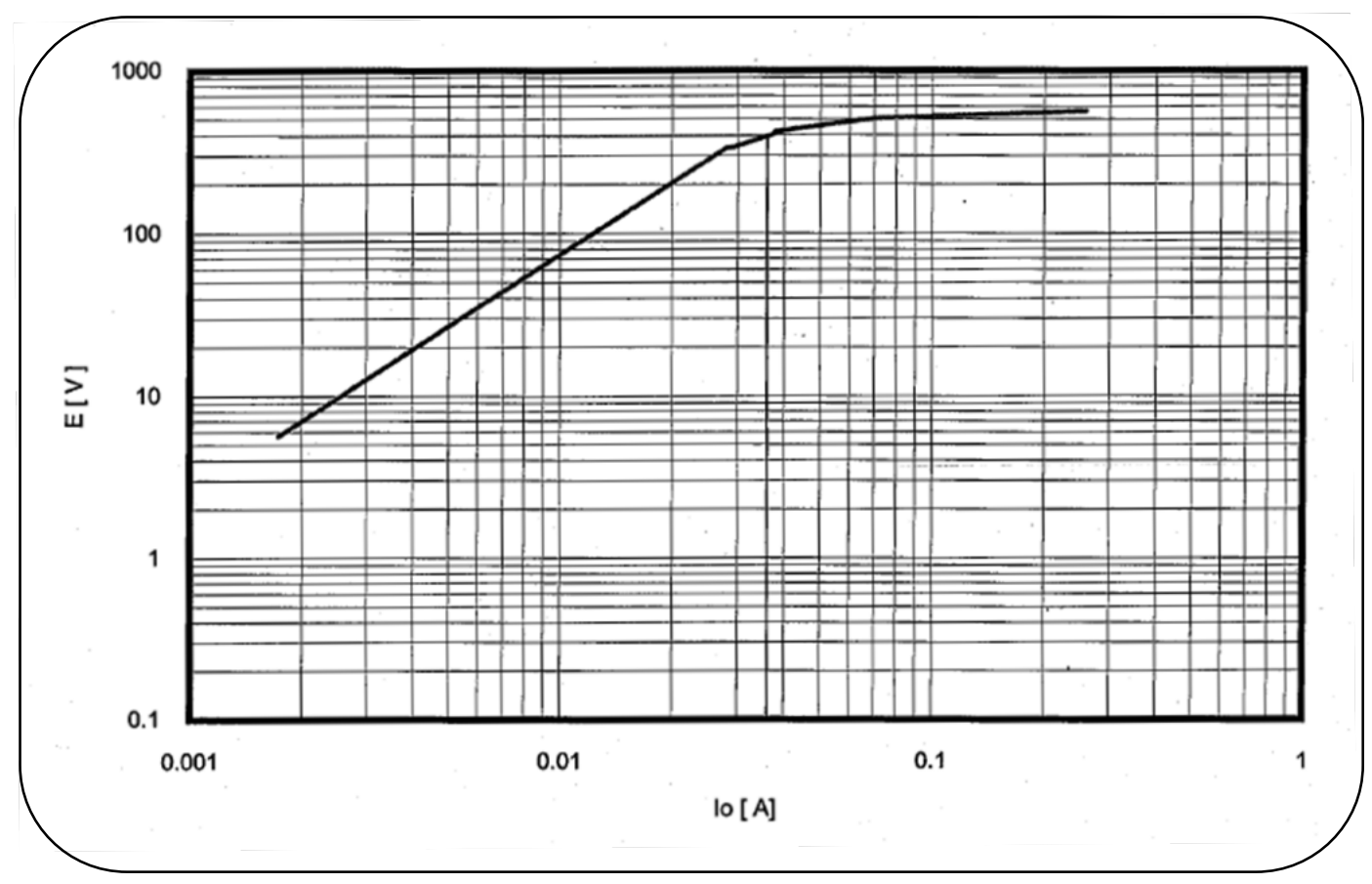

FIGURA 34 - Curva de Saturação (VxI) de um TC 10B400 - 3000:5A-460 kV.

\subsubsection{Filtro passa-baixa Butterworth}

Como fato, temos que normalmente é necessário perfazer uma filtragem analógica sobre os sinais provenientes dos TPC's e TC's, para então direcioná-los a entrada dos relés. Esta filtragem tem por objetivo atenuar as componentes harmônicas de alta freqüência superpostas ao sinal fundamental, para uma posterior amostragem do mesmo. Evita-se desta maneira, uma possível sobreposição de espectros, conhecida também como efeito aliasing, conforme mencionado por Johns [41] e Phadke [102]. Na prática, a filtragem analógica depende dos requisitos exigidos pelo dispositivo em questão. Geralmente são utilizados filtros passa-baixas para remover altas freqüências indesejadas antes de amostrar o sinal. Portanto, cabe ressaltar, que o processo de filtragem analógica mencionado, somente foi aplicado no desenvolvimento deste trabalho, quando necessário. Uma vez que sinais caracterizados por altas freqüências também serão empregados para se localizar a situação de falta observada.

Para o projeto do filtro, optou-se pelo uso de um filtro passa-baixa Butterworth de segunda ordem, por ser este um dos mais utilizados na prática e de simples implementação computacional. Por tal aplicação, busca-se uma reposta em amplitude plana e suave na faixa de passagem associada às baixas freqüências do sinal em análise (Figura 35). Desta idealização, o filtro de Butterworth vem a aproximar esta 
característica através de uma função polinomial no domínio da freqüência. Este é caracterizado por uma resposta em amplitude plana na faixa de passagem e decrescente a partir da banda de atenuação, conforme ilustra a Figura 36. O módulo ao quadrado da sua função de transferência é definido pela eq. (4.2):

$$
|H(j \Omega)|^{2}=\frac{1}{1+\left(\frac{\Omega}{\Omega_{C}}\right)^{2 N}}=\frac{1}{1+\left(\frac{-s^{2}}{\Omega_{C}^{2}}\right)^{N}}
$$

Na qual $\Omega$ é a freqüência; $\Omega_{c}$ é a freqüência de corte do filtro (caracterizada por um decréscimo de $3 \mathrm{~dB}$ na banda de passagem) e $\mathrm{N}$ é a ordem do filtro.

Quanto às especificações das características do filtro empregado nesta abordagem, essas serão posteriormente apresentadas. Todavia, as mais comuns são como as ilustradas na Figura 37. Nesta figura, a resposta em amplitude de um filtro passa-baixa é linearizada por partes, identificando três distintas regiões: i) uma banda de passagem (0 a $\left.\Omega_{\mathrm{p}}\right)$; ii) uma banda de transição $\left(\Omega_{\mathrm{p}}\right.$ a $\left.\Omega_{\mathrm{s}}\right)$ e iii) uma banda de atenuação ou de parada (acima de $\Omega_{\mathrm{s}}$ ). Em que $\Omega_{\mathrm{p}}$ é a freqüência da banda de passagem, $\Omega_{\mathrm{s}}$ é a freqüência da banda de atenuação, $\delta_{\max }$ e $\delta_{\min }$ são as atenuações máxima da banda de passagem e mínima de banda de parada, respectivamente.

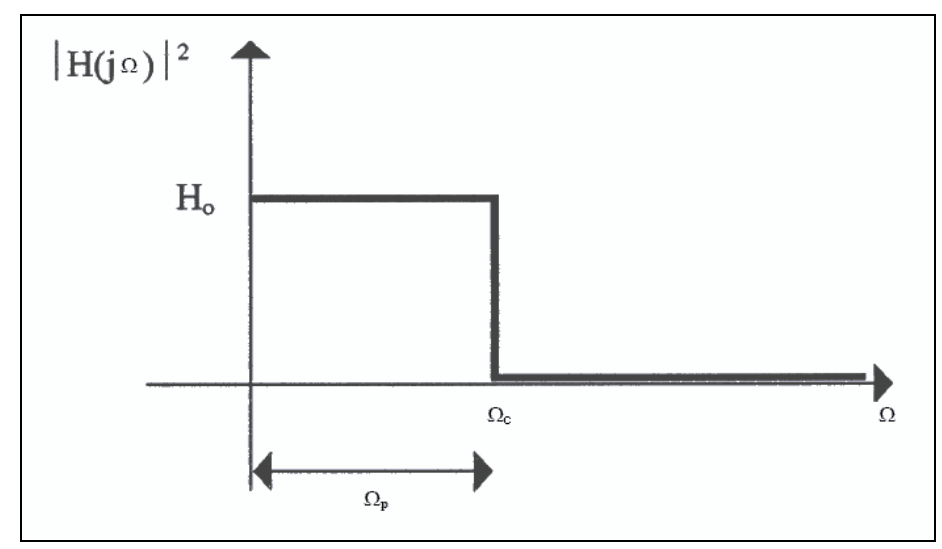

FIGURA 35 - Característica do filtro passa baixa ideal. 


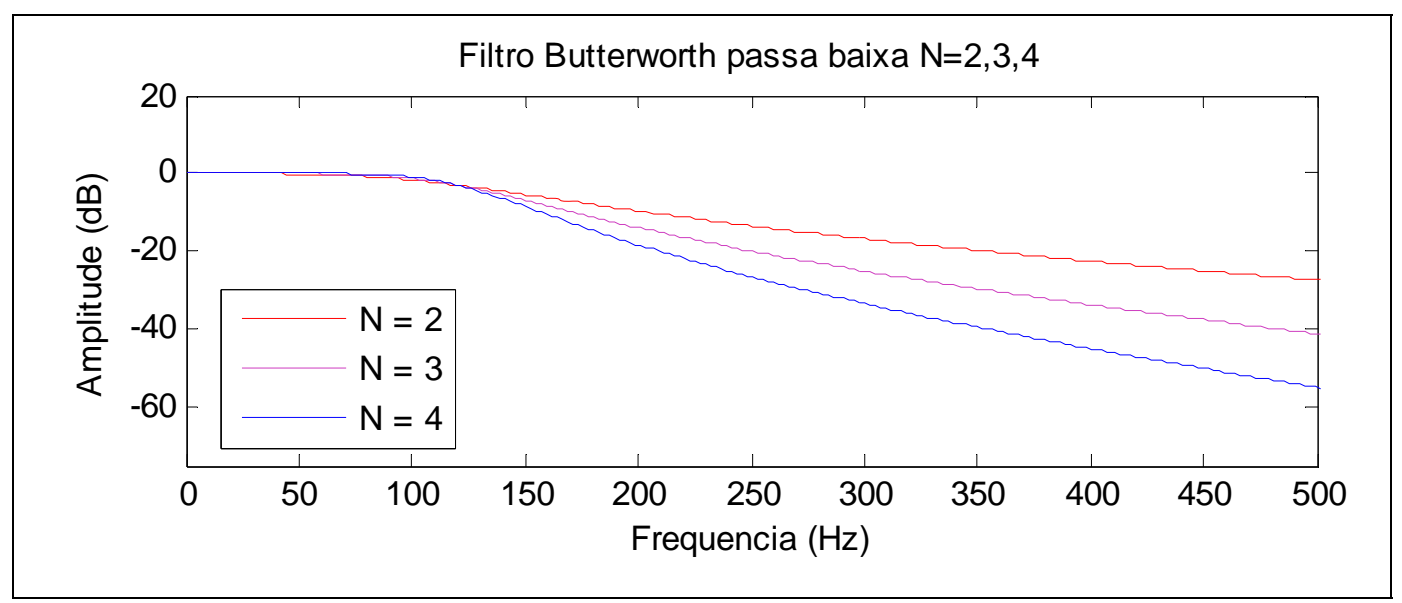

FIGURA 36 - Resposta em freqüencia de um filtro passa-baixa Butterworth.

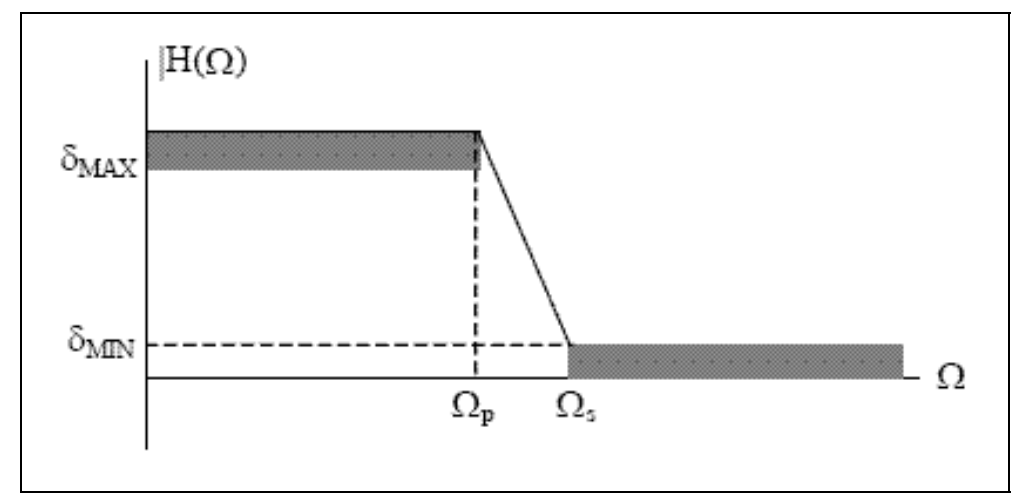

FIGURA 37 - Parâmetro para o projeto de filtros passa baixa.

O filtro passa-baixa Butterworth foi implementado em linguagem de programação Fortran seguindo o algoritmo descrito por Ungrad [103] e pelo software MATLAB $^{\circledR}$ [92] quando da utilização do toobox relativo a filtros.

A Figura 38 ilustra os sinais de tensão e corrente, originais e filtrados, medidos na fase A, quando da aplicação de um falta fase A-terra, alocada a $75 \mathrm{~km}$ da barra A. Neste exemplo foi utilizado um filtro passa-baixa Butterworth de $2^{\text {a }}$ ordem, com freqüência de corte de $300 \mathrm{~Hz}$, sendo o sinal original amostrado a $240 \mathrm{kHz}$.

No projeto proposto, os sinais a serem analisados são gerados a uma freqüência de $240 \mathrm{~Hz}$, que por sua vez são filtrados pelo filtro acima descrito com uma freqüência de corte de $300 \mathrm{~Hz}$, para serem usados pelo algoritmo baseado em componentes de baixa freqüência. Ressalta-se também que os sinais filtrados utilizados pelo algoritmo baseado em freqüência fundamental são reamostrados a uma freqüência de 2,4 kHz. 


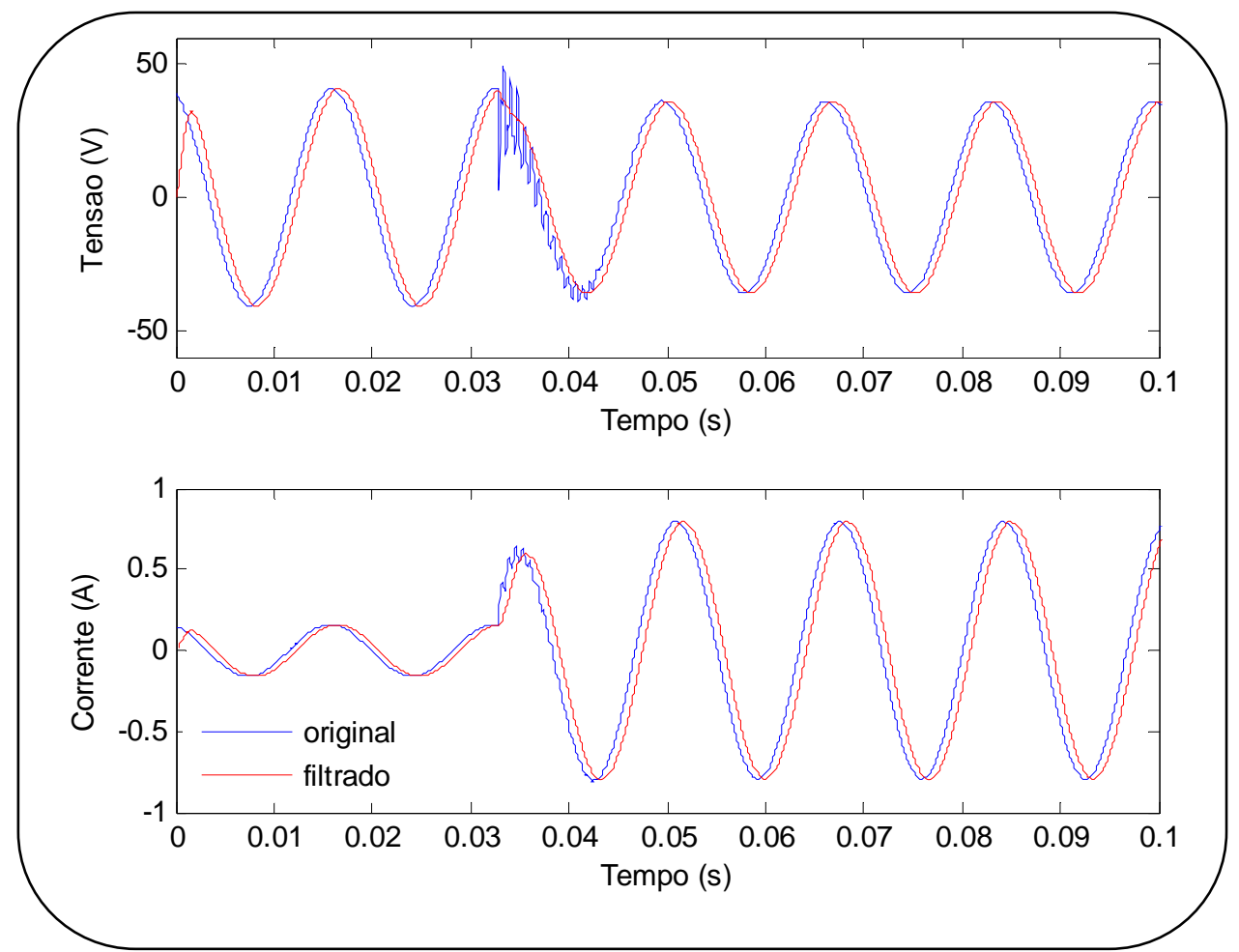

FIGURA 38 - Sinais de tensão e corrente, originais e filtrados pelo filtro passa-baixa Butterworth de $2^{a}$ ordem.

\subsubsection{Conversão Analógico-Digital}

A maior parte dos sistemas eletrônicos tem em seu núcleo um processamento digital; desde os sistemas mais familiares como televisão, computadores pessoais, vídeo cassetes, etc., até sistemas mais especializados em ambientes industriais e científicos. Desde que o mundo real é essencialmente de natureza analógica, há a necessidade de se usar dispositivos que convertam os sinais do mundo real para o domínio digital ocupado pelo processador.

Dado o exposto acima, utiliza-se de um conversor analógico-digital (CAD), o qual fornecerá uma aproximação digital ao sinal analógico original. A habilidade do conversor em representar um sinal analógico através de uma representação digital suficientemente detalhada está diretamente relacionada à sua resolução (Q), que por sua vez é expressa em termos de bits $(\mathrm{N})$. A resolução de um CAD é determinada pela eq. (4.3):

$$
Q=\frac{A_{m}}{2^{N}-1}
$$

Na qual $\mathrm{A}_{\mathrm{m}}$ é a amplitude máxima do CAD e N é o número de bits do conversor [103]. 
Se no instante da amostragem o valor do sinal analógico estiver entre dois níveis de quantização (Q), este será aproximado para um nível superior ou inferior. Tal aproximação insere aos sinais analisados um erro, denominado erro de quantização ou ruído de quantização. Este erro, definido basicamente sobre os níveis de quantização, corresponde à diferença entre a entrada e a saída quantizada, sendo expressa normalmente entre $\pm 0,5 Q$.

A amplitude do CAD não deve ser inferior ao máximo valor do sinal de entrada esperado, para que o mesmo não seja cortado e maiores erros sejam introduzidos ao sinal. Quanto ao máximo erro de quantização, o qual é inversamente proporcional ao número de bits do CAD, deve ser referido ao mínimo valor do sinal a ser medido e a precisão requerida pelo dispositivo [103]. Tipicamente, os relés digitais utilizam CAD's iguais ou maiores que 12 bits (IEE POWER SYSTEM PROTECTION) [104].

Neste contexto, e buscando-se sempre melhor reproduzir as situações encontradas na prática por meio de simulações e artifícios computacionais, utilizou-se neste trabalho da representação de um CAD de 24 bits, construído em linguagem de programação Fortran e Matlab ${ }^{\circledR}$.

\subsection{Variações nas simulações das condições de faltas aplicadas ao circuito de transmissão simples horizontal}

Os dados dos sinais faltosos foram obtidos utilizando-se do software ATP Altenative Transients Program, levando-se em conta vários tipos de falta em diferentes localizações ao longo da linha entre os barramentos, com diferentes ângulos de incidência e resistências de falta. As variações consideradas são descritas a seguir:

a) Tipos de faltas aplicadas:

- Fase-terra (A-terra, B-terra e C-terra);

- Fase-Fase-terra (AB-terra, AC-terra e BC-terra);

- Fase-Fase (AB, AC e BC);

- Trifásica $(\mathrm{ABC})$.

b) Distâncias em que as faltas foram aplicadas com referência à barra e o ponto de intersecção das linhas: 
- $\quad$ Barra A: 2, 3, 5, 10, 15, 20, 25, 30, 35, 40, 45, 50, 55, 60, 65, 70, 75, 80, 85, 90, $95,100,105,110,115,120,125,130,135,140,145,147$ e 148 km;

- $\quad$ Barra B: 2, 3, 5, 10, 15, 20, 25, 30, 35, 40, 45, 50, 55, 60, 65, 70, 75, 77 e $78 \mathrm{~km}$ e

- $\quad$ Barra C: 2, 3, 5, 10, 15, 20, 25, 30, 35, 40, 45, 50, 55, 60, 65, 70, 75, 80, 85, 90, 95, 97, e $98 \mathrm{~km}$;

c) Ângulo de incidência da falta:

- $0,30,90$ e 270 graus;

d) Resistências de faltas consideradas:

- $0,17,30,50,100,200,400$ e 800 ohms;

e) Níveis de ruído associados aos sinais:

- Sem ruído: nesta situação foram considerados apenas os ruídos gerados pela própria simulação e condicionamento dos sinais.

- Com ruído: nesta situação foi adicionado ruído branco aos sinais simulados na seguinte proporção: $80,70,60,50$ e $40 \mathrm{~dB}$.

f) Sinais utilizados:

- Tensões e correntes trifásicas medidas nos três terminais.

g) Intervalo de tempo entre as amostras com a conseqüente freqüência de amostragem:

- $4,1667 \mu$ s e $240 \mathrm{kHz}$.

Como resposta da simulação de cada situação de falta no software ATP, obtémse os valores de tensão e corrente trifásicos discretos medidos nos três terminais do sistema proposto. $\mathrm{O}$ arquivo de dados descrevendo cada situação de falta é apresentado

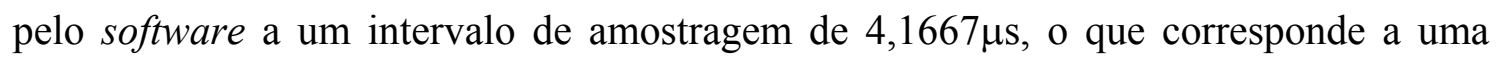
freqüência amostral de $240 \mathrm{kHz}$. Freqüência esta estabelecida pelo usuário de acordo com suas necessidades.

Dado as variações dos parâmetros descritos, foi possível a obtenção de um amplo e diversificado conjunto de simulações para testes do algoritmo de localização de 
faltas a ser proposto. Ressalta-se que este conjunto só foi aplicado em sua totalidade para testar o algoritmo baseado em ondas viajantes utilizando dados dos três terminais e uma seleção desta enorme gama de casos para testes dos demais algoritmos. Além deste conjunto de testes, também foram caracterizadas outras situações tais como: descargas atmosféricas, faltas transitórias e faltas induzindo a saturação dos TC's, faltas com modelo variante com a freqüência, variações de parâmetros do sistema, etc.

No desenvolvimento do trabalho, também foi analisada a influência do acoplamento mútuo quando da utilização de um circuito de transmissão duplo. Os dados referentes ao circuito duplo utilizado serão descritos no que segue.

\subsection{Modelagem e dados referentes ao circuito duplo vertical}

Como comentado anteriormente, no desenvolvimento da pesquisa foram realizados testes em outro tipo de linha, mais precisamente em uma linha de transmissão de $440 \mathrm{kV}$ com circuito duplo vertical. Tais testes buscam validar a aplicabilidade do algoritmo em diferentes configurações de linhas, considerando-se as particularidades envolvidas.

Estes testes também seguiram os procedimentos descritos anteriormente para o caso de uma linha de transmissão com circuito simples horizontal VVV. O modelo do sistema proposto para estes testes, assim como a silhueta da torre de transmissão utilizada, podem ser observadas através das Figuras 39 e 40, respectivamente.

Através da modelagem e simulações do sistema de transmissão duplo vertical em condição faltosa, também realizadas dispondo do software ATP, objetivou-se analisar os seguintes pontos: a influência do acoplamento mútuo entre as fases de ambos os circuitos e o efeito da assimetria do sistema.

Foram realizados testes variando-se a localização da falta entre os terminais A, $\mathrm{B}$ e $\mathrm{C}$ ao ponto comum $\mathrm{P}$, o ângulo de incidência e a resistência de falta. Quanto ao tipo da falta, utilizou-se apenas a falta envolvendo a fase "A" para a terra, por ser este tipo de falta que pode trazer mais influência nesta configuração de rede e por ser a mais presente nas ocorrências de defeitos.

A Figura 40 traz as disposições geométricas entre os cabos (fase e pára-raios) e a distância em relação ao solo. As alturas médias são indicadas entre parênteses e o espaçamento entre os condutores de uma mesma fase é de $0,4 \mathrm{~m}$. 


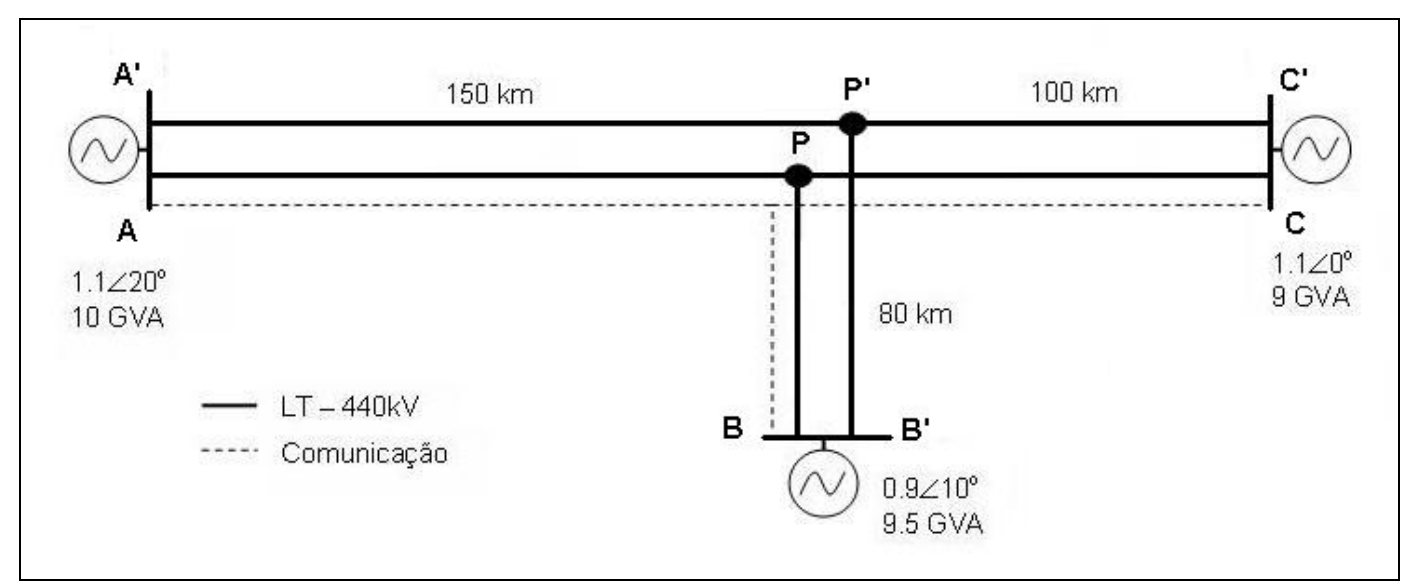

FIGURA 39 - Configuração do sistema com circuito duplo vertical

As especificações referentes aos condutores, denotando-se as suas principais características, bem como a resistividade do solo considerada, são as mesmas do circuito simples horizontal, apresentadas na seção 4.2. Em se tratando dos dados referentes ao sistema com circuito duplo, foram considerados os mesmos dados de barras do circuito simples, já apresentado na Tabela 4 e na Tabela 5. Já os dados referentes aos parâmetros das linhas de transmissão do circuito duplo (Tabela 6), estes foram obtidos por meio da rotina Line Constant do ATP, conforme o arquivo descrito na Figura 41. 


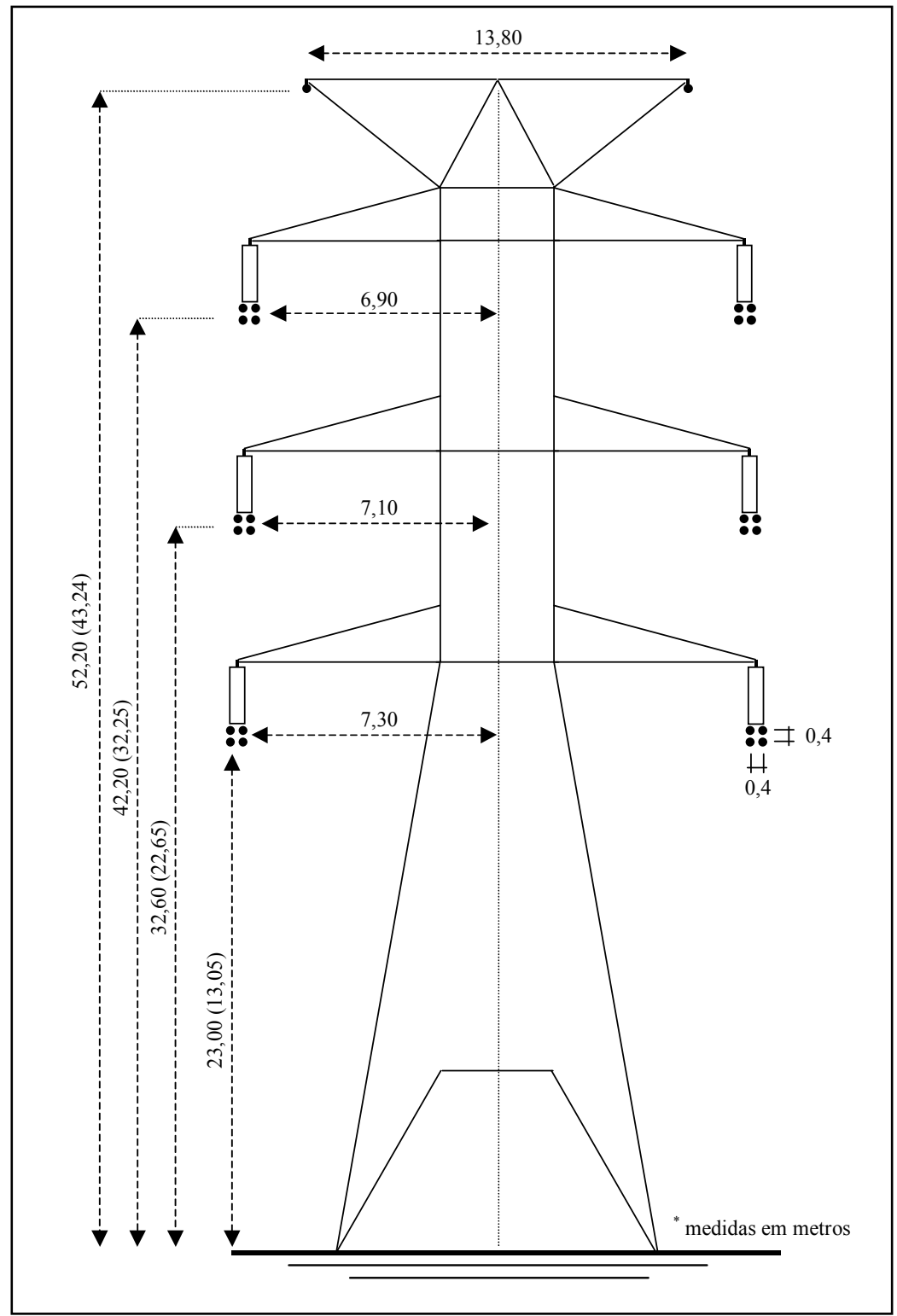

FIGURA 40 - Silhueta da torre de um circuito de transmissão duplo vertical de $440 \mathrm{kV}$.

TABELA 6 - Parâmetros da linha de transmissão em circuito duplo vertical.

\begin{tabular}{ccc|ccc}
\hline \multicolumn{3}{c|}{ Sequência Zero } & \multicolumn{3}{c}{ Sequência Positiva } \\
$\mathbf{R}$ (ohms/km) & $\mathbf{L}(\mathbf{m H} / \mathbf{k m})$ & $\mathbf{C}(\mathbf{u F} / \mathbf{k m})$ & $\mathbf{R}(\mathbf{o h m s} / \mathbf{k m})$ & $\mathbf{L}(\mathbf{m H} / \mathbf{k m})$ & $\mathbf{C}(\mathbf{u F} / \mathbf{k m})$ \\
\hline $3,044 \mathrm{E}+00$ & $3,298 \mathrm{E}+00$ & $1,183 \mathrm{E}-02$ & $2,223 \mathrm{E}-02$ & $7,633 \mathrm{E}-01$ & $1,790 \mathrm{E}-02$ \\
\hline
\end{tabular}

Uma vez obtido todos os dados referente ao sistema a ser modelado, desenvolvese o arquivo geral de entrada do ATP, por meio do qual serão feitas as diversas simulações necessárias.

A Figura 42 ilustra os sinais de tensão e corrente obtidos nos três terminais (A, $\mathrm{B}$ e C) do circuito duplo proposto frente à operação normal do sistema. 
BEGIN NEW DATA CASE

LINE CONSTANTS

METRIC

BRANCH BEG.S END.S BEG.R END.R BEG.T END.T

$\mathrm{C}$

C CONDUTORES DA PRIMEIRA FASE

$\begin{array}{llllllll}C & 1 & 2 & 3 & 4 & 5 & 6 & 7\end{array}$

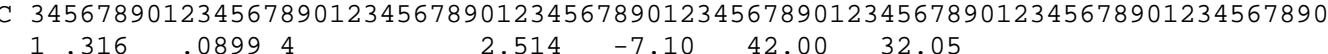

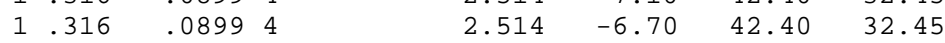

$\begin{array}{lllllll}1.316 & .0899 & 4 & 2.514 & -6.70 & 42.00 & 32.05\end{array}$

C CONDUTORES DA SEGUNDA FASE

$\begin{array}{llllllll}\mathrm{C} & 1 & 2 & 3 & 4 & 5 & 6 & 7\end{array}$

C 345678901234567890123456789012345678901234567890123456789012345678901234567890

$\begin{array}{lllllll}2 & .316 & .08994 & 2.514 & -7.30 & 32.40 & 22.45 \\ 2 & .316 & .08994 & 2.514 & -7.30 & 32.80 & 22.85 \\ 2 & .316 & .08994 & 2.514 & -6.90 & 32.80 & 22.85 \\ 2 & .316 & .08994 & 2.514 & -6.90 & 32.40 & 22.45\end{array}$

C CONDUTORES DA TERCEIRA FASE

$\begin{array}{llllllll}C & 1 & 2 & 3 & 4 & 5 & 6 & 7\end{array}$

C 345678901234567890123456789012345678901234567890123456789012345678901234567890

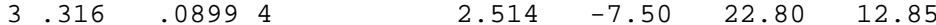

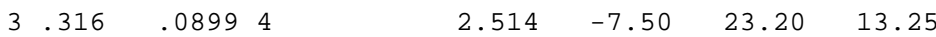

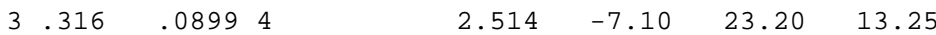

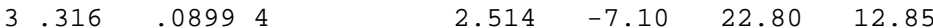

C CONDUTORES DA QUARTA FASE

$\begin{array}{llllllll}C & 1 & 2 & 3 & 4 & 5 & 6 & 7\end{array}$

C 345678901234567890123456789012345678901234567890123456789012345678901234567890

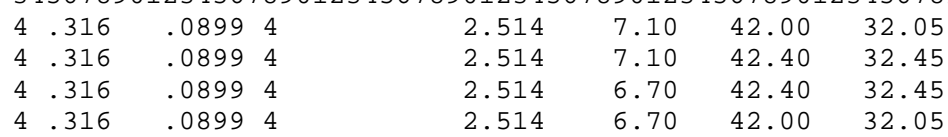

C CONDUTORES DA QUINTA FASE

$\begin{array}{llllllll}C & 1 & 2 & 3 & 4 & 5 & 6 & 7\end{array}$

C 345678901234567890123456789012345678901234567890123456789012345678901234567890

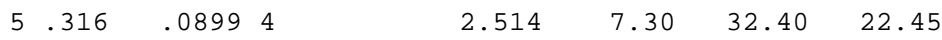

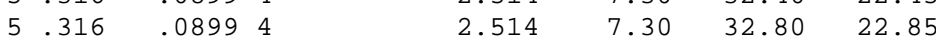

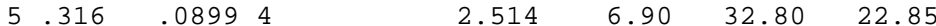

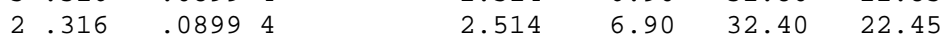

C CONDUTORES DA SEXTA FASE

$\begin{array}{llllllll}C & 1 & 2 & 3 & 4 & 5 & 6 & 7\end{array}$

C 345678901234567890123456789012345678901234567890123456789012345678901234567890

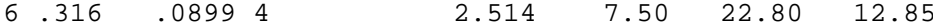

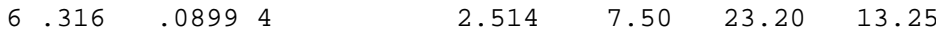

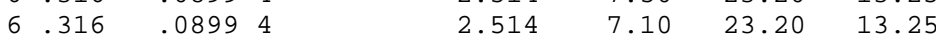

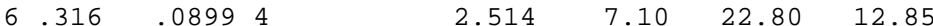

C CONDUTORES DOS CABOS PÁRA-RAIOS

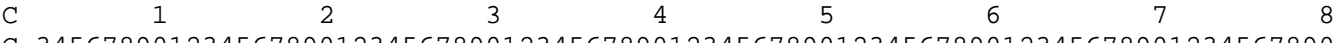

(1)
$0.500 \quad 4.18804$
0.914
$-6.90 \quad 52.20$
43.24

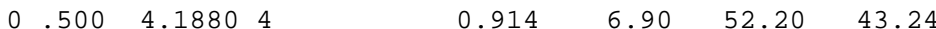

BLANK CARD ending all conductor cards of embedded "LINE CONSTANTS" data case $\begin{array}{lllllll}\mathrm{C} & 1 & 2 & 3 & 4 & 6 & 6\end{array}$ C 345678901234567890123456789012345678901234567890123456789012345678901234567890 250. 60. 6100100 \$PUNCH

BLANK CARD ending frequency cards of embedded "LINE CONSTANTS" data case

BLANK CARD ending "LINE CONSTANTS" data cases

BEGIN NEW DATA CASE

BLANK

FIGURA 41 - Arquivo de entrada para a rotina Line Constant referente ao circuito duplo 


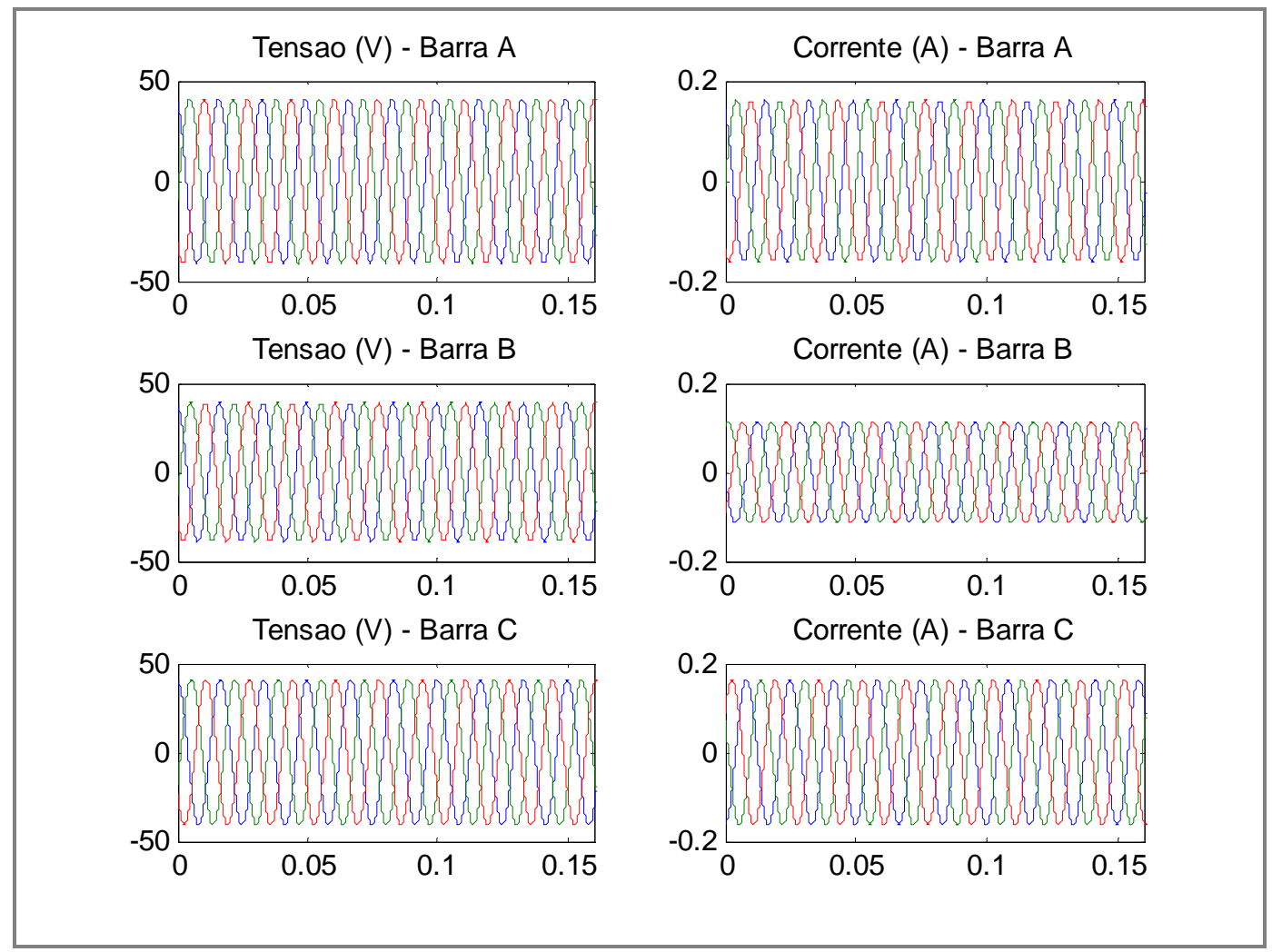

FIGURA 42 - Sinais de tensão e corrente em operação normal, medidos nos terminais do circuito duplo de transmissão proposto.

\subsubsection{Variações nas simulações das condições de faltas aplicadas ao circuito de transmissão duplo}

Seguindo a metodologia aplicada à linha com circuito simples, os dados dos sinais faltosos referentes ao circuito duplo também foram obtidos utilizando-se do software ATP - Altenative Transients Program, levando-se em conta faltas fase-terra (AT), aplicadas em diferentes localizações ao longo das linhas (AP, BP e CP), com diferentes ângulos de incidência e resistências de falta. As variações consideradas são descritas a seguir:

a) Tipo de falta aplicada:

- Fase A-terra;

b) Distâncias em que as faltas foram aplicadas sobre as linhas AP, BP e CP:

- $\quad$ Barra A: 2, 3, 5, 10, 20, 30, 40, 50, 60, 70, 80, 90, 100, 110, 120, 130, 140, 145, 147 e $148 \mathrm{~km}$. 
- $\quad$ Barra B: 2, 3, 5, 10, 20, 30, 40, 50, 60, 70, 75, 77 e $78 \mathrm{~km}$.

- $\quad$ Barra C: 2, 3, 5, 10, 20, 30, 40, 50, 60, 70, 80, 90, 95, 97, e $98 \mathrm{~km}$.

c) Ângulo de incidência da falta:

- $0,30,90$ e 270 graus.

d) Resistências de faltas consideradas:

- $0,17,30,50,100,200,400$ e 800 ohms.

No que segue, será abordado o desenvolvimento teórico do localizador de faltas proposto. 


\section{LOCALIZAÇÃO DE FALTAS UTILIZANDO A TRANSFORMADA WAVELET - ABORDAGEM TEÓRICA}

Nesta seção será abordado o problema da localização de faltas em linhas de transmissão com três terminais utilizando a Transformada Wavelet (TW), seguindo da descrição de ambas as metodologias de localização de faltas desenvolvidas, as quais caracterizam o algoritmo híbrido proposto.

\subsection{Princípio básico do método de localização de faltas híbrido}

O foco principal desta pesquisa é a localização de faltas em sistema de três terminais utilizando ondas viajantes e a TW. Todavia, da complexidade em se obter um método de localização $100 \%$ confiável, optou-se também ao desenvolvimento, ou adequação, de um método de localização de faltas baseado em componentes fundamentais, os quais também serão extraídos pela aplicação da TW. Portanto, dispondo-se tanto de componentes de alta, como de baixa freqüência para a tarefa de localizarem faltas, justifica-se o emprego da palavra "híbrido" nestes termos.

Para uma primeira etapa, vamos considerar um sistema de transmissão com três terminais, constituído por linhas de diferentes comprimentos, impedâncias características idênticas e velocidade de propagação v, como ilustrado pela Figura 43, juntamente com o diagrama Lattice correspondente.

Na ocorrência de uma falta a uma distância $d$ da barra A, baseado na teoria de ondas viajantes (BEWLEY) [40], esta aparecerá como uma abrupta injeção de corrente e tensão no ponto de falta. Esta injeção viajará como uma onda sobreposta ao sinal fundamental do sistema ao longo da linha em ambas as direções, a partir do ponto de ocorrência da falta. Ao encontrar uma descontinuidade, essas ondas se refletem e 
retornam ao ponto de falta onde haverá novas reflexões e assim sucessivamente até ser alcançado o estado permanente de falta. Os transitórios de falta registrados nos terminais da linha conterão abruptas mudanças em intervalos comensuráveis com o tempo de excursão dos sinais entre o ponto de falta e os terminais do sistema. Determinando-se o intervalo de tempo de viagem dos sinais entre o ponto de falta e o terminal de referência e, usando a velocidade de propagação $(v)$ das ondas, a qual é função dos parâmetros da linha em questão, a distância da falta pode ser facilmente estimada. Diferente do método de correlação, onde as ondas viajantes são computadas e usadas para correlação cruzada, na aplicação wavelet, o sinal decomposto (tensão ou corrente) é diretamente analisado e as reflexões determinadas através de limiares apropriados.

Numa segunda abordagem, utilizar-se-á o princípio de localização de faltas para linhas com três terminais, como apresentado por Coury [10], o qual se baseia em componentes fundamentais extraídos via TF para cálculo da impedância aparente, sendo esta função da distância. O propósito desta etapa é o de extrair os componentes fundamentais via TW, eliminando-se possíveis erros inerentes às técnicas de filtragem convencionais e, então, processar o cálculo da distância da falta.

Ressalta-se que o algoritmo híbrido foi concebido para trabalhar com dados dos três terminais simultaneamente quando operado no módulo de Ondas Viajantes ou Componente Fundamental, assim como, para trabalhar utilizando dados locais quando operado em módulo de Ondas Viajantes. A localização utilizando dados de um ou dos três terminais pode ser escolhida pelo usuário, dependendo dos recursos disponíveis, necessidade de canal de comunicação e sinal para sincronização dos dados. Além disso, o algoritmo seria dotado da função "automático", onde o mesmo (algoritmo como entidade) escolheria a técnica de dados locais ou sincronizados dos três terminais, dado a existência ou não dos recursos necessários ou caso algum algoritmo venha a falhar. Quanto ao método de localização, onda viajante ou tradicional, o algoritmo escolheria também de forma automática e decisória, a saída do método que melhor responda as características do sinal de entrada.

O módulo preferencial, ou se assim podemos dizer, "default", será o módulo baseado ondas viajantes utilizando dados sincronizados dos três terminais.

Destaca-se também, que no módulo de onda viajante, o algoritmo pode trabalhar com os sinais de detalhe da corrente ou tensão. Já no módulo tradicional, o mesmo pode utilizar os sinais de detalhe ou de aproximação da corrente e tensão. 


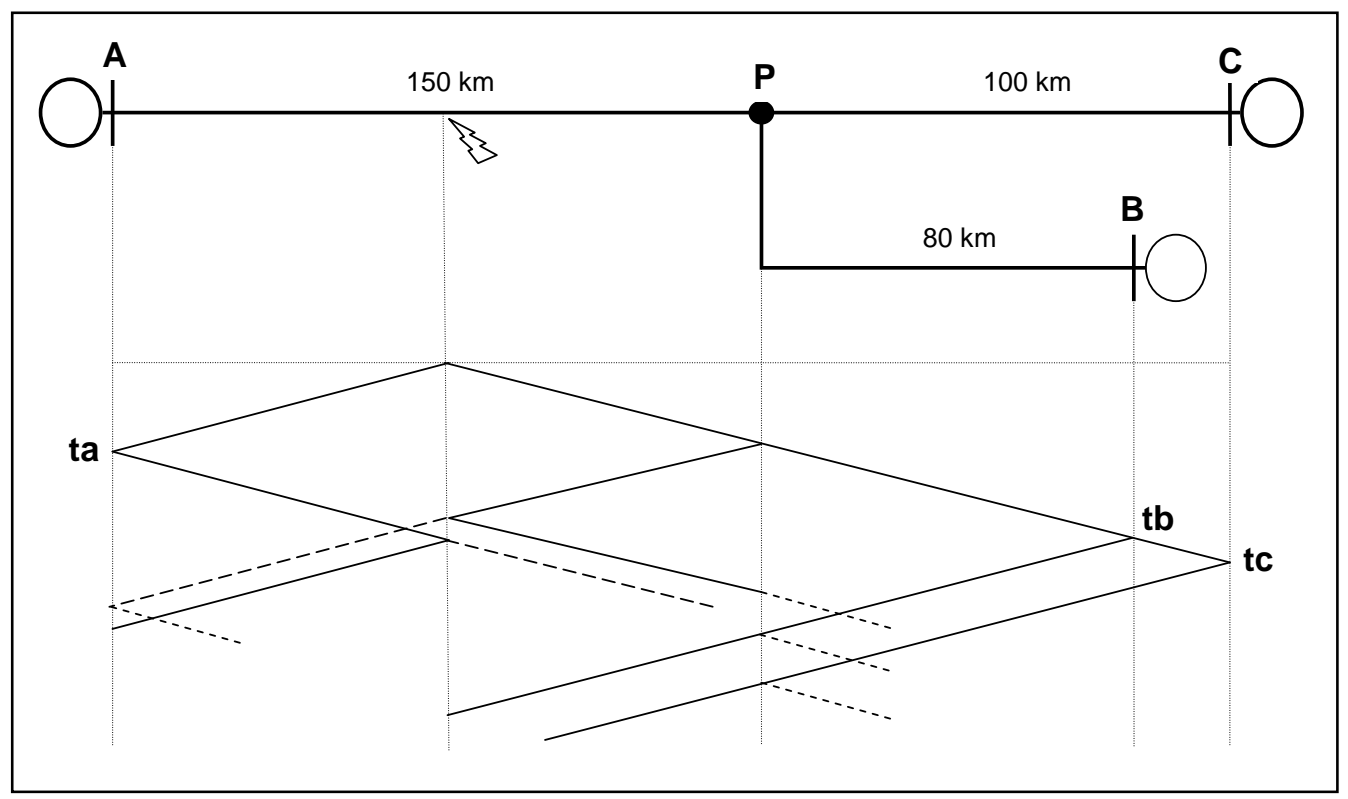

FIGURA 43 - Sistema Elétrico com três barras e diagrama Lattice

\subsection{O Algoritmo do Localizador de Faltas Híbrido}

Nesta seção é descrito todo o algoritmo de localização de faltas híbrido para linhas de dois ou três terminais, baseado em componente fundamental e de alta freqüência gerados por uma situação de falta, batizado como LFHTW 1.01 (Localizador de Faltas Híbrido via Transformada Wavelet - versão 1.01).

A Figura 44 exibe o fluxograma do algoritmo de localização de faltas proposto, denotando os seus diferentes estágios. Por sua vez, estes estágios podem ser agrupados em três diferentes etapas que compreendem basicamente:

1. aquisição, registro e condicionamento dos sinais;

2. localização de faltas via ondas viajantes (algoritmo principal)

a. utilizando dados dos três terminais;

b. utilizando dados somente do terminal local;

3. localização de faltas via componentes de freqüência fundamental.

a. utilizando dados dos três terminais.

Com base no fluxograma apresentado, os estágios que compõem o algoritmo para a determinação da posição da falta são os seguintes: 
1. Aquisição dos dados, condicionamento dos sinais, extração dos componentes via Transformada Wavelet Discreta, decisão entre método de três ou um terminal, decisão de utilizar ondas viajantes ou componentes fundamental para estimação da distância;

2. Detecção (onda viajante / três terminais), classificação da falta, transformação modal, estimação do tempo de chegada das ondas, identificação do ramo faltoso e estimação da distância da falta.

3. Detecção (onda viajante / dados locais), classificação da falta, transformação modal, estimação do tempo de chegada das ondas, classificação da metade faltosa da linha (somente para faltas fase-terra), identificação do ramo faltoso e estimação da distância da falta.

4. Decomposição do sinal via TWE, Detecção (algoritmo tradicional modificado / três terminais), classificação da falta, componentes superpostos, transformação modal, identificação do terminal faltoso e estimação da distância da falta.

No que segue, todos os estágios serão descritos detalhadamente. 


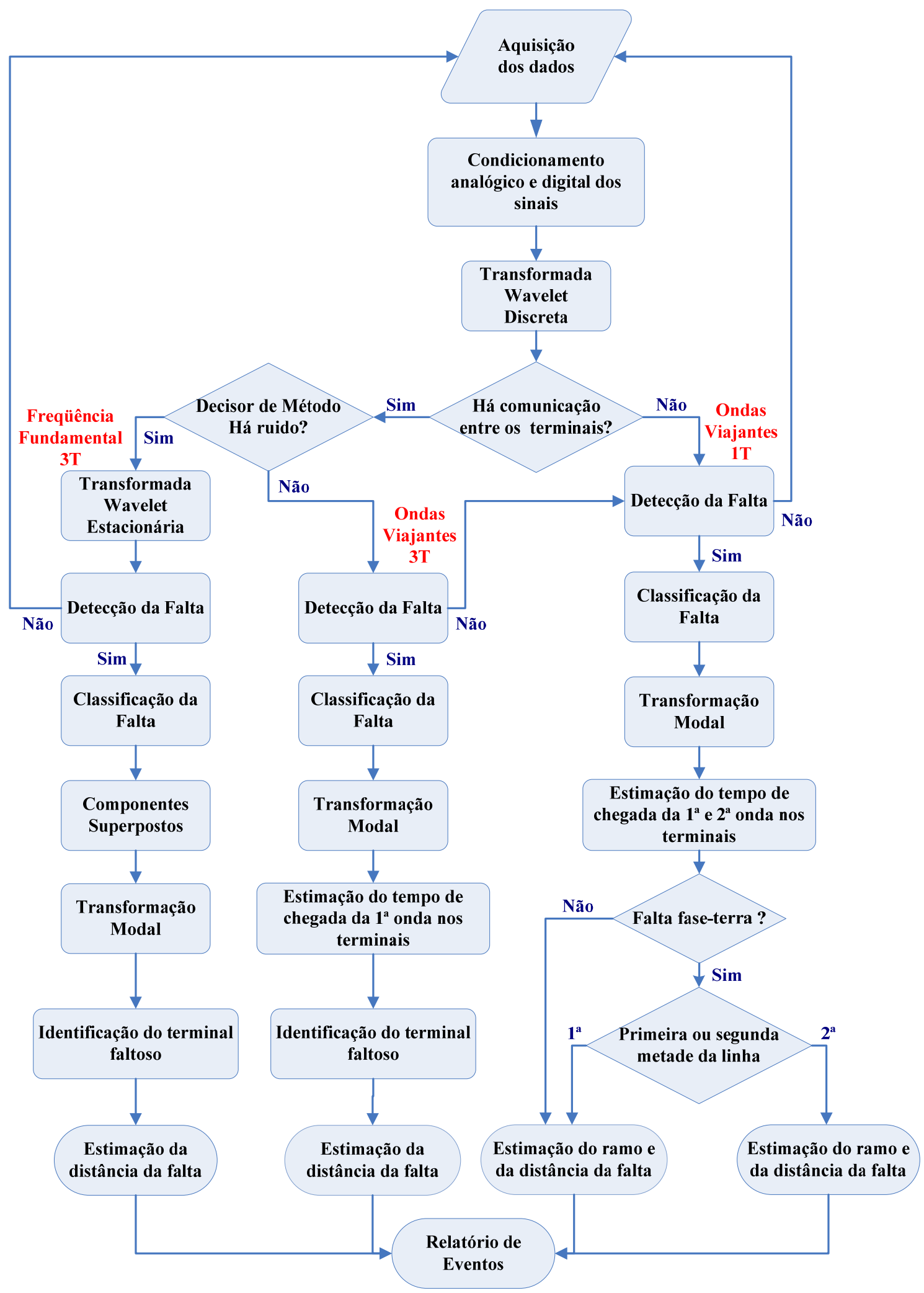

FIGURA 44 - Fluxograma do algoritmo de localização de faltas híbrido (LFHTW 1.01) 


\subsubsection{Aquisição dos dados}

Os dados podem ser obtidos através de TPC's e TC's, os quais reproduzem razoavelmente os transitórios de alta freqüência. Cabe comentar que, comumente, empregam-se os sinais de corrente para estimação da distância pelo método de ondas viajantes [9]. Deste ponto, os dados podem ser então armazenados via registradores digitais de sinais de alta freqüência posicionados nos terminais de cada linha, ou mesmo, oscilografados pelo próprio relé de proteção adequado para registrar altas freqüências. Os dados podem ser aquisitados a todo instante, porém, registrados somente quando da acusação de um distúrbio. Tal detecção, por exemplo, poderá ser feita pelas lógicas de proteção de sobrecorrente ou de distância dos próprios relés de proteção, cujo sinal de disparo habilitará o registro de certa quantidade de dados (ciclos de pré e de pós-falta do sinal). Outras maneiras da detecção de algum distúrbio no sistema, que fazem parte desta pesquisa, serão relatadas posteriormente.

Contudo, como já explicitado anteriormente, utilizando-se da técnica de localização com dados registrados em todos os terminais, torna-se necessário que haja um meio de comunicação entre os mesmos para a transferência e disponibilização dos dados, bem como de um método para a sincronização das respectivas medições.

Para resolver o problema de sincronização de dados, temos como proposta a utilização do GPS (Global Positioning System) (FRENCH) [105], como apresentado em (ZHAO et al) [106]. Outra opção seria a utilização do sistema europeu de localização e navegação por satélite denominado GALILEU ${ }^{1}$, ainda em fase de implantação. Através destes dispositivos, um sinal de referência de tempo, transmitido via satélite, ficaria disponível nos diversos pontos de uma rede elétrica, permitindo que os sinais fossem sincronizados considerando qualquer esquema de comunicação de dados entre os terminais da linha. Em cada terminal, para cada conjunto de amostras dos sinais, poderá ser armazenado o tempo real em que este foi obtido, utilizando a referência de tempo absoluta obtida, por exemplo, do GPS. Desta forma, um atraso na chegada dos dados do terminal remoto ao terminal local, poderá ser corrigido, verificando-se os instantes em que as amostras foram obtidas. Segundo a literatura sobre o uso de GPS, este pode introduzir um erro máximo de $1 \mu$ s, o que corresponderia a aproximadamente 300

\footnotetext{
${ }^{1}$ Sistema europeu de localização e navegação por satélite que começou a ser implantado em 2005 sob o comando de civis. (FAPESP - 28/12/2005 -

http://www.agencia.fapesp.br/boletim dentro.php?data $\% 5 \mathrm{Bid}$ materia boletim $\% 5 \mathrm{D}=4834$ ).
} 
metros de imprecisão na localização da falta. Segundo apontamentos encontrados, quando o sistema GALILEU estiver em operação, sua precisão será superior ao do GPS.

Quanto ao meio de comunicação para a transferência dos dados entre os dois terminais, pode-se empregar um meio que não exija tanta velocidade e canais de comunicação contínuos, uma vez que o nosso localizador opera em estado off-line. A comunicação dos dados pode ser feita via rádio, satélite, modem, microondas ou até, telefonia celular (GPRS/GSM - General Packet Radio Service / Global System for Mobile communication) (BETTSTETTER et. al.)[107] e (EICHELBURG)[108]. Outro meio de transmissão de dados que vem sendo utilizado é por meio de fibra óptica no interior dos cabos guarda (URUSAWA et al.) [109], conhecido pela designação técnica OPGW (do inglês, Fiber Optic Overhead Ground Wire), que garante alta capacidade, velocidade de transmissão e imunidade à interferências eletromagnéticas.

É importante ressaltar que, trabalhando-se com o algoritmo baseado em ondas viajantes, pode-se escolher pelo uso de um dos sinais, corrente ou tensão. O que não acontece quando do emprego de algoritmos baseados em componentes fundamentais, onde ambos os sinais de corrente e de tensão são necessários.

\subsubsection{Condicionamento Analógico e Digital dos sinais}

Os dados obtidos via simulações, ou mesmo em condições reais, devem ser condicionados de modo a se evitar a sobreposição de espectros (efeito aliasing) e então digitalizados, para posteriormente serem processados. Nesta aplicação os sinais são tratados de duas maneiras diferentes dependendo do método de localização a ser seguido. Quando trabalharmos com altas freqüências, os sinais não precisão passar por filtros passa baixa (anti-aliasing), uma vez que não precisaremos remover as altas freqüências presentes no sinal. Portanto, o sinal será diretamente digitalizado via conversores $\mathrm{A} / \mathrm{D}$ de alta freqüência. Já quando utilizarmos do método baseado em componentes fundamentais, os sinais precisarão primeiramente passar por um filtro passa baixa, a fim de se atenuar altas freqüências indesejáveis, para que posteriormente o sinal possa ser amostrado e corretamente convertido de analógico para digital.

Neste trabalho, tanto o filtro passa baixa como o CAD foram implementados computacionalmente. Quanto ao filtro passa baixa, optou-se por um filtro do tipo Butterworth de segunda ordem, com freqüência de corte de $300 \mathrm{~Hz}$. Em se tratando do 
conversor analógico-digital, foi programado um CAD de 24 bits considerando amostragens do sinal em 2,4 e $240 \mathrm{kHz}$, conforme o algoritmo de localização utilizado.

O CAD-24bits foi escolhido por melhor representar os sinais a serem analisados, evitando-se assim possíveis erros na localização da falta. Testes realizados, variando-se o número de bits, demonstram que a resposta do algoritmo de ondas viajantes utilizando dados de um ou dos três terminais pode ser influenciada quando utilizados CAD's inferiores a 16 bits, enquanto que, a resposta do algoritmo tradicional utilizando wavelet pode vir a sofrer alguma influência para CAD's menores que 12 bits. Nas Figuras 45, 46 e 47 são ilustrados alguns testes referentes à situações de faltas fase-fase (AB) com variação do número de bits do conversor analógico-digital, realizados sobre o algoritmo de ondas viajantes (com dados de um e dos três terminais) e sobre o algoritmo tradicional modificado, utilizando dados dos três terminais, respectivamente.

Maiores informações, assim como referências sobre os filtros e o CAD podem ser encontradas nas seções 4.3 .3 e 4.3 .4 descritas anteriormente.

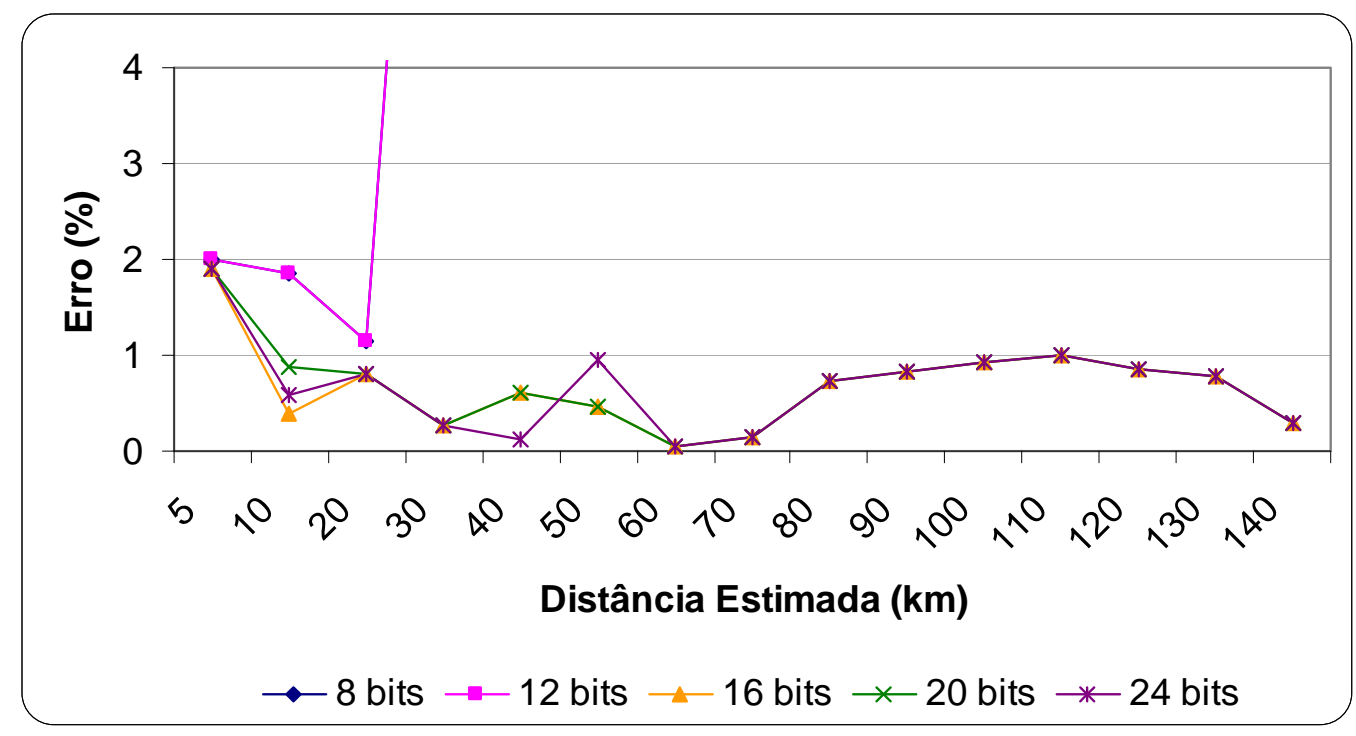

FIGURA 45 - Resultados alcançados pelo algoritmo de ondas viajantes utilizando dados locais frente à variação do número de bits do CAD. 


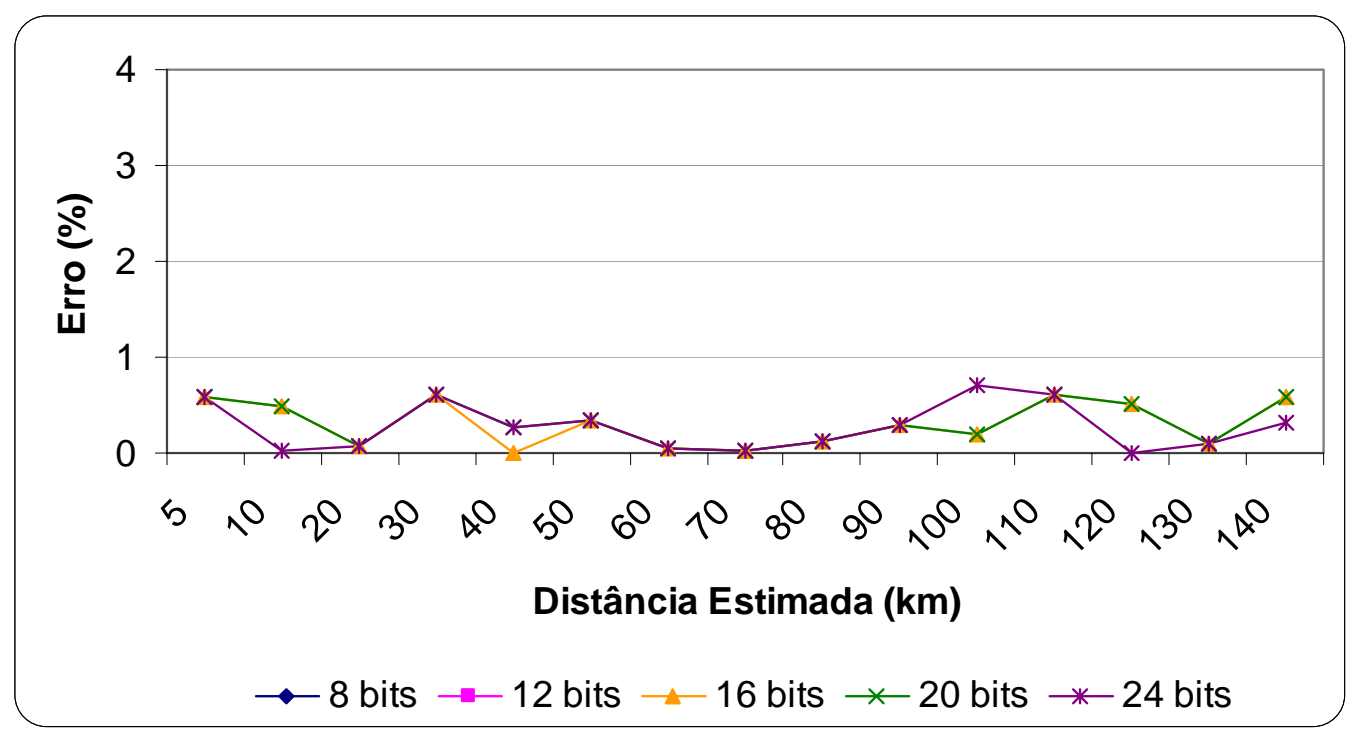

FIGURA 46 - Resultados alcançados pelo algoritmo de ondas viajantes utilizando dados dos três terminais frente à variação do número de bits do CAD.

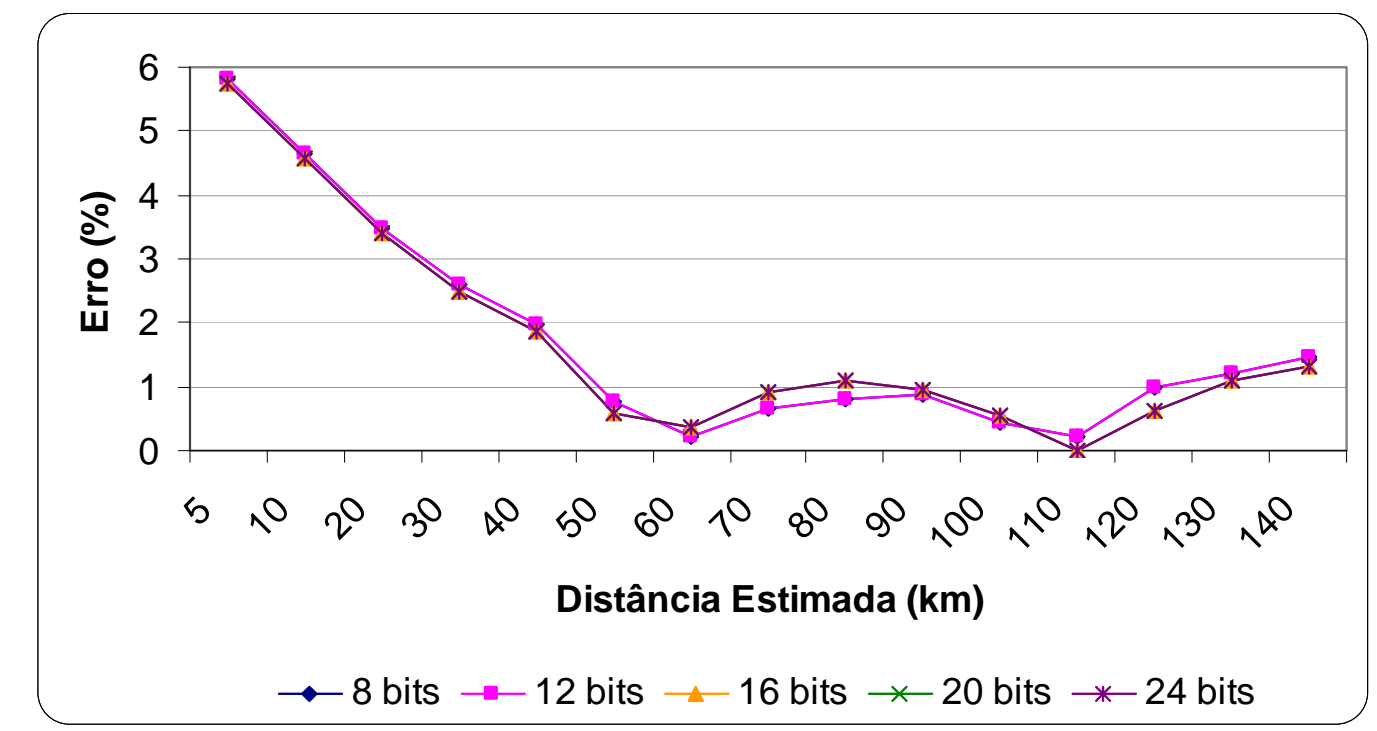

FIGURA 47 - Resultados alcançados pelo algoritmo baseando em freqüencia fundamental utilizando dados dos três terminais frente à variação do número de bits do CAD.

\subsubsection{Decomposição Wavelet Discreta}

Dando continuidade ao algoritmo de localização proposto, uma vez que os dados obtidos do sistema foram condicionados e digitalizados, estes são agora decompostos via AMR utilizando a TWD de modo a fornecer os sinais de aproximação e detalhes necessários aos próximos estágios. Os sinais de detalhe e aproximação extraídos via TWD serão usados exclusivamente pelas técnicas baseadas em ondas viajantes, assim 
como, para decidir se há muito ruído presente nos sinais de entrada que possam afetar o desempenho do algoritmo de ondas viajantes implementado.

Neste estágio os sinais de tensão ou corrente são decompostos utilizando as wavelets-mãe Symlet3 (sym3) e Daubechies4 (db4). Quanto aos níveis de decomposição, estes foram escolhidos conforme a aplicação, respeitando obviamente, o número de nível máximo permitido, dado o sinal analisado. As wavelets-mãe foram escolhidas por melhor representarem os problemas para as quais foram designadas (SILVA et al.) [110] e (ARRUDA et al.) [111].

A Tabela 7 ilustra os níveis de decomposição e a respectiva wavelet-mãe utilizada no algoritmo proposto, conforme o método e sua aplicação dentro do mesmo.

TABELA 7 - Níveis de decomposição utilizados no algoritmo proposto

\begin{tabular}{lcc}
\hline \multicolumn{3}{c}{ Níveis de Decomposição Wavelet Discreta } \\
\hline Aplicação & Aproximação & Detalhe \\
\hline Detecção de Ruído & - & 2 (sym3) \\
\hline Método de Localização & \multicolumn{2}{c}{ Ondas Viajantes } \\
\hline Detecção & \multicolumn{3}{c}{2 e 7 (sym3) } \\
\hline Classificação & $9(\mathrm{db} 4)$ & - \\
\hline Localização & - & $2(\mathrm{sym} 3)$ \\
\hline Taxa de amostragem & \multicolumn{3}{c}{$240 \mathrm{kHz}$} \\
\hline
\end{tabular}

\subsubsection{Decisão 1: Utilizar método com ou sem comunicação entre terminais}

Conforme comentado anteriormente, o algoritmo híbrido proposto pode trabalhar com dados disponíveis dos três terminais ou apenas com dados locais, não necessitando para esta última opção, a existência de meios de comunicação e sincronização de dados.

O usuário pode escolher manualmente a técnica a ser utilizada, com ou sem comunicação de dados, dependendo dos recursos existentes, ou deixar no modo automático, onde o próprio algoritmo detectará a existência ou não do canal de comunicação entre os terminais do sistema e habilitará a lógica de localização mais conveniente. $\mathrm{O}$ algoritmo priorizará as técnicas que utilizem dados sincronizados aliado ao método de ondas viajantes e posteriormente, ao método tradicional utilizando wavelet. 
Ressalta-se também que, caso o usuário escolha a técnica com comunicação de dados, mesmo que esta não exista ou venha a falhar, o algoritmo híbrido redicionará a localização da falta para o método baseado em dados locais.

$\mathrm{Na}$ Tabela 8 pode-se distinguir a técnica de localização a ser utilizada, a qual está relacionada diretamente a existência ou não de meios de comunicação e, a metodologia a ser empregada para localização da falta, conforme priorização.

TABELA 8-Decisão da técnica de localização de faltas

\begin{tabular}{cccc}
\hline $\begin{array}{c}\text { Comunicação } \\
\text { de Dados }\end{array}$ & $\begin{array}{c}\text { Técnica de } \\
\text { localização }\end{array}$ & $\begin{array}{c}\text { Método de } \\
\text { Localização }\end{array}$ & Prioridade \\
\hline \multirow{2}{*}{ SIM } & 3 terminais & Ondas Viajantes & 1 \\
\cline { 2 - 4 } & 3 terminais & Tradicional Wavelet & 2 \\
\hline NÃO & 1 terminal & Ondas Viajantes & 3 \\
\hline
\end{tabular}

\subsubsection{Decisão 2: Há presença de ruído no sinal de entrada?}

Partindo do pressuposto que existe o canal de comunicação entre os terminais e sinal para sincronização dos dados, o algoritmo deve decidir qual o método de localização mais adequado em função dos sinais de entrada, tensão e/ou corrente, uma vez que níveis de sinal/ruído abaixo de $60 \mathrm{~dB}$ podem vir a afetar o desempenho do método baseado em ondas viajantes.

A lógica proposta compara um limiar padrão $\left(\lambda_{\text {padrão }}\right)$ levantado empiricamente, dado a análise dos sinais de detalhe dois (DWT2) da corrente ou tensão, a um valor calculado $\left(\lambda_{\text {calculado }}\right)$ a cada aquisição de dados. Caso o limiar calculado supere o limiar ajustado, a falta será localizada utilizando o método tradicional via wavelet, caso contrário, utilizar-se-á o método de ondas viajantes.

A lógica acima pode ser descrita como segue:

$$
\begin{aligned}
& \lambda_{\text {padrão }}=7 e^{-3} \\
& \lambda_{\text {calculado }}=(2 \ln (N))^{1 / 2} \cdot \sigma \\
& S E \quad \lambda_{\text {calculado }}>\lambda_{\text {padrão }} \quad\left\{\begin{array}{c}
\text { Método Tradicional } \\
\text { Caso Contrário, Método das Ondas Viajantes }
\end{array}\right\}
\end{aligned}
$$


onde $\mathrm{N}$ é a quantidade de amostras do sinal da janela analisada $(1 / 4$ ciclo $=1000$ amostras), e $\sigma$ é a média do desvio absoluto do sinal da DWT2, dividido por 0,6745, conforme CAPOBIANCO [112].

A metodologia para a definição do método de localização, baseada em limiares de ruído, mostrou-se altamente satisfatória durante os testes, como os que ilustram as Figuras 48 e 49. Estas Figuras demonstram a resposta do decisor por ruído $(-1=\mathrm{SNR}<$ $60 \mathrm{~dB}$ e $1=\mathrm{SNR} \geq 60 \mathrm{~dB}$ ) estabelecido de maneira que, para valores iguais a -1 deveria ser utilizado o método tradicional, caso contrário, para valores igual a 1 , deveria ser utilizado o método por onda viajante.

O mesmo princípio também pode ser aplicado para escolha do método de localização de faltas quando da utilização de técnicas baseadas em dados locais.

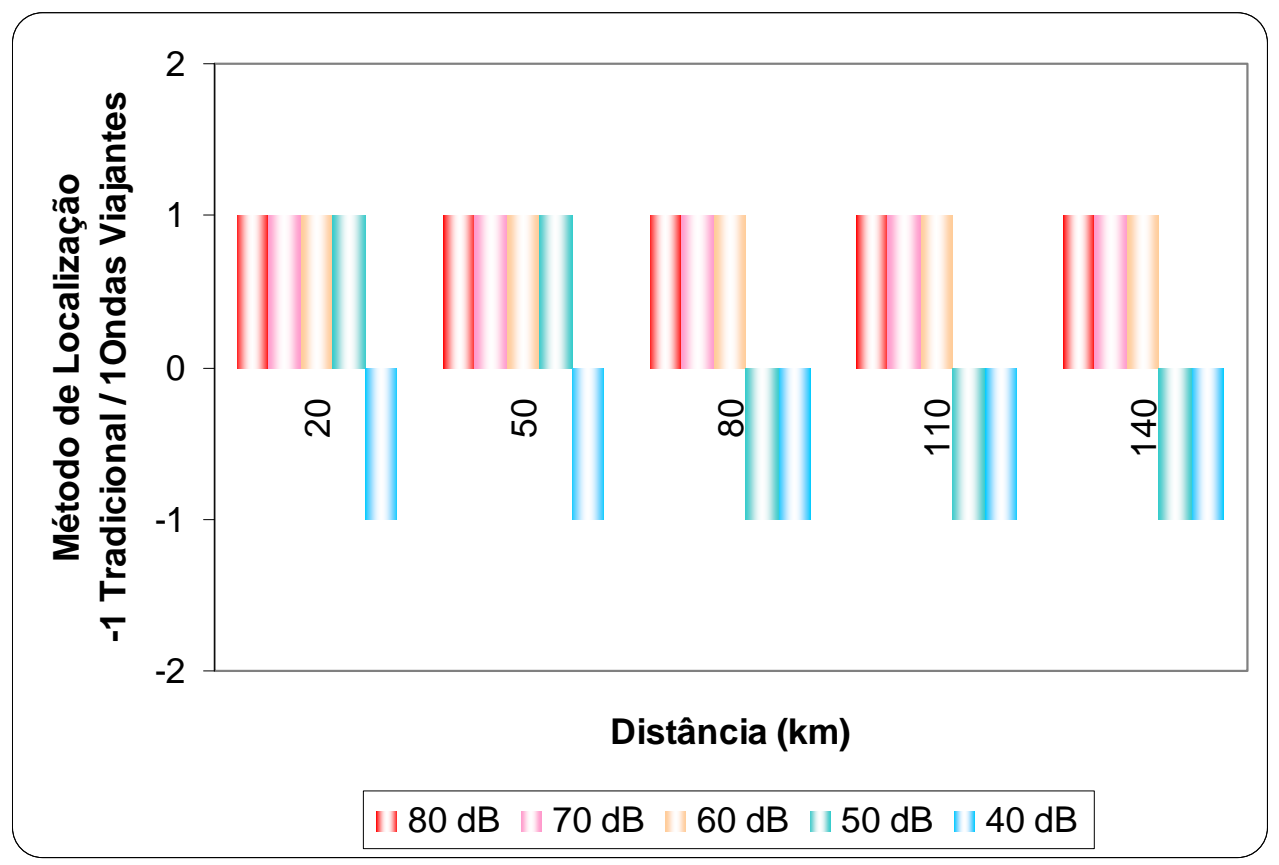

FIGURA 48 - Resultados utilizando o nível de ruído para definição do método de localização - Faltas fase-terra sobre o ramo 1 com ângulo de $90^{\circ}$ e resistência de $0 \mathrm{ohm}$. 


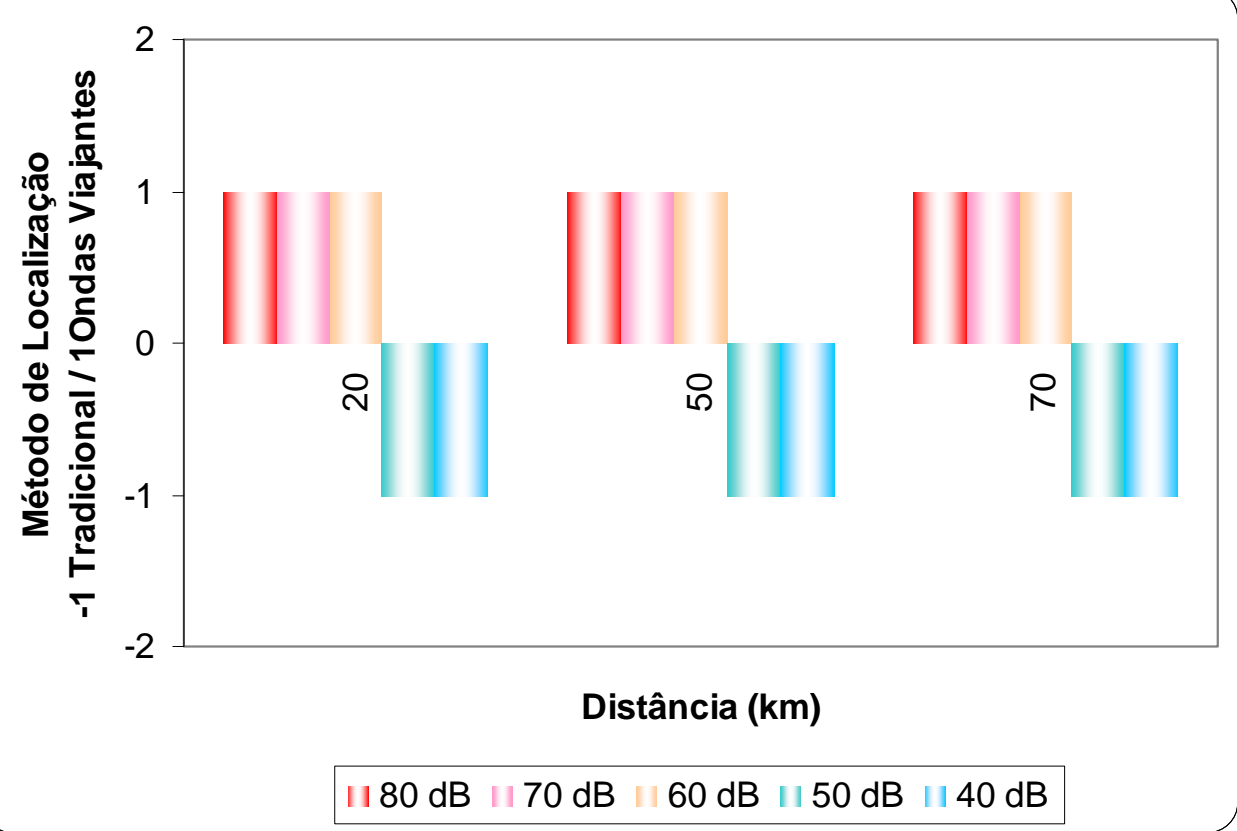

FIGURA 49 - Resultados utilizando o nível de ruído para definição do método de localização - Faltas fase-terra sobre o ramo 2 com ângulo de $0^{\circ}$ e resistência de $100 \mathrm{ohm}$.

\subsubsection{Metodologia de localização de faltas por ondas viajantes e Transformada Wavelet utilizando dados dos três terminais}

Por se tratar de um algoritmo de localização híbrido, ou seja, que utiliza dois métodos diferentes para localizar a falta abordaremos em primeiro lugar, a proposta principal que utiliza ondas viajantes, para posteriormente abordamos a proposta que utiliza componentes fundamentais.

Basicamente, a proposta que utiliza ondas viajantes para localizar a falta, baseiase na determinação de tempo viagem das ondas de corrente ou tensão provenientes de um distúrbio na linha, desde o ponto de falta aos terminais da linha. A determinação do tempo de viagem da onda do ponto de falta aos terminais do sistema é feita com base na detecção do tempo de chegada da primeira onda nos terminais do sistema, a qual por sua vez é obtida com emprego da TWD. Em outras palavras, a TWD será responsável em analisar e identificar o instante de chegada das ondas para que se possa proceder ao cálculo da distancia da falta.

O processo de localização da falta via ondas viajantes é composto pelos seguintes estágios: detecção, classificação da falta, transformação modal, estimação do tempo de chegada das ondas, determinação do ramo faltoso e a localização da falta propriamente dita. Tais estágios serão detalhados no que segue. 


\subsubsection{Detecção por ondas viajantes (detecção preliminar)}

O processo de detecção do início do distúrbio foi desenvolvido dispondo-se de dados registrados (off-line), não descartando, no entanto, uma possível aplicação em tempo real (on-line).

Basicamente, o processo de detecção desenvolvido compreende a análise de uma janela de dados de um quarto de ciclo que se desloca sobre o sinal com um passo de $1 \mathrm{~ms}$, comparando esta, a limiares alto ajustáveis a fim de acusar a janela contendo o distúrbio. Utiliza-se neste processo, 1/4 de ciclo dos sinais de detalhe 2 (D2) e detalhe 7 (D7), obtidos via decomposição wavelet dos sinais de fase de corrente. Além disso, os sinais D2 e D7 são elevados ao quadrado com o intuito de minimizar o ruído presente no sinal, como proposto em Santoso [93]. Prosseguindo, os máximos valores dos sinais trifásicos D2 e D7 são comparados a limiares auto-ajustáveis. Uma vez que tais limiares são superados, ativa-se um processo de confirmação, o qual aguardará que as duas próximas janelas consecutivas ( 2 passos da janela) também superem os limiares, para que a detecção da janela onde o distúrbio teve início seja confirmada. Caso uma das duas próximas janelas, após a detecção da primeira janela, não supere os limiares ajustados, o contador de confirmação é zerado e o processo de detecção continua até que haja a confirmação da detecção ou todo sinal registrado seja percorrido.

As Figuras 50 e 51 ilustram o processo de detecção janelada utilizando wavelet. Na Figura 50, temos o gráfico da corrente da fase A, referente a uma falta fase-terra, medido no terminal A do sistema proposto, juntamente com as janelas de detecção já em fase de confirmação do distúrbio. De maneira complementar, podemos observar na Figura 51, a decomposição wavelet ( $2^{\underline{0}}$ e $7^{\underline{0}}$ níveis de detalhes) dos sinais relativos às janelas de detecção, em comparação aos limiares de detecção auto-ajustáveis (linhas vermelhas). Nesta mesma figura, pode-se constatar que para esta dada situação haveria a confirmação da detecção, uma vez que os limiares foram superados.

Os limiares de detecção ( $l m_{-}$dec_D2 e $\left.l m \_d e c \_D 7\right)$ são ditos auto-ajustáveis, pois seus valores são ajustados a cada nova janela livre de distúrbio, de acordo com o valor máximo encontrado sobre a mesma. Esta atualização dos limiares busca garantir, ou mesmo atenuar, as possíveis falhas da detecção do distúrbio devido à presença de ruídos correlacionados aos sinais de fase, ou de situações que caracterizam faltas com elevadas impedâncias de aterramento. 
Uma vez detectada a janela onde o distúrbio teve início, esta mesma janela de 1/4 de ciclo, é então estendida para uma janela de 1 ciclo de dados, que conterá um mínimo de dados de pré-falta e o restante de pós-falta. Sobre esta nova janela de dados serão processados os estágios seguintes referentes à classificação e à localização da falta.

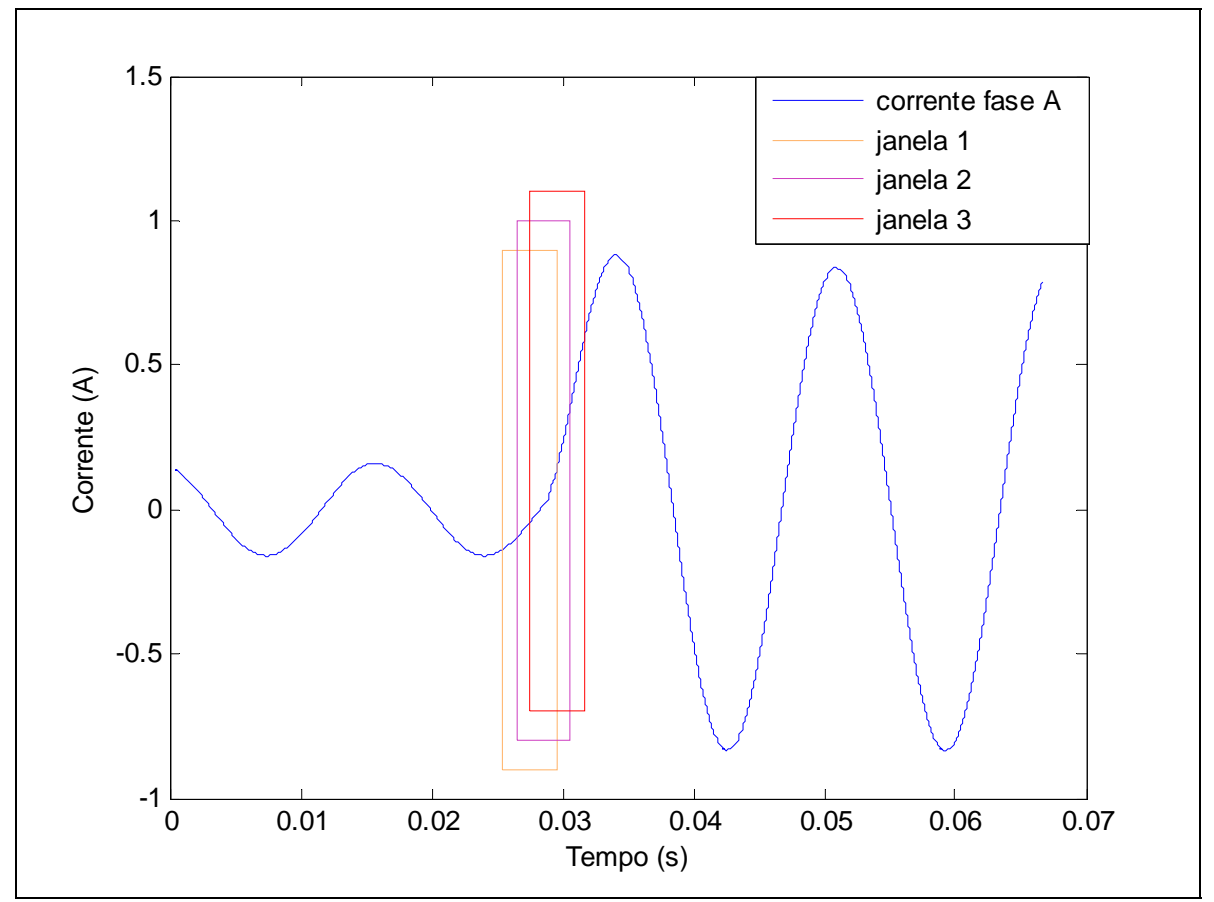

FIGURA 50 - Janelamento do processo de detecção

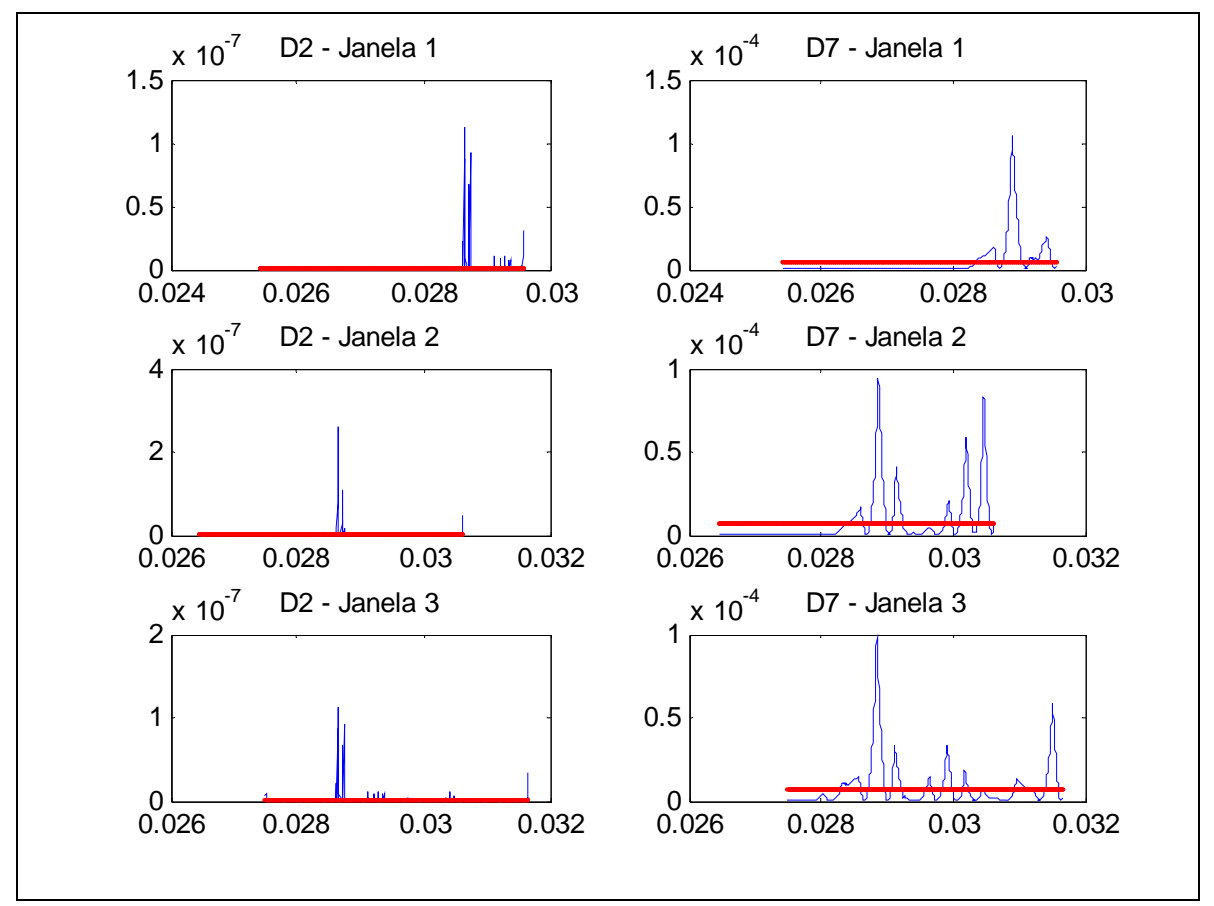

FIGURA 51 - Processo de deteç̧ão - sinais de detalhe 2 (D2) e 7 (D7) referentes às suas respectivas janelas de detecção (Figura 50) 


\subsubsection{Classificação da falta}

Embora a etapa de classificação da falta não seja necessária em outras etapas do algoritmo proposto, já que o mesmo trabalha com dados sincronizados dos diversos terminais, esta pode ser incorporada como uma função opcional, uma vez que a identificação do tipo da falta e das fases envolvidas facilita a restauração e manutenção da linha.

O método de classificação da falta aplicado nesta pesquisa foi inspirado no algoritmo apresentado por Coury [1], onde a classificação da falta é feita via comparação entre os fasores de corrente e de seqüência zero fundamental $\left(I_{a}^{\prime \prime}, I_{b}^{\prime \prime}, I_{c}^{\prime \prime}\right.$ e $\left.I_{0}^{\prime \prime}\right)$ registrados em um dado terminal de referência. $\mathrm{O}$ método implementado foi modificado no que diz respeito à extração das componentes fundamentais dos sinais de corrente. Esta era feita via Fourier e agora passa a ser feita via TW. Portanto, ao invés de se trabalhar com os fasores de corrente e de seqüência zero fundamental extraídos via TF, utilizar-se-á a comparação do nono nível de aproximação dos sinais de corrente (IA9) para classificar a falta. A nona aproximação foi escolhida por ser o máximo nível de decomposição permitido e por representar os componentes de baixa freqüência numa faixa de $0-125 \mathrm{~Hz}$, aproximadamente.

A Figura 52, ilustra a rotina de classificação da falta implementada neste trabalho. O parâmetro $k$ é a razão entre as correntes de fase sã e faltosa. Este parâmetro depende da configuração da falta e pode ser determinado empiricamente. Neste estudo, $k$ equivale a 0,3 . Na prática é necessário também aplicar um pequeno limiar $\left(I_{\min }\right)$ para as medidas, devido à existência de linhas não balanceadas, transdutores, etc. Neste caso, é considerado um $I_{\min }=0,001$, também determinado empiricamente.

Os valores dos fasores de $I A_{9 a}^{\prime \prime}, I A_{9 b}^{\prime \prime}, I A_{9 c}^{\prime \prime}$ e $I A_{90}^{\prime \prime}$ são normalizados com relação à fase que apresenta o maior valor. Considera-se que os fasores de corrente inferiores a 0,3 são não faltosos, e que os fasores de valor superior a $I_{f}=0,6$, são faltosos. A existência ou não do componente de seqüência zero, indica se a falta envolve ou não a terra. Os testes demonstram que a sub-rotina de classificação apresenta uma eficiência altamente satisfatória na classificação correta dos distúrbios. Contudo, alguma classificação errônea pode vir a acontecer, mesmo que ocasionalmente, quando da aplicação de alguns tipos de faltas muito próximas aos terminais remotos. Estas situações podem ser contornadas, tomando-se a classificação da falta em cada um dos respectivos terminais do sistema. 


$$
\begin{aligned}
& I A_{90}^{\prime \prime}>I_{\min } \quad e \\
& I A_{9 b}^{\prime \prime}<k I A_{9 a}^{\prime \prime} \text { e } I A_{9 c}^{\prime \prime}<k I A_{9 a}^{\prime \prime} \text { e } I A_{9 a}^{\prime \prime} \geq I_{f} \quad \text { Falta A-terra } \\
& I A_{9 a}^{\prime \prime}<k I A_{9 b}^{\prime \prime} \quad \text { e } I A_{9 c}^{\prime \prime}<k I A_{9 b}^{\prime \prime} \quad \text { e } I A_{9 b}^{\prime \prime} \geq I_{f} \quad \text { Falta B-terra } \\
& I A_{9 a}^{\prime \prime}<k I A_{9 c}^{\prime \prime} \text { e } I A_{9 b}^{\prime \prime}<k I A_{9 c}^{\prime \prime} \text { e } I A_{9 c}^{\prime \prime} \geq I_{f} \quad \text { Falta C-terra } \\
& I A_{9 c}^{\prime \prime}<k I A_{9 a}^{\prime \prime} \text { e } \quad I A_{9 a}^{\prime \prime} \geq I_{f} \quad \text { e } \quad I A_{9 b}^{\prime \prime} \geq I_{f} \quad \text { e } \\
& I A_{90}^{\prime \prime}>I_{\min } \\
& \text { caso contrário, } I A_{90}^{\prime \prime} \leq I_{\min } \\
& I A_{9 a}^{\prime \prime}<k I A_{9 b}^{\prime \prime} \quad \text { e } \quad I A_{9 c}^{\prime \prime} \geq I_{f} \quad \text { e } \quad I A_{9 b}^{\prime \prime} \geq I_{f} \quad \text { e } \\
& I A_{90}^{\prime \prime}>I_{\min } \\
& \text { caso contrário, } I A_{90}^{\prime \prime} \leq I_{\min } \\
& I A_{9 b}^{\prime \prime}<k I A_{9 a}^{\prime \prime} \quad \text { e } \quad I A_{9 a}^{\prime \prime} \geq I_{f} \quad \text { e } \quad I A_{9 c}^{\prime \prime} \geq I_{f} \quad \text { e } \\
& I A_{90}^{\prime \prime}>I_{\min } \\
& \text { Falta AC-terra } \\
& \text { caso contrário, } I A_{90}^{\prime \prime} \leq I_{\min } \\
& \text { Falta AC } \\
& I A_{9 a}^{\prime \prime} \geq I_{f} \quad \text { e } \quad I A_{9 b}^{\prime \prime} \geq I_{f} \quad \text { e } \quad I A_{9 c}^{\prime \prime} \geq I_{f} \quad \text { Fase ABC }
\end{aligned}
$$

FIGURA 52 - Sub-rotina para classificação do tipo da falta

Para efeito de ilustração é mostrado por meio de gráficos de barras (Figura 53), alguns resultados referentes à utilização da técnica de classificação de falta proposta, quando submetida a diferentes tipos de falta (A-terra, AB-T, AB e ABC), aplicadas a uma distância de $100 \mathrm{~km}$ da barra A e com um ângulo de incidência de $90^{\circ}$. Para a classificação destas situações foram utilizados dados registrados no terminal A. 


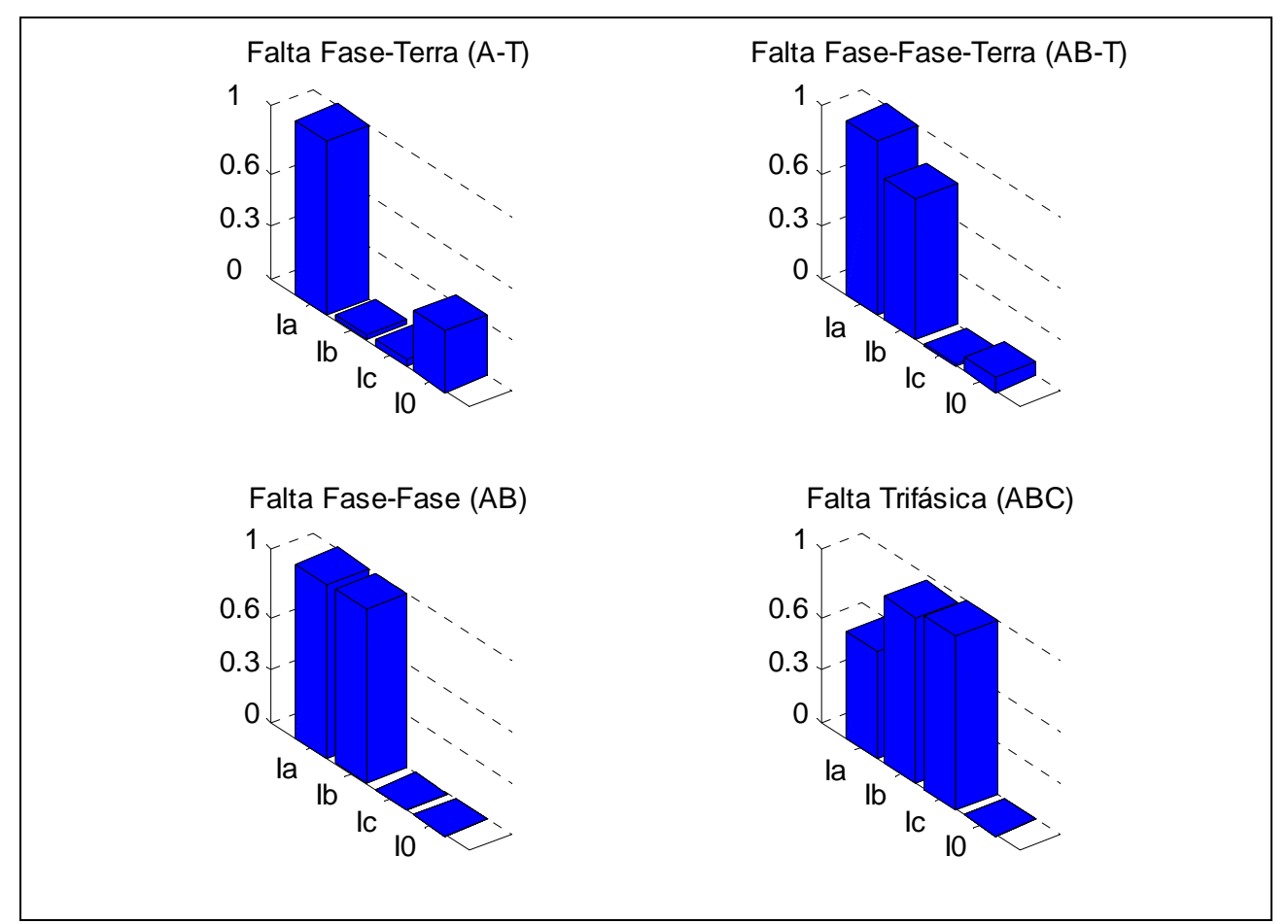

FIGURA 53 - Classificação dos diversos tipos de faltas

\subsubsection{Transformação modal}

Em linhas de transmissão trifásicas, as fases são mutuamente acopladas e, por conseguinte, as perturbações de alta freqüência geradas durante uma falta podem também aparecer nas fases não faltosas. Portanto, para implementar o método das ondas viajantes em sistemas trifásicos, os sinais no domínio do tempo são primeiramente decompostos em seus componentes modais.

A transformação modal permite que o sistema trifásico seja tratado como um sistema com três circuitos monofásicos independentes. Sendo assim, os valores de fase são transformados em três modos desacoplados: um modo terra (modo 0) e dois modos aéreos (modo $\alpha$ e modo $\beta$ ), também conhecidos como modo aéreo 1 e modo aéreo 2 . $O$ modo zero apresenta a impedância característica e a velocidade de propagação, distintas em relação aos modos aéreos.

Uma vez que, na modelagem do sistema, as linhas de transmissão são totalmente transpostas e apresentam uma boa simetria, podem ser utilizadas as transformações modais de Clarke [113] ou de Wedepohl [114]. Uma matriz de transformação um pouco mais precisa pode ser obtida, principalmente quando o sistema não é totalmente simétrico, com base na média dos valores da parte real da matriz de impedância da linha calculada para uma banda de freqüência de 0 a $6 \mathrm{kHz}$ (ANCELL e 
PAHALAWATHTHA) [115]. Neste estudo foi utilizada a matriz de transformação de Clarke dada por:

$$
T=\frac{1}{3} \cdot\left[\begin{array}{ccc}
1 & 1 & 1 \\
2 & -1 & -1 \\
0 & \sqrt{3} & -\sqrt{3}
\end{array}\right]
$$

Os sinais de fase (tensão e/ou corrente) são transformados em seus componentes modais pelo uso da matriz de transformação como segue:

$$
\left[\begin{array}{c}
V_{0} \\
V_{\alpha} \\
V_{\beta}
\end{array}\right]=T \cdot\left[\begin{array}{l}
V_{a} \\
V_{b} \\
V_{c}
\end{array}\right]
$$

Para as correntes temos:

$$
\left[\begin{array}{l}
I_{0} \\
I_{\alpha} \\
I_{\beta}
\end{array}\right]=T \cdot\left[\begin{array}{l}
I_{a} \\
I_{b} \\
I_{c}
\end{array}\right]
$$

Onde $\mathrm{V}_{0, \alpha, \beta}$ e $\mathrm{I}_{0, \alpha, \beta}$ são os vetores modais de tensão e corrente respectivamente, e, $\mathrm{V}_{\mathrm{a}, \mathrm{b}, \mathrm{c}}$ e $I_{a, b, c}$, são os vetores de fase da tensão e corrente.

A velocidade de propagação do modo terra $\left(v_{0}\right)$ e do modo aéreo $1\left(v_{l}\right)$ são dadas respectivamente por:

$$
\begin{aligned}
& v_{0}=\frac{1}{\sqrt{\left(L_{0} C_{0}\right)}} \\
& v_{1}=\frac{1}{\sqrt{\left(L_{1} C_{1}\right)}}
\end{aligned}
$$

Tal que $L_{0}, C_{0}, L_{1}$ e $C_{l}$ são as indutâncias e capacitâncias de seqüência zero e positiva das linhas de transmissão.

Uma vez feito o desacoplamento dos sinais de corrente ou tensão, utiliza-se no algoritmo, o sinal do modo aéreo 1. Como os sinais do modo 1 estão presentes em todos os tipos de falta, este será essencialmente utilizado para a determinação dos tempos de viagem das ondas aos terminais do sistema e, conseqüentemente, para o cálculo da distância da falta.

É importante ressaltar que, na prática, a maior parte das linhas de transmissão são assimétricas, como por exemplo, em circuitos verticais, e não há a prática da 
transposição de linhas a intervalos regulares. Estas características acarretam um mau desacoplamento das fases quando se tem este objetivo por meio da transformação modal. Incorporando assim, erros de menor ou maior proporção aos sinais dos modos calculados, o que pode afetar a precisão dos algoritmos de localização de falta [115], [42] e [8]. Contudo, na prática, as contribuições deste problema costumam ser desprezadas [42].

Diante dos apontamentos levantados, nesta pesquisa, pretende-se observar qual o nível de influência do mau desacoplamento do sistema sobre o desempenho do algoritmo de localização proposto.

\subsubsection{Determinação dos tempos de reflexão (Detecção Fina)}

A estimação da distância da falta nesta técnica é baseada na detecção do instante $\left(t_{a}, t_{b}\right.$ e $\left.t_{c}\right)$ de chegada da primeira onda nos respectivos terminais do sistema, conforme ilustra a Figura 54. Esses instantes são relatados pelos sinais de detalhe 2 (D2) do modo 1 da corrente ou da tensão, e são caracterizados por picos presentes nos mesmos.

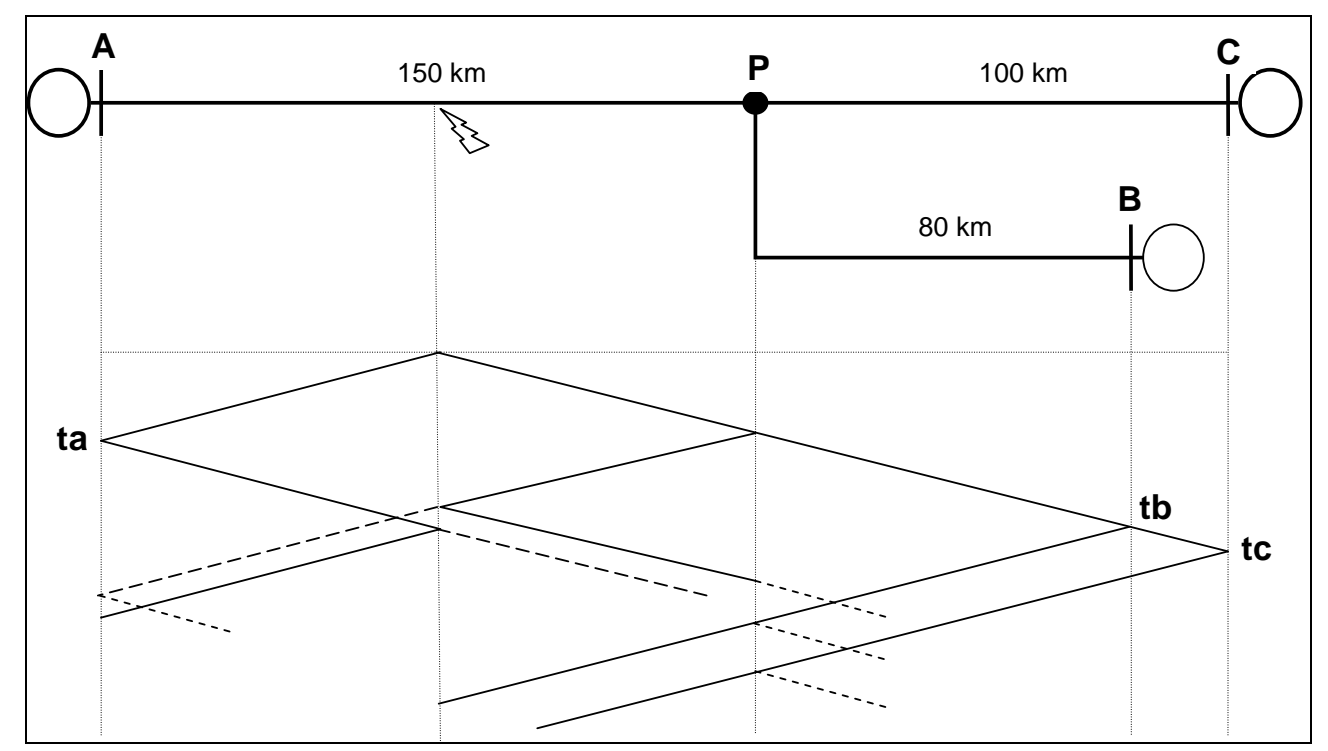

FIGURA 54 - Identificação da chegada da primeira onda via diagrama Lattice

A detecção precisa (detecção fina) desses instantes é feita através da comparação do quadrado dos sinais do detalhe 2, com um dado limiar, também auto-ajustável, chamado de limiar_1. O limiar_1 é estabelecido com base no limiar de detecção grossa (lm_dec_D2), o qual é auto-ajustável, acrescido de mais $10 \%$ do valor observado, ou seja: 
limiar_1 $=1,1 \cdot 1 \mathrm{~lm} \_$dec_D2

Portanto, o sinal do detalhe 2 , referente a cada barra do sistema, é comparado amostra por amostra com o limiar_1, até que este seja superado, mediante uma situação de anomalia sobre o sistema. Uma vez superado o valor do limiar_1, são consideradas mais treze amostras consecutivas à frente. Deste conjunto de treze amostras, o maior valor corresponderá ao instante da primeira reflexão nas barras e o processo de detecção fina será encerrado. O conjunto de 13 amostras foi estabelecido empiricamente de forma a contemplar todos os possíveis picos simultâneos revelados pela decomposição wavelet.

A Figura 55 ilustra o processo de detecção fina ou chegada das ondas nos três terminais do sistema proposto quando uma falta fase-fase $(\mathrm{AB})$ é aplica a $70 \mathrm{~km}$ da barra A. Os maiores picos destacados com um asterisco vermelho, representam a chegada da primeira onda nos terminais e revela o instante de tempo de sua chegada.

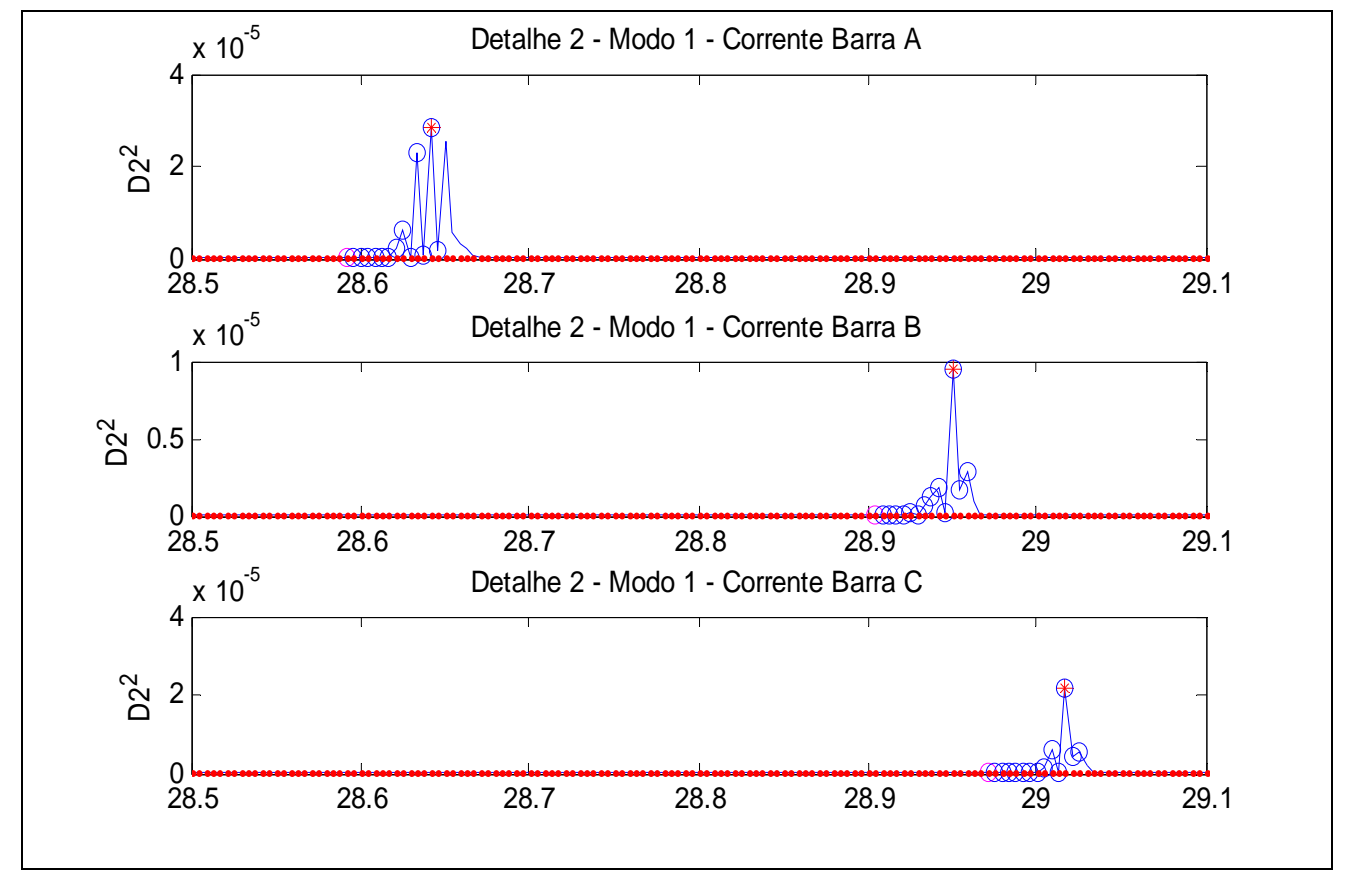

FIGURA 55 - Exemplo de deteç̧ão dos picos iniciais

\subsubsection{Identificação do Ramo faltoso}

Após a detecção do instante de chegada da primeira onda nos terminais do sistema, é necessário identificar a linha ou ramo onde está alocada a falta para que se possa, posteriormente, localizar com certa precisão a falta com referência ao terminal da linha faltosa. 
A identificação do ramo faltoso é baseada na comparação da distância da falta calculada previamente, tomando-se por referência dois terminais arbitrários, com o comprimento de cada linha do sistema. A lógica para a determinação do ramo faltoso, considerando a Figura 54, é dada pelos pontos que seguem.

a) Levantamento do comprimento das linhas do sistema em análise:

$$
\begin{array}{ll}
l_{A P}=150 \mathrm{~km} & l_{A B}=230 \mathrm{~km} \\
l_{B P}=80 \mathrm{~km} & l_{A C}=250 \mathrm{~km} \\
l_{C P}=100 \mathrm{~km} & l_{B C}=180 \mathrm{~km}
\end{array}
$$

b) Estimação da distância da falta, tomando-se por referência os terminais $\mathrm{AB}, \mathrm{AC}$ e $\mathrm{BC}$, conforme as seguintes equações:

$$
\begin{aligned}
& d_{A B}=\frac{l_{A B}-v_{1} \cdot\left(t_{B}-t_{A}\right)}{2} \\
& d_{A C}=\frac{l_{A C}-v_{1} \cdot\left(t_{C}-t_{A}\right)}{2} \\
& d_{B C}=\frac{l_{B C}-v_{1} \cdot\left(t_{C}-t_{B}\right)}{2}
\end{aligned}
$$

c) Comparação da distância estimada com o comprimento dos ramos:

$$
\begin{array}{ll}
\text { Se } & d_{A B} \leq l_{A P} \text { e } d_{A C} \leq l_{A P} \leftrightarrow \text { Ramo1 ou } A P \\
\text { Se } & d_{A B}>l_{A P} \text { e } d_{B C} \leq l_{B P} \leftrightarrow \text { Ramo } 2 \text { ou } B P \\
\text { Se } & d_{A C}>l_{A P} \text { e } d_{B C}>l_{B P} \leftrightarrow \text { Ramo } 3 \text { ou } C P
\end{array}
$$

Cabe adiantar que com base nesta última comparação, é possível se identificar o ramo faltoso com uma elevada precisão.

\subsubsection{Cálculo da distância da falta envolvendo dados dos três terminais}

Uma vez determinado os instantes de chegada das primeiras ondas e o ramo sobre o qual ocorreu o distúrbio, processa-se então, facilmente, o cálculo da distância da falta com referência ao terminal do ramo faltoso e dos demais terminais do sistema conforme a eq. (5.9): 


$$
d_{j i}=\frac{l_{i j}-v_{1} \cdot\left(t_{i}-t_{j}\right)}{2}
$$

Tal que $i$ identifica o terminal do ramo não faltoso, $j$ identifica o terminal do ramo faltoso, $d$ é a distância da falta $(\mathrm{km}), l$ o comprimento total da linha entre os terminais identificados por $i$ e $j, v_{l}$ velocidade de propagação da onda para o modo $1, t_{i}$ é o tempo de chegada da primeira onda com relação a um dos terminais com o ramo não faltoso e $t_{j}$ é o tempo de chegada da primeira onda no terminal do ramo faltoso.

Como se pode verificar, a distância da falta pode ser estimada com relação ao terminal do ramo faltoso e os demais terminais, perfazendo duas medidas de distância. Das quais, por sua vez, pode ser tirada uma medida média da distância da falta, perfazendo assim, uma terceira medida da distância da falta.

Neste trabalho será adotada apenas uma das medidas para efeito de ilustração dos resultados. No caso, será considerada a medida média da distância dada pela Eq. (5.10). Portanto, os erros percentuais (relativos) também serão apresentados com base na medida média da distância e do comprimento dos ramos mais extensos, conforme Eq. (5.11):

$$
\begin{aligned}
& d_{\text {media }}=\frac{\left(d_{j i_{1}}+d_{j i_{2}}\right)}{2} \\
& e_{(\%)}=\frac{\left|d_{\text {media }}-d_{\text {real }}\right| * 100}{l_{A C}} \\
& j=A, B, C
\end{aligned}
$$

\subsubsection{Relatório do evento}

Por último, e não menos importante, é gerado um relatório sobre o evento ocorrido em formato texto digital, o qual pode ser visualizado em computador, salvo, ou impresso para fins de análise ou registro físico do evento.

Este relatório conterá toda a informação sobre o distúrbio, como: data, hora, classificação do distúrbio, ramo do sistema afetado e localização da falta. Assim como, as oscilografias dos sinais de corrente e de tensão registradas nos terminais do sistema. O usuário também poderá optar por uma configuração mais simples ou mais detalhada do relatório, conforme suas necessidades. Os dados também poderão ficar disponíveis em um formato padrão, como por exemplo, no formato COMTRADE (Common Format 
for Transient Data Exchange for Power Systems - IEEE standard C37_111_1991)[116], para serem usados em outros dispositivos, testes, estudos ou pesquisas.

$\mathrm{Na}$ Figura 49, temos um exemplo preliminar de algumas informações que podem ser disponibilizadas no relatório. Este relatório foi gerado com base na simulação de uma falta fase-fase (AB) aplicada a $100 \mathrm{~km}$ da barra A (ramo 1).

\section{Teste de geração de relatório}

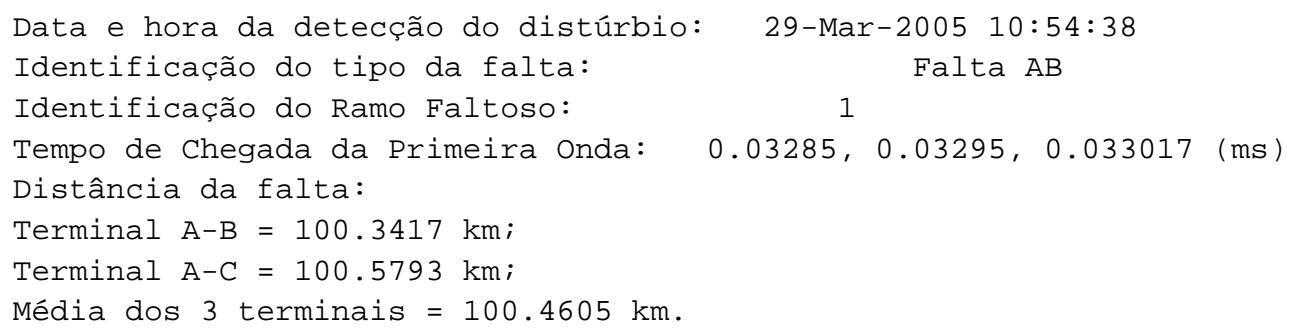

FIGURA 56 - Exemplo preliminar do relatório de eventos

\subsubsection{Metodologia de localização de faltas por ondas viajantes e Transformada Wavelet utilizando dados locais (terminal local)}

Quando não disponíveis meios comunicação e sincronização de dados entre os terminais do sistema o algoritmo híbrido passa a operar com metodologia de ondas viajantes para dados locais.

Nessa técnica, devido à carência do tempo medido no barramento remoto, todo o tempo medido será com respeito ao instante em que a falta é detectada, ou seja, em relação à primeira reflexão de onda no terminal local. Sendo assim, a princípio, o cálculo para a localização da falta é baseado no tempo de reflexão das ondas viajantes entre o ponto de falta e o terminal local. No entanto, para faltas com envolvimento do terra, não só as reflexões sobre o ponto de falta, mas também as do terminal remoto e do ponto de acoplamento das linhas serão observadas no terminal local ou de referência. Logo, nessa técnica, a sub-rotina de classificação da falta torna-se essencial para distinguir entre faltas aterradas ou não, uma vez que essas características conduzem a equacionamentos diferentes para o cálculo da distância da falta. 
Cabe salientar que, durante o desenvolvimento e teste do algoritmo, notou-se que as reflexões provenientes do terminal remoto não eram tão significativas no caso de faltas fase-fase-terra, devido a grande atenuação das mesmas. Já no caso de faltas faseterra, constatou-se que as reflexões do terminal remoto não podiam ser desconsideradas, pois apresentavam níveis significantes. Tendo em vista estas observações, o algoritmo foi modelado de maneira que os sinais do terminal remoto só fossem considerados no caso de faltas fase-terra.

Outra peculiaridade apresentada por essa técnica é a necessidade de distinguir em caso de faltas aterradas, ou mais precisamente faltas fase-terra, se a mesma está alocada próxima do terminal local ou do ponto de acoplamento das linhas, ou seja, se a falta fase-terra ocorreu na primeira ou segunda metade do ramo faltoso, o que também conduz a equacionamentos diferentes, pois estas podem produzir padrões semelhantes de reflexões (tempos semelhantes). Para resolver este problema, foi necessário introduzir uma nova sub-rotina, denominada de pré-localização da falta, utilizada somente em caso de faltas fase-terra.

O algoritmo para dados locais a ser descrito foi balizado sobre a proposta apresentada por Silva [117], o qual foi aperfeiçoado para atender as características de um sistema com três terminais.

O algoritmo de ondas viajantes para dados de um terminal é composto pelos seguintes estágios: detecção, classificação e transformação modal, determinação do tempo de chegada da primeira e segunda onda no terminal local, pré-localização da falta, culminando na identificação do ramo faltoso e localização da falta.

Uma vez que existem estágios comuns (idênticos) entre as técnicas com e sem comunicação de dados, como é o caso dos estágios de detecção, classificação, transformação modal e detecção da chegada da primeira onda ao terminal (seções 5.2.6.1-4), comentários sobre estes, serão suprimidos.

\subsubsection{Determinação dos tempos de reflexão da primeira e segunda onda no terminal local}

Nessa técnica a detecção ou determinação dos instantes de chegada das ondas no terminal local é mais complexa, pois envolve a detecção da primeira e segunda reflexão de onda no terminal local.

No caso da detecção do instante de chegada da primeira onda ao terminal local (T1), esta sempre será proveniente do ponto de falta e será determinada de maneira 
análoga à seção 5.2.6.1, diferindo apenas no número de amostras consecutivas consideradas após a detecção da primeira amostra. De maneira empírica, foi considerado como ideal a utilização de mais 5 amostras consecutivas após detecção da primeira amostra, perfazendo um conjunto de 18 amostras.

A determinação do segundo tempo (T2) referente à chegada da segunda onda no terminal local é mais complexa, pois envolve ondas provenientes do ponto de falta ou do terminal remoto ou ainda do ponto de interligação dos ramos, conforme o tipo de falta. Outro fator que dificulta esta detecção é a grande atenuação destas ondas durante a sua viagem pelo sistema.

O tempo T2 é determinado pela comparação do sinal de detalhe 2 do modo 1 com limiares auto-ajustáveis, conforme o sinal e o tipo de falta em específico. O primeiro limiar, chamado de limiar 2, é definido pelo máximo entre as amostras 4 e 6 do sinal de detalhe 2 com relação a amostra que corresponde a T1, sendo portanto o limiar 2 auto-ajustável conforme o sinal analisado. No caso de faltas fase AB-terra foram consideradas as amostras de 4 a 8 .

Para o caso de faltas sem conexão a terra, o tempo T2 é determinado pela simples comparação do limiar 2 com as amostras do sinal detalhe 2 subseqüentes a amostra que representa T1. Caso alguma amostra supere o limiar 2, T2 será determinado analisando-se um conjunto de amostras a partir desta detecção.

Em se tratando de faltas fase-terra e fase-fase-terra, é repetido o mesmo procedimento descrito para faltas sem conexão a terra. Porém, se um determinado conjunto de amostras iniciais não ultrapassarem o limiar 2, novos limiares são definidos para estes tipos de faltas. Tal procedimento busca eliminar o efeito da atenuação do sinal, mais presentes nos tipos de faltas com conexão a terra. Logo, para faltas fase-terra é estabelecido um novo limiar (limiar 3), definido pela razão entre o limiar 2 e um coeficiente de falta $(c f)$ determinado empiricamente e ilustrado na Tabela 9. O novo limiar 3 é então comparado com as amostras do sinal de detalhe 1. Caso alguma amostra exceda o seu valor, T2 é determinado analisando-se um conjunto de amostras prédefinido a partir desta detecção.

Em situações de faltas fase-fase-terra, a determinação do tempo T2 segue o mesmo procedimento delineado para o caso de faltas fase-terra, diferenciando-se apenas no tocante ao limiar 3, onde para o caso de faltas fase-fase-terra o limiar 3 é substituído por um limiar 4 , o qual equivale ao produto do limiar 2 com relação ao coeficiente de falta $(c f)$. Definido o limiar 4, o tempo T2 é determinado de modo análogo ao descrito 
para faltas fase-terra. É importante observar, que no caso de faltas fase-fase-terra, o limiar 4 é função de um produto, pois com isto conseguimos eliminar da análise, as reflexões provenientes do terminal remoto e ponto de conexão com as linhas, o que trouxe simplificações ao algoritmo.

TABELA 9-Coeficientes de falta (cf)

\begin{tabular}{ccc}
\hline & Faltas Fase-Terra & Faltas Fase-Fase-Terra \\
\hline CF & 3 & 2 \\
\hline
\end{tabular}

Visando uma melhor elucidação das etapas para determinação de $t_{1}$ e $t_{2}$, é apresentado, na Figura 57, o fluxograma referente a essa rotina.

Neste mesmo estágio, quando da ocorrência de faltas fase-terra, é determinado o tempo $t_{3}$, necessário para distinguir se a falta ocorreu na primeira ou segunda metade do ramo, o que conduz a equacionamentos diferentes.

A determinação do tempo $t_{3}$ é semelhante à determinação do tempo $t_{1}$ visto anteriormente, sendo que, neste caso, o sinal é comparado a um limiar 5. Para determinar-se $t_{3}$, ao invés de usar o sinal de detalhe 2 do modo 1 , utilizamos o sinal de detalhe 2 do modo terra (TWD2_terra). O limiar 5 é auto-ajustável e definido de modo análogo ao limiar 1. Entretanto, este é baseado na análise do sinal do modo terra.

O sinal de detalhe 2 do modo terra é comparado com o limiar 5 (TWD2_terra $>$ limiar 5), caso haja alguma variação, esta é detectada e mais 18 amostras consecutivas são consideradas, sendo que deste conjunto o maior valor denotará o respectivo tempo $t_{3}$.

\subsubsection{Pré-Localização para faltas fase-terra}

Refletindo os conceitos apresentados por Silva [117] ao nosso sistema de três terminais, temos que, no caso de faltas fase-terra, há a necessidade de pré-localizarmos a falta, ou seja, determinarmos se a mesma ocorreu na primeira ou segunda metade do ramo faltoso. Isto em virtude da observação da segunda onda viajante no terminal local, sendo que a mesma pode ser proveniente do ponto de falta, caso esta ocorra na primeira metade do ramo faltoso, ou proveniente do ponto de acoplamento dos ramos, caso a falta ocorra na segunda metade da linha. 


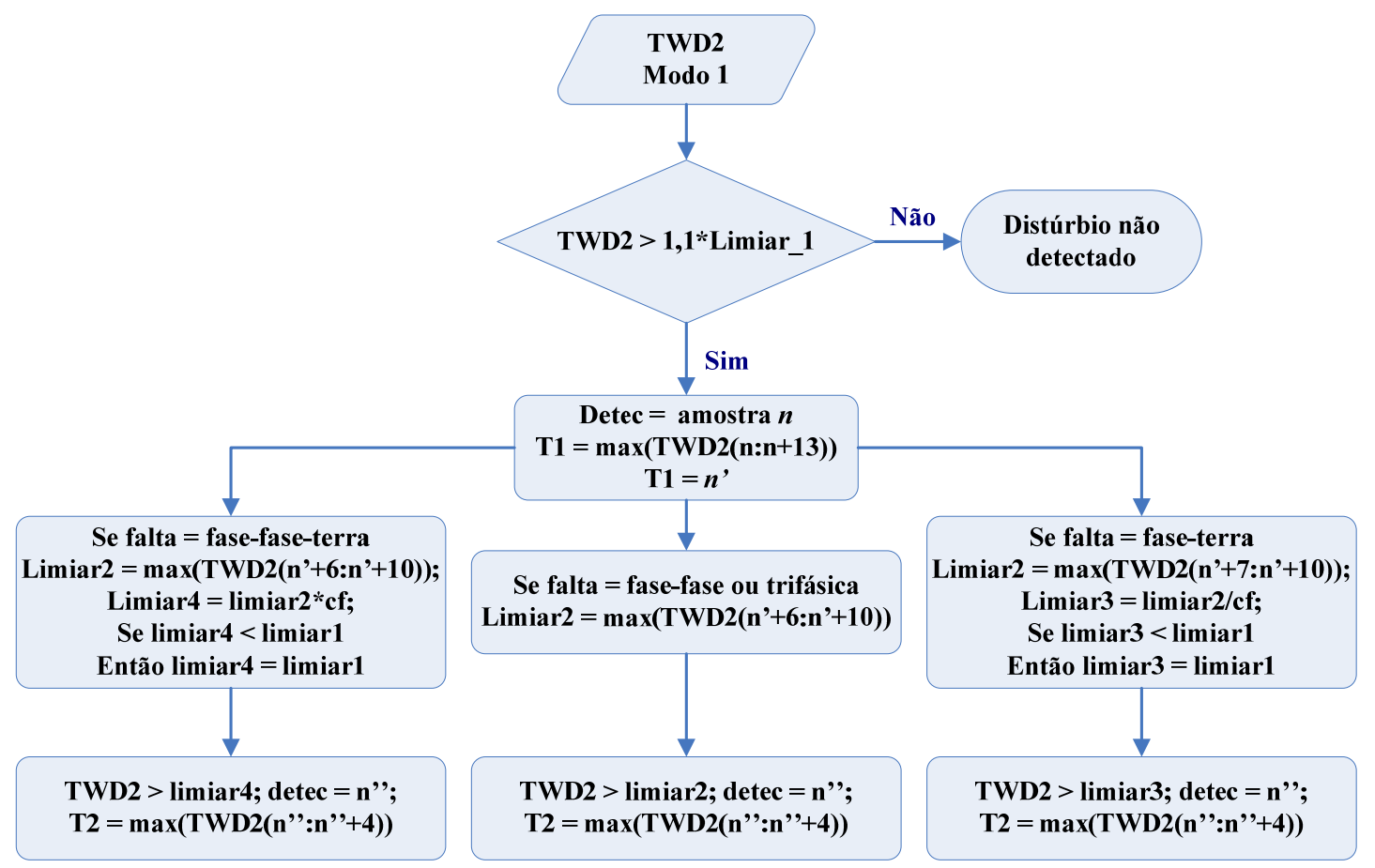

FIGURA 57 - Fluxograma referente às etapas para determinação dos tempos $t_{1}$ e $t_{2}$.

Esse procedimento é necessário, pois neste caso, podemos ter padrões de faltas semelhantes, ou seja, podemos ter intervalos de tempos entre a primeira e a segunda onda, iguais. Isto conduz a equacionamentos diferentes para o correto cálculo da distância da falta.

As Figuras 58a e 58b ilustram uma situação de falta fase-terra na primeira e segunda metade do ramo 1 (AP), respectivamente. Notamos que se calcularmos o intervalo de tempo entre as duas primeiras ondas que chegam ao barramento local (A), teríamos:

(a)

(b)

$$
\begin{aligned}
& t_{2 a}=3 t_{1 a} \\
& t_{2 a}=2 t_{1 p}+t_{1 a} \\
& t_{d}=t_{2 a}-t_{1 a}=3 t_{1 a}-t_{1 a}=2 t_{1 a} \\
& t_{d}=t_{2 a}-t_{1 a}=2 t_{1 p}+t_{1 a}-t_{1 a}=2 t_{1 p} \\
& 2 t_{1 a}=2 t_{1 p} \\
& \therefore \quad d_{a}=\frac{v_{1} * 2 t_{1 a}}{2} \quad e \quad d_{b}=\frac{v_{1} * 2 t_{1 p}}{2} \\
& \text { Logo: } d_{a}=d_{b}
\end{aligned}
$$




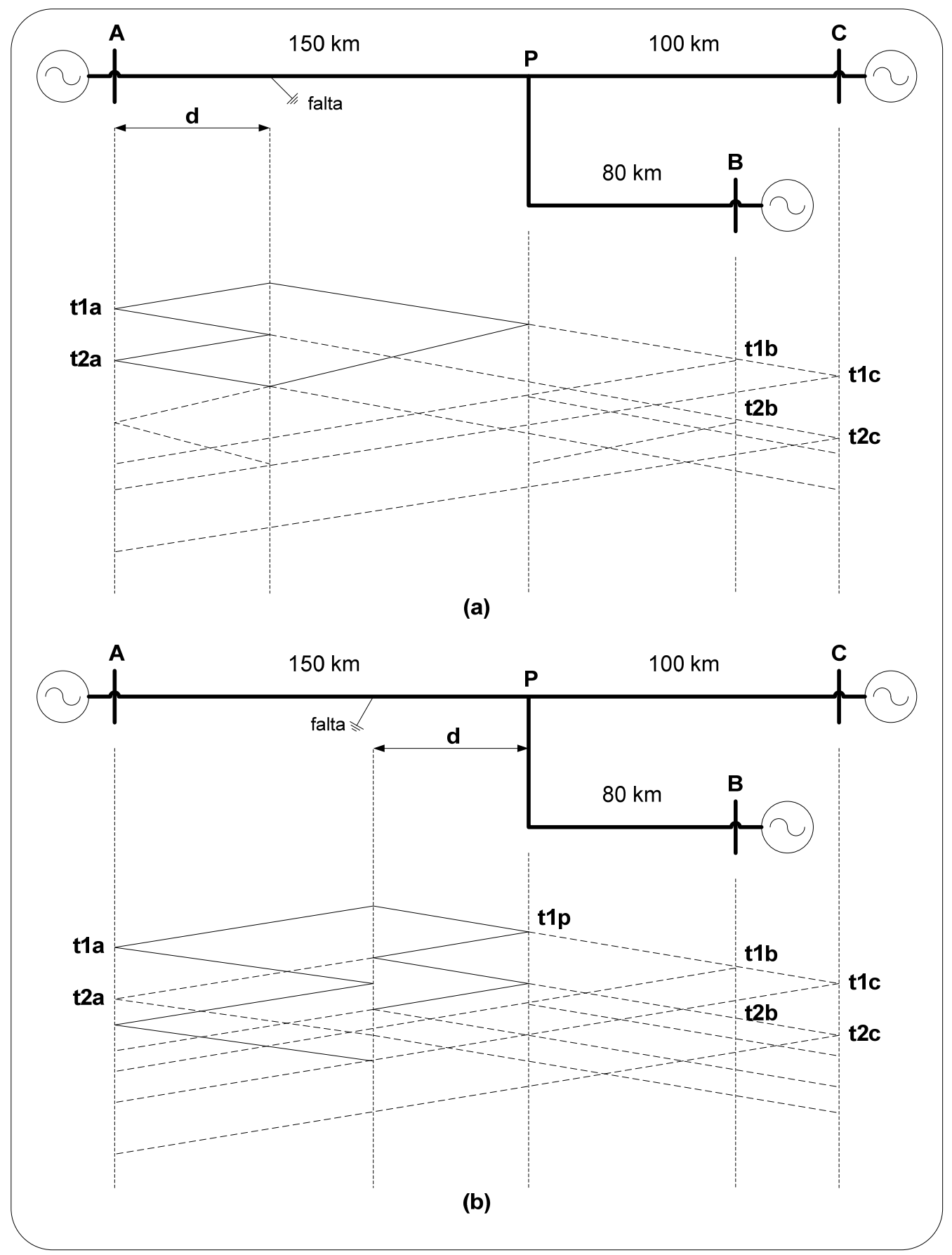

FIGURA 58 - Diagrama de reflexão para falta fase-terra: (a) falta na primeira metade do ramo AP e (b) falta na segunda metade do ramo $A P$

A pré-localização é feita baseada na comparação da diferença entre os tempos das reflexões iniciais revelados pela TWD com relação ao modo terra e modo aéreo 1, com a diferença entre os tempos de propagação do modo terra e aéreo 1 em relação ao meio do ramo faltoso coberto pelo localizador, como proposto por Abur e Magnago [53]. Em outras palavras, quanto maior a distância da falta, maior será a diferença entre os tempos de propagação das primeiras reflexões reveladas pela TWD com relação a 
ambos os modos, sendo isso possível devido à diferença da velocidade de propagação da onda entre os modos aéreos e terra. Caso esse valor seja maior que a diferença dos tempos de reflexão para a metade do ramo em questão, a falta estará alocada na segunda metade, caso contrário, a falta estará alocada na primeira metade da mesma. A subrotina para pré-localizar faltas fase-terra pode ser formulada como segue:

$$
\begin{aligned}
& t_{m 0}=\frac{l_{i P}}{2 \cdot v_{m 0}} ; \quad t_{m 1}=\frac{l_{i P}}{2 \cdot v_{m 1}} \\
& t_{l / 2}=\left|t_{m 0}-t_{m 1}\right| \\
& t_{d m}=\left|t_{1}-t_{3}\right| \\
& \text { Se } t_{d m}>t_{l / 2} \Leftrightarrow 2^{a} \text { metade do ramo } \\
& \text { Caso contrário } \Leftrightarrow 1^{a} \text { metade do ramo }
\end{aligned}
$$

onde, $t_{m 0}$ e $t_{m l}$ são os tempos com relação a velocidade dos modos terra e aéreo 1 que a onda leva para ir do terminal local ao meio do ramo, $t_{1}$ e $t_{3}$ são os tempos relacionados aos primeiros picos dos sinais de detalhe 2 dos modos aéreo 1 (TWD2) e terra (TWD2_terra), respectivamente.

Esta técnica de pré-localização mostrou-se bastante eficaz na maioria dos testes realizados, apresentando alguns erros em casos de faltas muito próximas a metade da linha.

O processo de pré-localização de faltas fase-terra pode também identificar o ramo faltoso em caso de faltas fase-terra ajustando o valor de $t_{l / 2}$ para abranger todo o comprimento do ramo $\left(t_{l / 2}=t_{l}\right)$. Dessa forma, caso $t_{d m} \leq t_{l}$, a falta estará localizada sobre o ramo em análise.

\subsubsection{Cálculo da distância para faltas fase-fase-terra, fase-fase e trifásica}

No caso de faltas fase-fase-terra, fase-fase e trifásicas, observa-se que estas não geram reflexões do terminal remoto durante o transitório de falta. Assim, medindo-se o tempo entre os dois primeiros picos consecutivos dos coeficientes wavelets do detalhe 2 , referente ao modo aéreo 1, e tomando o produto da velocidade de propagação, a distância da falta pode ser estimada. Logo, a distância da falta pode ser expressa por: 


$$
d_{i}=\frac{v_{1} \cdot\left(t_{2 i}-t_{1 i}\right)}{2}
$$

onde $d_{i}$ é a distância da falta em $(\mathrm{km})$ com relação ao terminal $i, v_{l}$ a velocidade de propagação do modo $1(\mathrm{~km} / \mathrm{s})$, e, $t_{1 i}$ e $t_{2 i}$ são os tempos de reflexão da primeira e segunda onda no terminal $i$, respectivamente.

\subsubsection{Cálculo da distância para faltas fase-terra}

Conforme foi explicitado anteriormente, em caso de faltas fase-terra é necessário que seja feito uma pré-localização da falta conforme o item 5.2.7.2. Determinado em qual metade da linha ocorreu a falta, o cálculo da distância da falta pode ser feito como segue:

- para faltas fase-terra na primeira metade da linha a distância da falta é calculada conforme a Eq.(5.13);

- para faltas fase-terra na segunda metade da linha, temos que:

$$
d_{i}=l_{i P}-\frac{v_{1} \cdot\left(t_{2 i}-t_{1 i}\right)}{2}
$$

onde, $l_{i P}$ é o comprimento do ramo entre o terminal $i$ e o ponto de acoplamento das linhas $P$.

\subsubsection{Metodologia de localização de faltas por componentes fundamentais via Transformada Wavelet Estacionária para dados de Três terminais}

A metodologia proposta é fundamentada sobre o algoritmo de localização de faltas para linhas com três terminais proposta por Coury [10], o qual utiliza os fasores fundamentais $(60 / 50 \mathrm{~Hz})$ dos sinais de corrente e tensão trifásicos extraídos via Transformada Discreta de Fourier (TDF) para o cálculo da distância da falta. Contudo, neste contexto, propõe-se aqui utilizar a própria Transformada Wavelet na sua versão estacionária (TWE) para se extrair os fasores fundamentais dos sinais de corrente e tensão para o cálculo da distância da falta.

Justifica-se por esta proposta, a possibilidade de se ter uma filtragem mais eficiente dos componentes fundamentais por meio da TWE, minimizando assim, possíveis erros introduzidos pela TDF, como, por exemplo, devido à má filtragem do componente DC (Direct Current). 
No que segue, serão detalhados os estágios que compõem a metodologia supracitada.

\subsubsection{Decomposição dos sinais via TWE}

Ressalta-se que este módulo baseado em componentes fundamentais fez uso da TWE para decompor os sinais de corrente e tensão, ao invés de usar a TWD, pelo fato da primeira reconstituir com mais precisão os níveis de decomposição utilizados por este módulo de localização.

Neste método foram utilizados os sinais de detalhe 5 (D5: 37,5-75 Hz) e aproximação 3 (A3: 0-150 Hz), da tensão e corrente, obtidos via TWE utilizando a wavelet-mãe a Symlet de ordem 14 (sym14). O número de níveis de decomposição, assim como a utilização de um ou outro nível foi determinado conforme cada aplicação, respeitando é claro, o número máximo de níveis permitidos, dado o sinal analisado.

\subsubsection{Deteç̧ão do distúrbio via componentes fundamentais}

Neste método é necessário fazer a detecção do ponto ou amostra a partir da qual se deu o distúrbio, pois o mesmo trabalha somente com os sinais de corrente e tensão pós-falta.

O processo de detecção proposto é conhecido e baseia-se na simples comparação das amostras da A3 ou do D5 de corrente das três fases da linha com as amostras correspondentes a um ciclo anterior. Caso haja uma mudança significativa (em torno de 5\%) nas magnitudes de 6 amostras consecutivas, caracteriza-se então a detecção de algum distúrbio e, consequentemente, o ponto exato de ocorrência do distúrbio [6].

\subsubsection{Classificação da falta}

A classificação da falta é feita de forma análoga à descrita anteriormente no item 5.2.6.2, exceto por se utilizar agora os sinais da aproximação 3 (A3) de corrente, obtidos via TWE, e não mais os da aproximação 7 (A7) extraídos via TWD.

\subsubsection{Componentes Superpostos}

O processo de extração dos componentes superpostos consiste basicamente na realização da diferença entre o sinal faltoso e o sinal de pré-falta, conforme Eq. (5.15). 


$$
\begin{aligned}
& {\left[V_{a, b, c}^{\text {sup erposto }}\right]=\left[V_{a, b, c}^{\text {falta }}\right]-\left[V_{a, b, c}^{\text {pré-falta }}\right]} \\
& {\left[I_{a, b, c}^{\text {sup erposto }}\right]=\left[I_{a, b, c}^{\text {falta }}\right]-\left[I_{a, b, c}^{p r e ́-f a l t a}\right]}
\end{aligned}
$$

O emprego dos componentes superpostos ao invés dos valores totais justifica-se pelo aumento da precisão do algoritmo decorrente da redução dos erros devido ao carregamento do sistema.

\subsubsection{Transformação Modal}

A transformação modal segue os conceitos já apresentados na seção 5.2.6.3, sendo desacoplados os sinais de detalhe 5 (D5) e aproximação 3 (A3) da corrente e da tensão.

Nesta pesquisa utilizamos nos testes apenas os sinais do modo aéreo 1, podendo também os outros modos (aéreo 2 e terra) serem utilizados nesta metodologia para o cálculo da distância da falta.

\subsubsection{Equacionamento para Localização da falta e identificação do ramo faltoso via componentes fundamentais extraídos via TWE}

O equacionamento desta metodologia baseia-se na relação entre os fasores do ponto de falta e do ponto de acoplamento das linhas em função dos fasores medidos nos terminais do sistema.

O equacionamento pode ser mais bem compreendido com o auxilio da Figura 59, a qual faz referência a um sistema de três terminais com um falta no ramo AP.

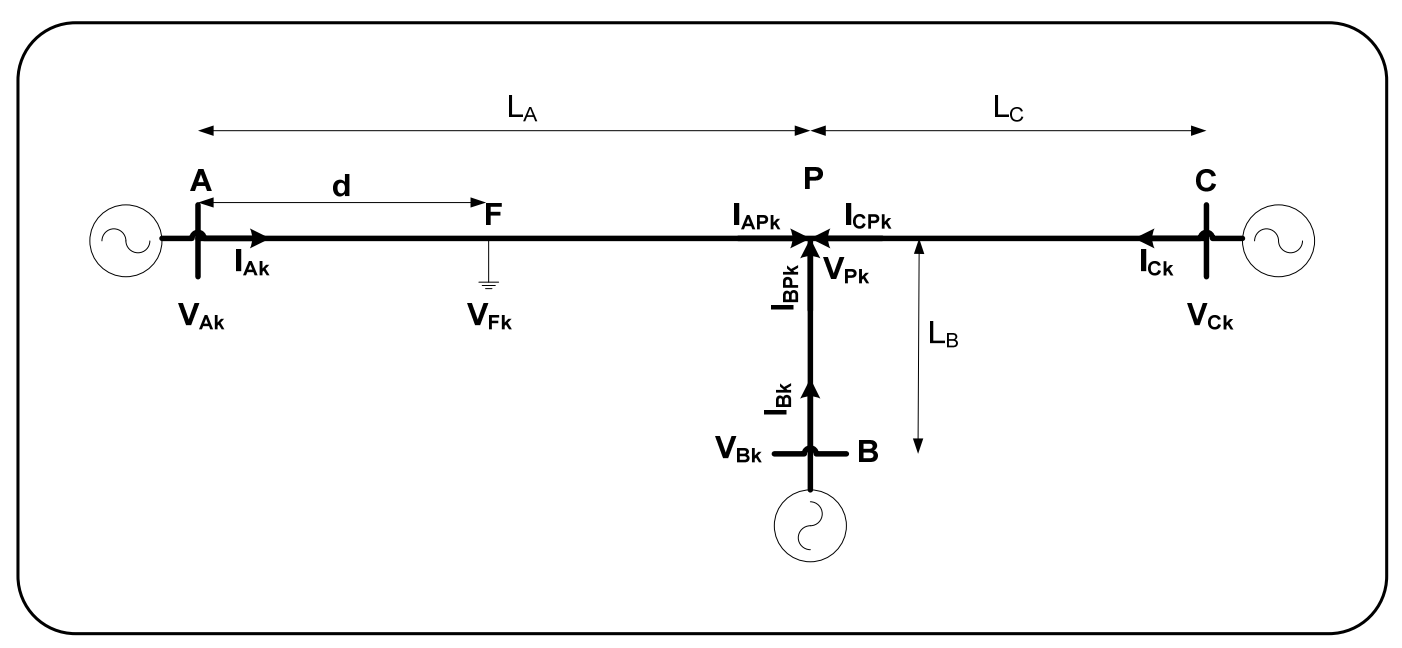

FIGURA 59 - Modelo do sistema sob falta no ramo 1 (AP) 
A tensão no ponto de falta $(\mathrm{F})$ pode ser expressa por:

$$
V_{F k}=\operatorname{Cosh}\left(\gamma_{k} \cdot d\right)-Z_{0 k} \operatorname{Sinh}\left(\gamma_{k} \cdot d\right) \cdot I_{A k}
$$

$\mathrm{Ou}$,

$$
V_{F k}=\operatorname{Cosh}\left(\gamma_{k} L_{A k}-\gamma_{k} \cdot d\right) V_{P k}+Z_{0 k} \operatorname{Sinh}\left(\gamma_{k} L_{P k}-\gamma_{k} \cdot d\right) \cdot I_{A P k}
$$

Temos também que:

$$
\begin{aligned}
V_{P k} & =\operatorname{Cosh}\left(y_{k} \cdot L_{B k}\right) V_{B k}-Z_{0 k} \operatorname{Sinh}\left(\gamma_{k} \cdot L_{B k}\right) I_{B k} \\
I_{A P k} & =Y_{0 k} \operatorname{Sinh}\left(\gamma_{k} \cdot L_{C k}\right) V_{C k}-\operatorname{Cosh}\left(\gamma_{k} \cdot L_{C k}\right) I_{C k} \\
& +Y_{0 k} \operatorname{Sinh}\left(\gamma_{k} \cdot L_{B k}\right) V_{B k}-\operatorname{Cosh}\left(\gamma_{k} \cdot L_{B k}\right) I_{B k}
\end{aligned}
$$

onde $k=0$ para o modo terra, 1 e 2 para os modos aéreos; $\gamma$ a constante de propagação modal; $Z_{0 k}=1 / Y_{0 k}$ a impedância de onda modal; $d$ distância da falta.

Manipulando as Eq. (5.16) à (5.19) obtemos a equação para o cálculo da distância da falta com referência ao terminal A:

$$
d=\frac{\operatorname{Arctanh}\left(D_{k} / C_{k}\right)}{\gamma_{k}}
$$

tal que:

$$
\begin{aligned}
D_{k}= & -V_{A k}+A_{k} \operatorname{Cosh}\left(\gamma_{k} \cdot L_{A k}\right)+Z_{0 k} B_{k} \operatorname{Sinh}\left(\gamma_{k} \cdot L_{A k}\right) \\
C_{k}= & -Z_{0 k} I_{A k}+A_{k} \operatorname{Sinh}\left(\gamma_{k} \cdot L_{A k}\right)+Z_{0 k} B_{k} \operatorname{Cosh}\left(\gamma_{k} \cdot L_{A k}\right) \\
B_{k}= & -\operatorname{Cosh}\left(\gamma_{k} \cdot L_{C k}\right) I_{C k}+Y_{0 k} \operatorname{Sinh}\left(\gamma_{k} \cdot L_{B k}\right) V_{B k} \\
& -\operatorname{Cosh}\left(\gamma_{k} \cdot L_{B k}\right) I_{B k}+Y_{0 k} \operatorname{Sinh}\left(\gamma_{k} \cdot L_{C k}\right) V_{C k} \\
A_{k}= & \operatorname{Cosh}\left(\gamma_{k} \cdot L_{C k}\right) V_{C k}-Z_{0 k} \operatorname{Sinh}\left(\gamma_{k} \cdot L_{C k}\right) I_{C k}
\end{aligned}
$$


De modo análogo, as equações podem ser manipuladas para se obter a distância da falta com relação a qualquer um dos terminais.

O ramo faltoso é determinado resolvendo-se a Eq. (5.18) com relação a todos os terminais. As tensões estimadas no ponto $\mathrm{P}$ com relação aos terminais dos ramos não faltosos serão aproximadamente iguais entre si diferindo-se da tensão estimada no ponto $\mathrm{P}$ para o terminal do ramo faltoso, podendo-se deste modo determinar o terminal faltoso. Caso os valores de tensão no ponto $\mathrm{P}$, estimada com referencia aos três terminais, sejam aproximadamente iguais, indicará que a falta está muito próxima ao ponto de conexão das linhas (ponto P). 



\section{TESTES E RESULTADOS UTILIZANDO O LFHTW 1.01}

O algoritmo de localização completo, LFHTW 1.01 (Localizador de Faltas Hibrido utilizando a TW - versão 1.01), foi implementado através do uso do software Matlab ${ }^{\circledR} \mathrm{e}$ testado usando-se de dados obtidos através de simulações pelo software ATP/EMTP. Como descrito no Capítulo 4, foram considerados vários tipos de faltas, em diferentes localizações das linhas, com diferentes ângulos de incidência e resistências de faltas. No decorrer dos testes também foi avaliada a influência de altas resistências de falta e do acoplamento mútuo entre as fases de um circuito de transmissão duplo vertical, assim como, o desempenho do algoritmo na presença níveis de ruído.

Embora extensivos testes tenham sido realizados para se verificar e comprovar o desempenho do algoritmo localizador de faltas proposto, a grande maioria destes foram aplicados para testes sobre o algoritmo baseado em ondas viajantes, por ser este o algoritmo principal. Além disso, como o montante de teste é muito expressivo, somente uma parte destes, com seus respectivos comentários, serão apresentados no corpo deste documento.

Os resultados serão apresentados conforme o método de localização utilizado, e serão ilustrados através de tabelas, gráficos, histogramas, etc. Ressalta-se que os gráficos dos erros, refletirão o erro médio das distâncias estimadas com relação ao terminal de referência, e os demais terminais quando da apresentação dos resultados utilizando o método de ondas viajantes. Nos demais casos, os gráficos refletirão o erro percentual simples, calculado com relação ao comprimento das linhas AC que formam o sistema de três terminais. 


\subsection{Resultados preliminares utilizando-se do algoritmo baseado em ondas viajantes}

Assumindo o registro dos sinais de corrente ou tensão nos três terminais do sistema, com a correta sincronização por GPS, uma falta fase-terra é simulada a $70 \mathrm{~km}$ da barra $\mathrm{A}$, com um ângulo de incidência de zero grau e resistência de falta de $100 \Omega$. A velocidade de propagação da onda referente ao modo aéreo 1 do sistema de transmissão simples horizontal equivale a 2,931659E5 km/s. A Figura 60 ilustra os sinais de detalhe 2 do modo 1 da corrente para cada terminal do sistema (A, B e C), respectivamente. Com base na análise destes sinais, os tempos de chegada da primeira onda nos terminais foram estimados como sendo: $t_{A}=28,6419 \mathrm{~ms}, t_{B}=28,9502 \mathrm{~ms}$ e $t_{C}=29,0169 \mathrm{~ms}$. No passo seguinte, o localizador identifica corretamente o ramo faltoso (ramo 1 ou AP) e estima a localização da falta conforme a Eq. (5.9). Para este caso, a falta foi localizada a $69,81 \mathrm{~km}$ da barra $\mathrm{A}$, com relação à barra $\mathrm{B}$, ou a 70,03 km da barra $\mathrm{A}$ com relação à barra C. O erro percentual foi de respectivamente $0,076 \%$ e $0,012 \%$ do comprimento do ramo faltoso. Quanto ao erro médio absoluto e relativo, estes foram de 69,92 km e $0,032 \%$.

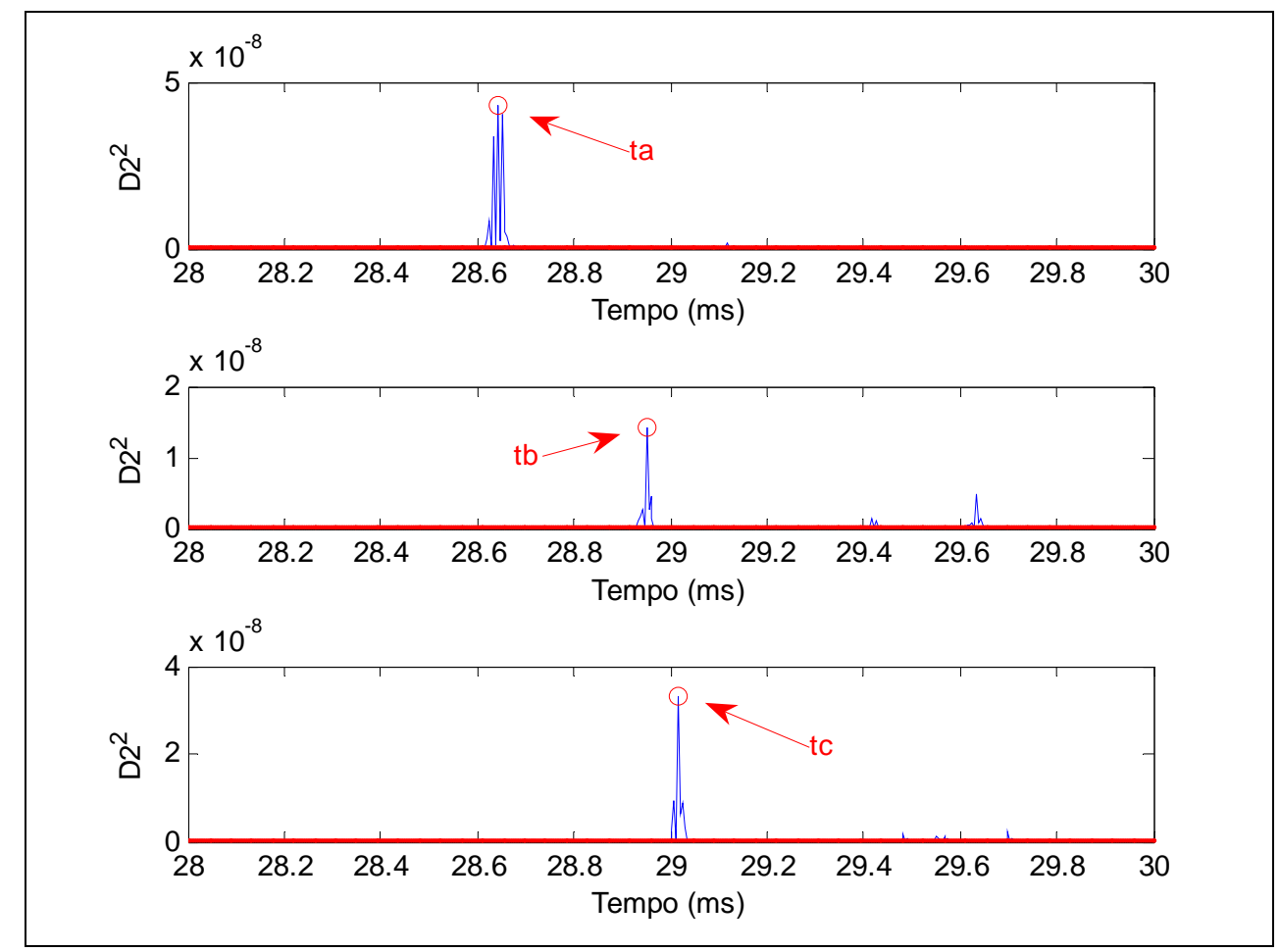

FIGURA 60 - Sinais de detalhe 2 do modo 1 das correntes nos três terminais para uma falta fase Aterra a $70 \mathrm{~km}$ da barra A, com resistência de falta de 100 ohms e ângulo de incidência de $0^{\circ}$. 
De maneira análoga ao descrito anteriormente, temos neste exemplo a mesma situação de falta fase-terra simulada a $70 \mathrm{~km}$ da barra A, com um ângulo de incidência de zero grau e resistência de falta de $100 \Omega$, porém, empregando para a localização da falta os sinais de tensão. Neste caso, os tempos de chegada da primeira onda nos terminais foram estimados como sendo: $t_{A}=28,6336 \mathrm{~ms}, t_{B}=28,9502 \mathrm{~ms}$ e $t_{C}=29,0169 m s$, conforme ilustra a Figura 61. Utilizando os sinais de tensão, a falta foi localizada a 68,59 km da barra $\mathrm{A}$, com relação à barra $\mathrm{B}$, ou a 68,81 km da barra $\mathrm{A}$ com relação à barra $\mathrm{C}$. Os erros percentuais em relação aos terminais $\mathrm{AB}$ e $\mathrm{AC}$ foram de $0,56 \%$ e $0,48 \%$ respectivamente. Quanto ao erro médio absoluto e relativo, estes foram de $68,70 \mathrm{~km} \mathrm{e} 0,52 \%$.

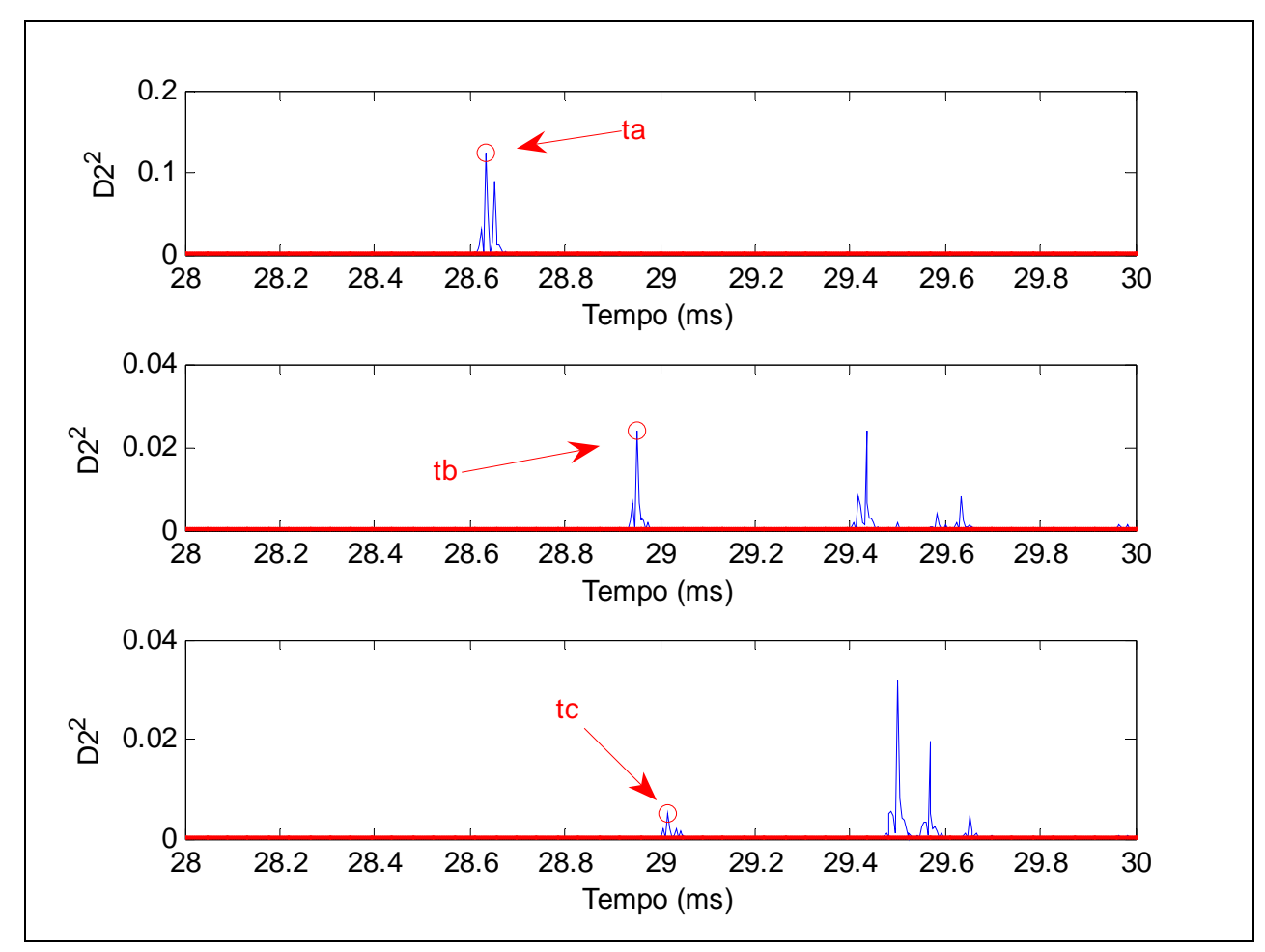

FIGURA 61 - Sinais de detalhe 2 do modo 1 das tensões nos três terminais para uma falta fase A-terra a $70 \mathrm{~km}$ da barra A, com resistência de falta de 100 ohms e ângulo de incidência de $0^{\circ}$.

Nos dois exemplos apresentados, pode-se notar a grande habilidade da TW em detectar com precisão o instante da chegada das primeiras ondas, o que possibilitou um grande desempenho do algoritmo quanto à identificação do ramo e da precisa localização da falta. A TW também se mostrou adequada quando utilizada nos estágios de detecção e classificação do distúrbio, de forma que ambos os estágios responderam acertadamente à situação aplicada. 
Ao considerarmos as mesmas situações anteriores aplicadas ao algoritmo baseado em ondas viajantes utilizando apenas dados locais (sem comunicação), a falta foi localizada a $69,63 \mathrm{~km}(0,148 \%)$ da barra A, analisando os sinais de corrente e, a $70,84 \mathrm{~km}(0,36 \%)$, analisando os sinais de tensão.

\subsubsection{Influência dos diferentes tipos de faltas}

É imprescindível verificarmos se os diferentes tipos de faltas (10 tipos) influenciam no desempenho do algoritmo localizador, principalmente no caso de faltas fase-terra, já que estas são predominantes nos diversos tipos de configurações de linhas de transmissão. Essa predominância é ainda mais acentuada em linhas de alta tensão, uma vez que os grandes espaçamentos entre os condutores dificultam o surgimento de faltas bifásicas ou trifásicas.

Uma série de testes foi realizada com o intuito de se verificar a influência do tipo da falta. Destes testes podemos destacar os ilustrados pelas Figuras 62 a 65, onde temos os resultados para 04 diferentes situações faltosas aplicadas ao longo da linha 1 (AP) utilizando dados dos três terminais. Cabe ressaltar que para estes testes, somente os sinais de corrente foram analisados. Pode-se verificar que a variação do tipo da falta apenas não influência significativamente o desempenho do método de ondas viajantes utilizando dados sincronizados dos três terminais, uma vez que, a maioria dos erros ficou abaixo de $1,0 \%$.

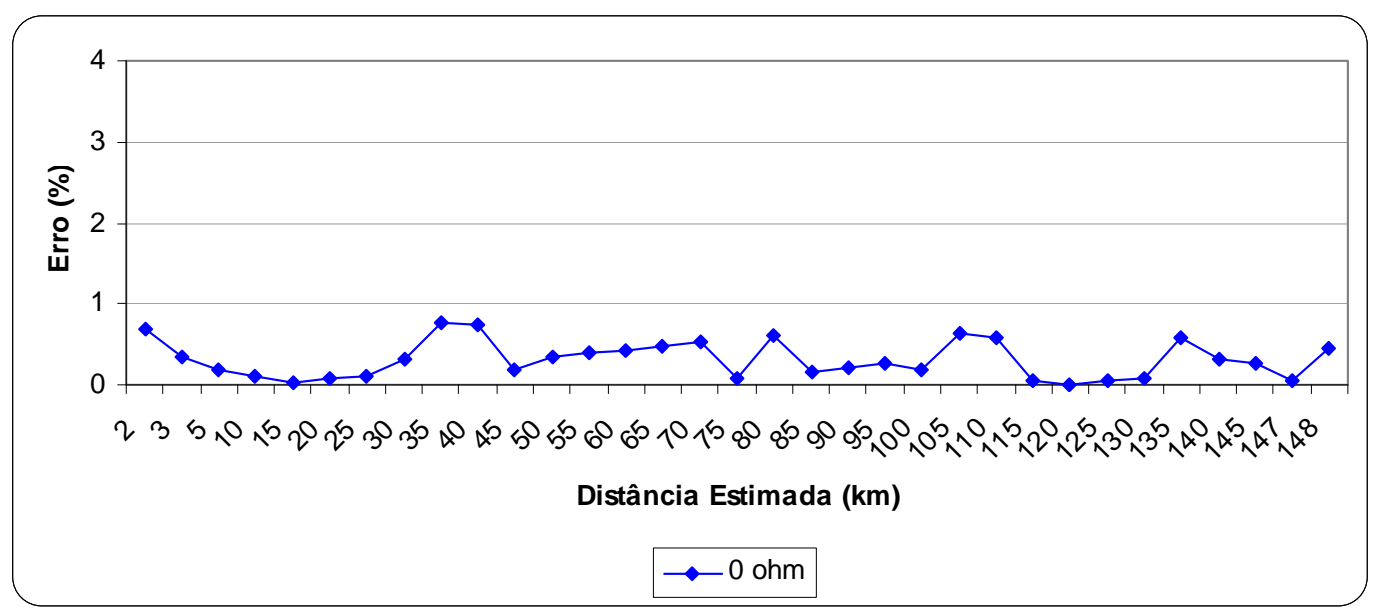

FIGURA 62 - Resultados referentes à aplicação de faltas AT em diferentes localizações do ramo 1, com resistência de falta de $0 \mathrm{ohm}$ e ângulo de incidência de $90^{\circ}$ - Dados 3 terminais. 


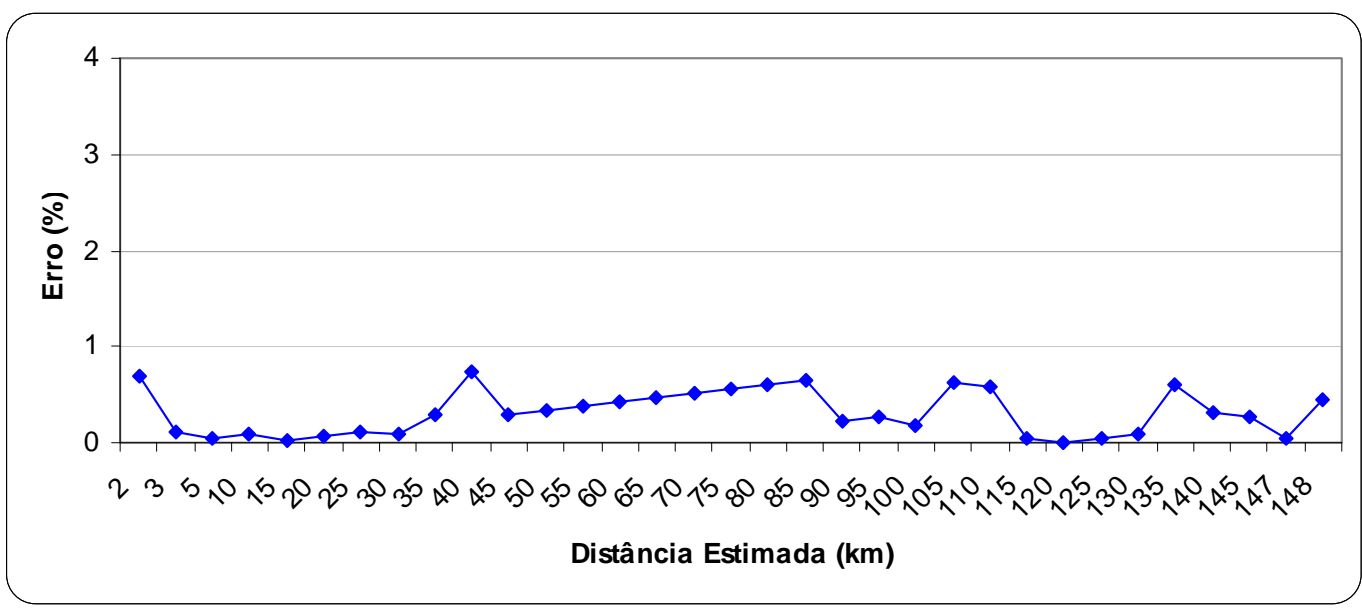

FIGURA 63 - Resultados referentes à aplicação de faltas ABT em diferentes localizações do ramo 1, com resistência de falta de 0 ohm e ângulo de incidência de $90^{\circ}$ - Dados 3 terminais.

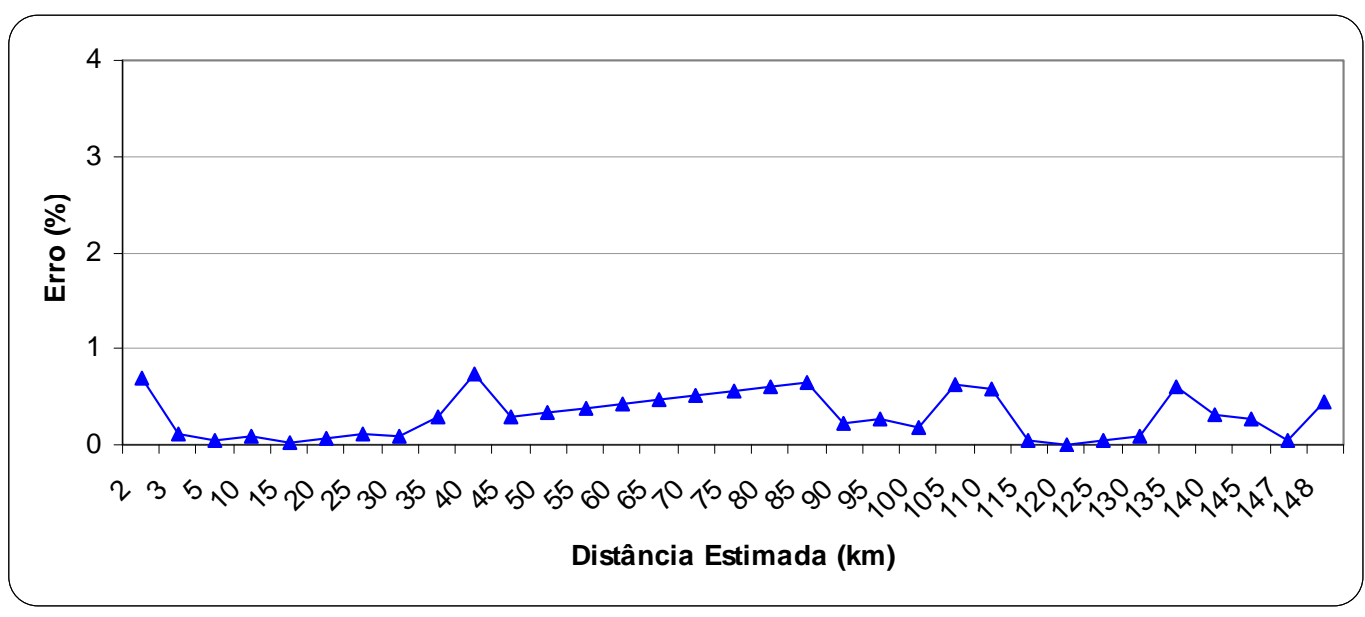

FIGURA 64 - Resultados referentes à aplicação de faltas AB em diferentes localizações do ramo 1, com ângulo de incidência de $90^{\circ}$ - Dados 3 terminais.

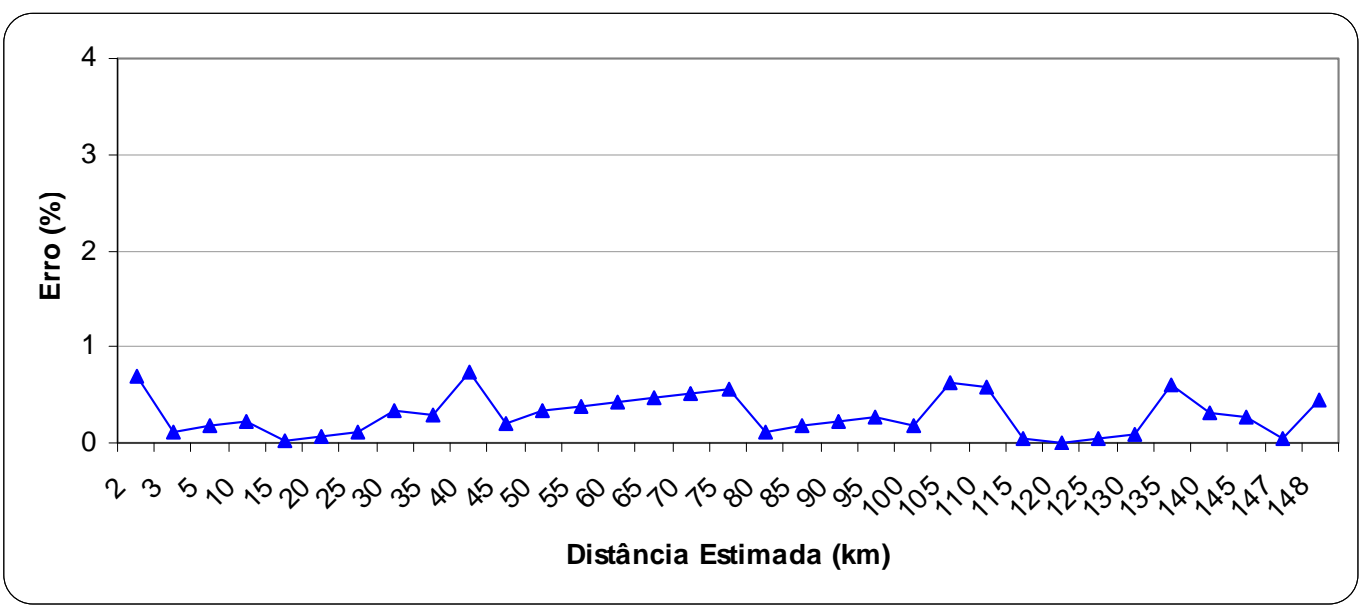

FIGURA 65 - Resultados referentes à aplicação de faltas trifásicas em diferentes localizações do ramo 1, com ângulo de incidência de $90^{\circ}$ - Dados 3 terminais. 
O método de ondas viajantes utilizando dados locais (um terminal) também se mostrou pouco sensível a variação do tipo da falta, conforme ilustra os resultados apresentados nas Figuras de 66 a 69. Nestas mesmas Figuras, excetuando-se as faltas aplicadas próximas ao barramento, notamos que todos os erros mantiveram-se na faixa de até $1,0 \%$.

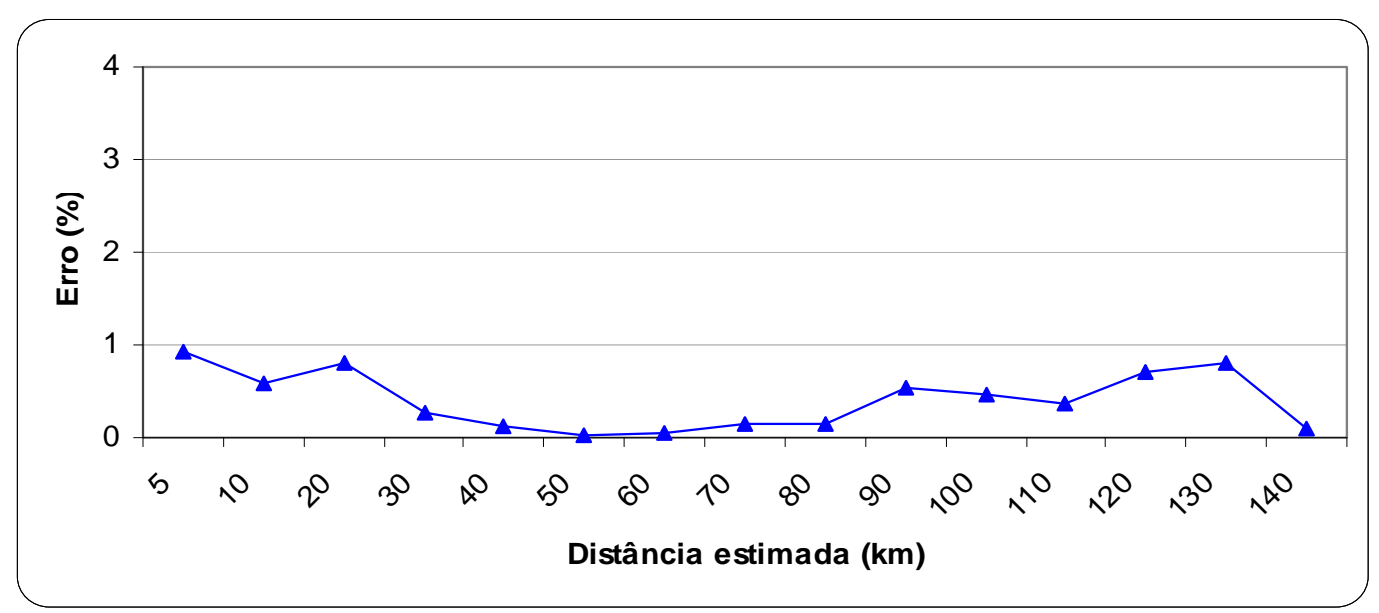

FIGURA 66 - Resultados referentes à aplicação de faltas AT em diferentes localizações do ramo 1, com resistência de falta de 0 ohm e ângulo de incidência de $90^{\circ}$ - Dados Locais.

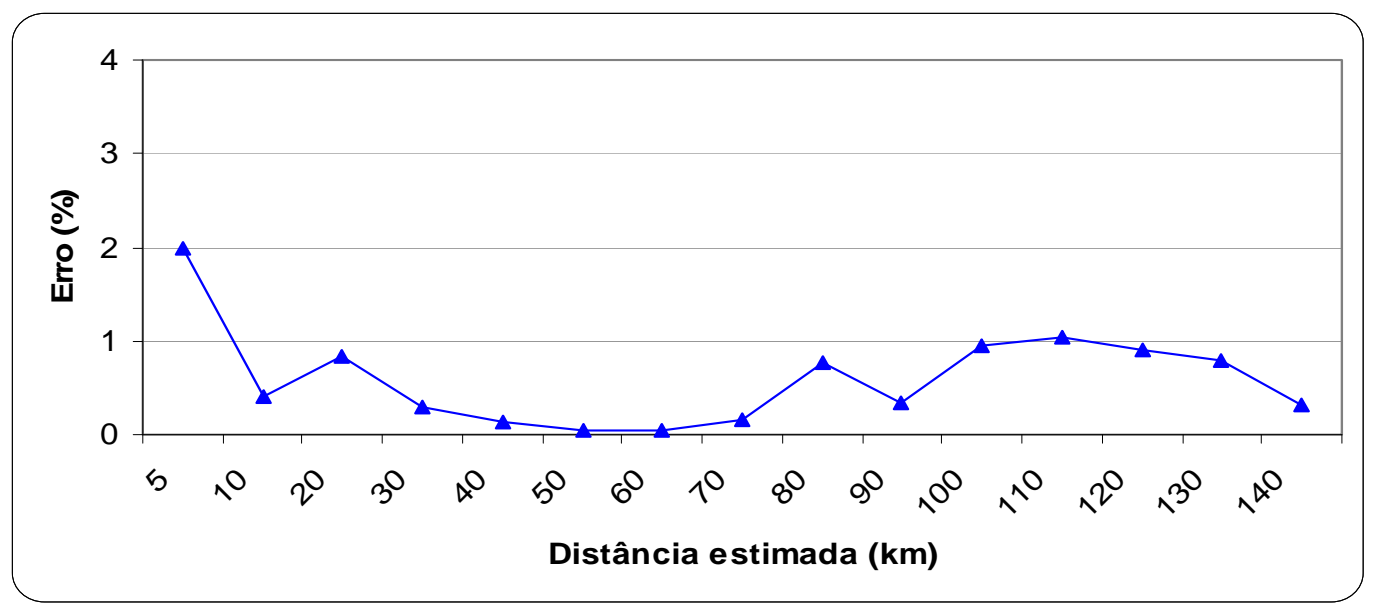

FIGURA 67 - Resultados referentes à aplicação de faltas ABT em diferentes localizações do ramo 1, com resistência de falta de 0 ohm e ângulo de incidência de $90^{\circ}$ - Dados locais. 


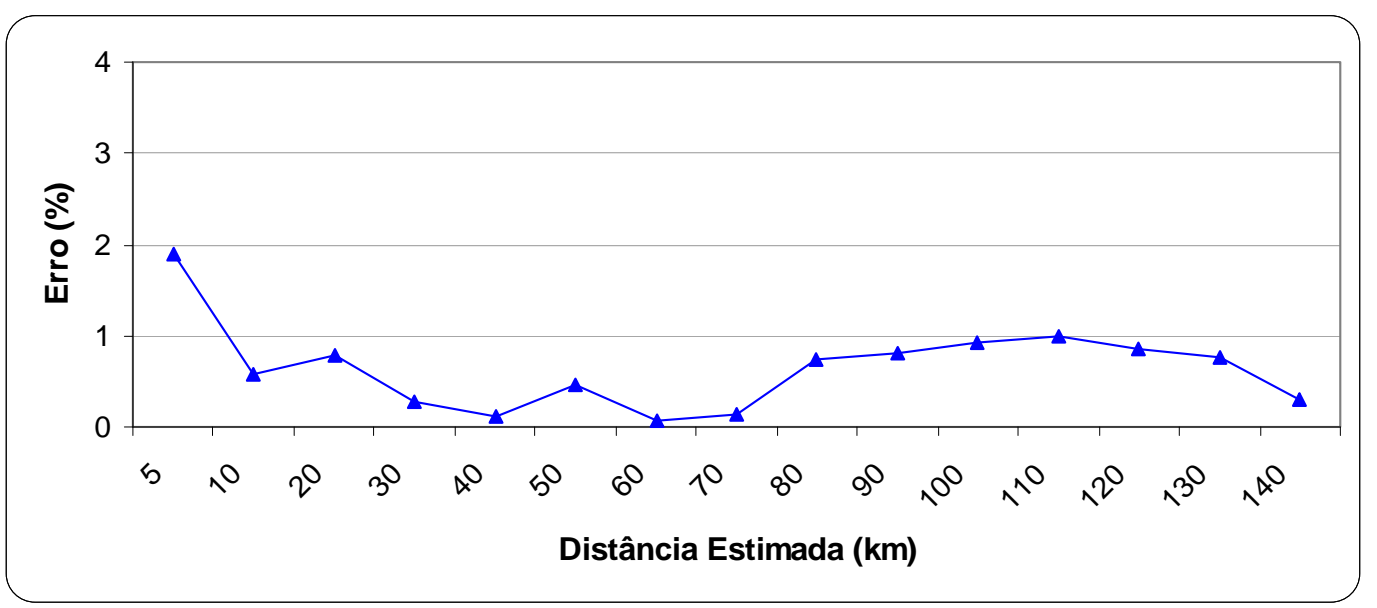

FIGURA 68 - Resultados referentes à aplicação de faltas AB em diferentes localizações do ramo 1, com ângulo de incidência de $90^{\circ}$ - Dados locais.

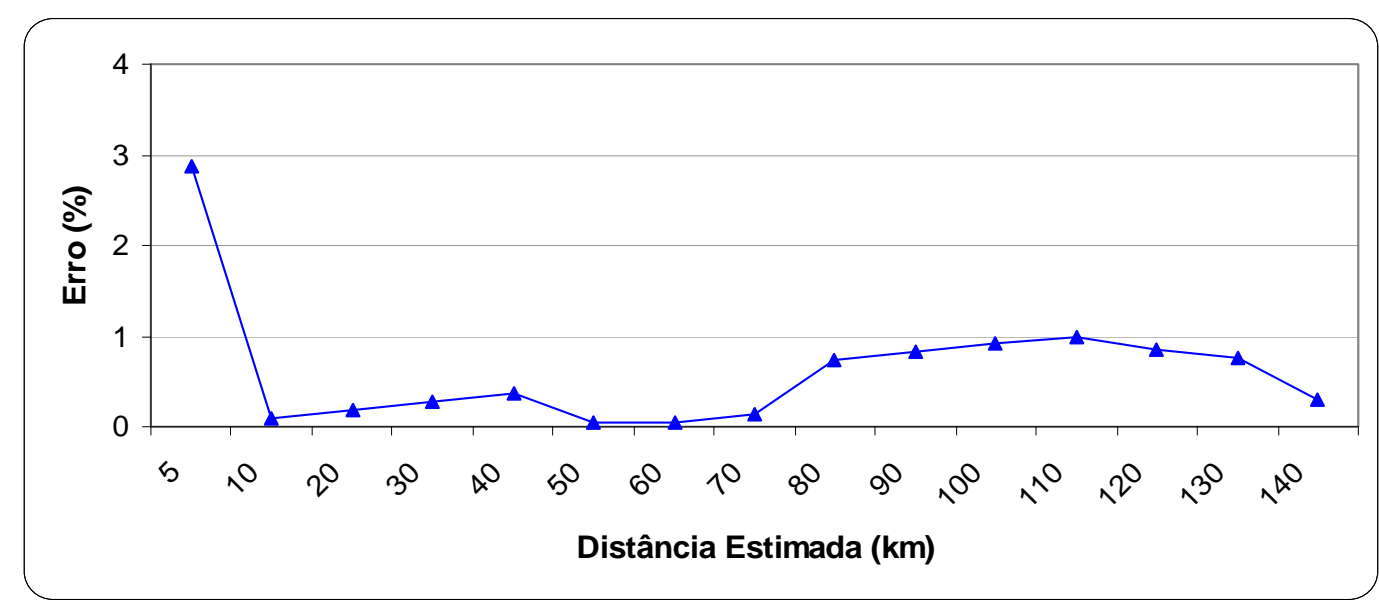

FIGURA 69 - Resultados referentes à aplicação de faltas trifásicas em diferentes localizações do ramo 1, com ângulo de incidência de $90^{\circ}$ - Dados locais.

Pode-se inferir que, de uma maneira geral, o algoritmo proposto baseado em ondas viajantes, em seus módulos com ou sem comunicação, é praticamente insensível do tipo de falta aplicado, o que já era esperado.

Afirma-se que as mesmas conclusões são validas, quando utilizados os sinais de tensão para se localizar a falta.

\subsubsection{Influência do terminal de referência}

Como foi anteriormente delineado, a localização da falta é dada com referência ao terminal faltoso, o qual pode influenciar o desempenho do algoritmo devido ao valor 
da impedância equivalente da fonte e de uma má caracterização da chegada da primeira e/ou segunda onda nos terminais da linha.

No primeiro caso, quanto maior o valor da impedância, menor será o coeficiente de refração da barra, consequentemente, menor será o pulso (amplitude) de corrente a ser detectado. Quando trabalhamos com os sinais de tensão, vale o contrário do que foi expresso, ou seja, quanto maior a impedância, maior será o pulso de tensão a ser apontado. Em geral, não é comum haver um grau de desequilíbrio muito acentuado em relação às impedâncias dos respectivos terminais. Nos testes realizados, não se buscou avaliar a influência da impedância das fontes, uma vez que se tomou por base valores fixos e aproximados para as três barras.

$\mathrm{Na}$ segunda situação, a chegada da onda no terminal do sistema pode ser um pouco descaracterizada, em decorrência de atenuações e distorções da onda. Isto pode levar a uma detecção da chegada da onda não tão precisa, com um erro na ordem de uma a três amostras, o que acarretará em uma leve imprecisão na localização da falta.

A seguir, são apresentados resultados de alguns testes, tomando-se por base o terminal de referência e os demais terminais para se localizar a falta (Figuras 70-72), assim como, apenas o terminal local (Figuras 73-75).

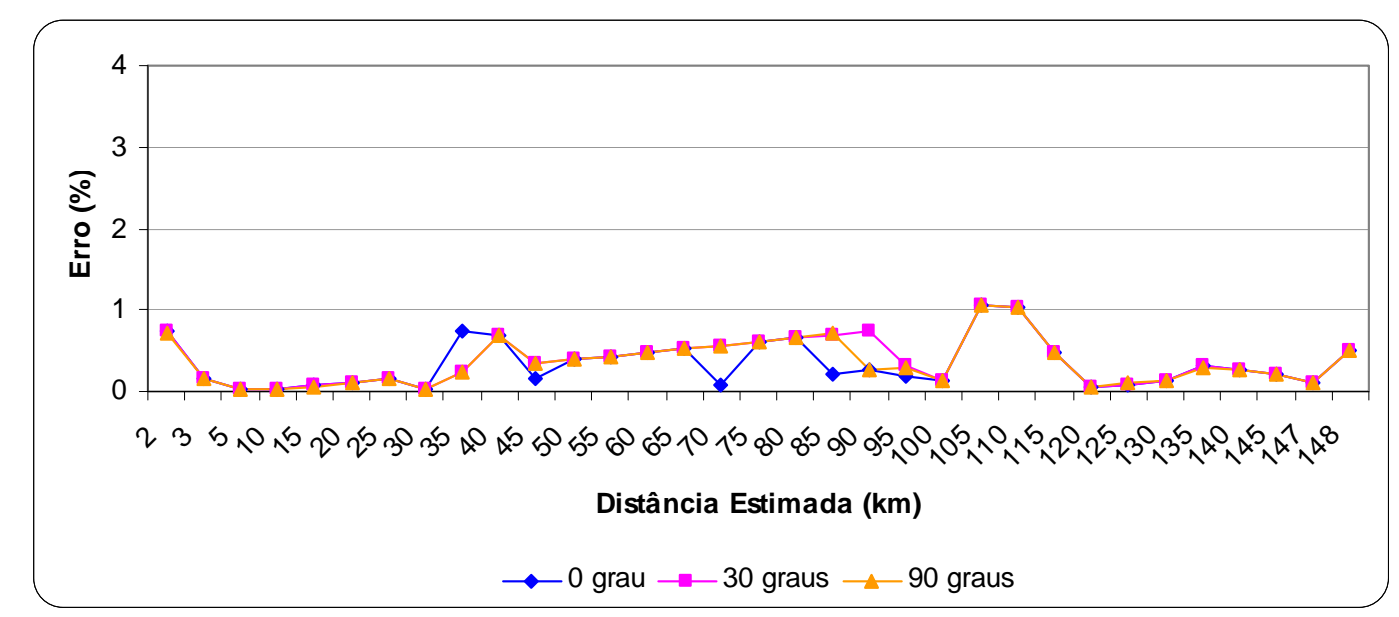

FIGURA 70 - Resultados obtidos com referência ao terminal A em relação ao terminal B, para faltas fase-fase aplicadas no ramo 1 -dados sincronizados. 


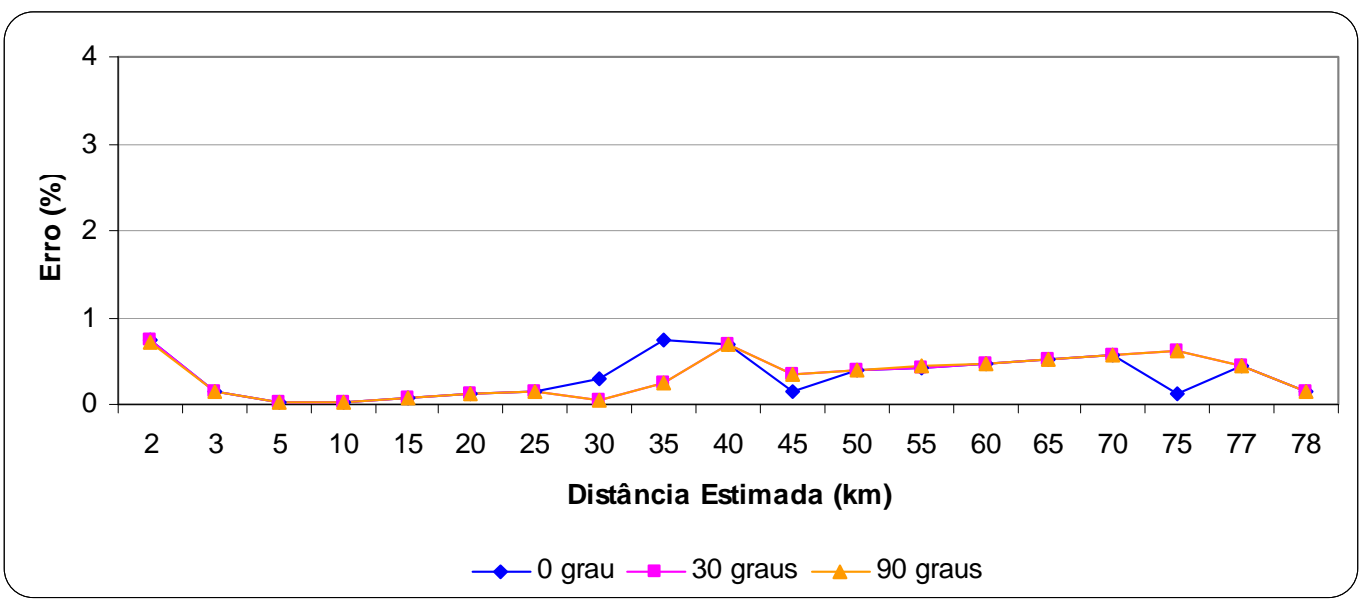

FIGURA 71 - Resultados obtidos com referência ao terminal B em relação ao terminal A, para faltas fase-fase aplicadas no ramo 2 - dados sincronizados.

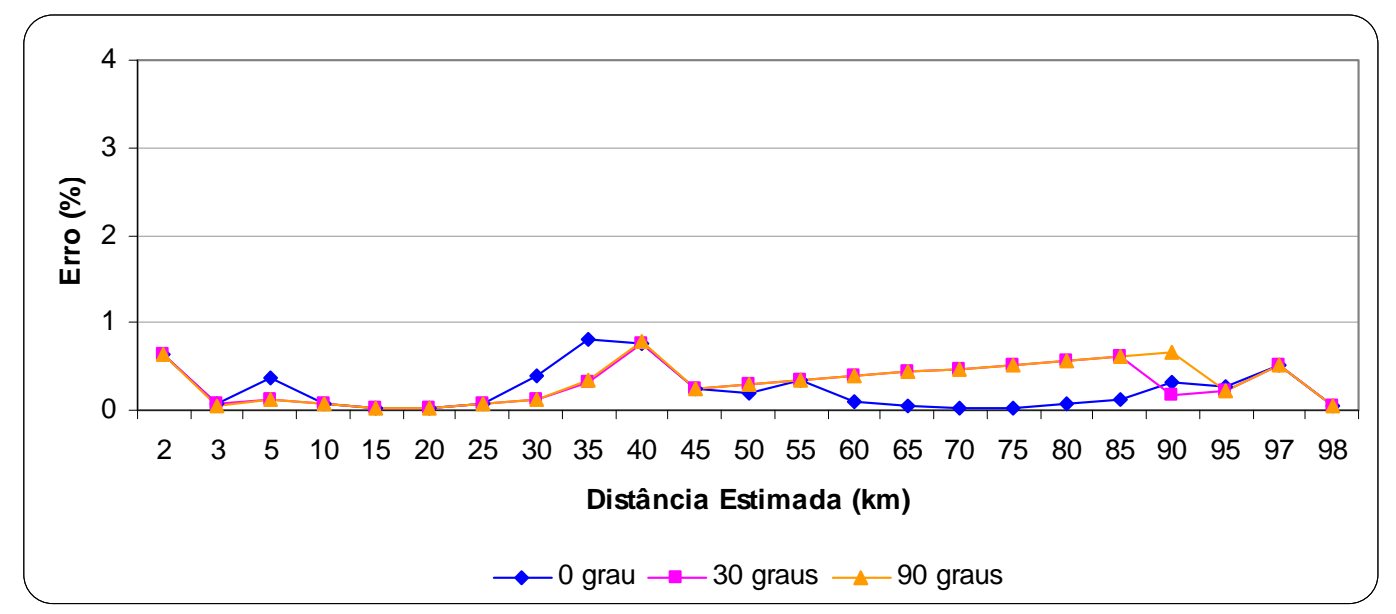

FIGURA 72 - Resultados obtidos com referência ao terminal C em relação ao terminal A, para faltas fase-fase aplicadas no ramo 3 - dados sincronizados.

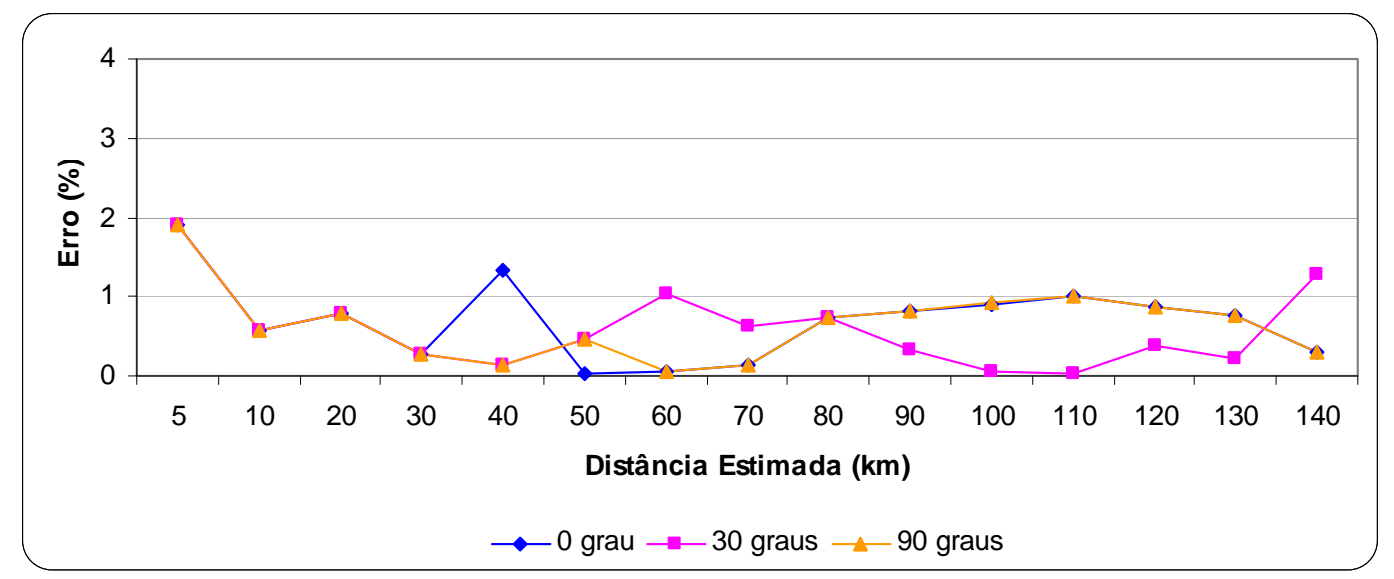

FIGURA 73 - Resultados obtidos com referência ao terminal A, para faltas fase-fase aplicadas no ramo 1 -dados locais. 


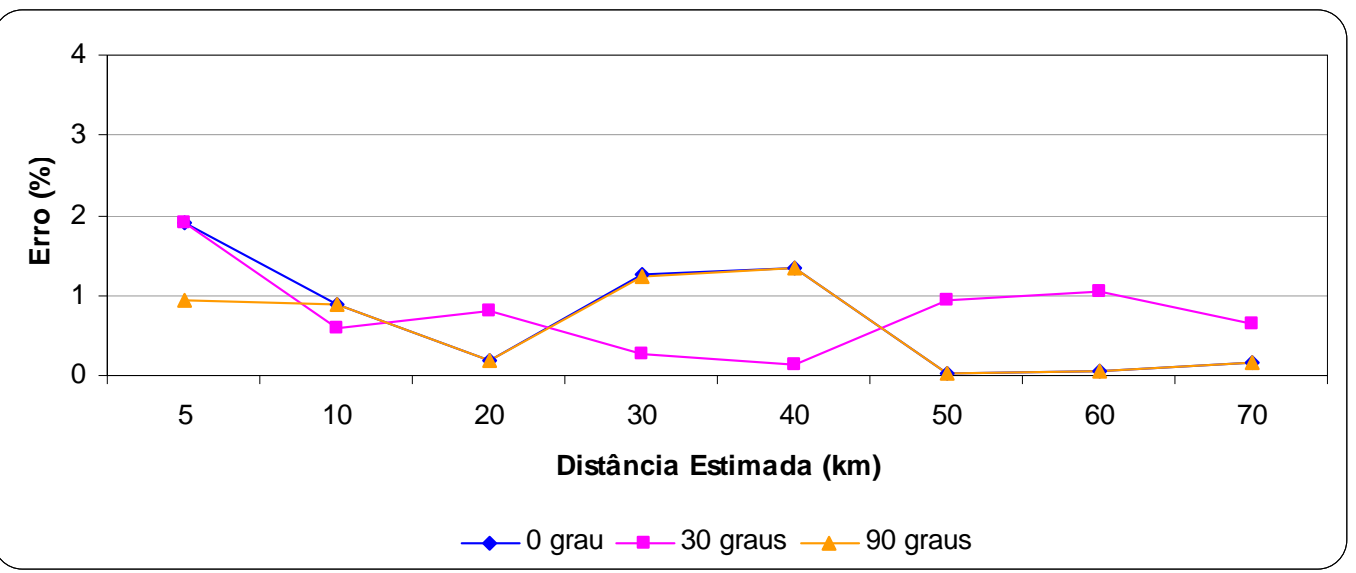

FIGURA 74 - Resultados obtidos com referência ao terminal B, para faltas fase-fase aplicadas no ramo 2 - dados locais.

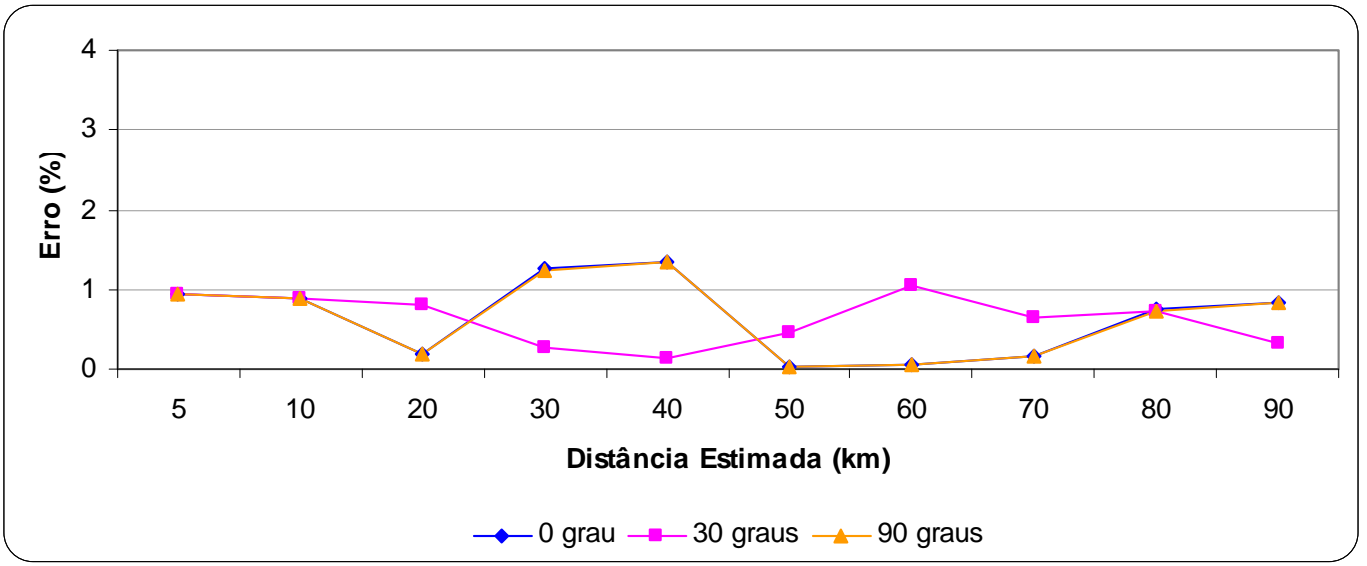

FIGURA 75 - Resultados obtidos com referência ao terminal C, para faltas fase-fase aplicadas no ramo 3 - dados locais.

Ao comparamos os resultados apresentados, de uma forma generalizada, podemos afirmar que existem pequenas diferenças ao se localizar a falta dado o terminal de referência, devido em grande parte a certa imprecisão na detecção da chegada das ondas nos terminais do sistema. Ambos os algoritmos, com dados provenientes de um ou dos três terminais, mostram um bom comportamento na situação em analisada.

\subsubsection{Influência do ângulo de incidência da falta}

Na prática, as faltas podem ter origem em qualquer ponto da forma de onda da corrente ou da tensão, podendo ser desde um valor mínimo (onda passando por zero), até um valor máximo (forma de onda passando por um máximo positivo a $90^{\circ}$ ou negativo a $270^{\circ}$ ) na fase ou fases faltosas. 
Do ponto de vista de distorções devido às ondas viajantes, uma melhor análise será decorrente da presença de faltas próximas do ponto de máximo da corrente ou da tensão. Neste ponto de máximo, a caracterização de ambas as ondas será marcante. No outro extremo, quando as faltas ocorrem próximas ou na tensão passando por zero, as ondas viajantes são extremamente atenuadas, devido à forma de onda não ter uma grande e repentina mudança.

Com respeito à influência do ângulo de incidência da falta sobre o desempenho do algoritmo baseado em ondas viajantes, os testes demonstraram que são alcançados melhores resultados quando a inserção da falta não ocorre muito próxima do valor mínimo (próximo à zero). Todavia, de uma maneira geral, quando o ângulo de inserção da falta não está associado a outros parâmetros que também podem afetar o algoritmo, o desempenho do algoritmo, dado a sua precisão, é praticamente independente do ângulo de incidência da falta. Tal observação pode ser comprovada, por exemplo, através dos resultados apresentados pelas Figuras 76 e 77, para as quais se utilizou dados de corrente e tensão dos três terminais, e pelas Figuras 78 e 79 onde foram analisados os sinais de corrente e tensão obtidos localmente. Para estes testes, foram aplicadas faltas fase-fase ao longo de todo o comprimento do ramo 1, levando-se em conta diferentes ângulos de inserção da falta. Analisando os resultados apresentados pelas Figuras supracitadas, observa-se que tanto para os sinais de corrente, como para os de tensão, provenientes de um ou mais terminais, a maioria dos erros foi inferior a 1,0\% e que, realmente, a variação do ângulo não traz significativas alterações na precisão do método.

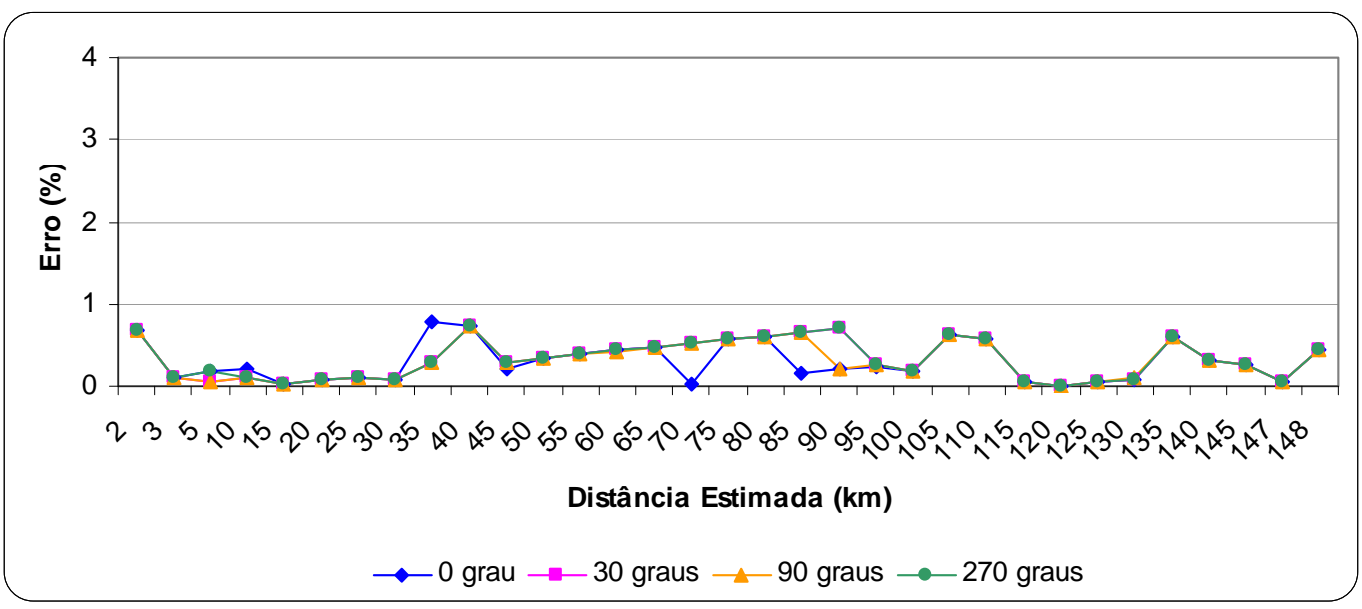

FIGURA 76 - Influência do ângulo incidência da falta sobre os sinais de corrente frente situações de faltas fase-fase (AB) aplicadas sobre o ramo 1 - dados sincronizados. 


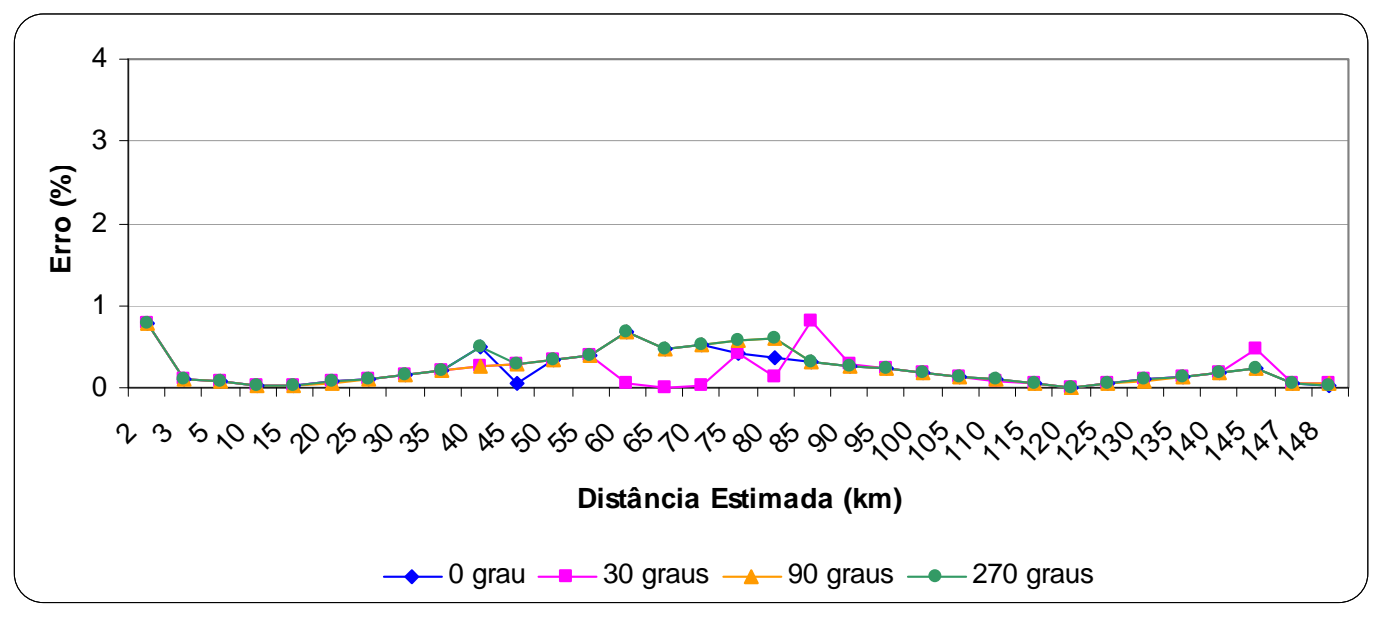

FIGURA 77 - Influência do ângulo incidência da falta sobre os sinais de tensão frente situações de faltas fase-fase (AB) aplicadas sobre o ramo 1 - dados sincronizados.

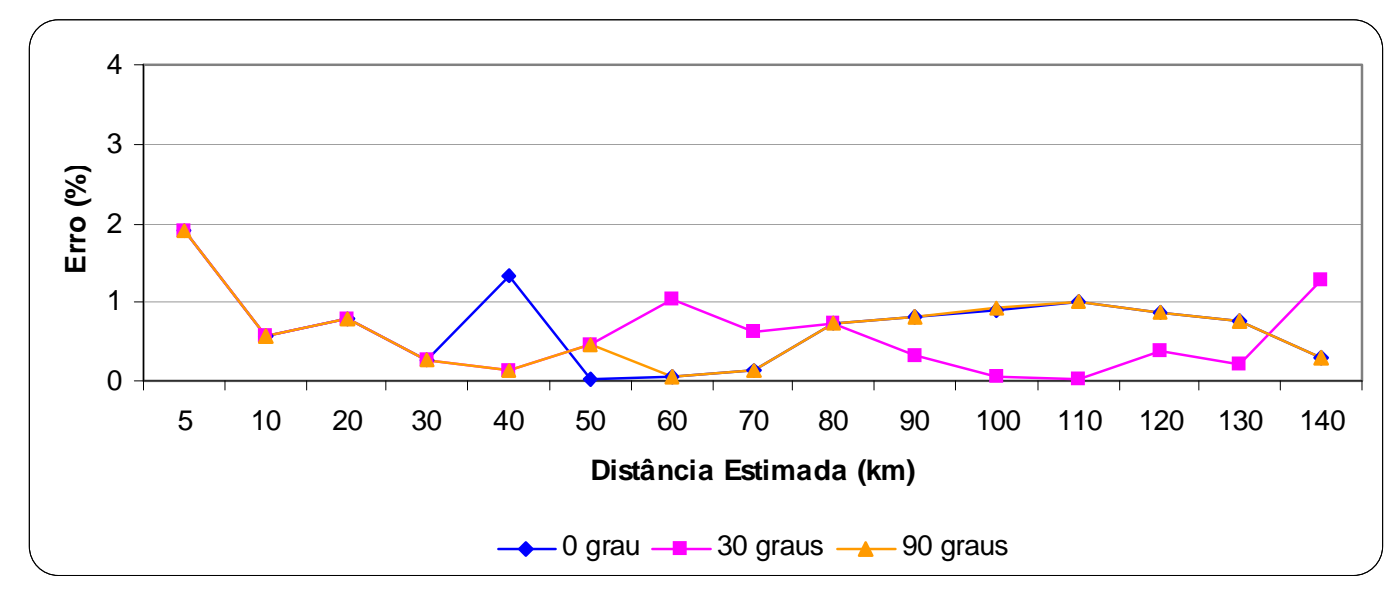

FIGURA 78 - Influência do ângulo incidência da falta sobre os sinais de corrente frente situações de faltas fase-fase (AB) aplicadas sobre o ramo 1 -dados locais.

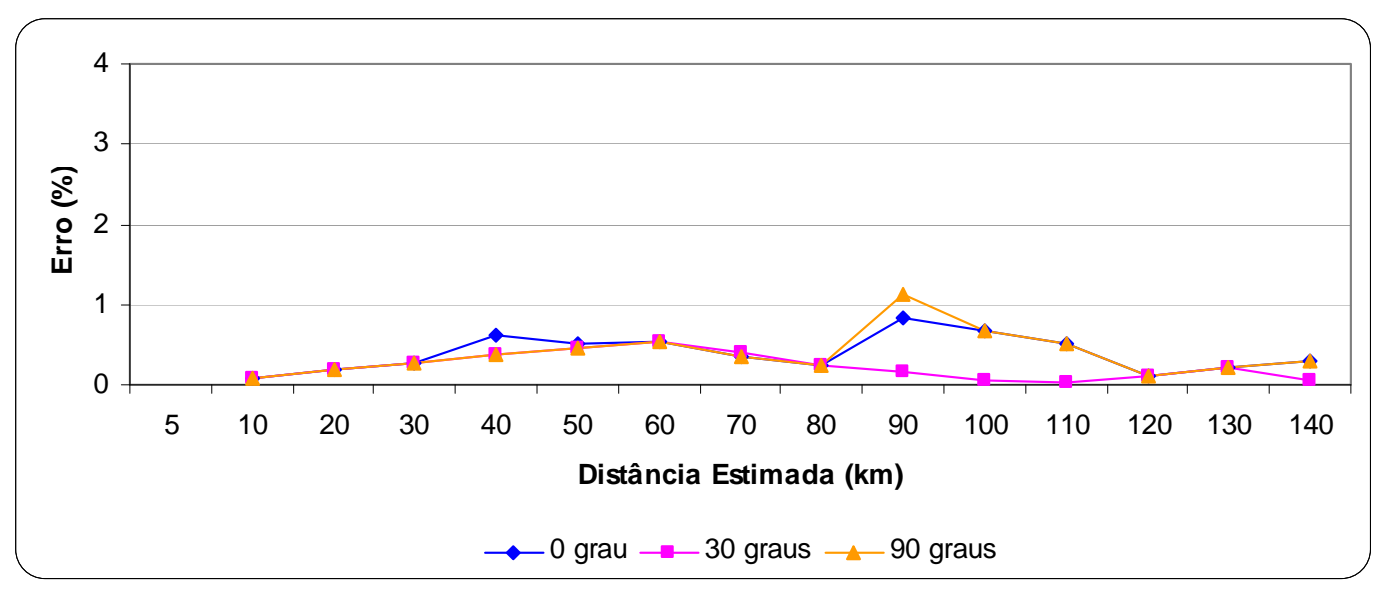

FIGURA 79 - Influência do ângulo incidência da falta sobre os sinais de tensão frente situações de faltas fase-fase $(A B)$ aplicadas sobre o ramo 1 -dados locais. 


\subsubsection{Influência da resistência de falta}

Uma vez que há predominância de faltas fase-terra, é de suma importância verificar se o cálculo da localização de falta não é significantemente influenciado pelas mudanças na resistência de falta. Com este intuito, foram realizados vários testes considerando valores práticos de resistências, como: 0,1, 17, 30, 50 e 100 ohms, assim como, valores elevados, como: 200, 400 e 800 ohms, para caracterizar situações de altas impedâncias.

As Figuras 80 a 82 ilustram alguns resultados de testes efetuados utilizando-se dos sinais de corrente provenientes dos três terminais, dado condições de faltas faseterra aplicadas sobre o ramo 3.

Para as situações apresentadas, assim como nos demais testes realizados, o desempenho global do algoritmo foi altamente satisfatório. Pode-se observar também que, a resistência não causa grande influência na precisão do algoritmo. Contudo, percebe-se que quando da combinação entre os parâmetros da resistência de falta e baixo ângulo de incidência, a precisão do algoritmo pode ser influenciada, a ponto de apresentar erros mais elevados ou mesmo não localizar a falta. Embora estes casos sejam ocasionais, geralmente ocorreram para faltas fase-terra próximas aos terminais do sistema. Já para as situações de faltas fase-fase-terra aplicadas, não se evidenciou problemas associados à combinação dos parâmetros mencionados.

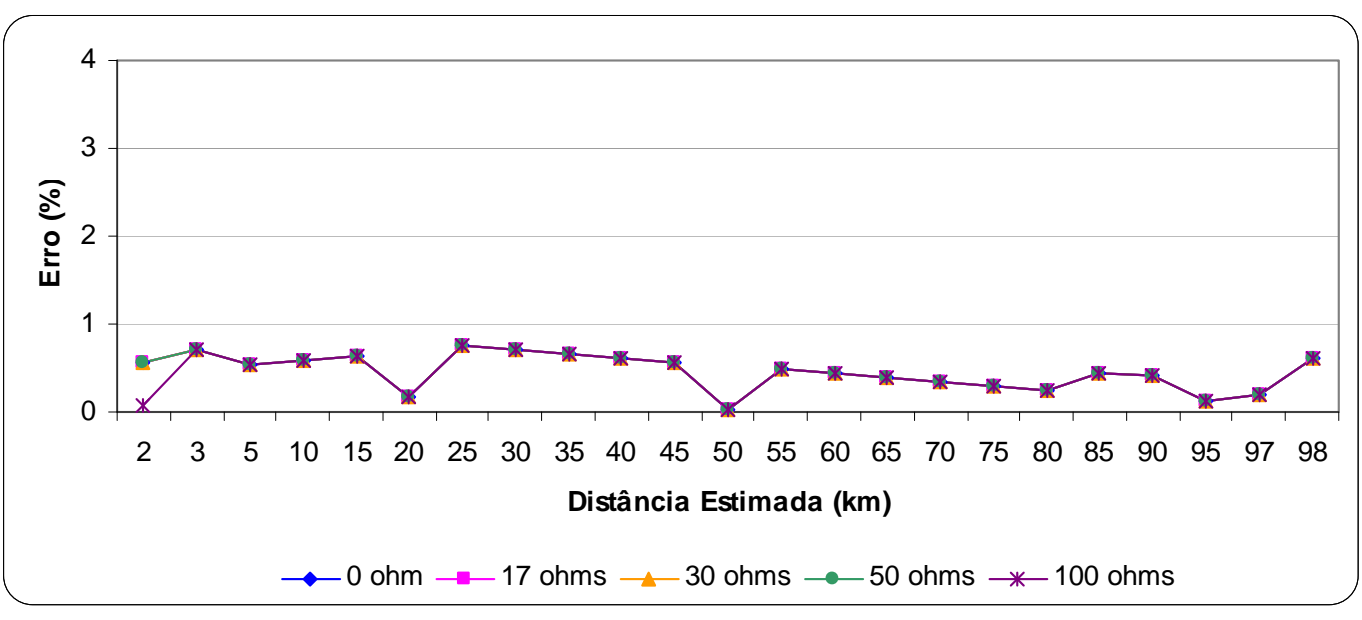

FIGURA 80 - Resultados médios referentes às situações de faltas fase-terra aplicadas sobre o ramo 3, com ângulo de incidência de $0^{\circ}$ e variação da resistência de falta em 0, 17, 30, 50 e $100 \mathrm{ohms}$. 


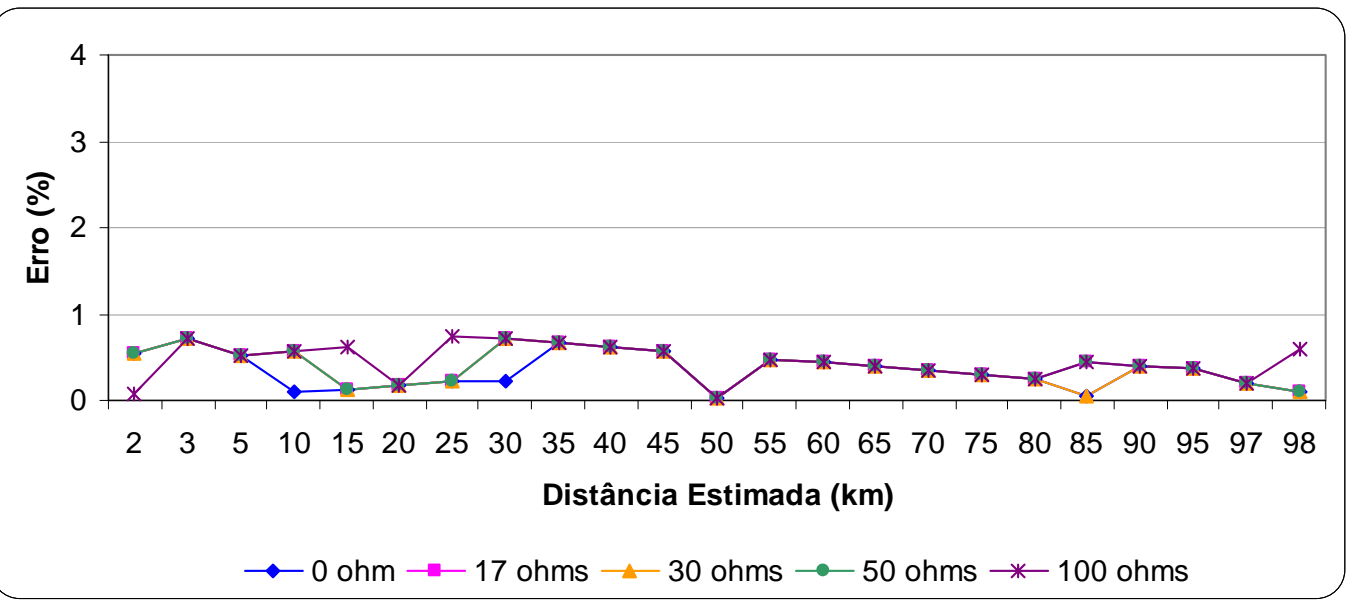

FIGURA 81 - Resultados médios referentes a situações de faltas fase-terra aplicadas sobre o ramo 3 com ângulo de incidência de $30^{\circ}$ e variação resistência de falta em 0, 17, 30, 50 e $100 \mathrm{ohms}$.

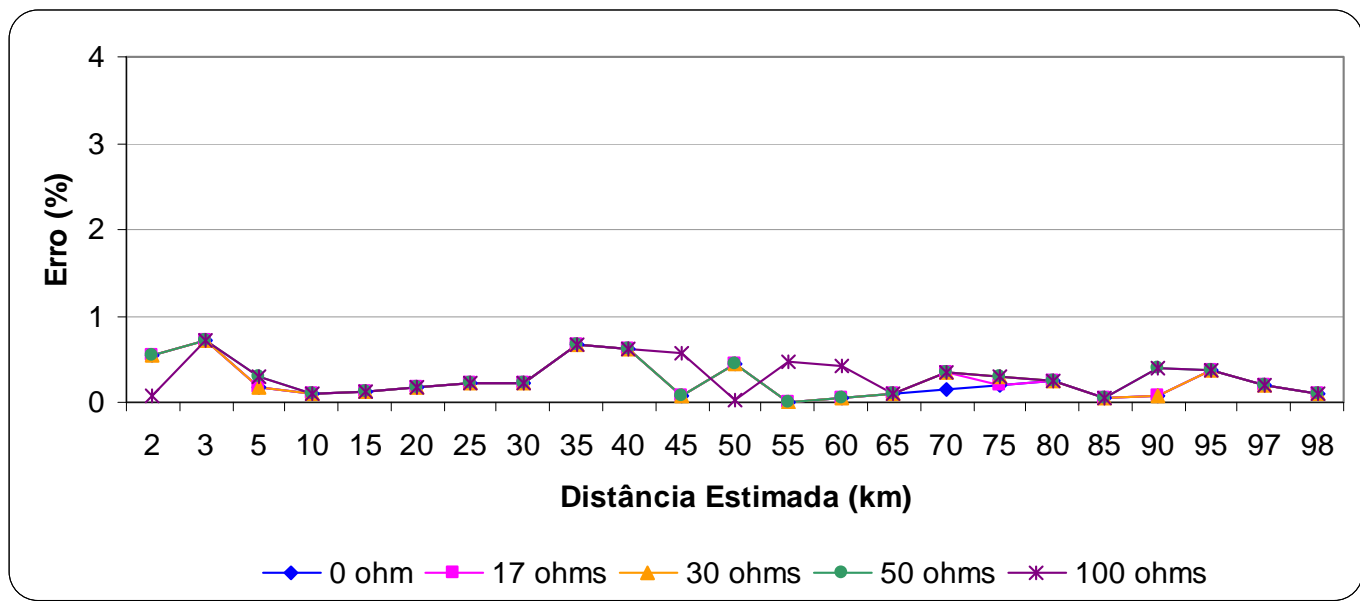

FIGURA 82 - Resultados médios referentes a situações de faltas fase-terra aplicadas sobre o ramo 3 com ângulo de incidência de $90^{\circ}$ e variação da resistência de falta em 0, 17, 30, 50 e 100 ohms.

A fim de confirmar o desempenho do algoritmo e da técnica em questão, o mesmo também foi exposto às situações de faltas fase-terra e fase-fase-terra, considerando-se elevadas resistências de faltas (200, 400 e 800 ohms), que apesar de serem incomuns, podem vir a se manifestar sobre os sistemas elétricos.

Ainda com uma análise sobre os sinais de corrente, para estes casos, o algoritmo dispondo dos dados dos três terminais também manteve uma ótima precisão conforme podemos verificar pelas Figuras 83 a 85 . Estas apresentam alguns casos de faltas A-terra aplicadas sobre o ramo 3, levando-se em conta a variação da distância, do ângulo de incidência e da resistência de falta. Analogamente ao descrito anteriormente, em alguns casos de faltas fase-terra próximos aos terminais do sistema, com ângulo de incidência 
da falta de 0 grau, o algoritmo apresentou um decréscimo na sua precisão, ou mesmo, veio a não localizar alguns casos (próximos ao terminal A), embora os mesmos tenham sido detectados e classificados corretamente.

Analisando as situações de faltas fase-fase-terra quando da consideração de elevadas resistências de falta, o algoritmo se mostrou robusto e menos influenciado, como demonstrado na Figura 86. Afirma-se que não foi constatada nenhuma falha na localização da falta, mesmo para faltas próximas aos terminais do sistema.

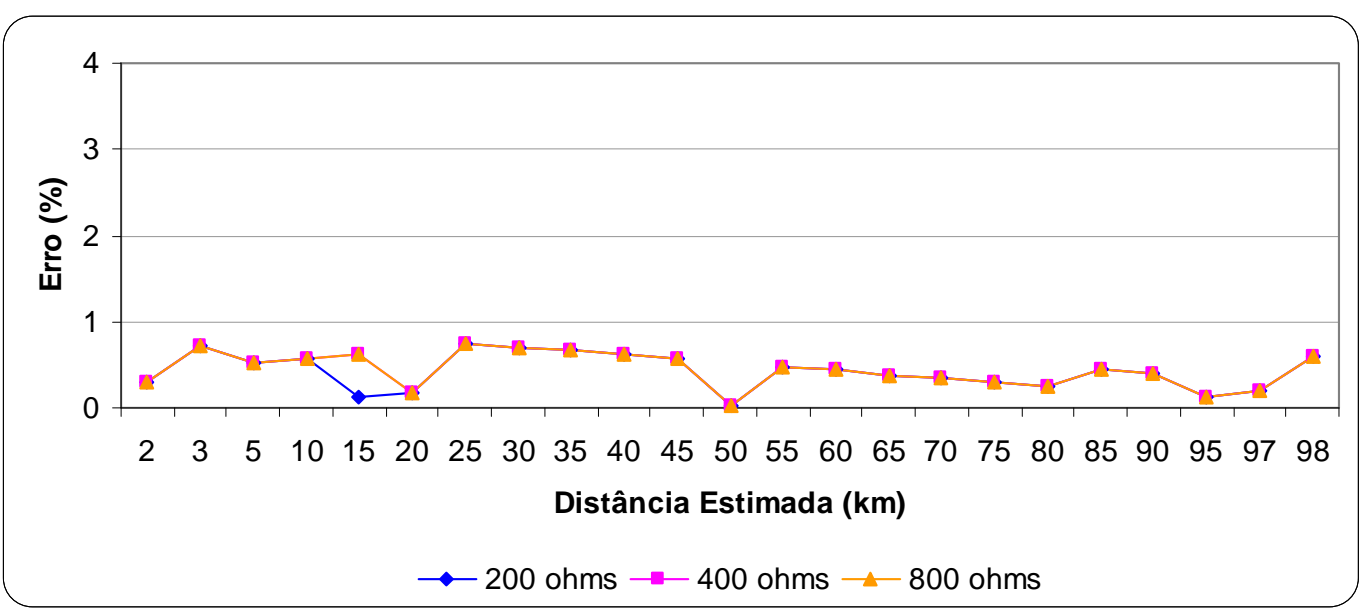

FIGURA 83 - Resultados médios referentes a situações de faltas fase-terra aplicadas sobre o ramo 3, com ângulo de incidência de $0^{\circ}$ e variação da resistência de falta em 200, 400 e 800 ohms.

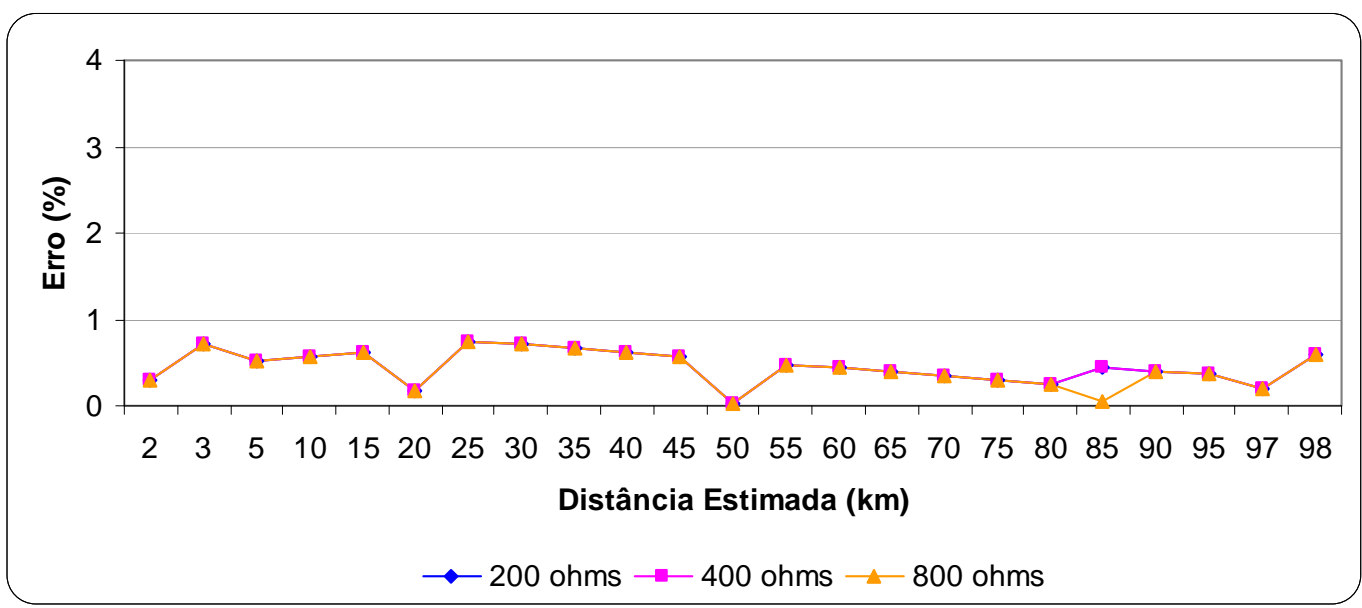

FIGURA 84 - Resultados médios referentes a situações de faltas fase-terra aplicadas sobre o ramo 3, com ângulo de incidência de $30^{\circ}$ e variação da resistência de falta em 200, 400 e 800 ohms. 


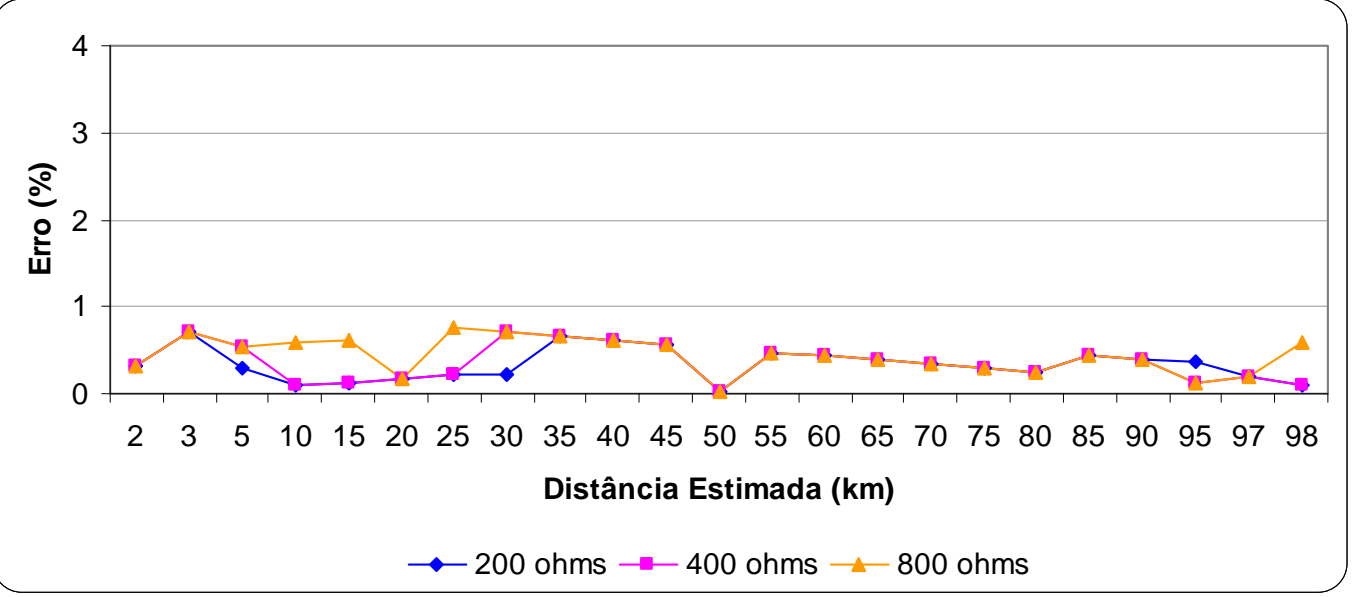

FIGURA 85 - Resultados médios referentes a situações de faltas fase-terra aplicadas sobre o ramo 3 , com ângulo de incidência de $90^{\circ}$ e variação da resistência de falta em 200, 400 e 800 ohms.

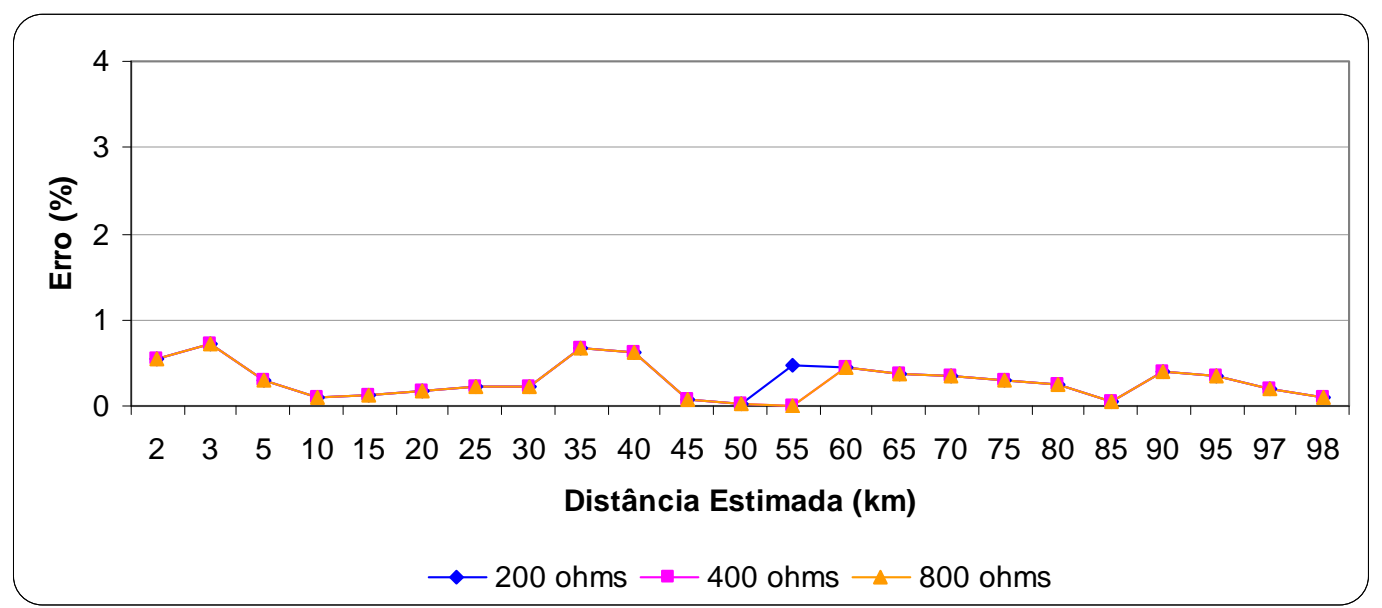

FIGURA 86 - Resultados médios referentes a situações de faltas fase-fase-terra aplicadas sobre o ramo 3, com ângulo de incidência de $0^{\circ}$ e variação da resistência de falta em 200, 400 e $800 \mathrm{ohms}$.

Analisando os resultados alcançados, considerando-se agora que a localização da falta é feita via sinais de tensão provenientes dos três terminais do sistema, pôde-se confirmar também o elevado desempenho do algoritmo proposto frente a influência da resistência de falta, sendo as vezes até superior quando se comparado ao desempenho do mesmo ao se utilizar os sinais de corrente. Neste contexto, o algoritmo conseguiu detectar e localizar todas as situações, salvo alguns erros de localização do ramo com referência ao terminal B para faltas a $78 \mathrm{~km}$ do mesmo terminal. O bom desempenho do algoritmo de ondas viajantes utilizando sinais de tensão para localizar a falta pode ser constado pela análise das Figuras 87 a 91, as quais ilustram os erros médios, dado situações de falta fase-terra e fase-fase-terra com variação dos seguintes parâmetros: distância, ângulo de incidência e resistência de falta. 


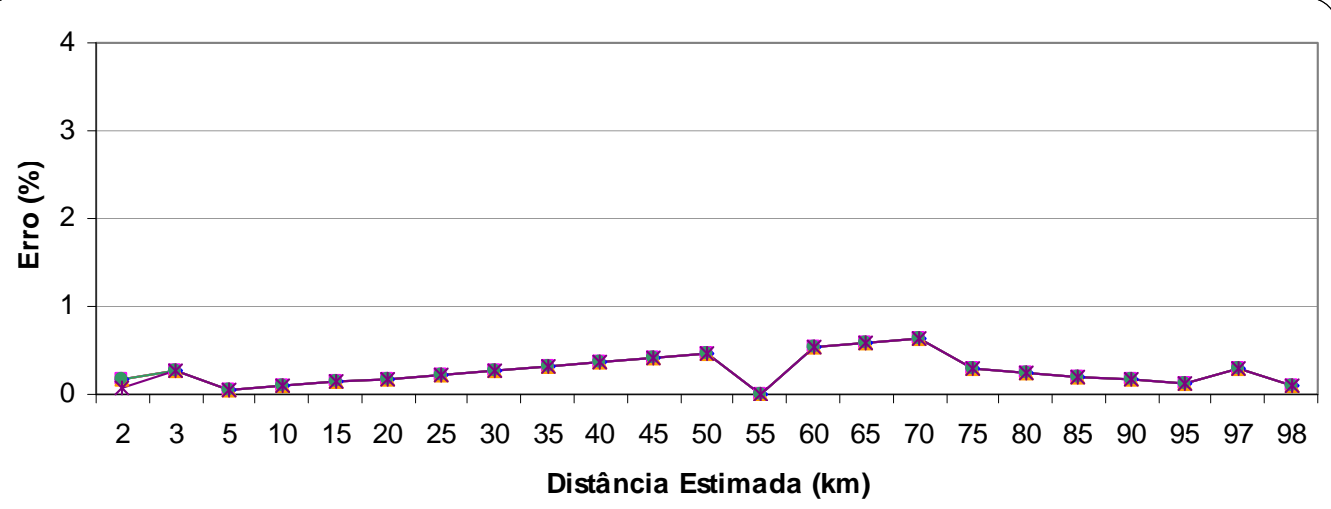

$\multimap 0$ ohm $\rightarrow-17$ ohms $\longleftarrow-30$ ohms $\multimap 50$ ohms $\rightarrow-100$ ohms

FIGURA 87 - Resultados médios referentes à utilização dos sinais de tensão para situações de faltas fase-terra aplicadas sobre o ramo 3, com ângulo de incidência de $0^{\circ}$ e variação da resistência de falta em 0, 17, 30, 50 e 100 ohms.

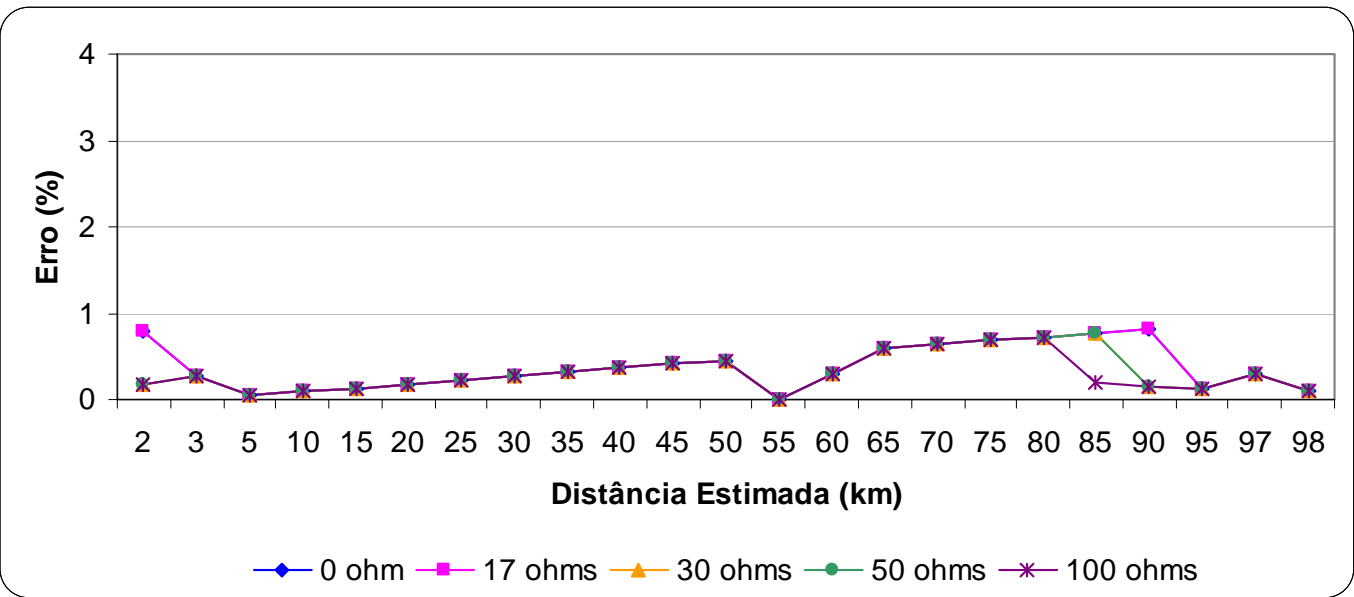

FIGURA 88 - Resultados médios referentes à utilização dos sinais de tensão para situações de faltas fase-terra aplicadas sobre o ramo 3, com ângulo de incidência de $30^{\circ}$ e variação da resistência de falta em 0, 17, 30, 50 e $100 \mathrm{ohms}$.

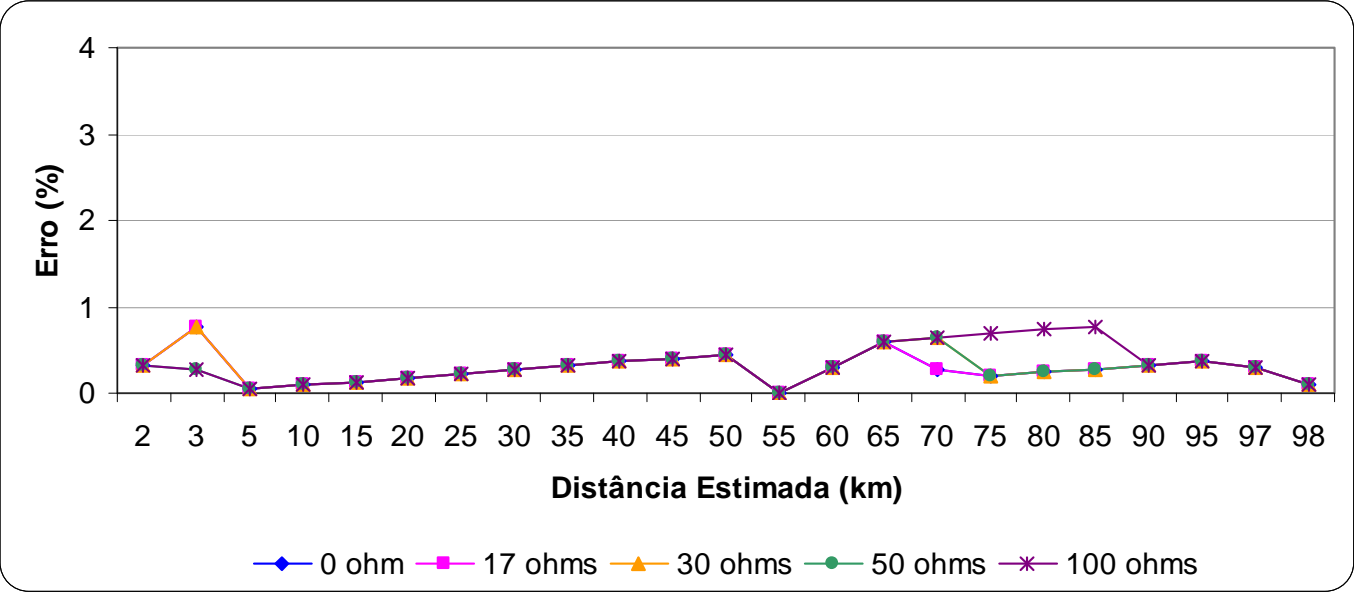

FIGURA 89 - Resultados médios referentes à utilização dos sinais de tensão para situações de faltas fase-terra aplicadas sobre o ramo 3, com ângulo de incidência de $90^{\circ}$ e variação da resistência de falta em 0, 17, 30, 50 e $100 \mathrm{ohms}$. 


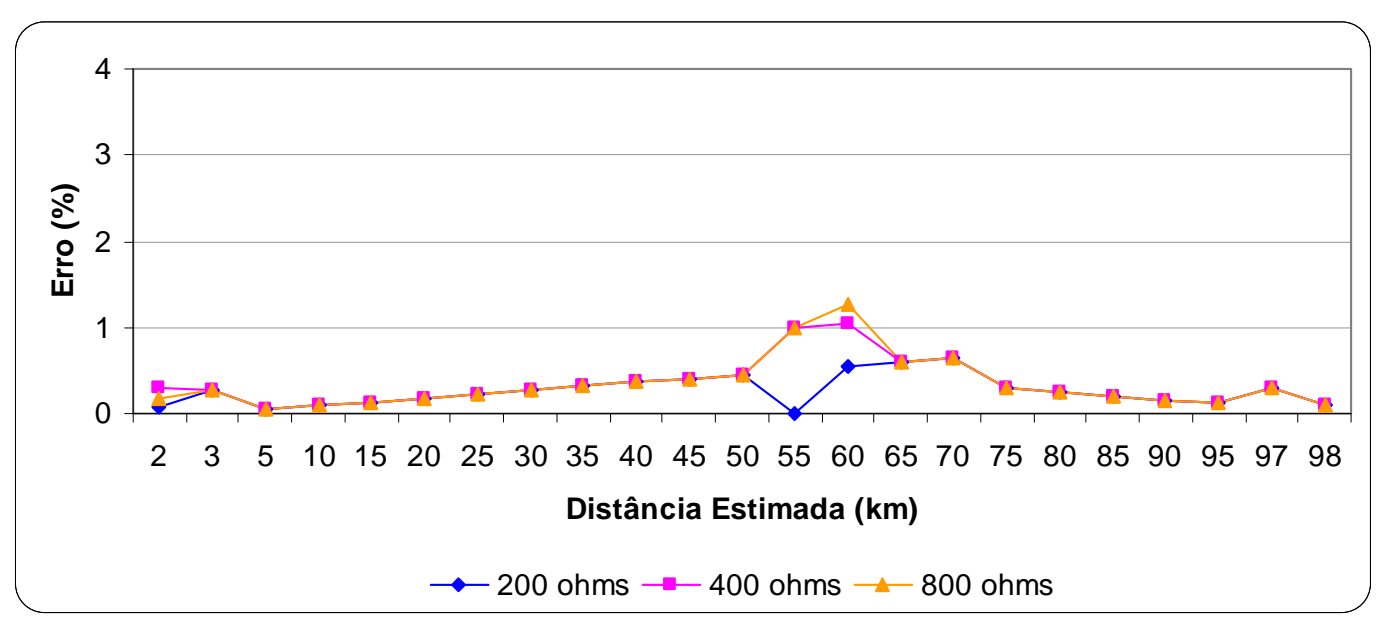

FIGURA 90 - Resultados médios referentes à utilização dos sinais de tensão para situações de faltas fase-terra aplicadas sobre o ramo 3, com ângulo de incidência de $0^{\circ}$ e variação da resistência de falta em 200, 400 e 800 ohms.

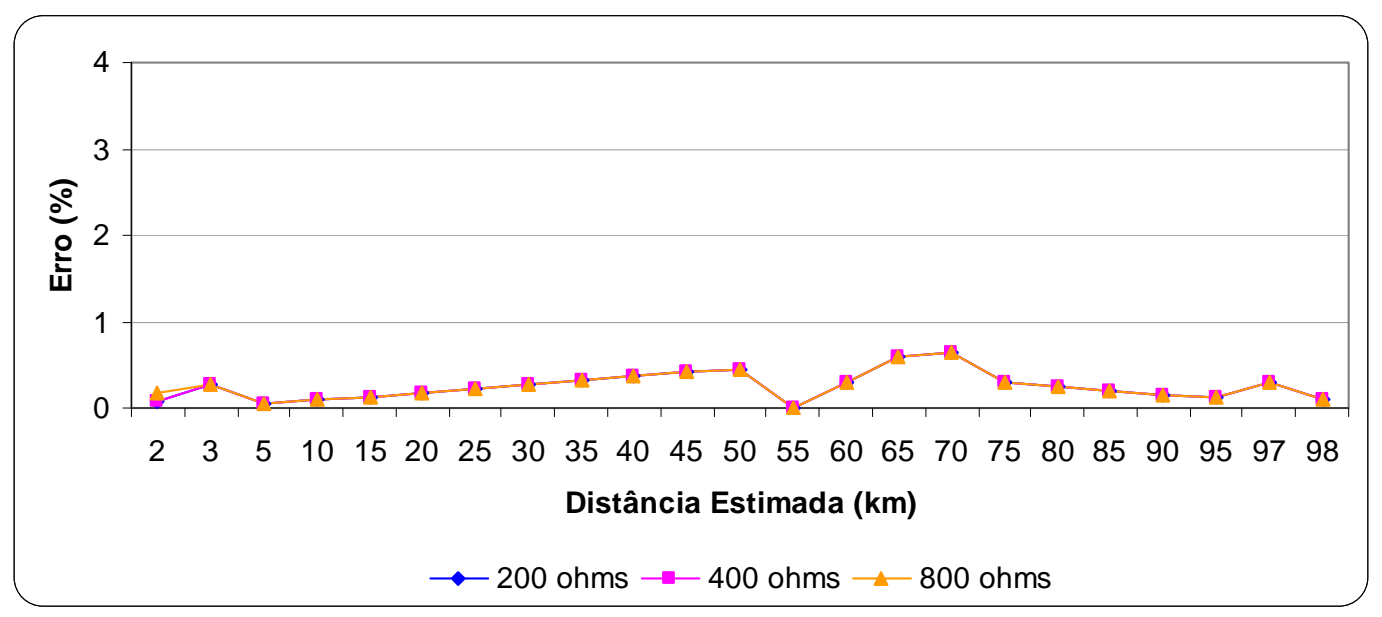

FIGURA 91 - Resultados médios referentes à utilização dos sinais de tensão para situações de faltas fase-terra aplicadas sobre o ramo 3, com ângulo de incidência de $30^{\circ}$ e variação da resistência de falta em 200, 400 e 800 ohms.

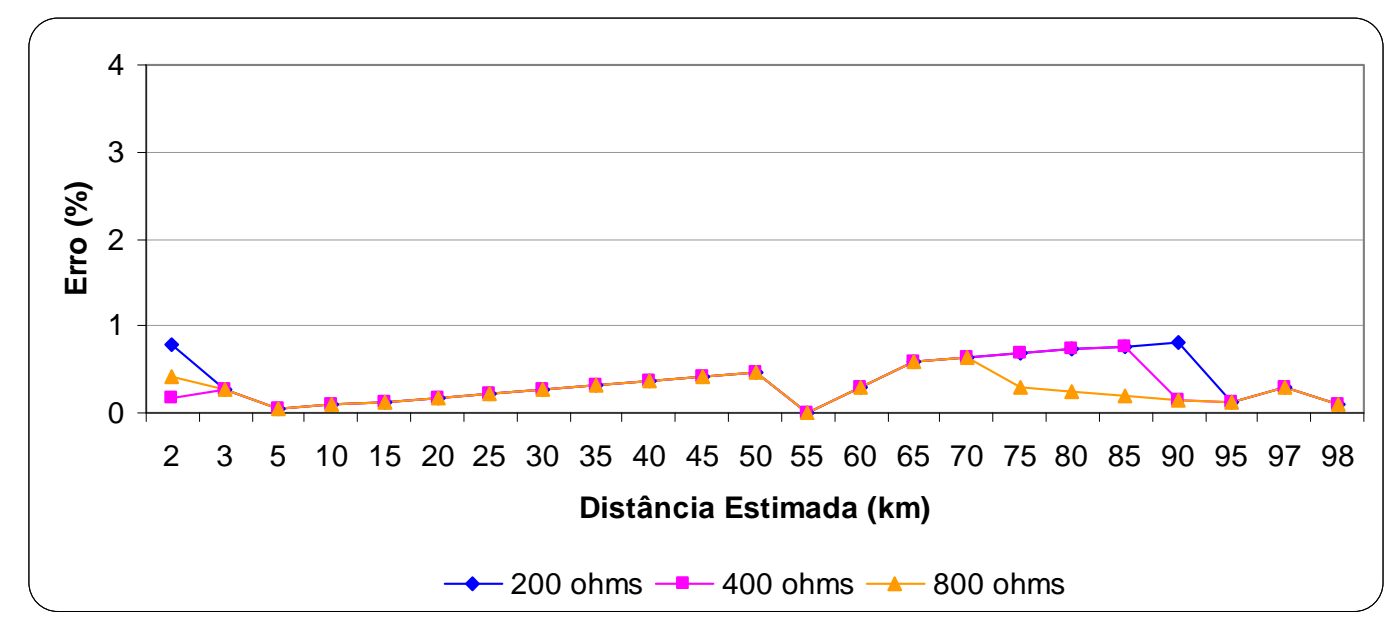

FIGURA 92 - Resultados médios referentes à utilização dos sinais de tensão para situações de faltas fase-terra aplicadas sobre o ramo 3, com ângulo de incidência de $90^{\circ}$ e variação da resistência de falta em 200, 400 e 800 ohms. 


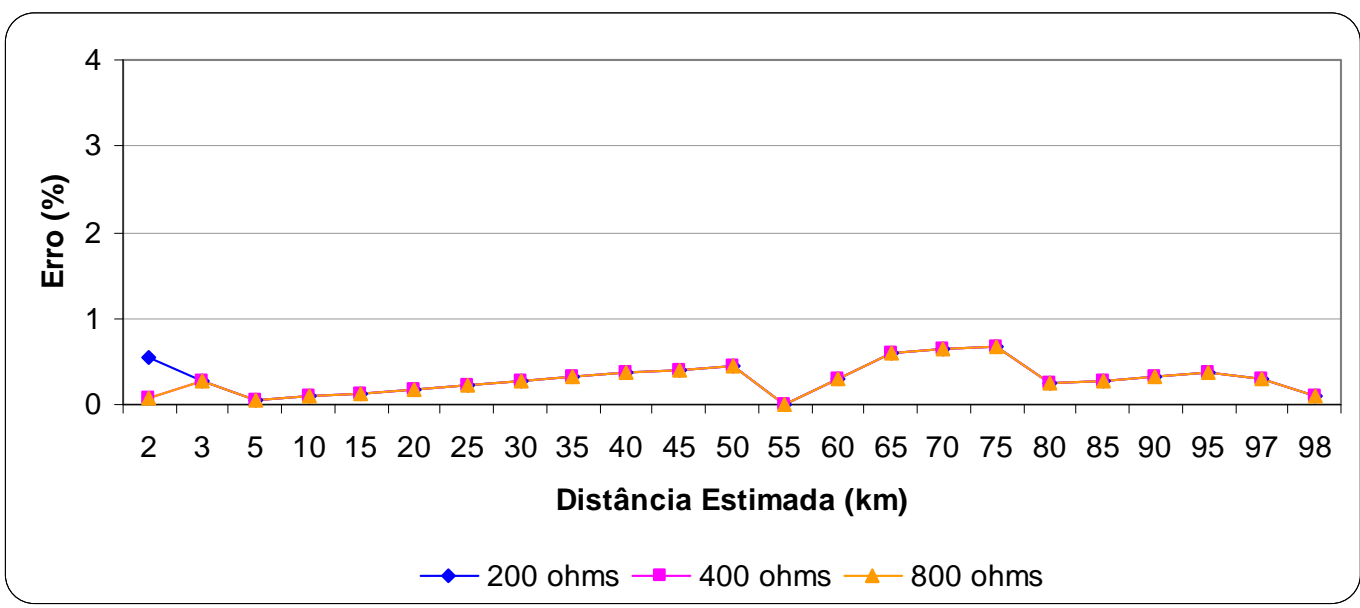

FIGURA 93 - Resultados médios referentes à utilização dos sinais de tensão para situações de faltas fase-fase-terra aplicadas sobre o ramo 3, com ângulo de incidência de $0^{\circ}$ e variação da resistência de falta em 200, 400 e 800 ohms.

O desempenho do módulo de localização baseado em ondas viajantes manipulando apenas dados locais também foi verificado no tocante a presença da resistência de falta.

Tanto analisando os sinais de corrente como os de tensão, podemos constatar que o algoritmo apresentou resultados altamente satisfatórios mesmo na presença de elevadas resistências de falta. Todavia, vale comentar que o algoritmo pode ter sua precisão prejudicada, ou mesmo falhar, frente a situações de faltas fase-terra com elevadas resistência de falta associadas a baixo ângulos de incidência da mesma. Estes erros, em sua grande parte, são frutos da dificuldade em se detectar a chegada da segunda onda no terminal local devida a atenuação e distorção dos sinais.

Nas Figuras 94 a 99 são demonstrados alguns resultados de testes executados sobre o algoritmo de ondas viajantes utilizando dados locais de corrente (Figuras 94-96) ou de tensão (Figuras 97-99), sobre os quais podemos constatar um desempenho elevado do algoritmo frente à variação da resistência de falta, mantendo-se a maioria dos erros na faixa de $1,0 \%$.

Quando analisado os casos de faltas fase-fase-terra, percebe-se que as observações feitas para o caso de faltas fase-terra não eram validas nestes casos, pois o algoritmo apresentou um melhor desempenho mesmo na presença de faltas com elevadas resistências e baixos ângulos de incidência da falta. Pode-se observar o desempenho e precisão do algoritmo frente a faltas fase-fase-terra pela análise das Figuras 100 a 102, onde percebemos que a maioria dos erros também se manteve na faixa de $1,0 \%$. 


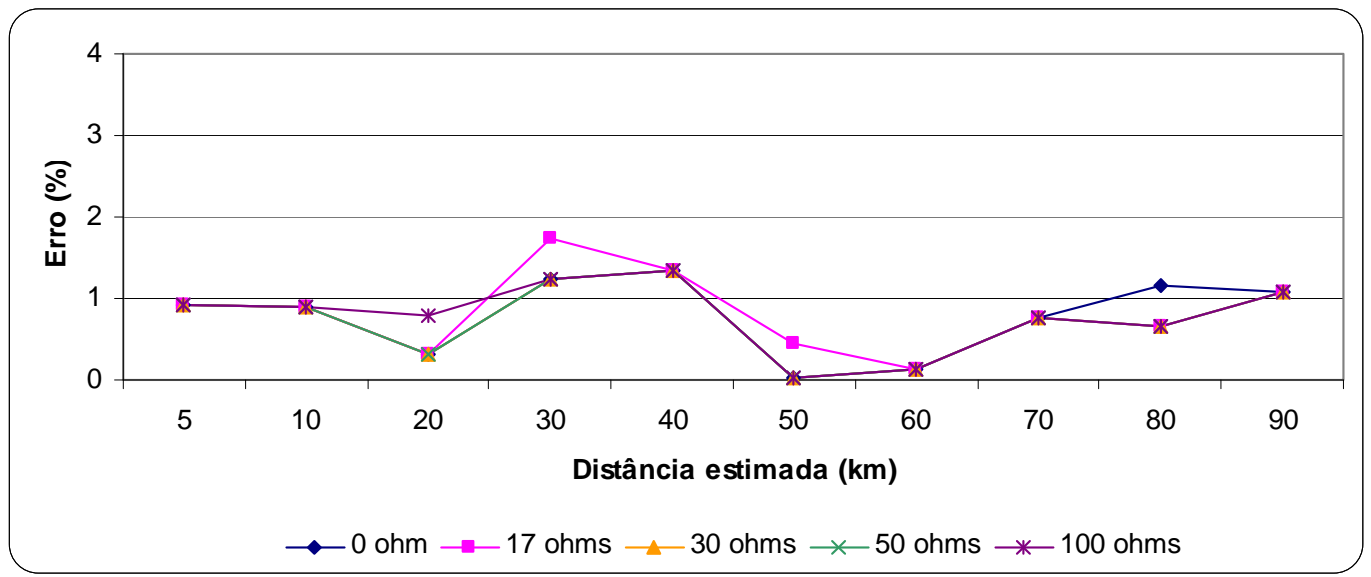

FIGURA 94 - Resultados médios referentes a situações de faltas fase-terra aplicadas sobre o ramo 3 com ângulo de incidência de $0^{\circ}$ e variação da resistência de falta em 0, 17, 30, 50 e 100 ohms-dados locais.

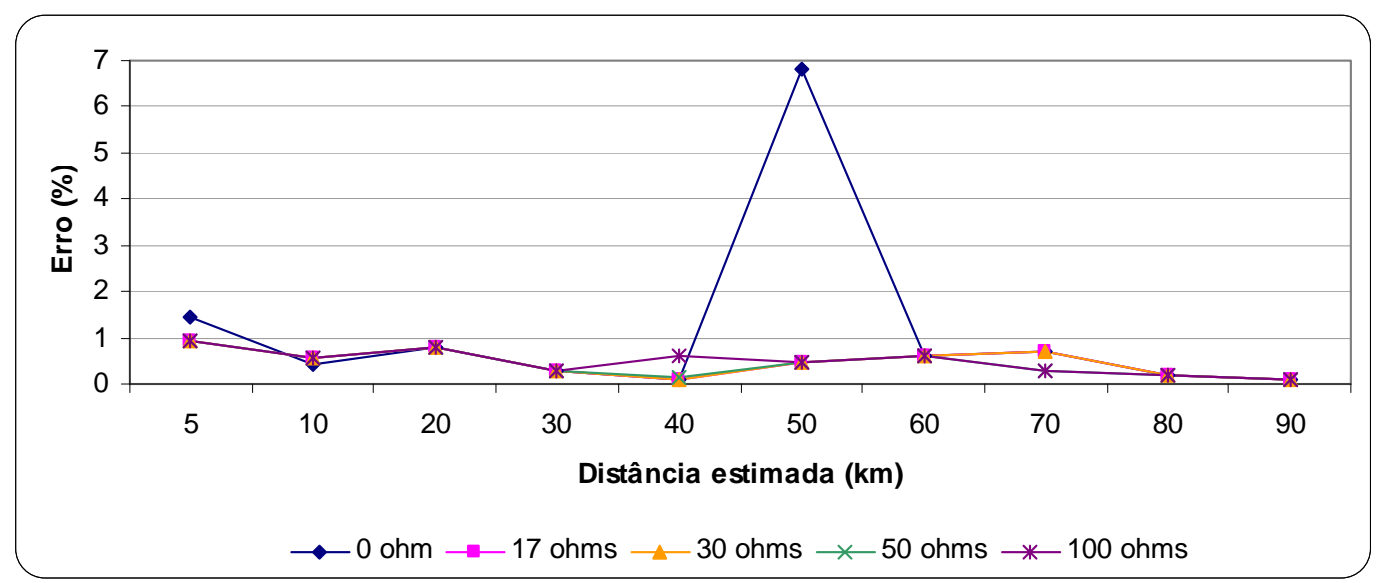

FIGURA 95 - Resultados médios referentes a situações de faltas fase-terra aplicadas sobre o ramo 3 com ângulo de incidência de $30^{\circ}$ e variação da resistência de falta em 0, 17, 30, 50 e 100 ohms-dados locais.

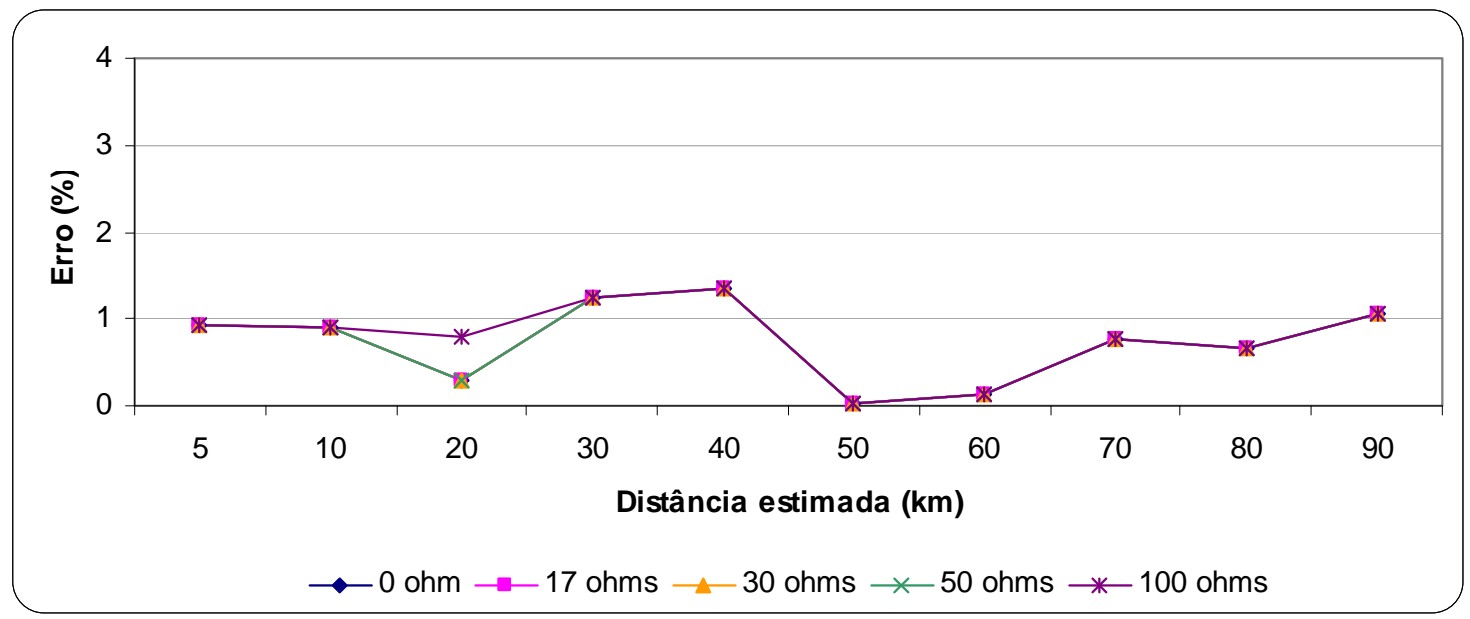

FIGURA 96 - Resultados médios referentes a situações de faltas fase-terra aplicadas sobre o ramo 3 com ângulo de incidência de $90^{\circ}$ e variação da resistência de falta em 0, 17, 30, 50 e 100 ohms-dados locais. 


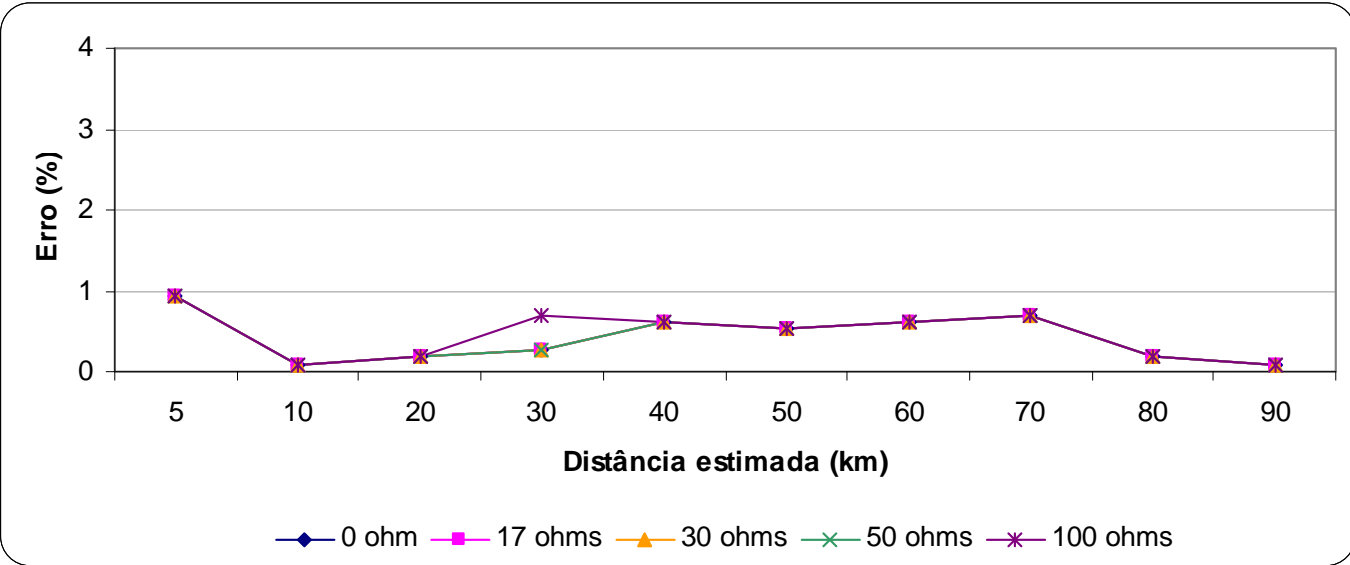

FIGURA 97 - Resultados médios referentes à utilização dos sinais de tensão para situações de faltas fase-terra aplicadas sobre o ramo 3, com ângulo de incidência de $0^{\circ}$ e variação da resistência de falta em $0,17,30,50$ e 100 ohms - dados locais.

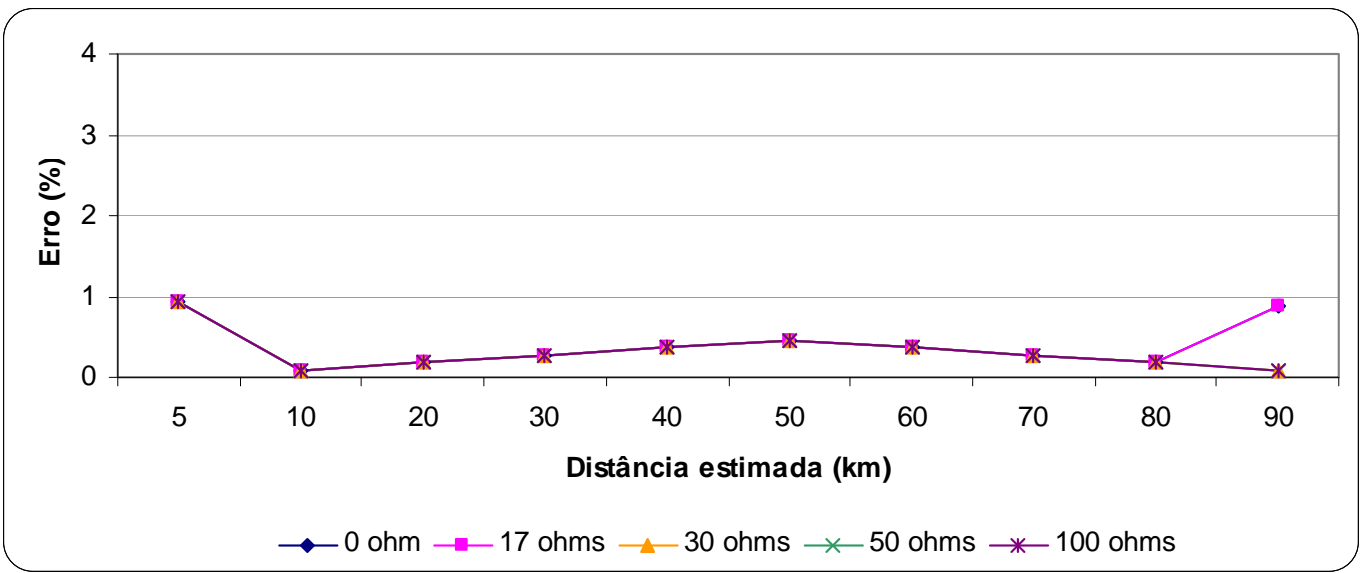

FIGURA 98 - Resultados médios referentes à utilização dos sinais de tensão para situações de faltas fase-terra aplicadas sobre o ramo 3 , com ângulo de incidência de $30^{\circ}$ e variação da resistência de falta em 0, 17, 30, 50 e 100 ohms - dados locais.

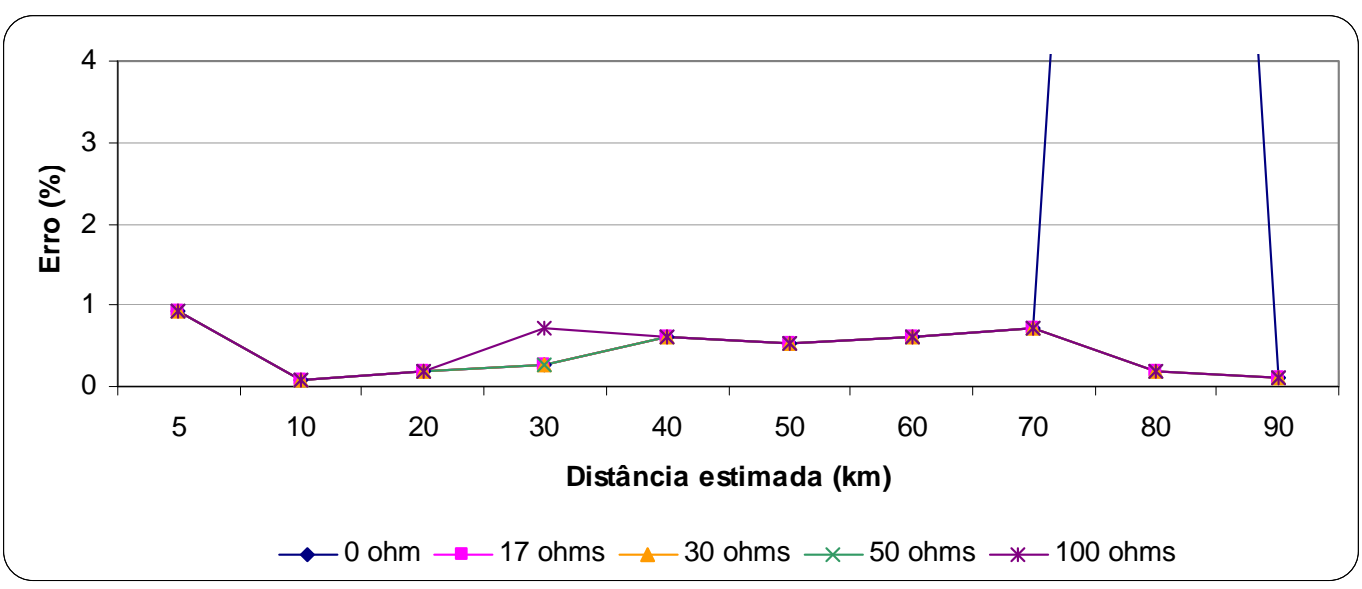

FIGURA 99 - Resultados médios referentes à utilização dos sinais de tensão para situações de faltas fase-terra aplicadas sobre o ramo 3, com ângulo de incidência de $90^{\circ}$ e variação da resistência de falta em 0, 17, 30, 50 e 100 ohms - dados locais. 


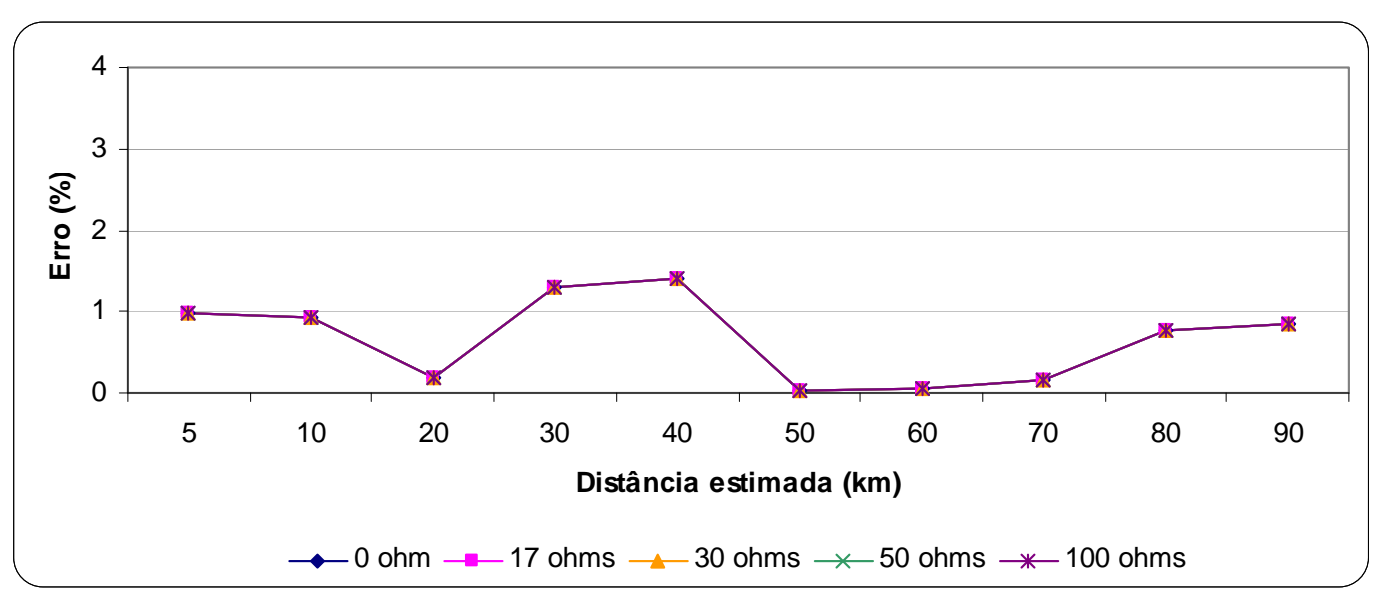

FIGURA 100 - Resultados médios referentes a situações de faltas fase-fase-terra aplicadas sobre o ramo 3 com ângulo de incidência de $0^{\circ}$ e variação da resistência de falta em 0, 17, 30, 50 e 100 ohms-dados locais.

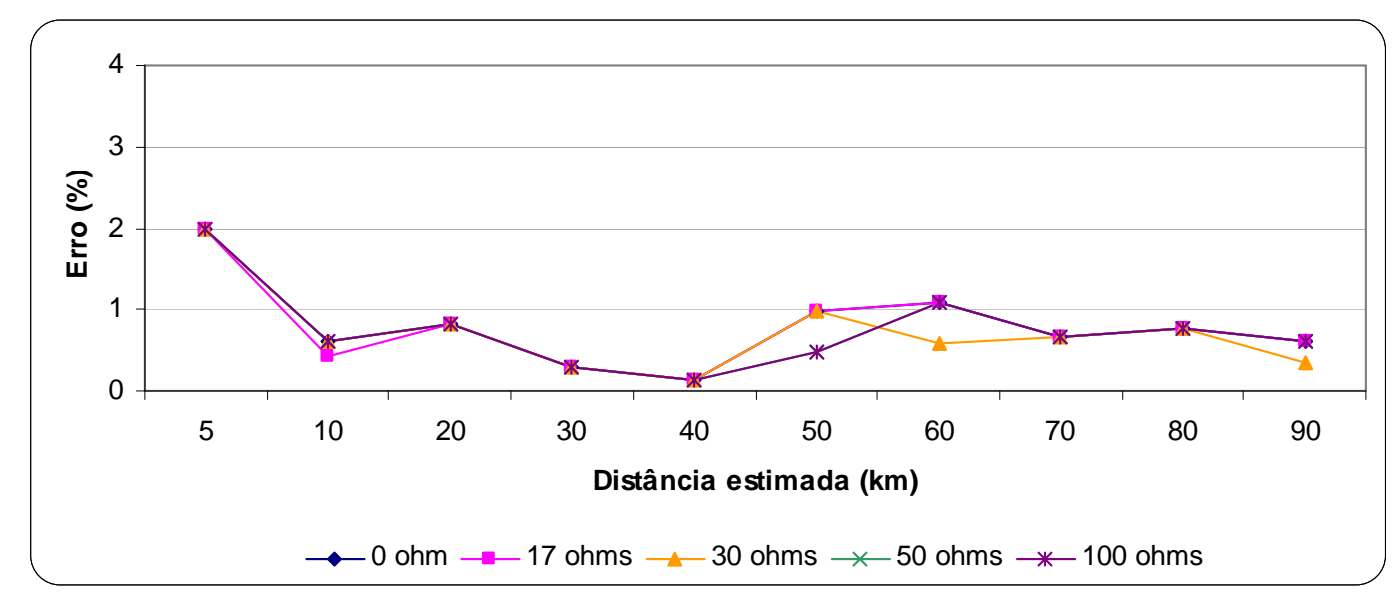

FIGURA 101 - Resultados médios referentes a situações de faltas fase-fase-terra aplicadas sobre o ramo 3 com ângulo de incidência de $30^{\circ}$ e variação da resistência de falta em 0, 17, 30, 50 e 100 ohms - dados locais.

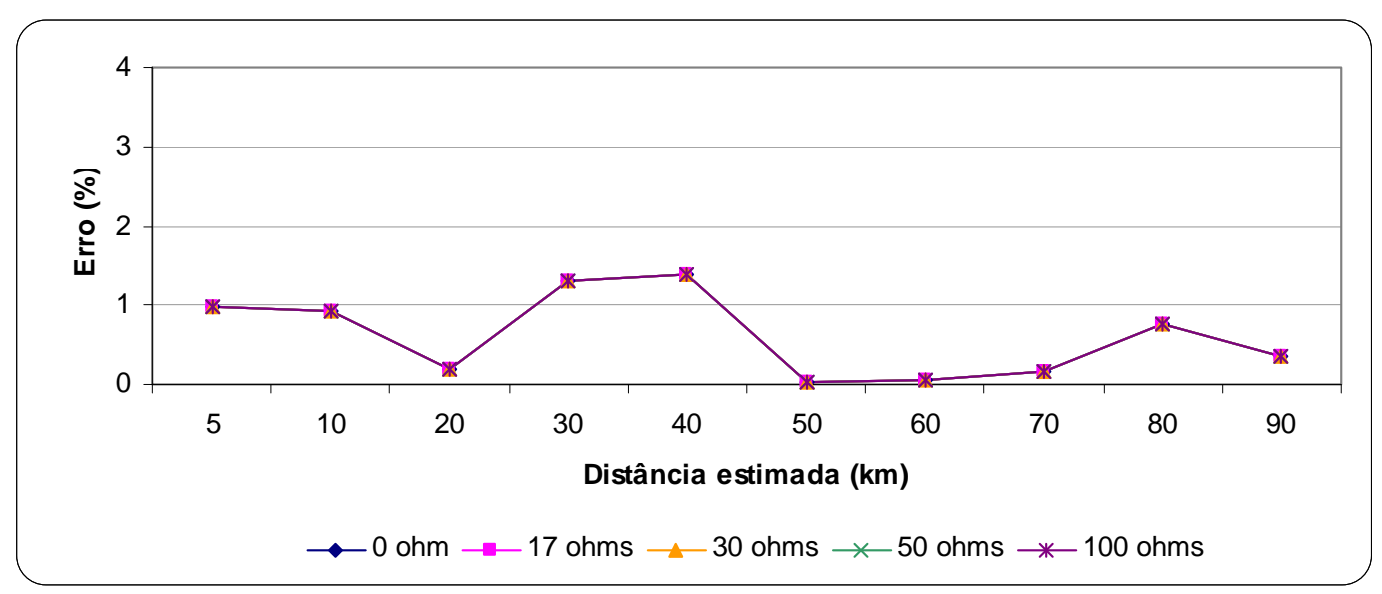

FIGURA 102 - Resultados médios referentes a situações de faltas fase-fase-terra aplicadas sobre o ramo 3 com ângulo de incidência de $90^{\circ}$ e variação da resistência de falta em 0, 17, 30, 50 e 100 ohms-dados locais. 
Finalizando esta subseção, pode-se concluir com base na análise de todos os testes executados, que o algoritmo de localização de faltas baseado em ondas viajantes, dispondo de dados de um ou dos três é praticamente insensível a variação da resistência da falta, mesmo diante de valores elevados, tanto para análise dos sinais de corrente como para os de tensão. Restrição dada a poucas circunstâncias, aonde o algoritmo veio a localizar com uma precisão insatisfatória ou mesmo veio a falhar.

\subsubsection{Influência do ruído correlacionado ao sinal}

O termo ruído em sistemas elétricos de potência pode ser definido como sinais elétricos não desejáveis com conteúdo espectral abaixo de $200 \mathrm{kHz}$ superpostos aos sinais de tensão e corrente dos sinais de fase, ou sobre os sinais do condutor neutro (DUGAN et al.)[118]. Estes podem ser causados por alguns tipos de equipamentos ligados a rede, por distúrbios na linha, por interferência eletromagnética ou mesmo pelas etapas de condicionamento do sinal.

Logo, uma vez que trabalhamos com a análise dos sinais de alta freqüência gerados por um distúrbio para localizar a falta, faz-se necessário avaliar a sensibilidade do algoritmo frente a ruídos presentes nos sinais analisados.

Para avaliar a influência do nível de ruído sobre o algoritmo baseado em ondas viajantes, foi adicionado aos sinais simulados via ATP, diferentes níveis de ruído branco gaussiano. Os níveis de ruído sobrepostos aos sinais de corrente e tensão foram estabelecidos segundo a taxa de sinal/ruído (do inglês, SNR - signal noise rate) em 40 , $50,60,70$ e $80 \mathrm{~dB}$. Na prática, o nível de SNR presente nos sinais elétricos pode variar de 50 a $70 \mathrm{~dB}$, conforme apresentado por Sidhu [119] e Pereira et al. [120]. A Figura 103 ilustra os sinais de tensão e corrente da fase A tomados a partir da barra A, com adição de diferentes níveis de ruído branco gaussiano.

Analisando os resultados obtidos quando se considerou a adição dos níveis de ruído descritos acima, pode-se concluir que, dependendo do nível incorporado, dos parâmetros relacionados à situação de falta aplicada e dos sinais analisados (corrente ou tensão), o desempenho do algoritmo baseado em ondas viajantes, trabalhando com dados locais ou múltiplos terminais, pode ser severamente prejudicado, vindo a não localizar a falta. 


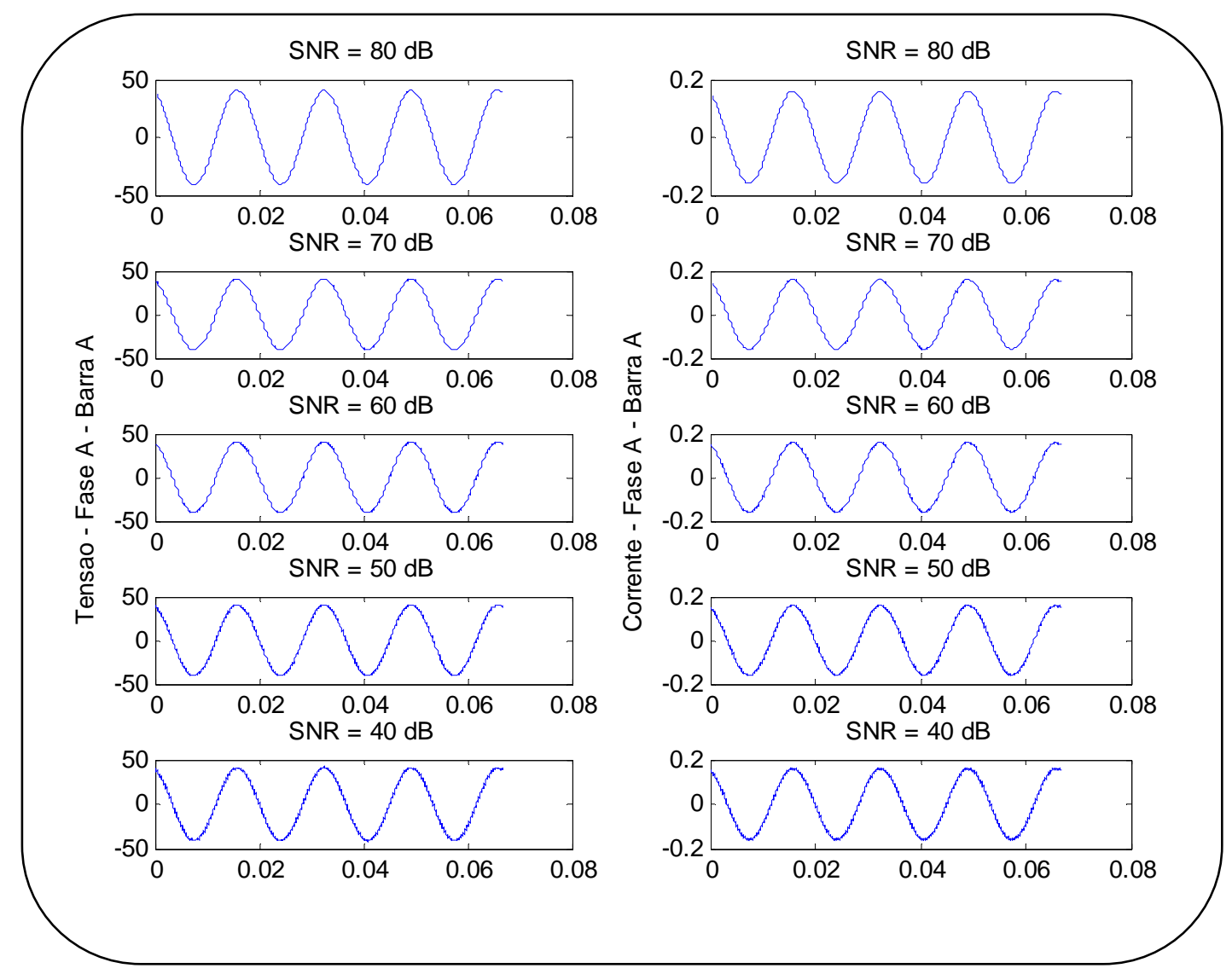

FIGURA 103 - Sinais de tensão e corrente em regime permanente com adição de diferentes níveis de ruido branco gaussiano.

Considerando-se os testes para dados dos três terminais, quando foram utilizados os sinais de corrente para localizar a falta, o algoritmo mostrou-se pouco eficiente para um SNR abaixo de $60 \mathrm{~dB}(50$ e $40 \mathrm{~dB})$, agravando-se quando o ângulo de incidência da falta foi próximo a zero grau e/ou com uma resistência de falta baixa associada, conforme denotam as Figuras de 104 a 106. Quando utilizado os sinais de tensão, o algoritmo mostrou-se um pouco mais robusto, sendo mais afetado para níveis de SNR inferior a $50 \mathrm{~dB}$ aliados a baixos níveis de resistência de falta e/ou a baixos ângulos de incidência. Porém, em muitos casos, utilizando os sinais de tensão, o algoritmo conseguiu localizar com uma satisfatória precisão até casos com SNR igual a $40 \mathrm{~dB}$, conforme podemos constatar pelas Figuras de107 a 109.

Considerando-se agora a localização da falta por meio de dados locais, utilizando-se os sinais de corrente, nota-se que o algoritmo começa a ser influenciado a partir de $60 \mathrm{~dB}$, principalmente para baixos ângulos de incidência da falta, como pode ser observado pelas Figuras de 110 a 112. Já quando analisado os sinais de tensão, percebe-se que o desempenho do algoritmo quanto à precisão, em princípio, foi menos 
influenciado, respondendo com precisão a níveis abaixo de $50 \mathrm{~dB}$, conforme ilustram as Figuras de 113 a 115.

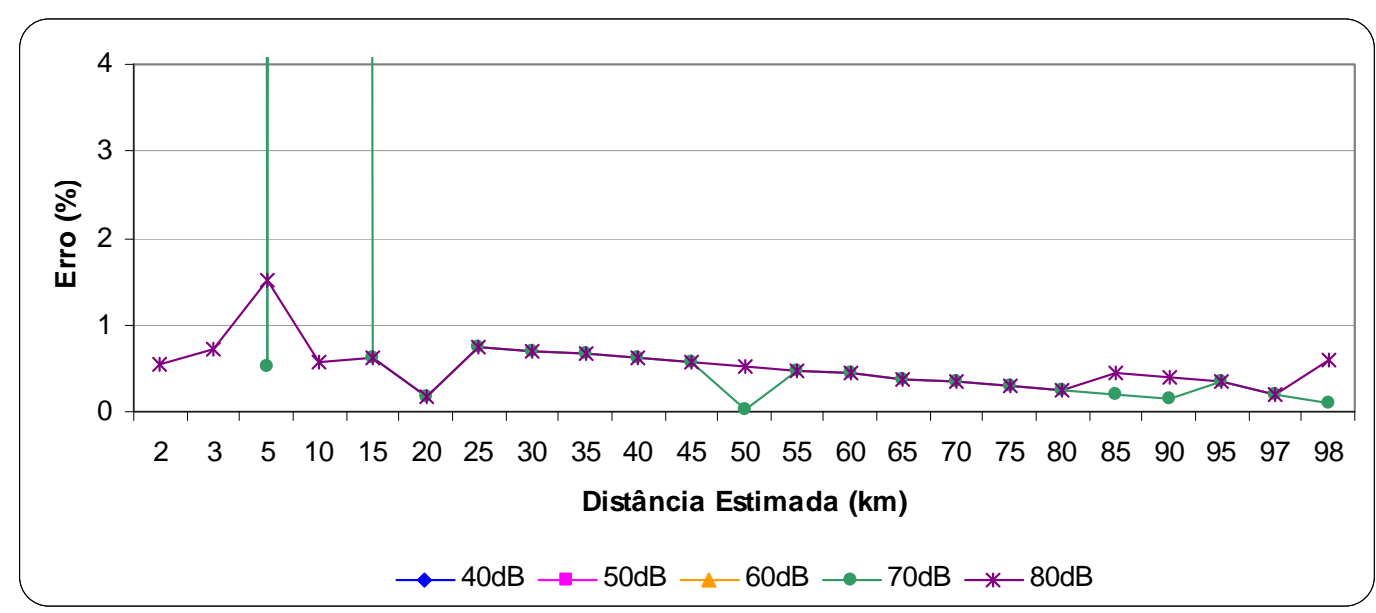

FIGURA 104 - Resultados médios obtidos utilizando sinais de corrente dado situações de faltas faseterra aplicada sobre o ramo 3, com ângulo de incidência de $0^{\circ}$, resistência de falta de 0 ohm e presença de ruído branco.

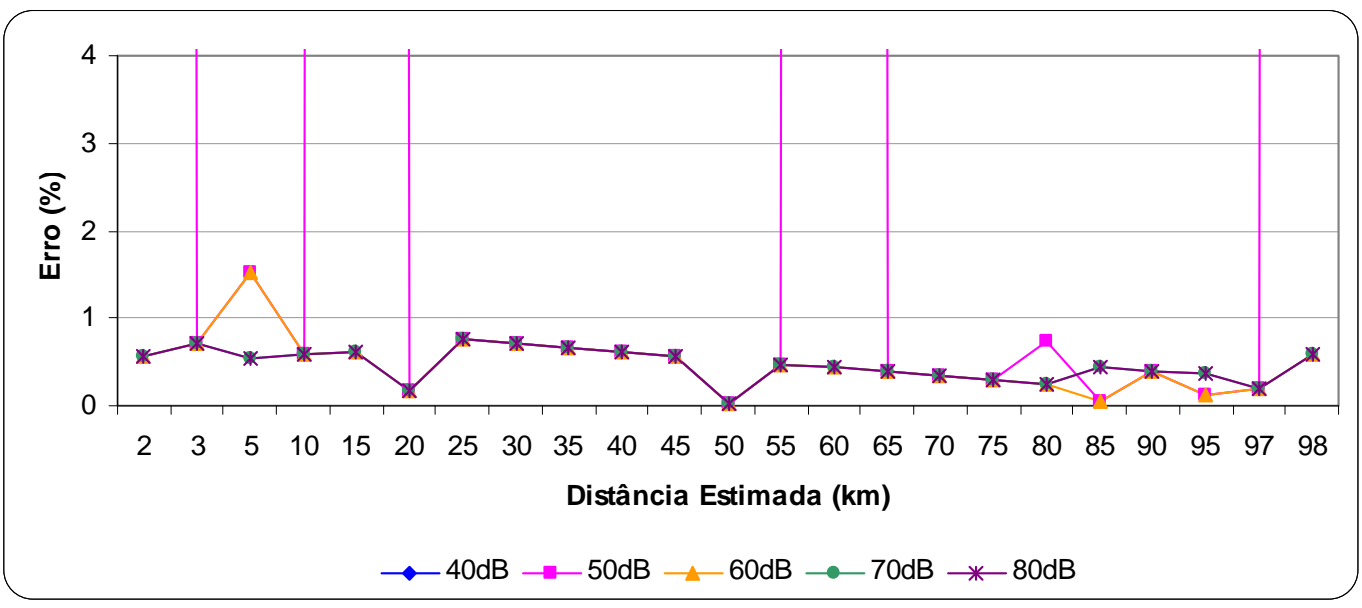

FIGURA 105 - Resultados médios obtidos utilizando sinais de corrente dado situações de faltas faseterra aplicada sobre o ramo 3, com ângulo de incidência de $90^{\circ}$, resistência de falta de $50 \mathrm{ohm}$ e presença de ruído branco. 


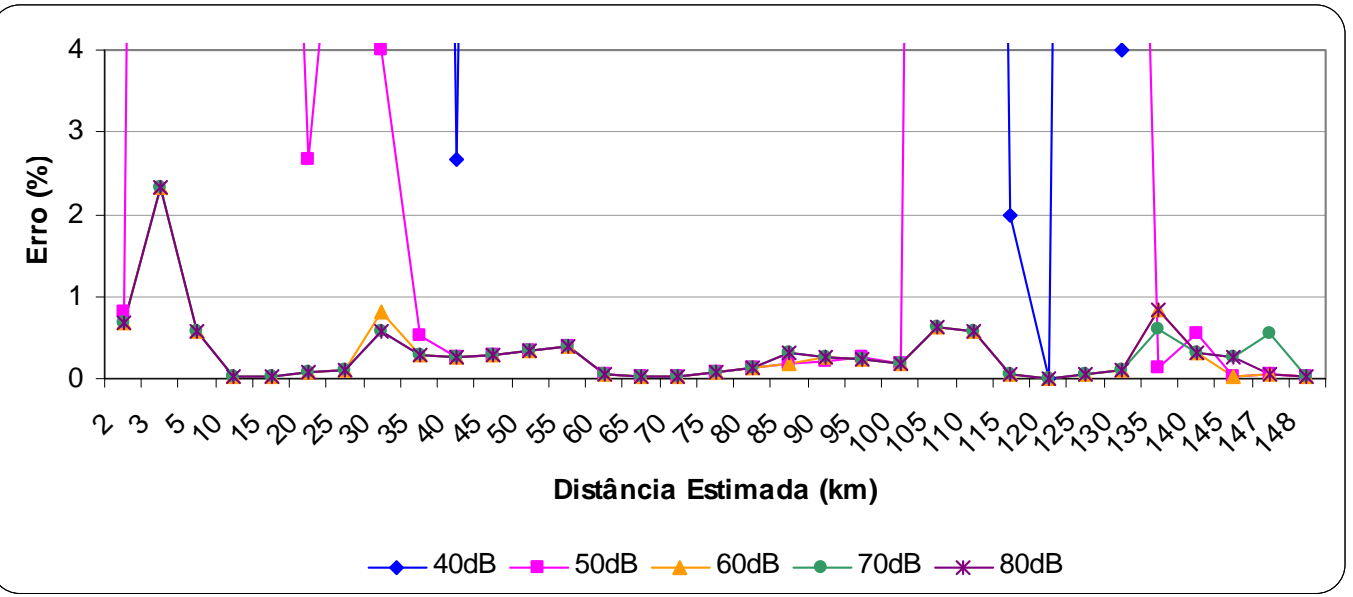

FIGURA 106 - Resultados médios obtidos utilizando sinais de corrente dado situações de faltas fase-fase aplicadas sobre o ramo 1, com ângulo de incidência de $90^{\circ}$ e presença de ruído branco.

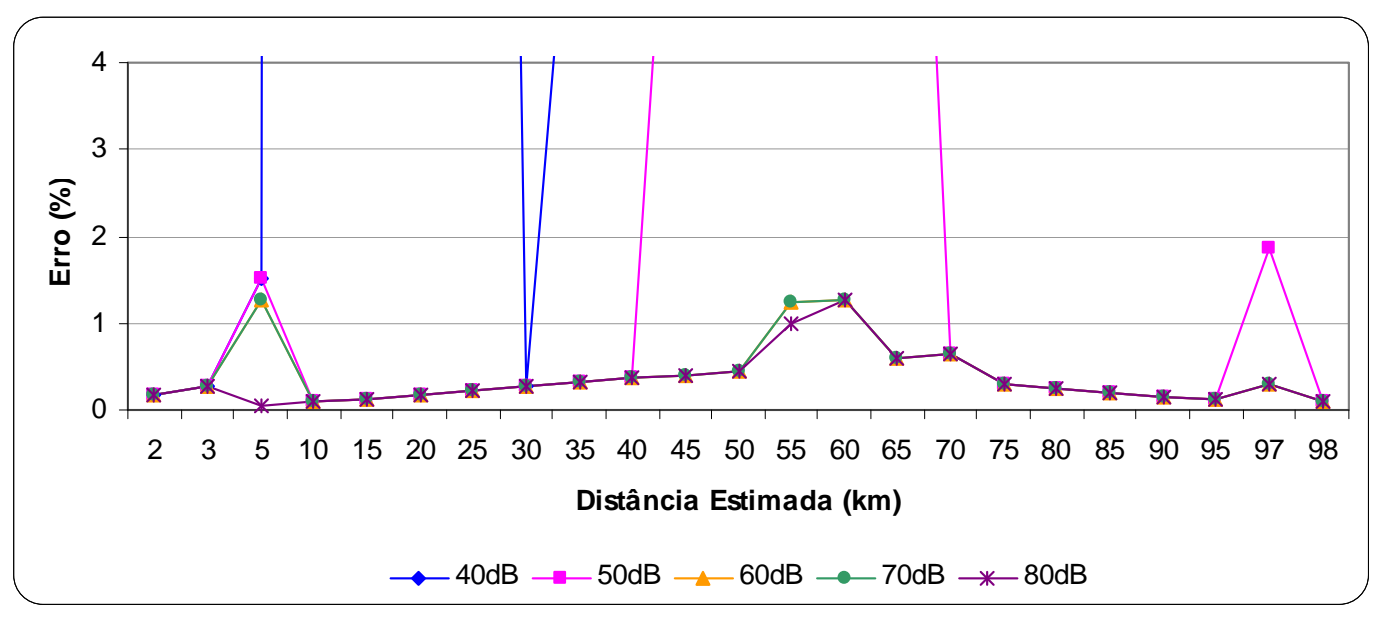

FIGURA 107 - Resultados médios obtidos utilizando sinais de tensão dado situações de faltas fase-terra aplicadas sobre o ramo 3, com ângulo de incidência de $0^{\circ}$ resistência de falta de $0 \mathrm{ohm}$ e presença de ruído branco

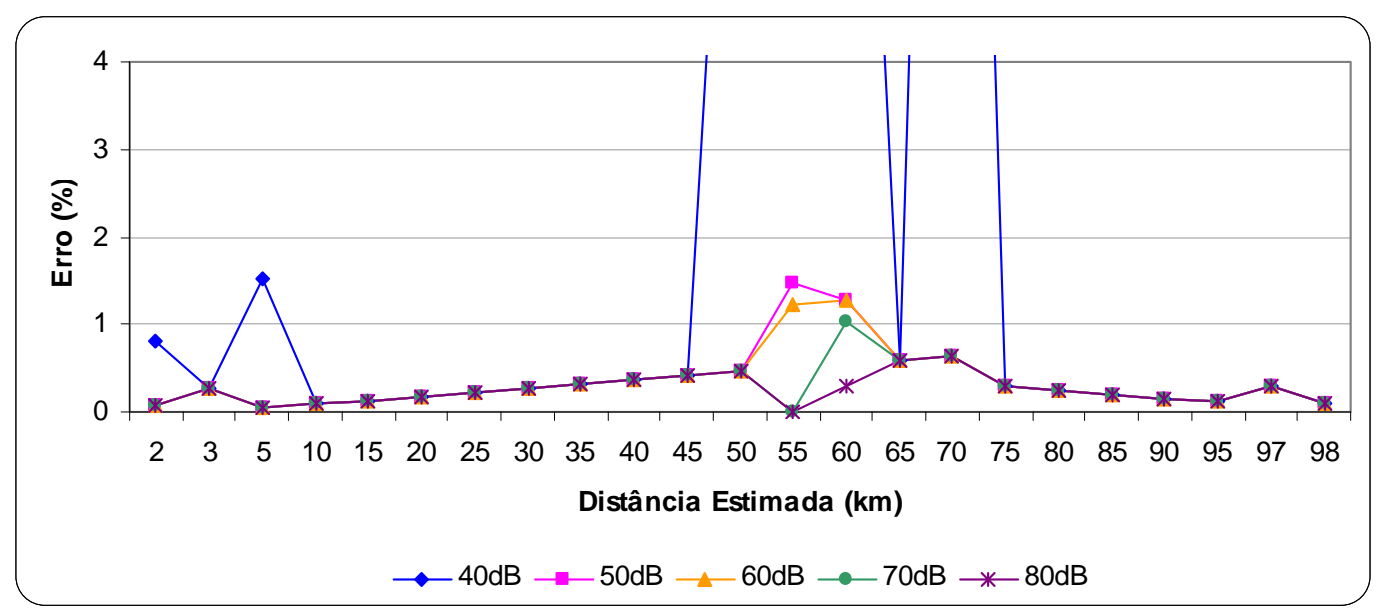

FIGURA 108 - Resultados médios obtidos utilizando sinais de tensão dado situações de faltas fase-terra aplicadas sobre o ramo 3 com ângulo de incidência de $90^{\circ}$, resistência de falta de 50 ohm e presença de ruído branco 


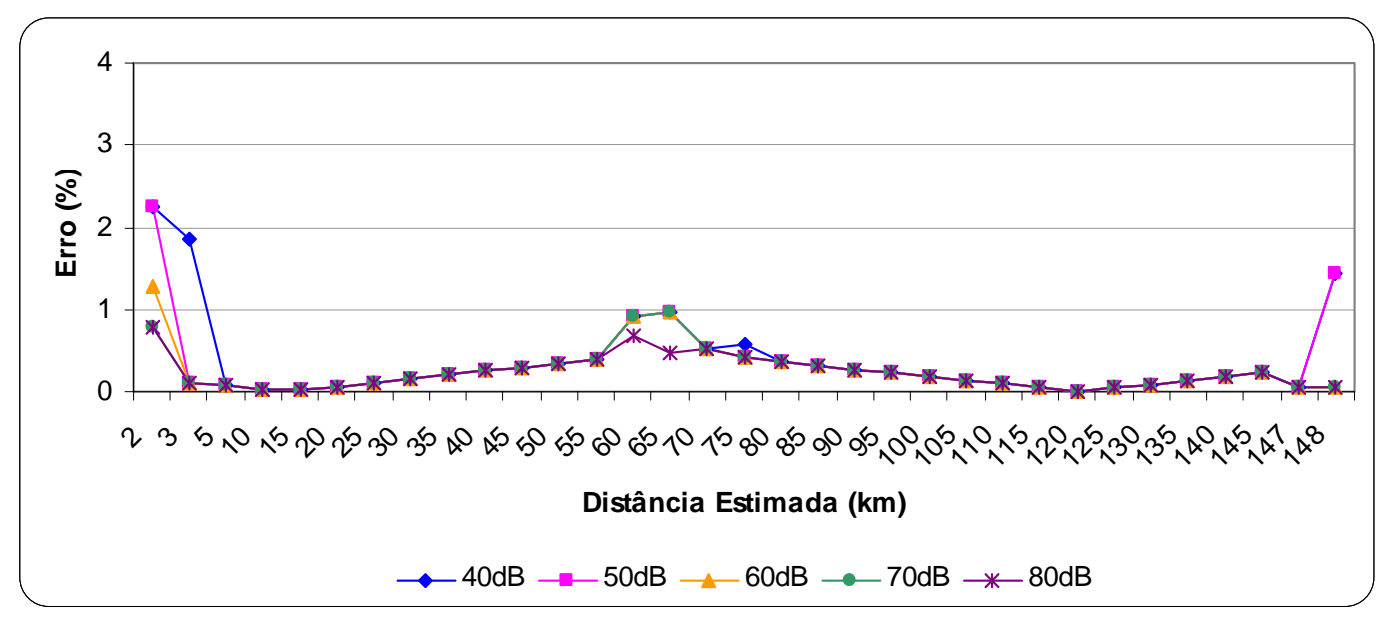

FIGURA 109 - Resultados médios obtidos utilizando sinais de tensão dado situações de faltas fase-fase aplicadas sobre o ramo 1, com ângulo de incidência de $90^{\circ}$ e presença de ruído branco.

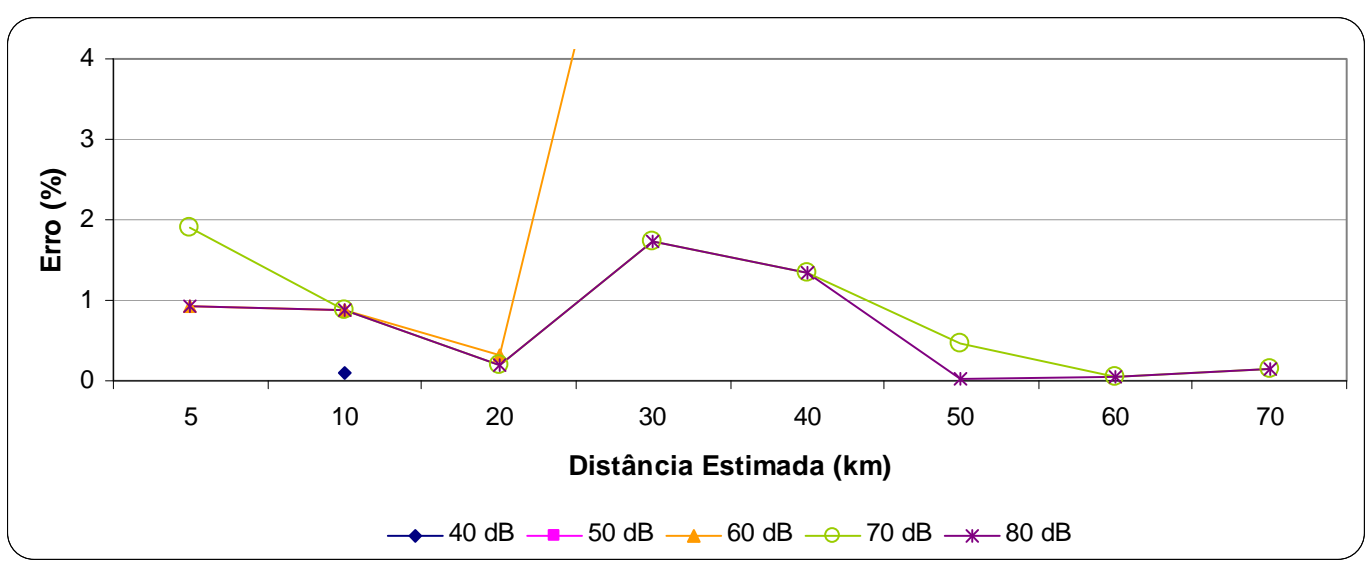

FIGURA 110 - Resultados médios obtidos utilizando sinais de corrente dado situações de faltas fase-fase aplicadas sobre o ramo 2, com ângulo de incidência de $0^{\circ}$ e presença de ruído branco - dados locais.

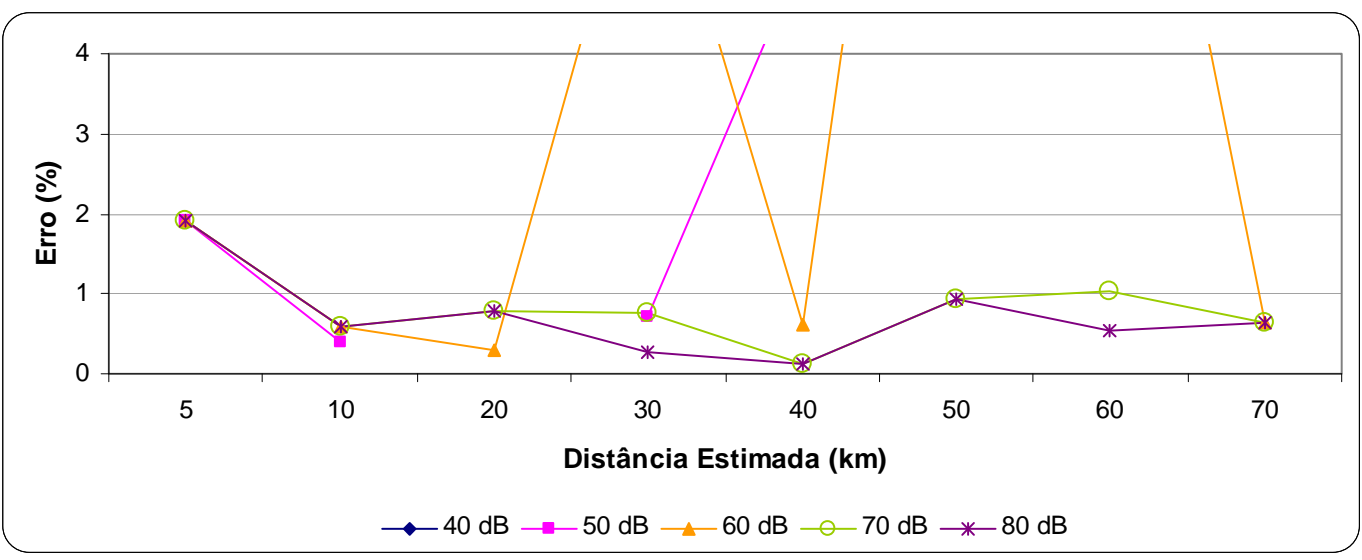

FIGURA 111 - Resultados médios obtidos utilizando sinais de corrente dado situações de faltas fase-fase aplicadas sobre o ramo 2, com ângulo de incidência de $30^{\circ}$ e presença de ruído branco-dados locais. 


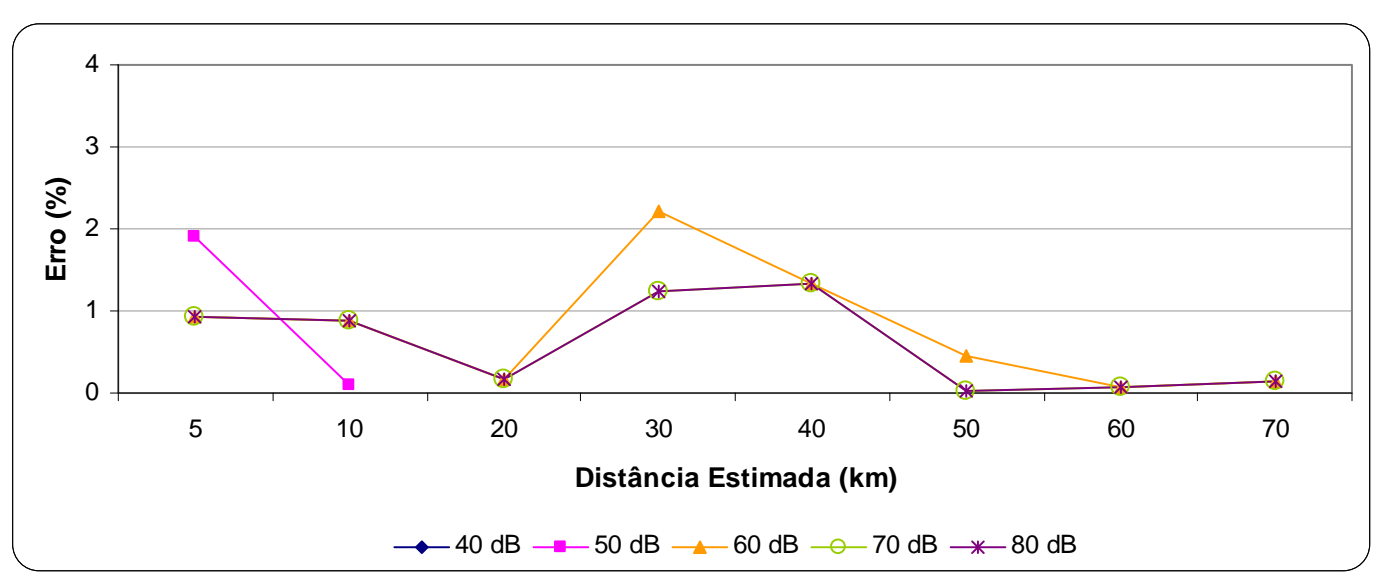

FIGURA 112 - Resultados médios obtidos utilizando sinais de corrente dado situações de faltas fase-fase aplicadas sobre o ramo 2, com ângulo de incidência de $90^{\circ}$ e presença de ruído branco - dados locais.

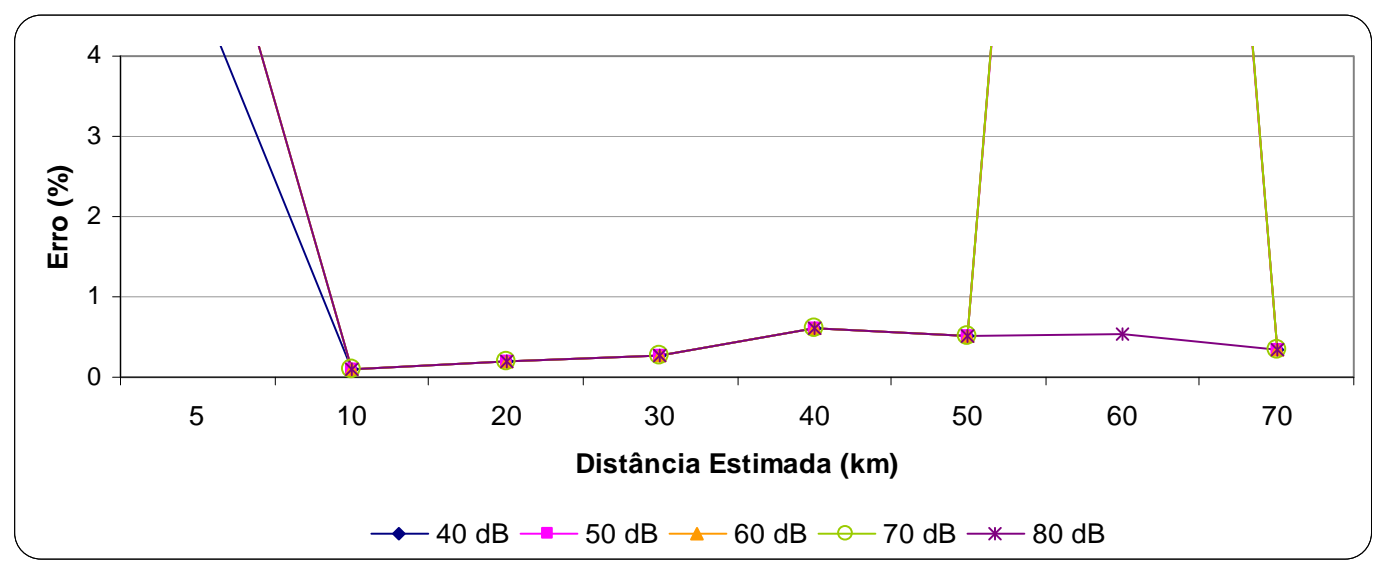

FIGURA 113 - Resultados médios obtidos utilizando sinais de tensão dado situações de faltas fase-fase aplicadas sobre o ramo 2, com ângulo de incidência de $0^{\circ}$ e presença de ruído branco-dados locais.

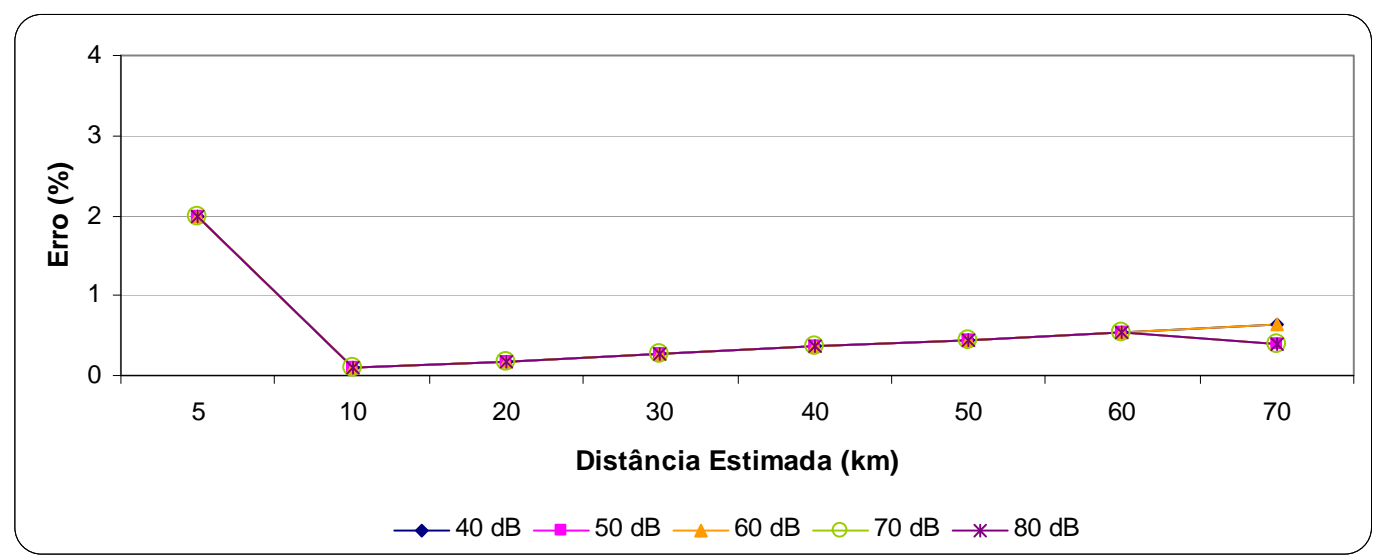

FIGURA 114 - Resultados médios obtidos utilizando sinais de tensão dado situações de faltas fase-fase aplicadas sobre o ramo 2, com ângulo de incidência de $30^{\circ}$ e presença de ruído branco - dados locais. 


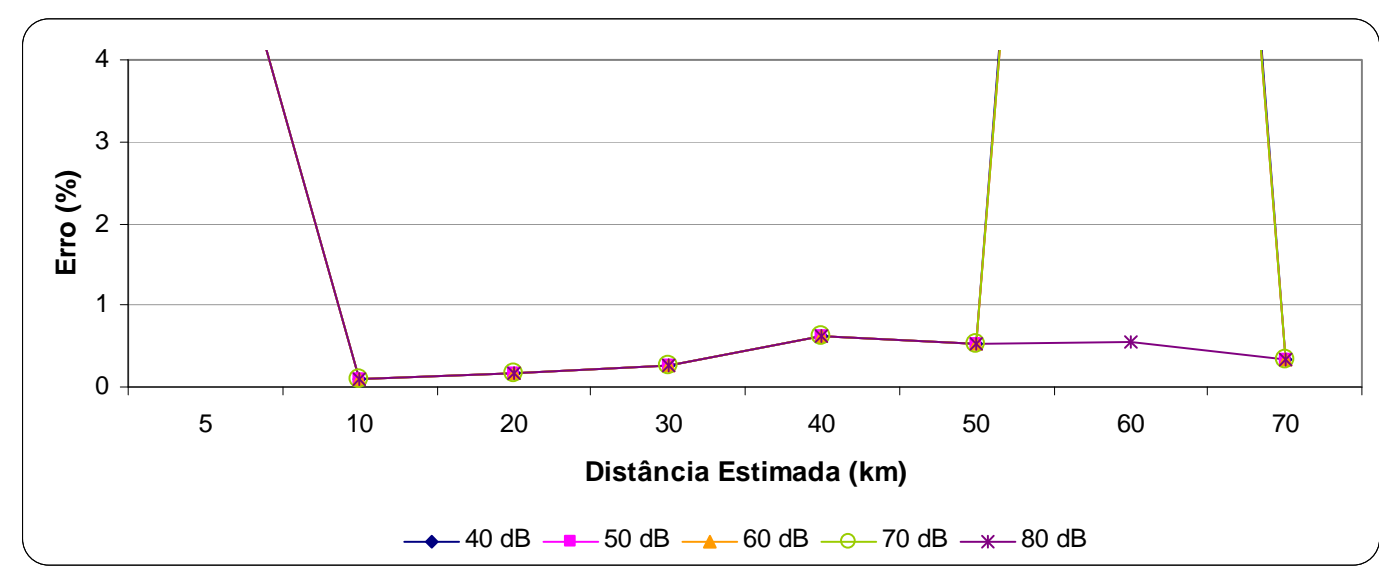

FIGURA 115 - Resultados médios obtidos utilizando sinais de tensão dado situações de faltas fase-fase aplicadas sobre o ramo 2, com ângulo de incidência de $90^{\circ}$ e presença de ruído branco - dados locais.

\subsubsection{Influência do acoplamento mútuo dado um circuito duplo de transmissão}

É comum encontrarmos no sistema elétrico, circuitos duplos de transmissão, por estes possibilitarem uma maior transmissão de potência a um custo menor de investimento, necessitando apenas, de uma torre para a sustentação de dois circuitos.

Portanto, neste contexto, é importante verificarmos o desempenho do localizador de faltas aplicado a um sistema de transmissão duplo. Aparentemente, ao invés de um simples circuito, teríamos dois circuitos em paralelos sustentados pelas mesmas torres. Mas isso não é tão simples, pois devemos considerar o acoplamento mútuo que existe entre as fases de ambos os circuitos e a assimetria deste circuito, principalmente com relação ao solo, podendo este último, ocasionar um mau desacoplamento do sistema e, conseqüentemente, introduzir possíveis erros aos modos aéreos e terra. Em particular ao modo aéreo 1, sobre o qual está baseada a localização da falta em nosso estudo, podendo então, a vir a afetar o desempenho do modelo proposto.

Diante destes fatos, o algoritmo localizador foi testado, utilizando-se de dados registrados nos três terminais, simultâneos ou apenas locais, de um circuito duplo vertical de transmissão, o qual já foi descrito no Capítulo 4. Os dados das tensões e correntes trifásicas também foram obtidos através da simulação de um circuito duplo vertical em situação faltosa por meio do software ATP.

Constatou-se pelos resultados, que ao utilizar-se de dados sincronizados dos três terminais, não houve grandes variações na precisão do algoritmo, mesmo quando da variação dos seguintes parâmetros: distância, resistência, ângulo e incidência da falta. Como exemplo, nas Figuras de 116 a 118, têm-se os resultados de simulações de faltas 
fase-terra aplicadas nos três ramos do sistema em análise, onde se pode observar o desempenho do módulo de localização de faltas baseado em ondas viajantes e dados sincronizados dos três terminais. Nestes exemplos, o maior erro apresentado não foi superior a $1,0 \%$.

Ao utilizar-se o módulo de localização de faltas baseado em dados locais, percebeu-se também que este não veio a sofrer grande influência do acoplamento mútuo introduzido por um circuito duplo de transmissão, apresentando um desempenho favorável na maioria dos testes executados, salvo algumas situações, como se pode observar pelas Figuras 119 e 120, onde a maioria dos erros encontrados também foi inferior a $1,0 \%$.

Outra importante observação foi que ambos os módulos de localização por ondas viajantes, mostraram-se também independentes da influência da resistência e do ângulo de incidência de falta, salvo alguns casos com elevadas resistências de falta e ângulo de incidência igual a zero grau, principalmente quando utilizado o módulo que trabalha com dados locais (um terminal).

No geral, pode-se afirmar que o acoplamento mútuo e a assimetria encontrada no circuito duplo vertical de $440 \mathrm{kV}$, não causaram significativa influência no desempenho dos módulos de localização por ondas viajantes.

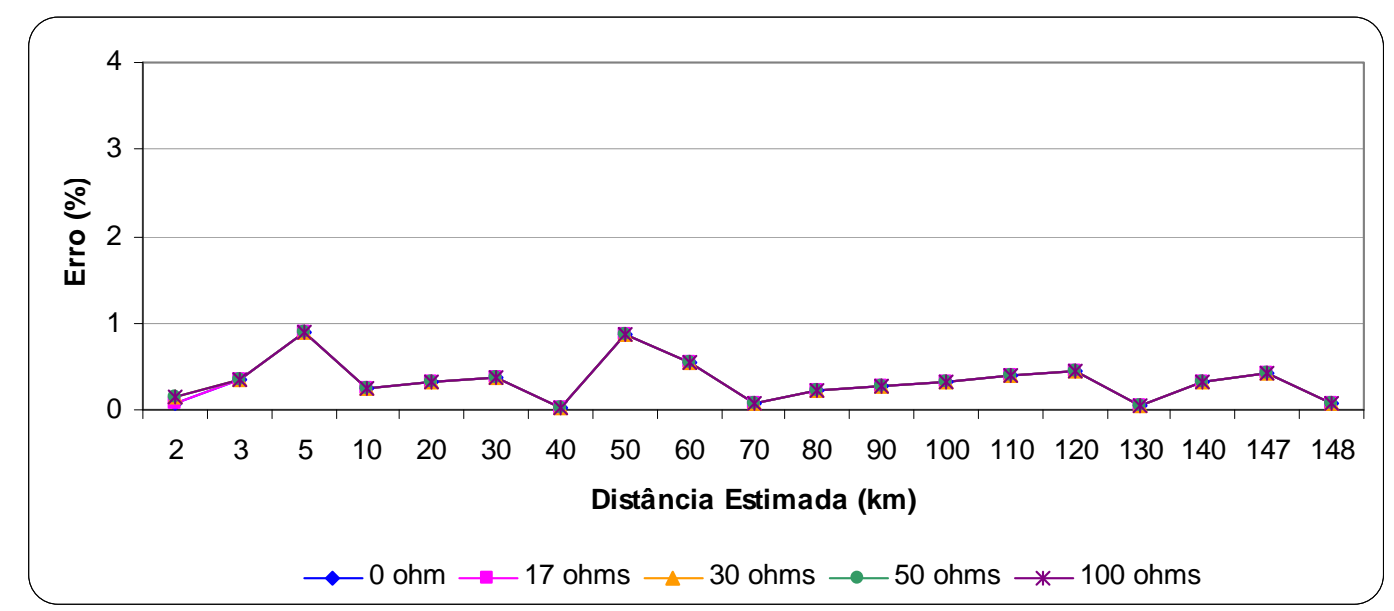

FIGURA 116 - Resultados médios obtidos utilizando sinais de corrente, dado situações de faltas faseterra aplicadas sobre o ramo 1 de um circuito duplo vertical com ângulo de incidência de $30^{\circ}$. 


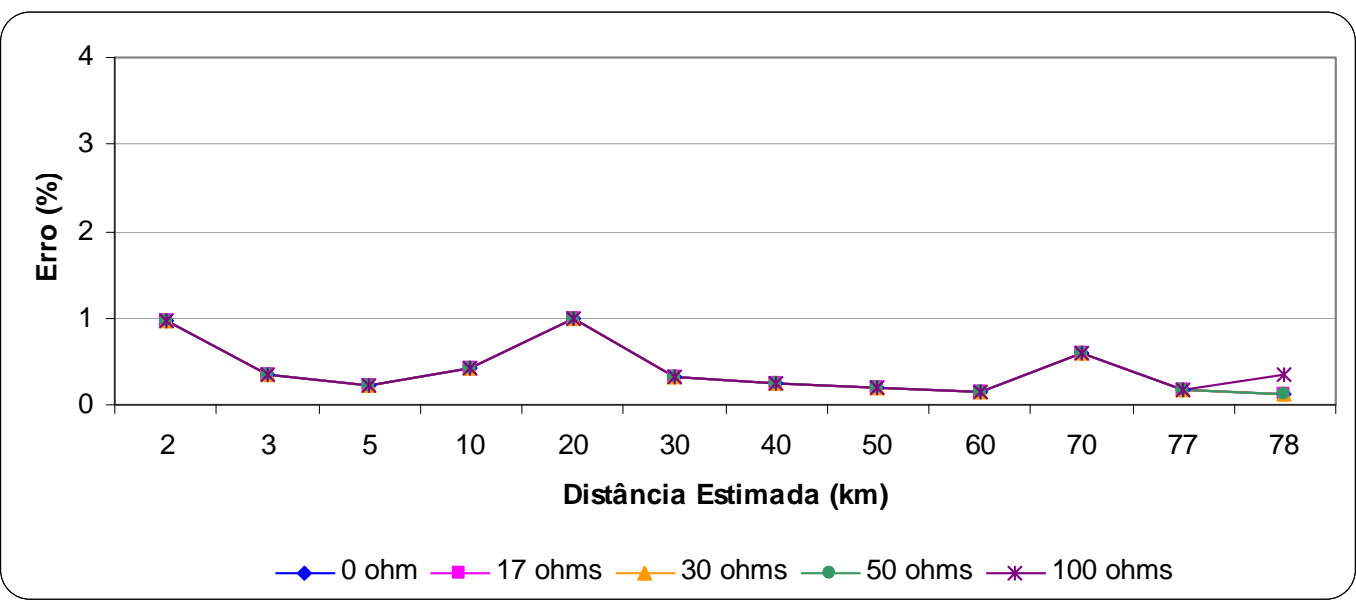

FIGURA 117 - Resultados médios obtidos utilizando sinais de corrente, dado situações de faltas faseterra aplicadas sobre o ramo 2 de um circuito duplo com ângulo de incidência de $0^{\circ}$.

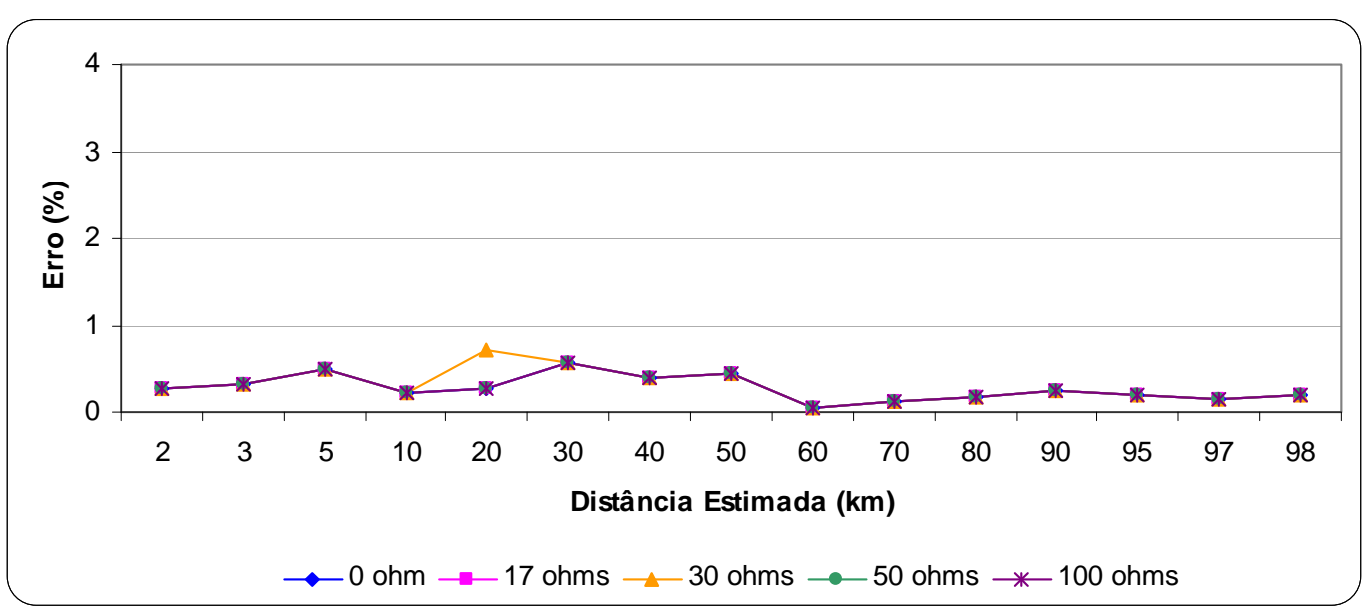

FIGURA 118 - Resultados médios obtidos utilizando sinais de corrente, dado situações de faltas faseterra aplicadas sobre o ramo 3 de um circuito duplo vertical com ângulo de incidência de $90^{\circ}$.

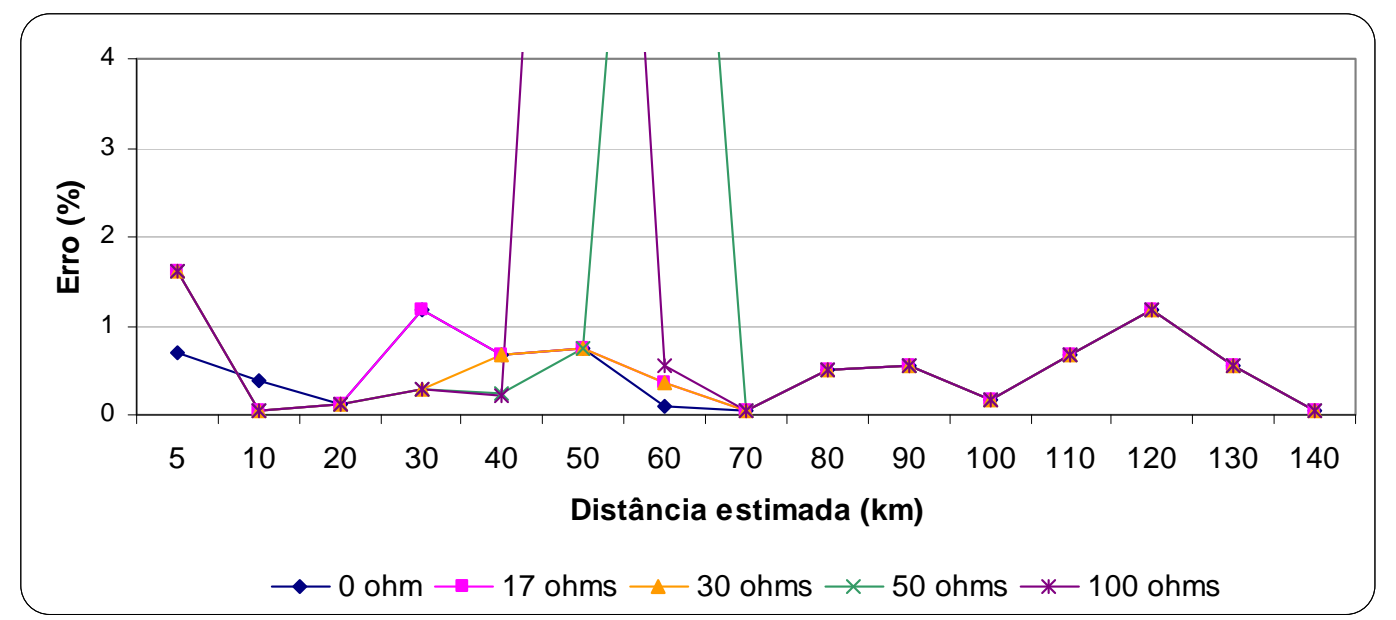

FIGURA 119 - Resultados médios obtidos utilizando sinais de corrente, dado situações de faltas faseterra aplicadas sobre o ramo 1 de um circuito duplo vertical com ângulo de incidência de $30^{\circ}$ - dados locais. 


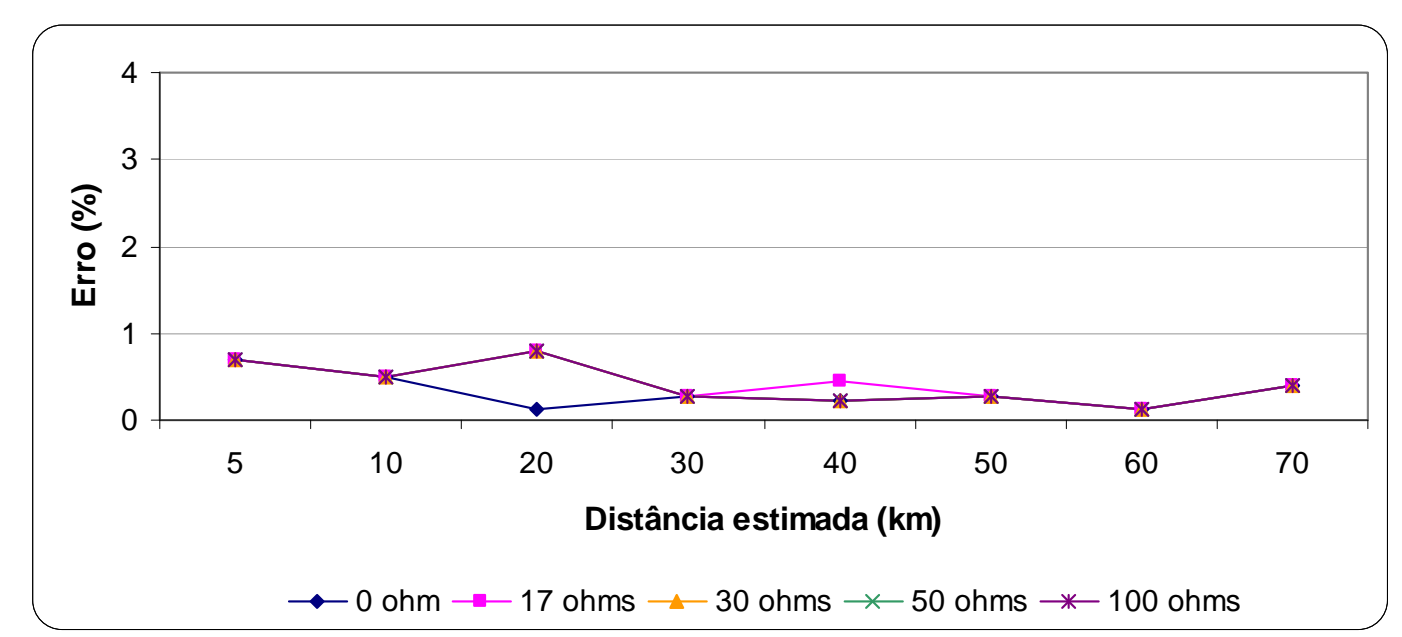

FIGURA 120 - Resultados médios obtidos utilizando sinais de corrente, dado situações de faltas faseterra aplicadas sobre o ramo 2 de um circuito duplos com ângulo de incidência de $0^{\circ}$ - dados locais.

\subsubsection{Comportamento do algoritmo de ondas viajantes sobre linhas com parâmetros variando com a freqüência.}

A maior parte dos testes realizados com o algoritmo híbrido de localização de faltas foi feita utilizando-se o modelo de linha com parâmetros distribuídos constantes com variação de freqüência, sendo este um dos modelos mais completos e preciso para modelagem de sistemas elétricos. O mesmo também é recomendado pelo próprio manual do ATP [94] para ser trabalhar com ondas viajantes. Todavia, sabe-se que em um sistema real, há a variação dos parâmetros do sistema (resistência, indutância e capacitância) em função da variação da freqüência.

Visto que a variação da freqüência poderia influenciar de alguma forma o algoritmo de localização de faltas híbrido aqui proposto, buscou-se verificar o comportamento do algoritmo frente a dados proveniente de um sistema de três terminais em circuito simples contemplando linhas com parâmetros variantes na freqüência, conforme modelo JMARTI do próprio ATP [94]-[95].

Durante os testes, utilizando-se de dados sincronizados dos três terminais, observou-se que pode haver algumas pequenas variações na precisão do algoritmo frente à variação da freqüência, tanto trabalhando com os sinais de corrente como com os de tensão. Contudo, esta variação além de ser pequena pode afetar no sentido de piorar, ou de melhorar a precisão do algoritmo. As Figuras de 121 a 123 ilustram alguns resultados de testes utilizando-se linhas com parâmetros variantes com a freqüência. Pode-se observar que tanto para os sinais de corrente (Figuras 121 e 122) como para os 
sinais de tensão (Figura 123), o maior erro encontrado (para a maioria dos casos) não foi superior a 2,0\%, salvo algumas situações onde o algoritmo apresentou erros maiores, provenientes de uma má detecção da onda em algum dos terminais, dado a atenuação do sinal em análise.

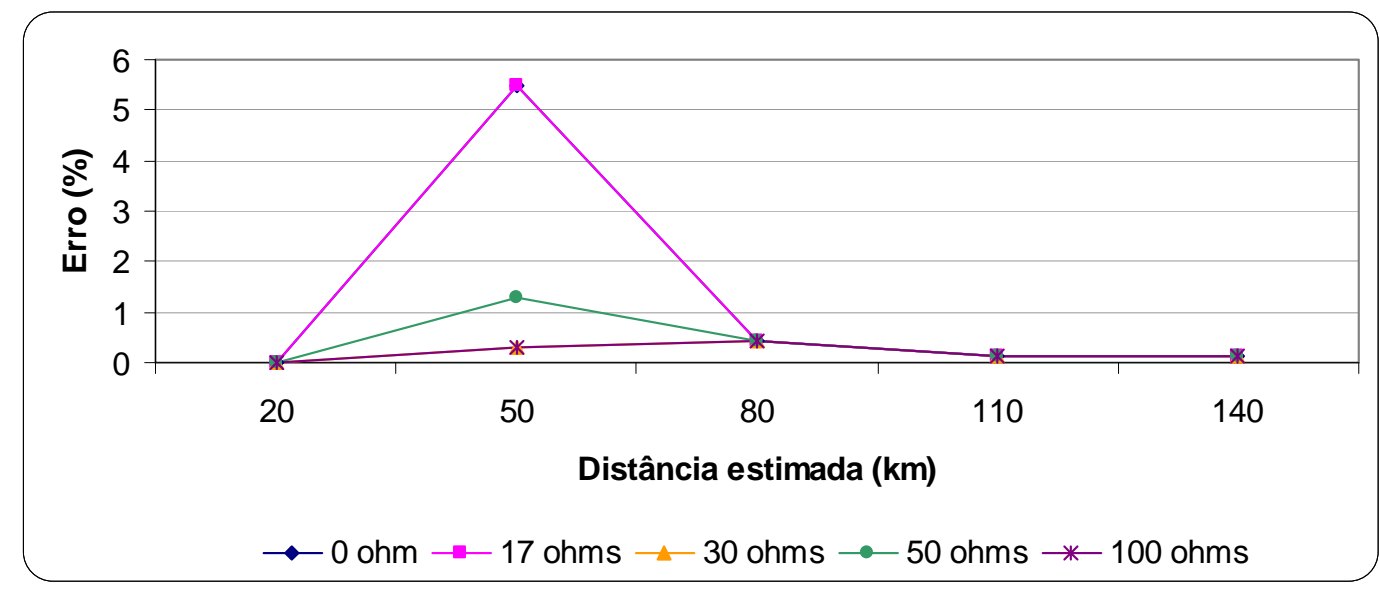

FIGURA 121 - Resultados obtidos utilizando sinais de corrente, dado situações de faltas fase-terra aplicadas sobre o ramo 1 com ângulo de incidência de $0^{\circ}$ e linhas com parâmetros variando com a freqüência.

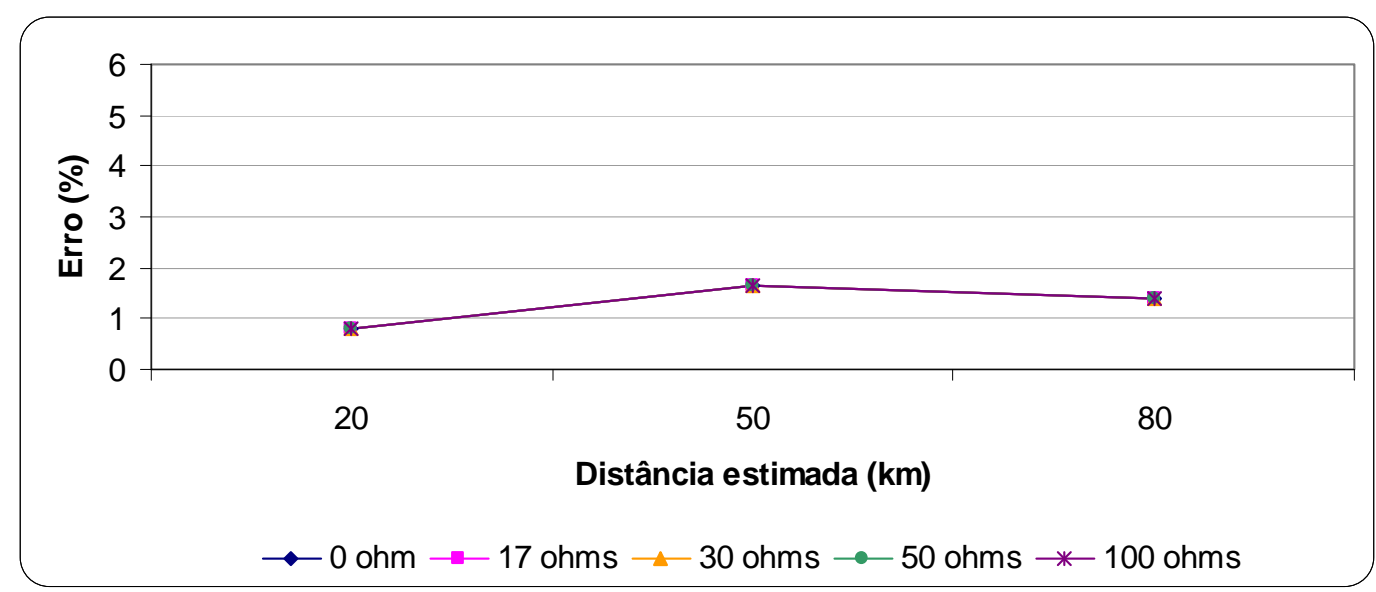

FIGURA 122 - Resultados obtidos utilizando sinais de corrente, dado situações de faltas fase-terra aplicadas sobre o ramo 3 com ângulo de incidência de $90^{\circ}$ e linhas com parâmetros variando com a freqüência. 


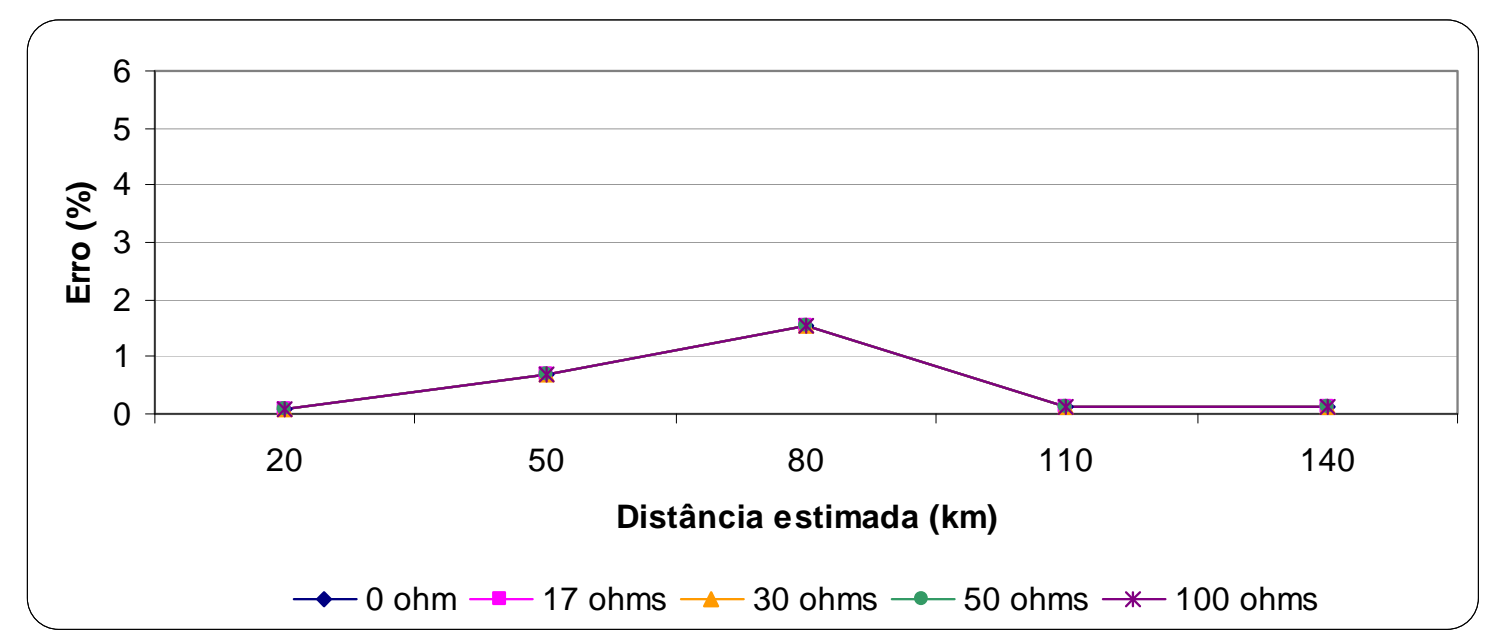

FIGURA 123 - Resultados obtidos utilizando sinais de tensão, dado situações de faltas fase-terra aplicadas sobre o ramo 1 com ângulo de incidência de $0^{\circ}$ e linhas com parâmetros variando com a freqüencia.

Quando utilizado dados de um único terminal, o algoritmo também apresentou variação em suas respostas, podendo estas variações serem benignas ou malignas no tocante a precisão do algoritmo. Analisando os sinais de corrente e excluindo situações com ângulo de incidência a 0 grau, onde o algoritmo pode vir a apresentar erros elevados, o mesmo mostrou um desempenho satisfatório como se pode observar pelas Figuras 124 e 125. Analisando os sinais de tensão, o algoritmo apresentou erros mais elevados para faltas com ângulo de incidência próximo a 0 grau aplicadas sobre o ramo 1 do sistema em teste, porém manteve uma precisão satisfatória para maioria dos testes, conforme se pode observar pelas Figura 126 e 127.

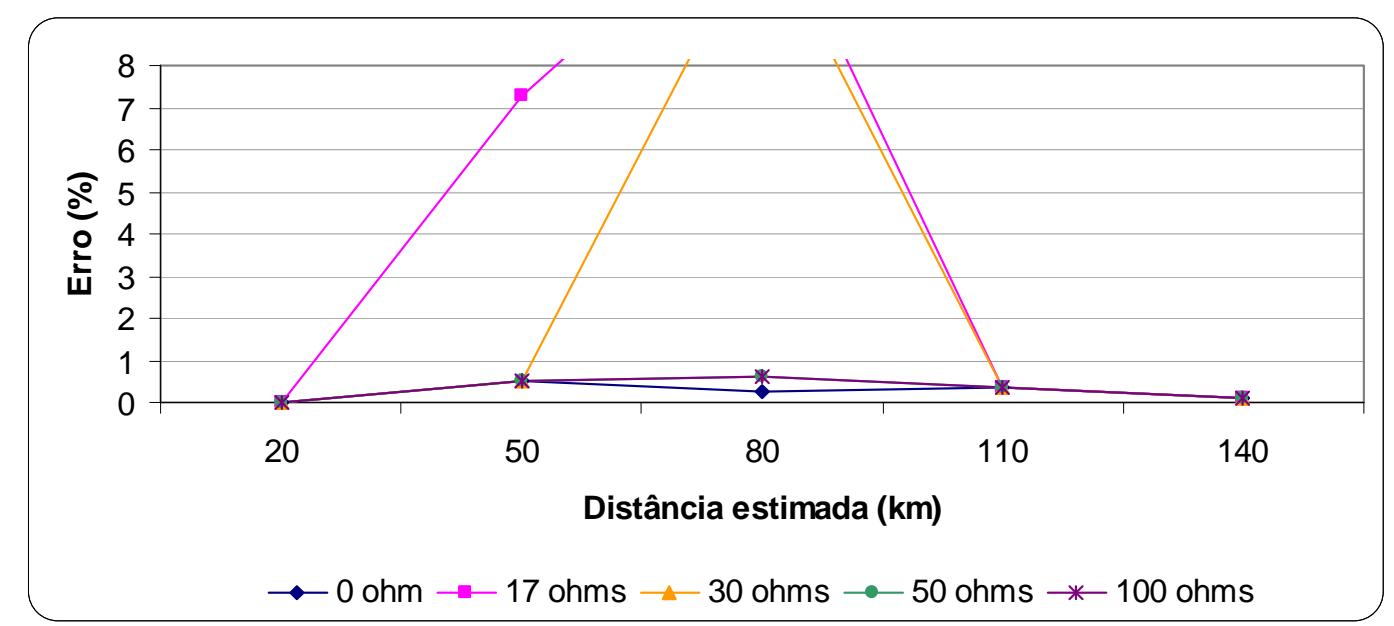

FIGURA 124 - Resultados obtidos utilizando sinais de corrente, dado situações de faltas fase-terra aplicadas sobre o ramo 1 com ângulo de incidência de $0^{\circ}$ e linhas com parâmetros variando com a freqüencia-Dados locais. 


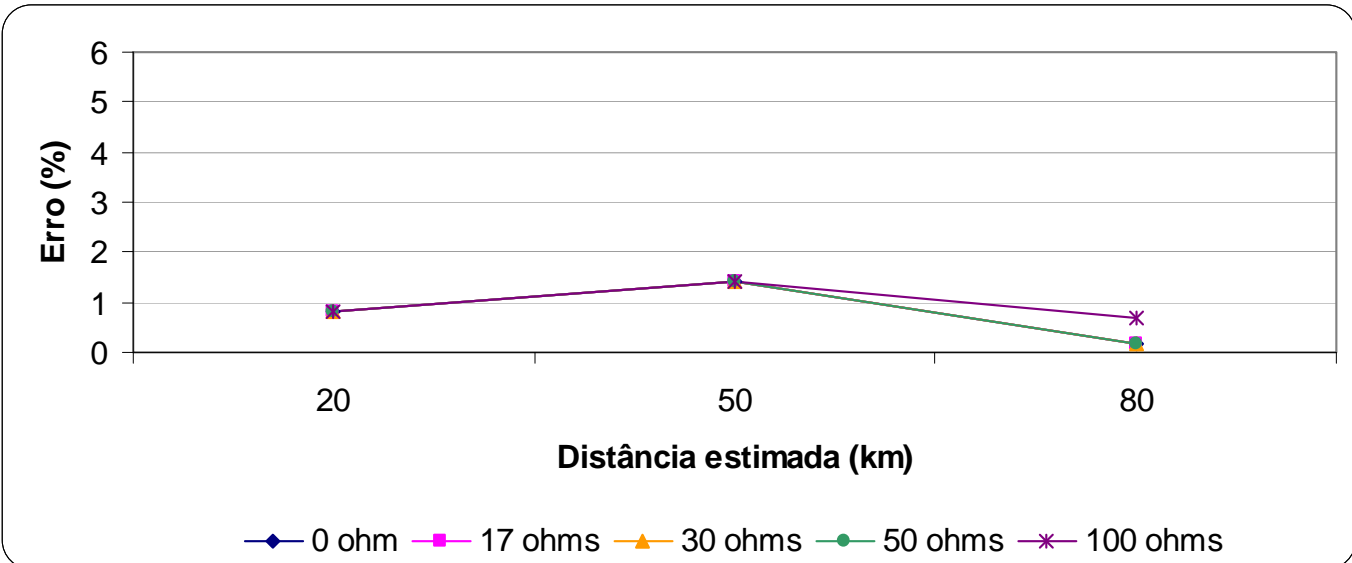

FIGURA 125 - Resultados obtidos utilizando sinais de corrente, dado situações de faltas fase-terra aplicadas sobre o ramo 3 com ângulo de incidência de $90^{\circ}$ e linhas com parâmetros variando com a freqüencia-dados locais.

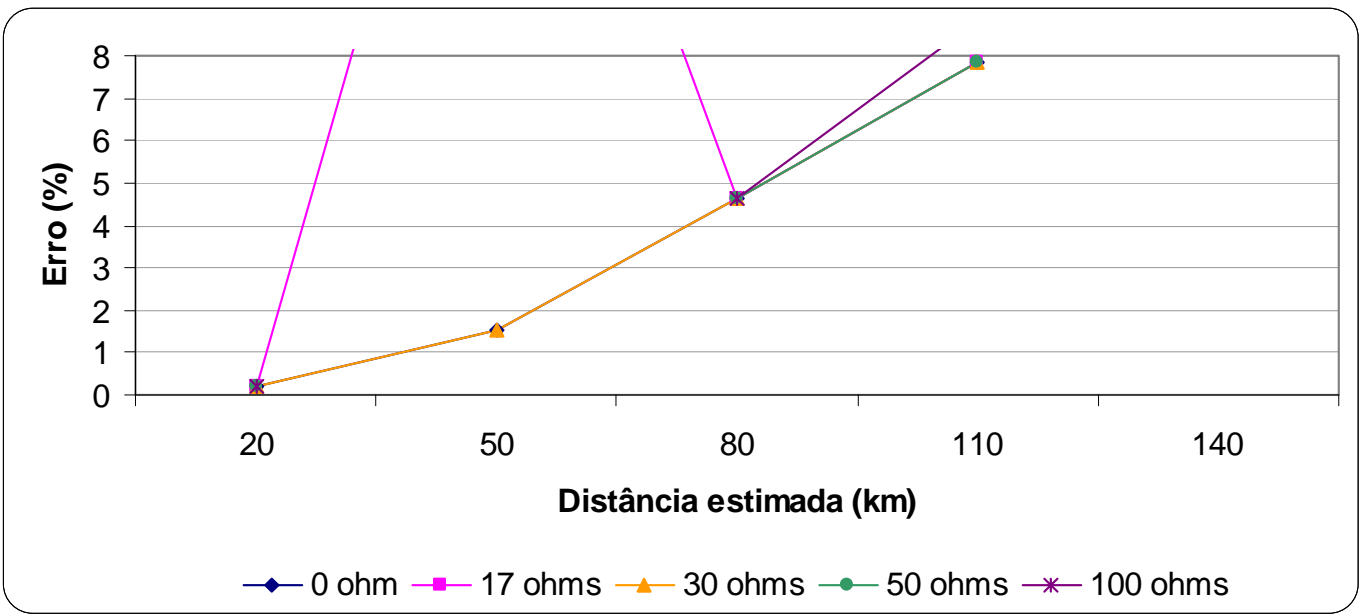

FIGURA 126 - Resultados obtidos utilizando sinais de tensão, dado situações de faltas fase-terra aplicadas sobre o ramo 1 com ângulo de incidência de $0^{\circ}$ e linhas com parâmetros variando com a freqüencia-dados locais.

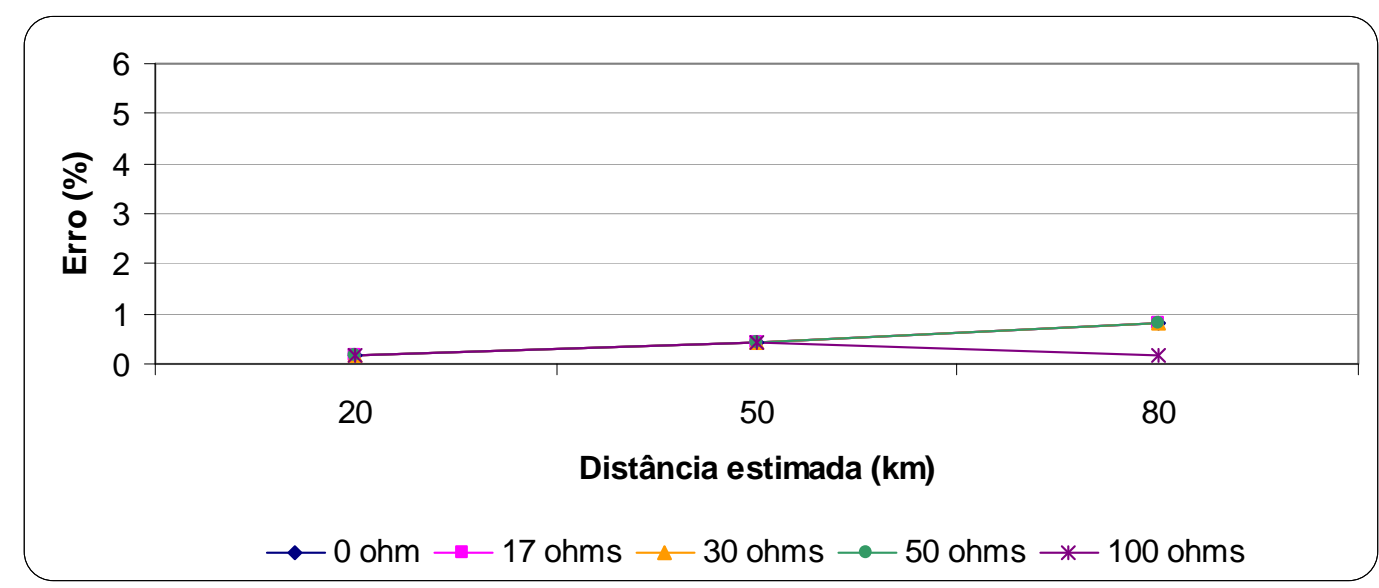

FIGURA 127 - Resultados obtidos utilizando sinais de tensão, dado situações de faltas fase-terra aplicadas sobre o ramo 3 com ângulo de incidência de $90^{\circ}$ e linhas com parâmetros variando com a freqüencia-dados locais. 
Resumindo-se, pôde-se verificar pelos testes, considerando a variação dos parâmetros da linha com a freqüência, que esta pode acarretar uma pequena influência na precisão do algoritmo, podendo ser benéfica ou não, o que não vem a comprometer a eficiência do algoritmo como um todo.

\subsubsection{Localização de distúrbios transitórios}

Como bem evidente, um SEP está susceptível a distúrbios de diversas naturezas, os quais podem ocorrer em qualquer ponto do sistema, mas com uma maior freqüência sobre as linhas de transmissão aéreas, devido a sua extensão, exposição e ao ambiente em que se encontram. Os distúrbios podem ser transitórios, quando caracterizados por um pequeno instante de duração, ou permanentes, havendo a necessidade de isolamento de determinada parte do sistema.

No caso das LTs, na grande maioria das vezes, estas estão sujeitas a distúrbios transitórios, provocados principalmente por descargas atmosféricas, contato de animais de grande envergadura, etc. Dependendo do caso, algumas situações transitórias podem evoluir para situações permanentes.

Todavia, mesmo no caso de defeitos transitórios, a identificação do tipo e da distância da falta é muito importante para fornecer informações que possam ser úteis, por exemplo, a estudos da proteção e desempenho do sistema frente a surtos atmosféricos, além de permitir a montagem de uma base histórica sobre a ocorrência de distúrbios numa LT (PEREIRA) [121]. Com base nesses levantamentos, manutenções preventivas ou melhorias no sistema podem ser feitas ou previstas, a fim de se evitar problemas futuros de maior grandeza.

Visando avaliar o comportamento do módulo de localização por ondas viajantes frente a distúrbios transitórios, o mesmo foi colocado a teste com base em simulações de descargas atmosféricas incidindo diretamente no condutor fase e a situações de faltas fase-terra transitórias.

As descargas atmosféricas foram simuladas a partir do modelo de fonte dupla exponencial (TYPE 15 - two-exponentials surge function) existente no ATP [94]. Já as faltas transitórias foram simuladas a partir do fechamento e abertura de chaves temporizadas conforme o caso estudado.

Nesta pesquisa foram avaliadas oito distintas situações: duas situações de descargas atmosféricas $(1,2-50 \mu \mathrm{s},+10 \mathrm{kA}$ - Figura 128) incidindo diretamente sobre 
fase $\mathrm{A}$, a uma distância de $75 \mathrm{~km}$ da barra $\mathrm{A}$ (ramo 1 - circuito simples), com ângulos de incidência de 0 e $90^{\circ}$, e seis situações envolvendo faltas fase-terra transitórias aplicadas também a $75 \mathrm{~km}$ da barra $\mathrm{A}$, com resistência de falta de $17 \mathrm{ohms}$, ângulos de incidência de $0^{\circ}$ e $90^{\circ}$ e com uma duração de $1 / 4,1 / 2$ e 1 ciclo.

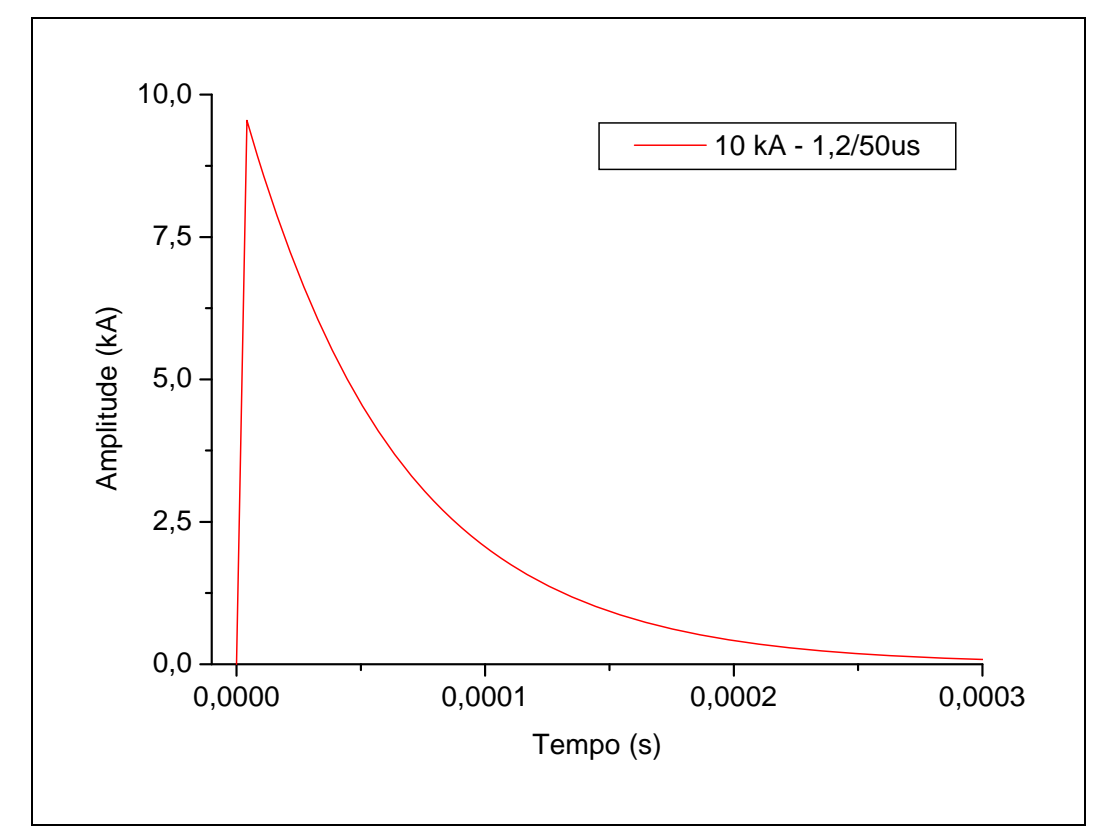

FIGURA 128 - Forma e características da descarga atmosférica gerada.

A Figura 129 ilustra as formas de onda da tensão e da corrente, medidas nos três terminais do circuito simples, para um caso de falta transitória (fase-terra) com duração de $1 / 4$ de ciclo e incidência a zero grau, aplicada a $75 \mathrm{~km}$ da barra A. Neste caso, tanto pela análise dos sinais de corrente como pelos de tensão, o algoritmo foi capaz detectar, classificar e localizar a ocorrência do distúrbio. No caso do uso dos sinais de corrente e tensão, o distúrbio foi caracterizado como sendo a 74,8 km e a 76,06 km da barra A, respectivamente.

No que segue, o algoritmo foi avaliado frente a simulações de descargas atmosféricas incidindo diretamente sobre a fase A. Em um dos testes foi aplicada uma descarga a uma distância de $75 \mathrm{~km}$ da barra $\mathrm{A}$ com ângulo de incidência de $0^{\circ}$. Neste caso o módulo de localização por ondas viajantes utilizando dados dos três terminais foi capaz detectar e localizar com um desempenho altamente satisfatório tal distúrbio, podendo utilizar para isto, tanto dos sinais de corrente como os de tensão.

Um resumo dos resultados referentes a distúrbios transitórios e descargas atmosféricas aplicados sobre o módulo de localização por ondas viajantes utilizando 
dados dos três terminais, assim como do terminal local, são apresentado nas Tabelas 10 e 11, respectivamente. Em ambas as Tabelas podemos constatar a aplicabilidade e o bom desempenho dos módulos de localização sob teste.
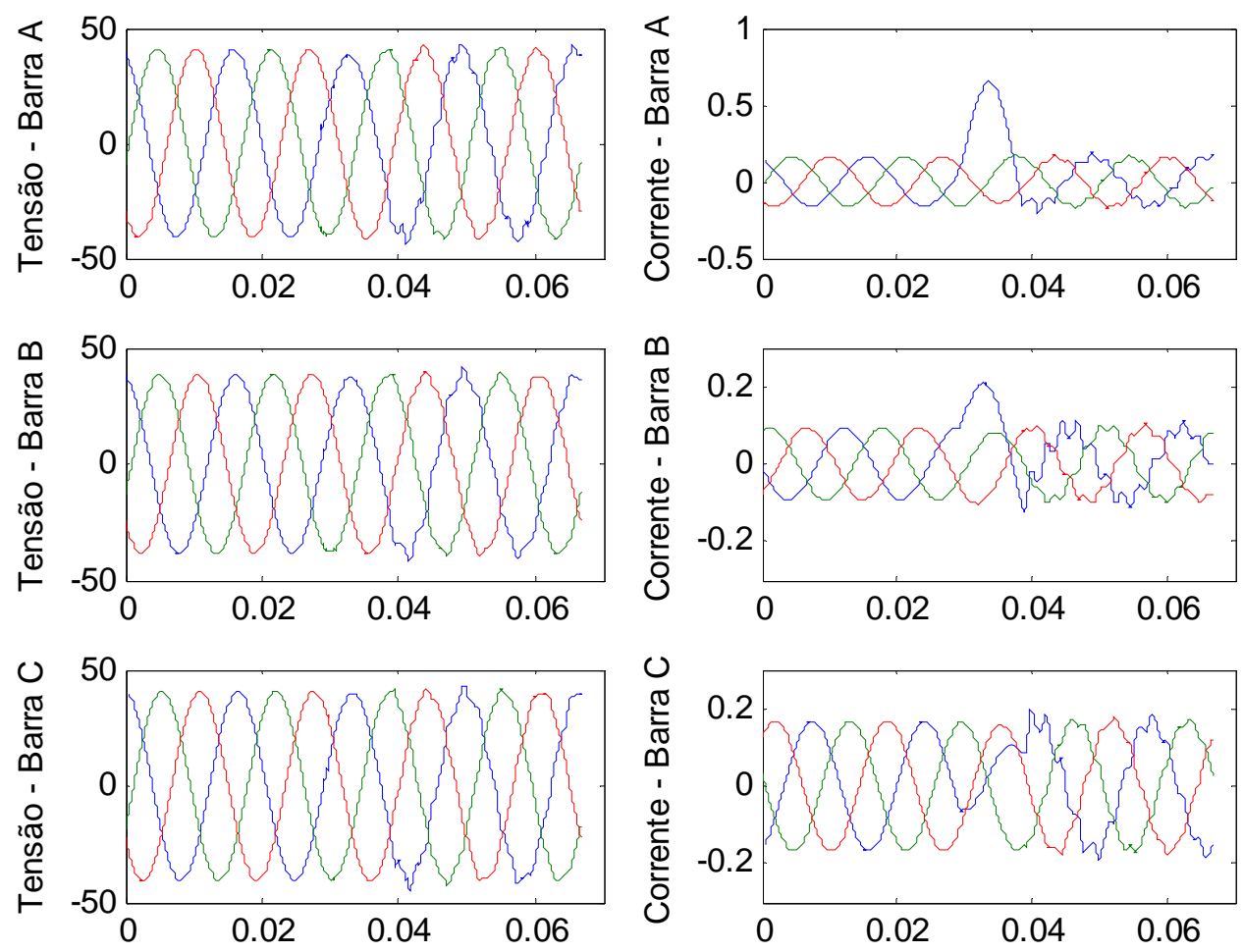

FIGURA 129 - Formas de ondas da tensão e corrente, medidas nos três terminais para uma situação de falta fase-terra com duração de $1 / 4$ de ciclo aplicada a $75 \mathrm{~km}$ da barra $\mathrm{A}$.

TABELA 10 - Resultados referentes à aplicação de faltas transitórias e descarga atmosférica, utilizando sinais de corrente ou tensão.

\begin{tabular}{|c|c|c|c|c|c|c|c|c|c|}
\hline Tipo da Falta & $\begin{array}{c}\text { Distância } \\
\text { Real } \\
\text { (km) }\end{array}$ & $\begin{array}{c}\text { Ângulo de } \\
\text { incidência } \\
\text { (graus) }\end{array}$ & $\begin{array}{l}\text { Duração } \\
\text { (ciclos) }\end{array}$ & $\begin{array}{c}\text { Classificação } \\
\text { da Falta } \\
(A B C / T)\end{array}$ & $\begin{array}{c}\text { Ramo } \\
\text { Faltoso }\end{array}$ & $\begin{array}{c}\text { Localização } \\
\text { Média Absoluta } \\
\text { (D2 - Corrente) } \\
\text { (km) }\end{array}$ & $\begin{array}{l}\text { Erro } \\
(\%)\end{array}$ & $\begin{array}{c}\text { Localização } \\
\text { Média Absoluta } \\
\text { (D2 - Tensão) } \\
\text { (km) }\end{array}$ & $\begin{array}{l}\text { Erro } \\
(\%)\end{array}$ \\
\hline Faltas transitórias & 75 & 0 & $1 / 4$ & AT & AP & 74,80 & 0,08 & 76,02 & 0,41 \\
\hline Faltas transitórias & 75 & 0 & $1 / 2$ & AT & AP & 74,80 & 0,08 & 76,02 & 0,41 \\
\hline Faltas transitórias & 75 & 0 & 1 & AT & AP & 74,80 & 0,08 & 76,02 & 0,41 \\
\hline Faltas transitórias & 75 & 90 & $1 / 4$ & AT & AP & 74,80 & 0,08 & 73,58 & 0,57 \\
\hline Faltas transitórias & 75 & 90 & $1 / 2$ & AT & AP & 74,80 & 0,08 & 73,58 & 0,57 \\
\hline Faltas transitórias & 75 & 90 & 1 & AT & AP & 74,80 & 0,08 & 73,58 & 0,57 \\
\hline Desc. Atmosférica & 75 & 0 & 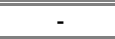 & AT & AP & 75,47 & 0,19 & 75,43 & 0,17 \\
\hline Desc. Atmosférica & 75 & 90 & - & AT & AP & 73,59 & 0,57 & 76,03 & 0,41 \\
\hline $\begin{array}{c}\text { Falta com } \\
\text { saturação do TC }\end{array}$ & 20 & 90 & - & $A B C$ & AP & 19,83 & 0,07 & - & - \\
\hline
\end{tabular}


TABELA 11 - Resultados referentes à aplicação de faltas transitórias e descarga atmosférica, utilizando sinais de corrente ou tensa-dados locais.

\begin{tabular}{|c|c|c|c|c|c|c|c|c|c|}
\hline Tipo da Falta & $\begin{array}{c}\text { Distância } \\
\text { Real } \\
(\mathrm{km}) \\
\end{array}$ & $\begin{array}{c}\text { Ângulo de } \\
\text { incidência } \\
\text { (graus) }\end{array}$ & $\begin{array}{l}\text { Duração } \\
\text { (ciclos) }\end{array}$ & $\begin{array}{c}\text { Classificação } \\
\text { da Falta } \\
(\mathrm{ABC} / \mathrm{T})\end{array}$ & $\begin{array}{c}\text { Ramo } \\
\text { Faltoso }\end{array}$ & $\begin{array}{c}\text { Localização } \\
\text { Média Absoluta } \\
\text { (D2 - Corrente) } \\
\text { (km) }\end{array}$ & $\begin{array}{l}\text { Erro } \\
(\%) \\
\end{array}$ & $\begin{array}{c}\text { Localização } \\
\text { Média Absoluta } \\
\text { (D2 - Tensão) } \\
\text { (km) }\end{array}$ & $\begin{array}{l}\text { Erro } \\
\text { (\%) } \\
\end{array}$ \\
\hline Faltas transitórias & 75 & 0 & $1 / 4$ & AT & AP & 74,51 & 0,20 & 73,29 & 0,68 \\
\hline Faltas transitórias & 75 & 0 & $1 / 2$ & AT & AP & 74,51 & 0,20 & 73,29 & 0,68 \\
\hline Faltas transitórias & 75 & 0 & 1 & AT & AP & 74,51 & 0,20 & 73,29 & 0,68 \\
\hline Faltas transitórias & 75 & 90 & $1 / 4$ & AT & AP & 73,29 & 0,68 & 73,89 & 0,44 \\
\hline Faltas transitórias & 75 & 90 & $1 / 2$ & AT & AP & 73,29 & 0,68 & 73,89 & 0,44 \\
\hline Faltas transitórias & 75 & 90 & 1 & AT & $\mathrm{AP}$ & 73,29 & 0,68 & 73,89 & 0,44 \\
\hline Desc. Atmosférica & 75 & 0 & - & AT & AP & 75,72 & 0,29 & 75,72 & 0,29 \\
\hline Desc. Atmosférica & 75 & 90 & - & AT & AP & 78,17 & 1,27 & 73,29 & 0,68 \\
\hline $\begin{array}{c}\text { Falta com } \\
\text { saturação do TC }\end{array}$ & 20 & 90 & - & $A B C$ & AP & 19,54 & 0,18 & - & - \\
\hline
\end{tabular}

\subsubsection{Influência da saturação dos TC's na localização por ondas viajantes}

Em situações normais os TC's devem representar o mais precisamente possível, a níveis reduzidos, as elevadas correntes presentes nos sistemas primários de potência. Contudo, situações anormais podem ocorrer, ocasionando, por exemplo, elevadas correntes com alto nível DC, as quais podem levar à saturação o TC e, consequentemente, a uma imperfeita representação (medida) das correntes primárias. Esta saturação dos TC's pode causar atuações errôneas dos sistemas de proteção ou pior ainda, ocasionar a não atuação dos dispositivos de proteção frente a uma situação de distúrbio.

Analogamente, a imperfeita representação das correntes em caso de saturação dos TC's, também pode influir diretamente sobre os localizadores de falta, os conduzindo a indicações errôneas, ou mesmo, a não indicação do ponto da falta.

Portanto, julga-se importante avaliar ambos os módulos de localização do LFHTW 1.0, iniciando pelo módulo de ondas viajantes, frente a eminente situação de saturação de um TC.

A condição de saturação foi obtida, considerando-se uma falta trifásica aplicada a $20 \mathrm{~km}$ da barra $\mathrm{A}$ e com a elevação da relação $\mathrm{R} / \mathrm{X}$ da fonte $\mathrm{A}$ e da impedância do terminal secundário do TC. Mesmo assim, obteve-se um pequeno nível de saturação dos TC's, como pode ser visto na Figura 130.

Neste caso, observou-se também que o módulo de ondas viajantes foi capaz de detectar e localizar a ocorrência a uma distância de $19,83 \mathrm{~km}$ da barra A ao se utilizar dados sincronizados dos três terminais e a uma distância de 19,54 km da barra A, 
quando utilizado apenas dados do terminal local. Tais resultados também estão expressos nas Tabelas 10 e 11, respectivamente.

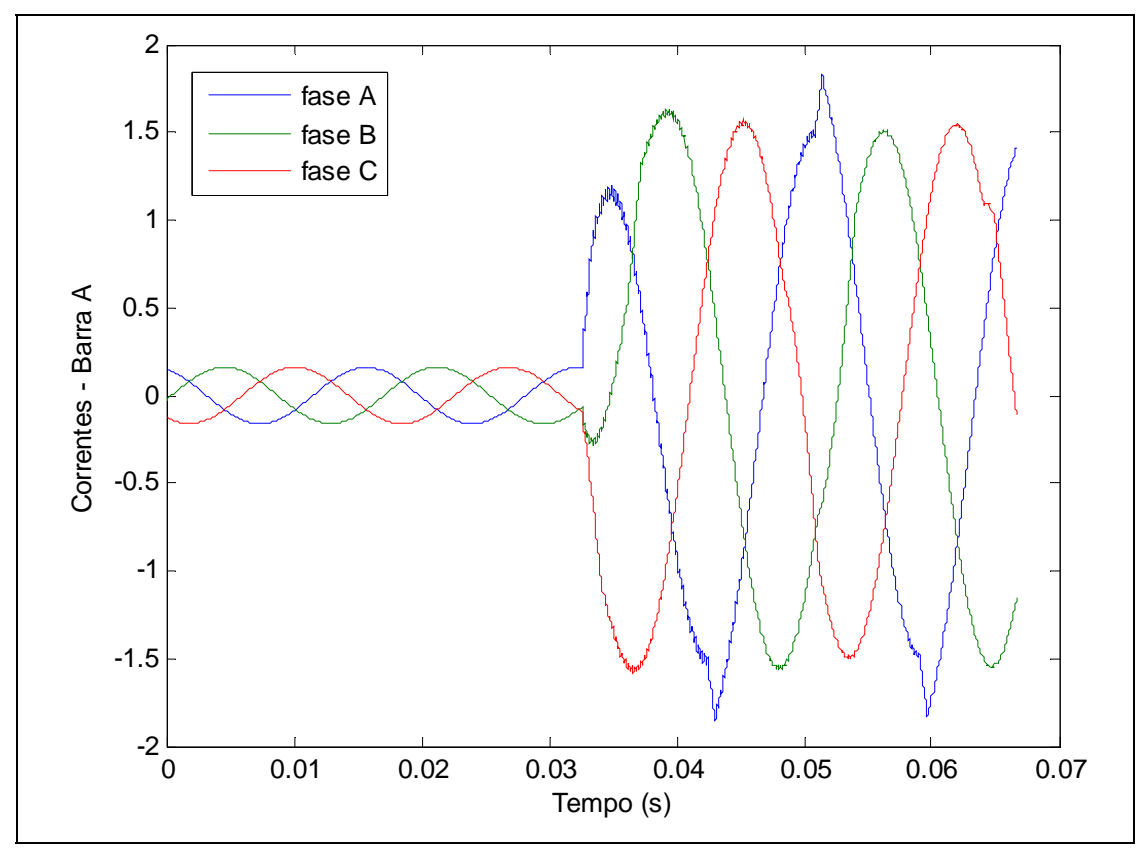

FIGURA 130 - Correntes provenientes da saturação dos TC's (barra A) no caso de uma falta trifásica aplicada a $20 \mathrm{~km}$ com relação à mesma barra.

\subsubsection{Análise de sensibilidade dos módulos baseados em ondas viajantes}

A análise de sensibilidade busca avaliar o desempenho do algoritmo de localização quanto a variações de parâmetros que alimentam o algoritmo, ou seja, da situação de quando os valores não condizem com os valores reais.

Ao considerarmos os módulos de ondas viajantes, um dos principais parâmetros susceptível a erros e que está diretamente ligado a precisão do algoritmo denomina-se velocidade de propagação da onda. A velocidade de propagação da onda pode vir a ser calculada conhecendo-se os parâmetros da linha ou determinada em campo por meio de medições.

Diante do contexto, buscou-se avaliar a sensibilidade dos módulos de localização de ondas viajantes aplicando-se testes, ou seja, situações faltosas com parametrização errônea da velocidade de propagação da onda para o modo aéreo 1. Nos testes considerou-se uma introdução de erro de $\pm 5,0 \%$ na velocidade de propagação da onda.

Como esperado, pode-se perceber pelos resultados que ambos os módulos de onda viajantes trabalhando com dados dos três terminais (Figuras 131 e 132), ou dados 
locais (Figuras 133 e 134), sofrem influência da variação do parâmetro velocidade de propagação, uma vez que, está diretamente interligada ao perfeito cálculo da distância da falta.

Todavia, mesmo para uma variação de $\pm 5 \%$ na velocidade de propagação da onda, ambos os módulos de ondas viajantes apresentaram resultados satisfatórios, podendo também a imprecisão do parâmetro em questão trazer melhorias quanto a precisão do algoritmo. Nos casos ilustrados, Figuras de 131 a 134, o maior erro encontrado foi inferior a $3,0 \%$.

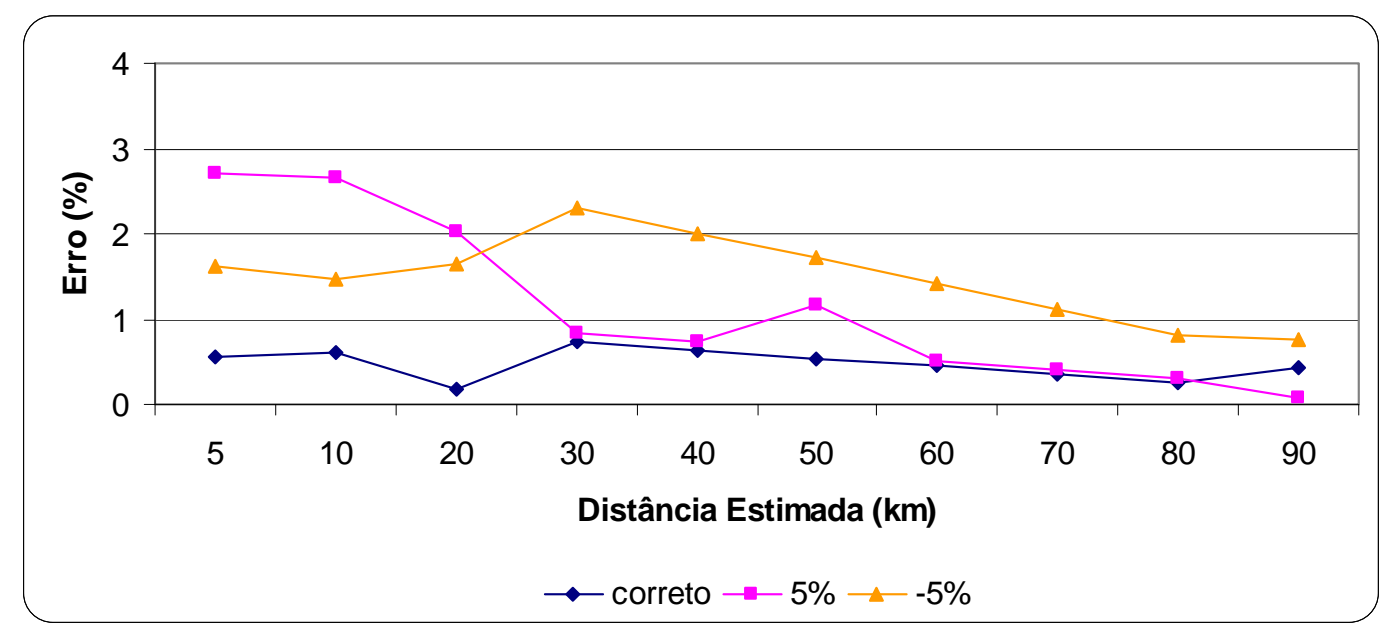

FIGURA 131 - Sensibilidade do módulo de ondas viajante utilizando dados de três terminais em situações de faltas fase-fase com ângulo de incidência de $0^{\circ}$ e com variação da velocidade de propagação.

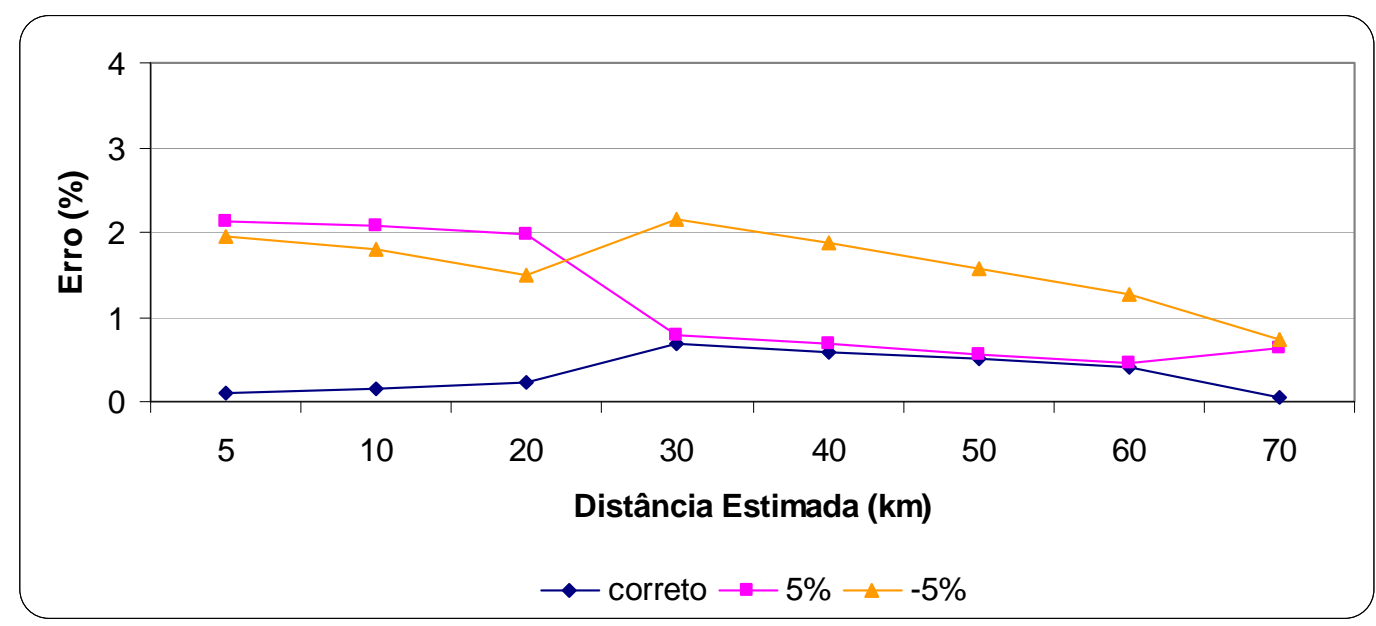

FIGURA 132 - Sensibilidade do módulo de ondas viajante utilizando dados de três terminais em situações de faltas fase-fase com ângulo de incidência de $90^{\circ}$ e com variação da velocidade de propagação. 


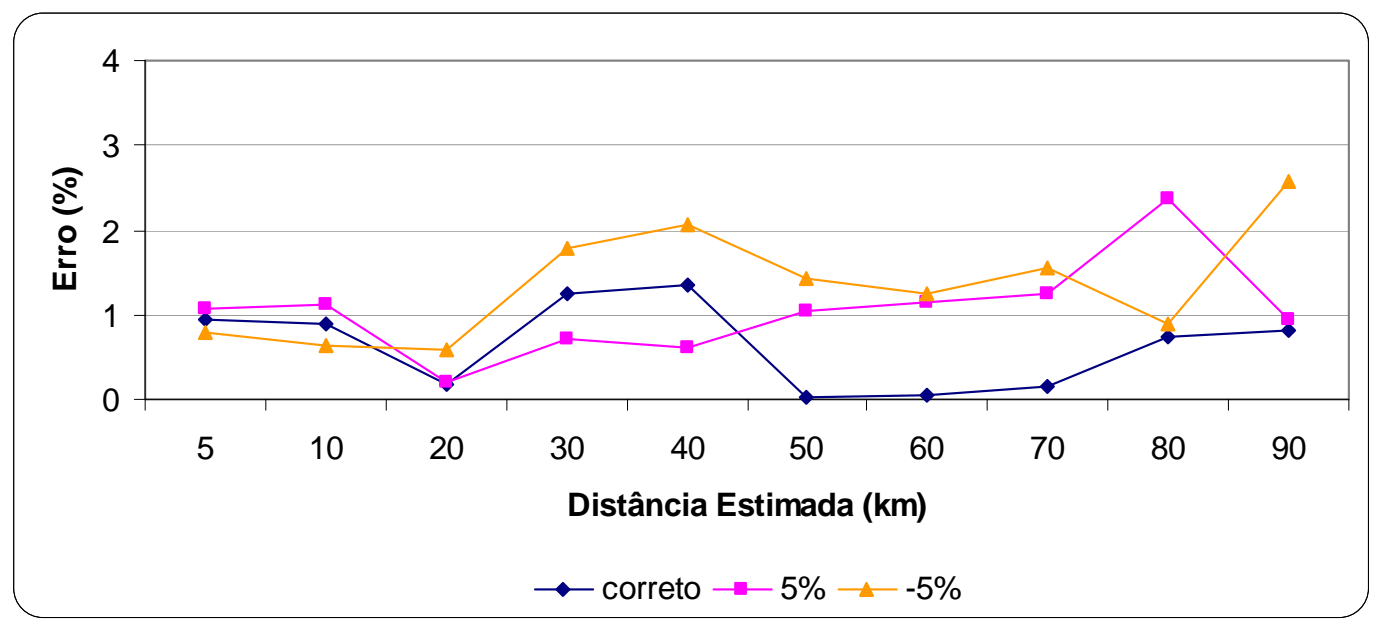

FIGURA 133 - Sensibilidade do módulo de ondas viajante utilizando dados locais em situações de faltas fase-fase com ângulo de incidência de $0^{\circ}$ e com variação da velocidade de propagação.

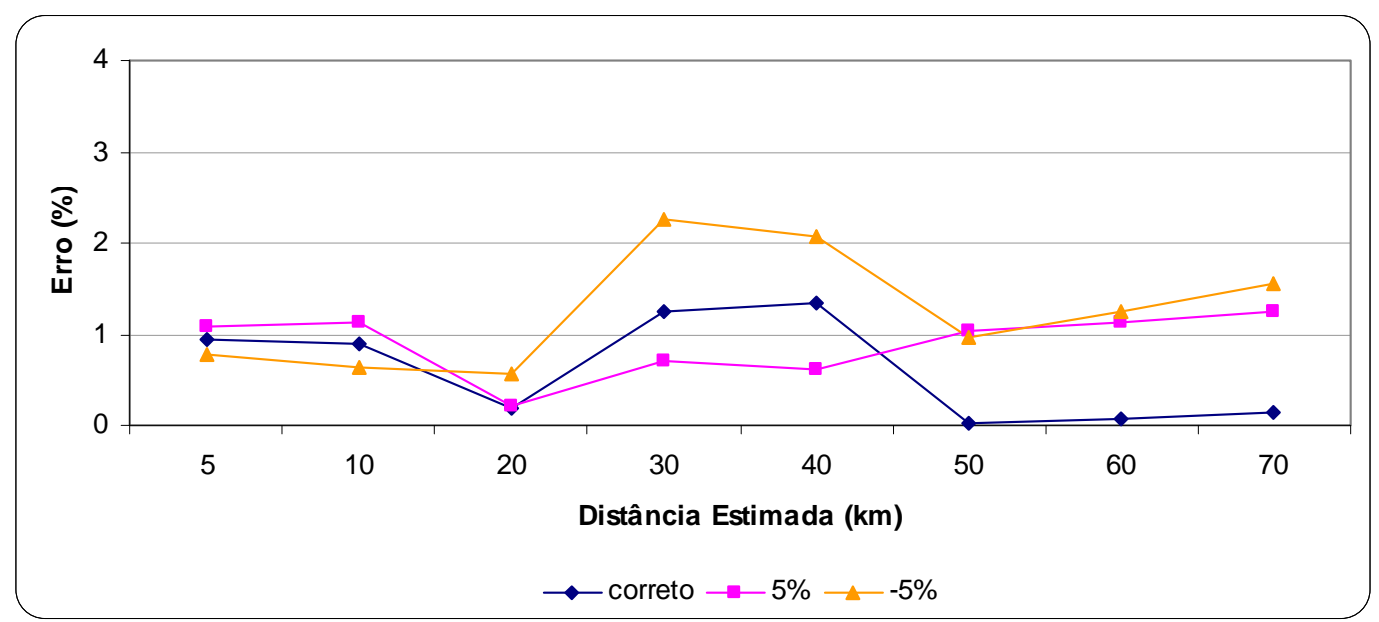

FIGURA 134 - Sensibilidade do módulo de ondas viajante utilizando dados locais em situações de faltas fase-fase com ângulo de incidência de $0^{\circ}$ e com variação da velocidade de propagação.

\subsection{Resultados alcançados pelo módulo de localização baseado em componentes fundamentais extraídos via TWE}

Passamos agora a apresentar e a comentar os resultados obtidos quando utilizado o módulo de localização baseado em componentes fundamentais extraídos via TWE.

Primeiramente, é importante relembrar que o módulo baseado em componentes fundamentais utiliza simultaneamente dos sinais trifásicos de corrente e de tensão, dos quais são extraídos os seus componentes fundamentais via TWE para o cálculo da distância da falta. Por sua vez, pode-se utilizar para o cálculo da distância da falta, tanto 
os sinais de detalhe como os sinais de aproximação. Mostrar-se-á, no decorrer deste trabalho, os resultados obtidos utilizando-se de ambos os sinais.

Considerando o sistema simples horizontal utilizado para testes com o algoritmo, temos que a impedância da onda linha levantada pelo próprio ATP, são as mesmas para os três ramos de linha, já que estas apresentam as mesmas características em função da topologia e condutores empregados. Logo, a impedância de onda para o modo aéreo 1, das linhas do sistema analisado é dada por:

$$
Z_{L T}=2,172410751288417 \mathrm{e}^{2}-1,498046166631060 \mathrm{i}
$$

Definido a impedância de onda do sistema, consideremos que uma falta faseterra (AT) venha a ocorrer a $70 \mathrm{~km}$ da barra $\mathrm{A}$, com ângulo de incidência de $0^{\circ} \mathrm{e}$ resistência de falta de $100 \mathrm{ohms}$. Os sinais registrados referentes a esta situação passam a ser analisados pelo algoritmo de localização, o qual extrairá o componente fundamental da tensão e da corrente pelo emprego da TWE, permitindo assim, que o algoritmo possa processar a localização da falta. As Figuras 135 e 136 ilustram os sinais originais de tensão e corrente correspondentes a fase A, medidas nos três terminais, juntamente com os sinais de detalhe 5 (D5, 38 a $75 \mathrm{~Hz}$ ) e aproximação 3 (A3, 0 a 150 $\mathrm{Hz}$ ), respectivamente. A partir dos sinais de detalhe e aproximação, levantam-se as impedâncias fundamentais e se processa o cálculo da distância da falta. Neste caso em específico, a falta foi localizada a 67,66 km utilizando os sinais de detalhe, e a 67,73 km utilizando os sinais de aproximação. $\mathrm{O}$ algoritmo original baseado na TF estimou a distância da falta como sendo a $68,71 \mathrm{~km}$. Percebe-se neste caso que foi possível localizar a falta com uma boa precisão, utilizando-se da filtragem wavelet, embora os resultados não tenham diferido muito do resultado apresentado pelo algoritmo original utilizando a TF.

No que segue serão apresentados e comentados os resultados dos testes aplicados para avaliar o módulo de localização de faltas baseado em componentes fundamentais integrado ao LFHTW 1.01. 


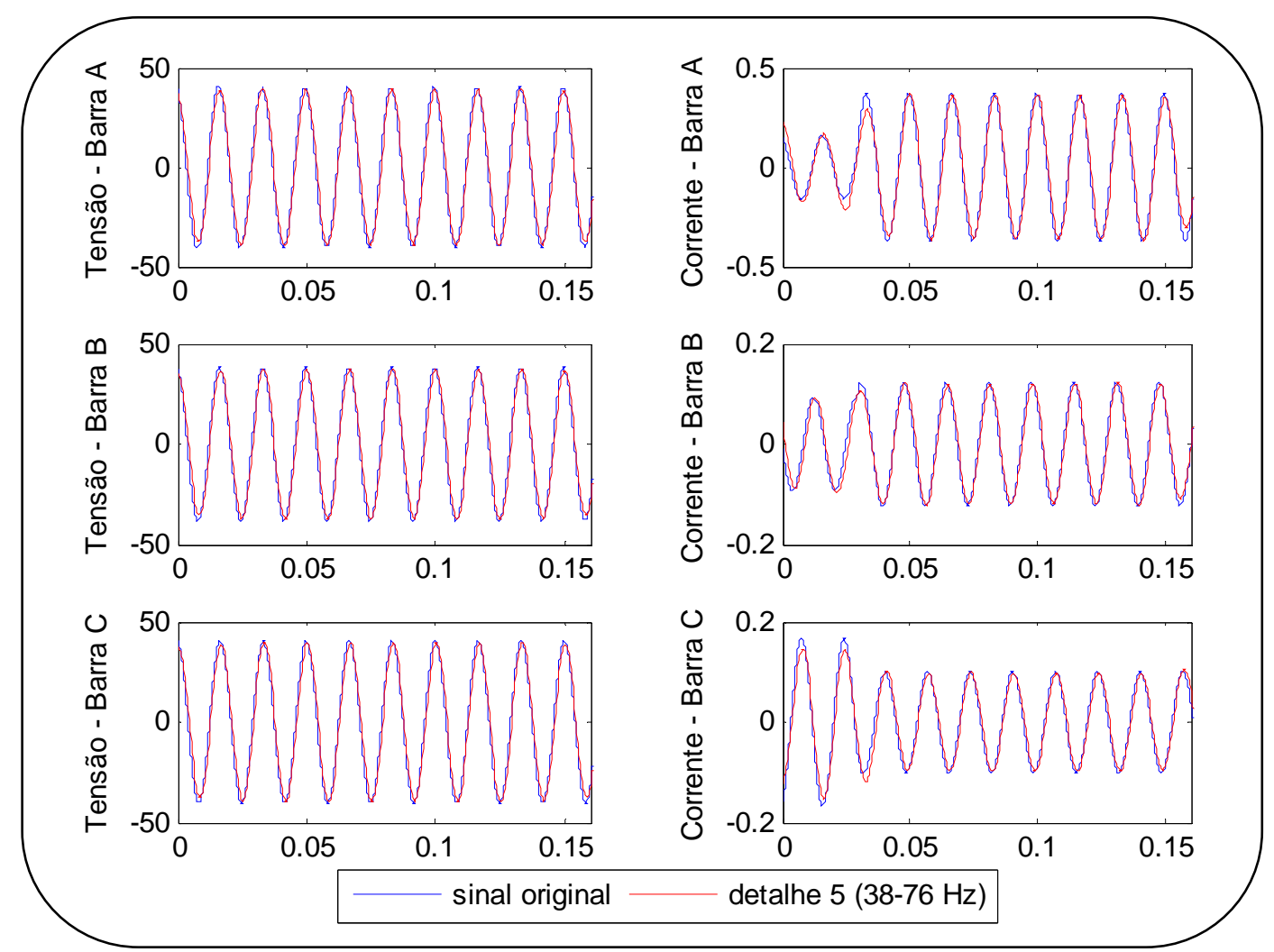

FIGURA 135 - Sinais de tensão e corrente não filtrados e de detalhe 5 dado uma falta fase-terra a $70 \mathrm{~km}$ da barra $A$, com ângulo de incidência de $0^{\circ}$ e resistência de $100 \mathrm{ohms}$.
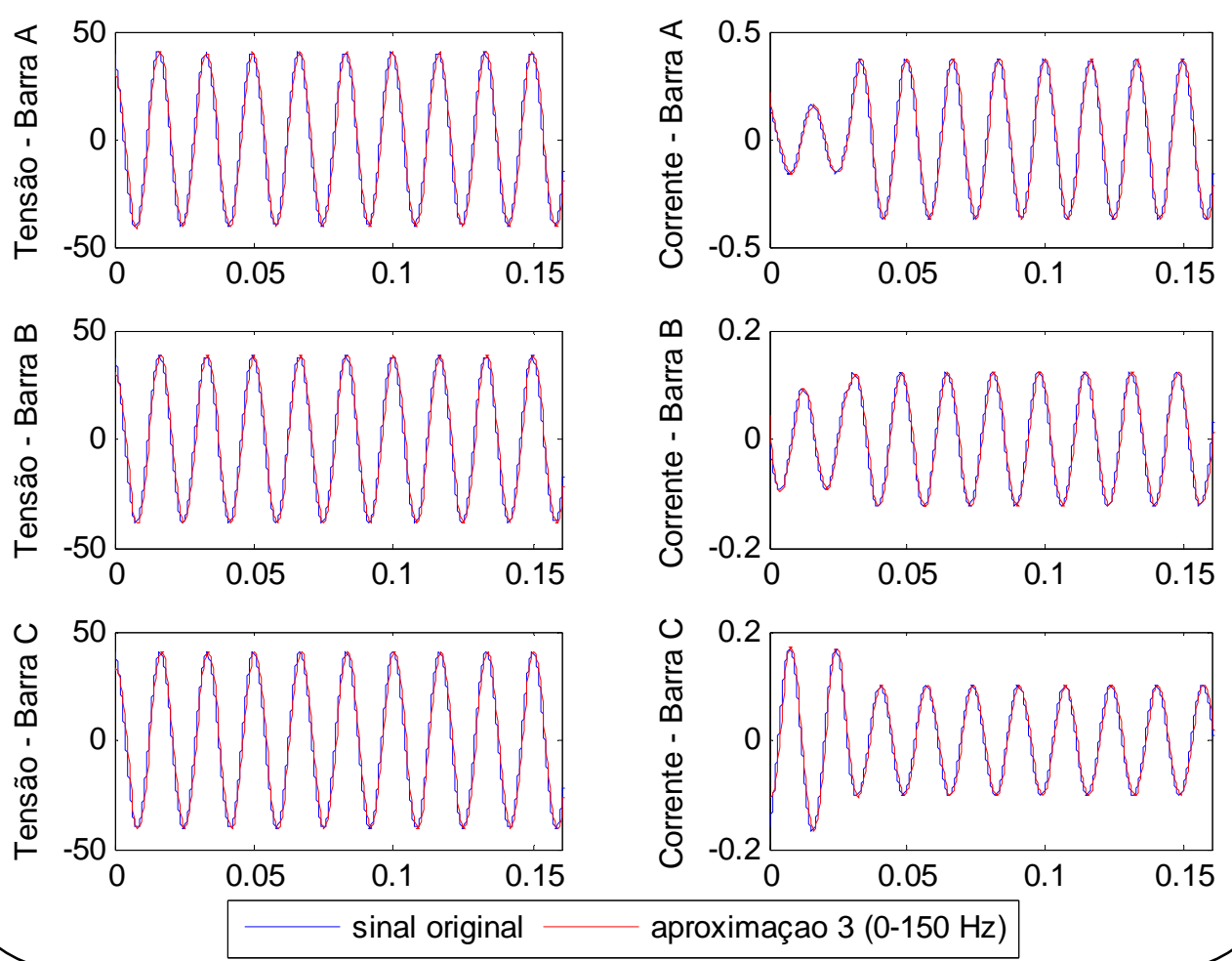

FIGURA 136 - Sinais de tensão e corrente não filtrados e de Aproximação 3 dado uma falta fase-terra a $70 \mathrm{~km}$ da barra A com ângulo de incidência de $0^{\circ}$ e resistência de $100 \mathrm{ohms}$. 


\subsubsection{Influência dos diferentes tipos de falta}

Similar aos outros módulos, verificou-se o comportamento do módulo baseado em componentes fundamentais diante a diferente tipos de faltas: fase-terra, fase-faseterra, fase-fase e trifásica.

Os resultados demonstraram que o módulo analisado mostrou-se praticamente imune aos diferentes tipos de falta, seja utilizando os sinais de detalhe ou de aproximação.

Nas Figuras 137 e 138, ilustram-se alguns resultados referentes às situações faltosas onde foram variados os tipos de falta e a distância da falta. Nota-se pelas figuras que não há grande variação da precisão do algoritmo em função do tipo de falta.

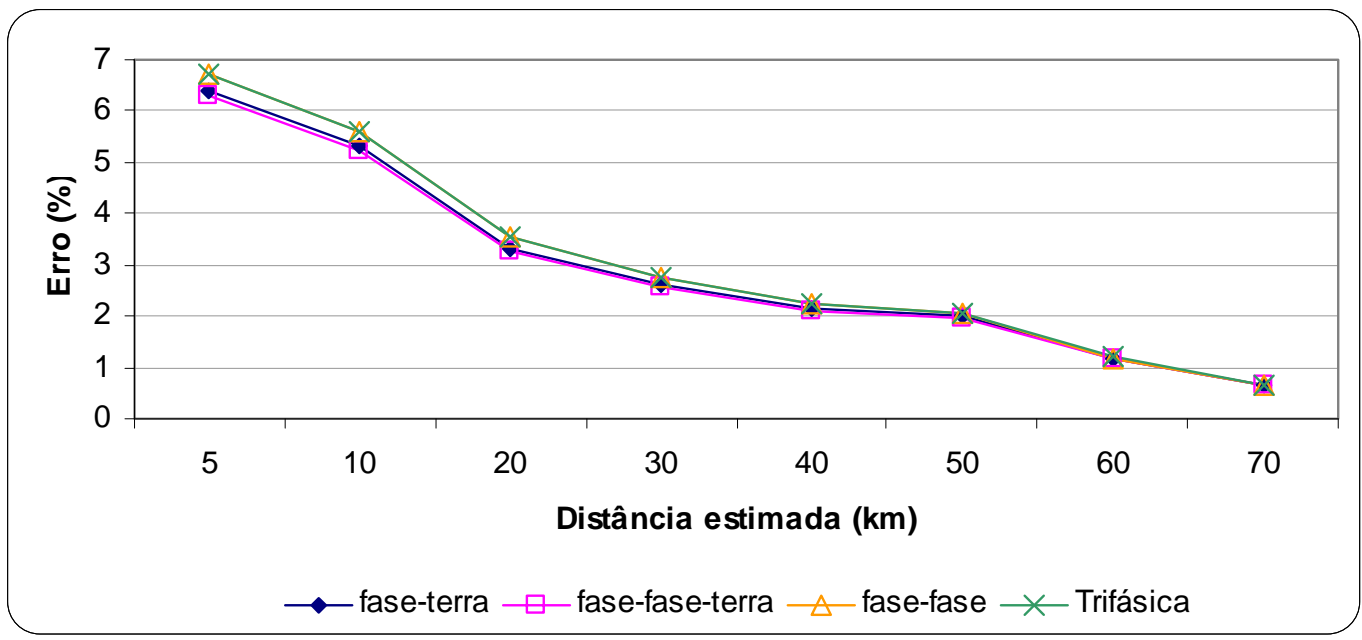

FIGURA 137 - Influência do tipo de falta sobre o módulo de localização baseado em componentes fundamental quando analisado os sinais de detalhe.

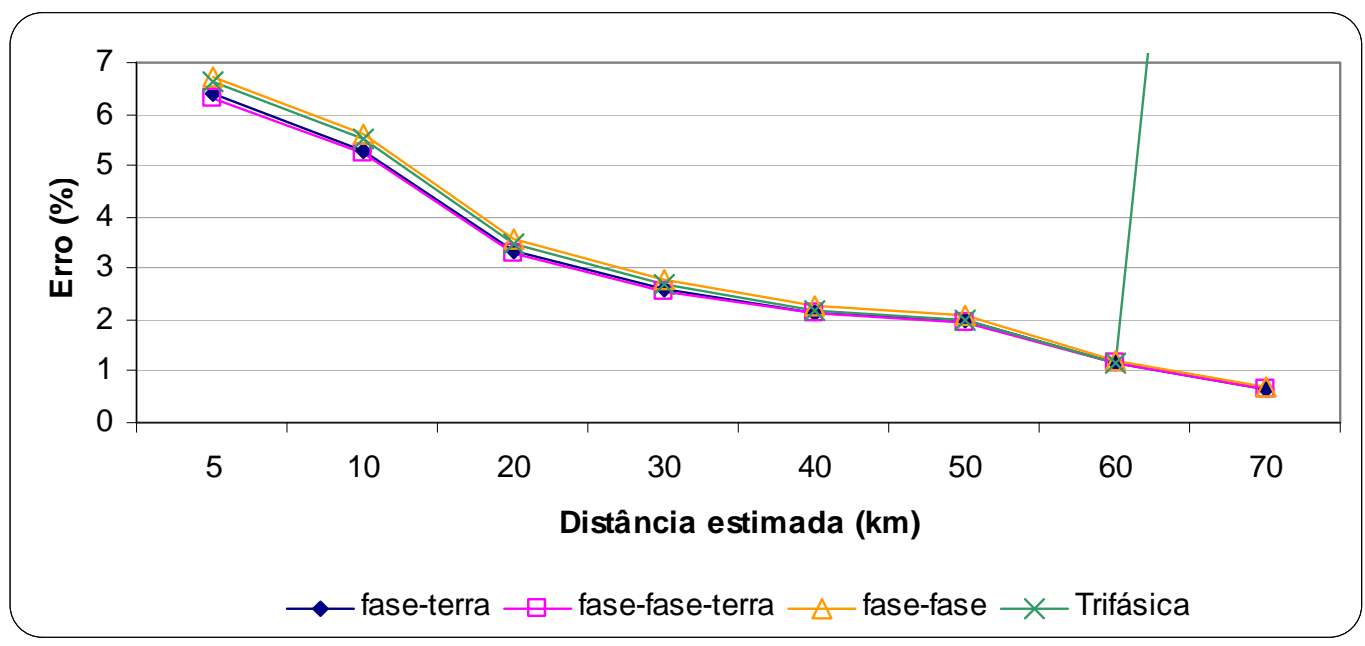

FIGURA 138 - Influência do tipo de falta sobre o módulo de localização baseado em componentes fundamental quando analisado os sinais de aproximação. 


\subsubsection{Influência da variação do ângulo de incidência da falta}

Com respeito à influência do ângulo de incidência da falta sob o desempenho e precisão do módulo de localização por componente fundamental, os testes demonstraram que tal variável não influencia no desempenho deste módulo, seja utilizando os sinais de detalhe ou de aproximação. Todavia, este módulo apresenta uma precisão inferior quando comparado ao do módulo de localização por ondas viajantes para faltas próximas ao terminal faltoso, onde erros da ordem de $8 \%$ podem ser encontrados. Esta última observação, assim como, o desempenho deste módulo pode ser verificado com o auxílio das Figuras de 139 a 142, as quais ilustram alguns resultados obtidos ao utilizar-se dos sinais de detalhe e aproximação para casos de faltas fase-fase, com variações do ângulo de incidência e da distância da falta.

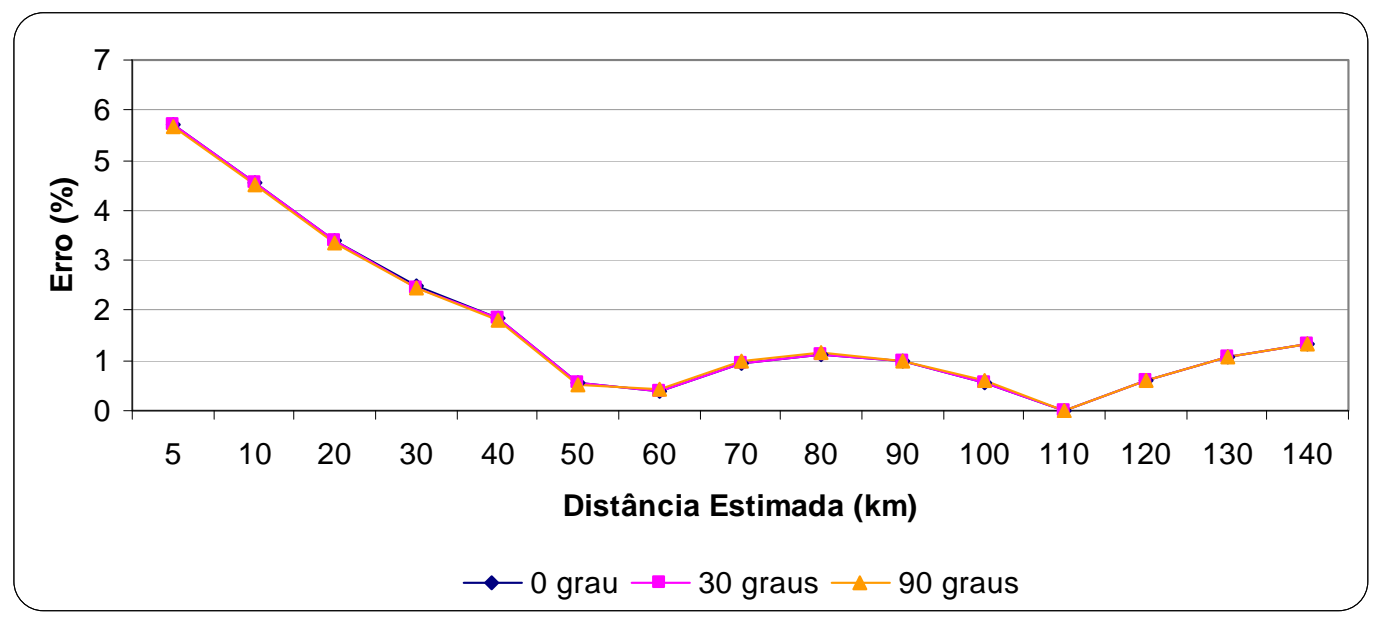

FIGURA 139 - Influência do ângulo de incidência sob o módulo de localização por componente fundamental utilizando dos sinais de detalhe para casos de falta fase-fase aplicadas no ramo 1.

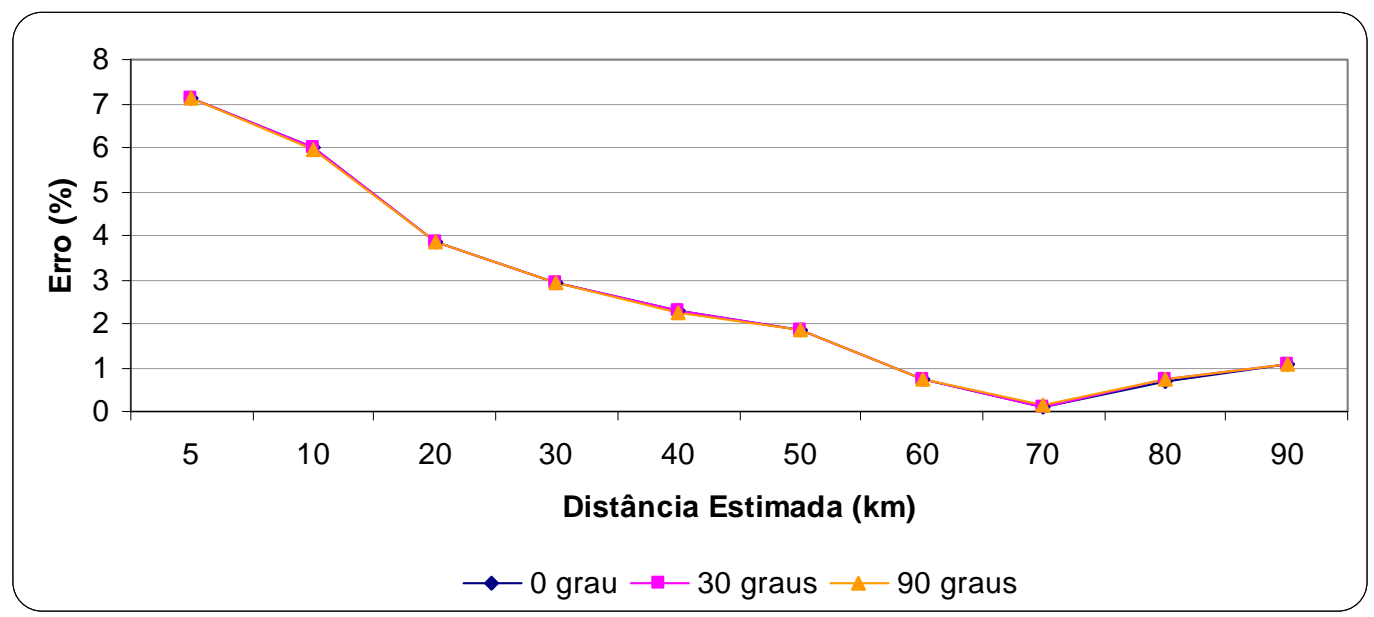

FIGURA 140 - Influência do ângulo de incidência sob o módulo de localização por componente fundamental utilizando dos sinais de detalhe para casos de falta fase-fase aplicadas no ramo 3. 


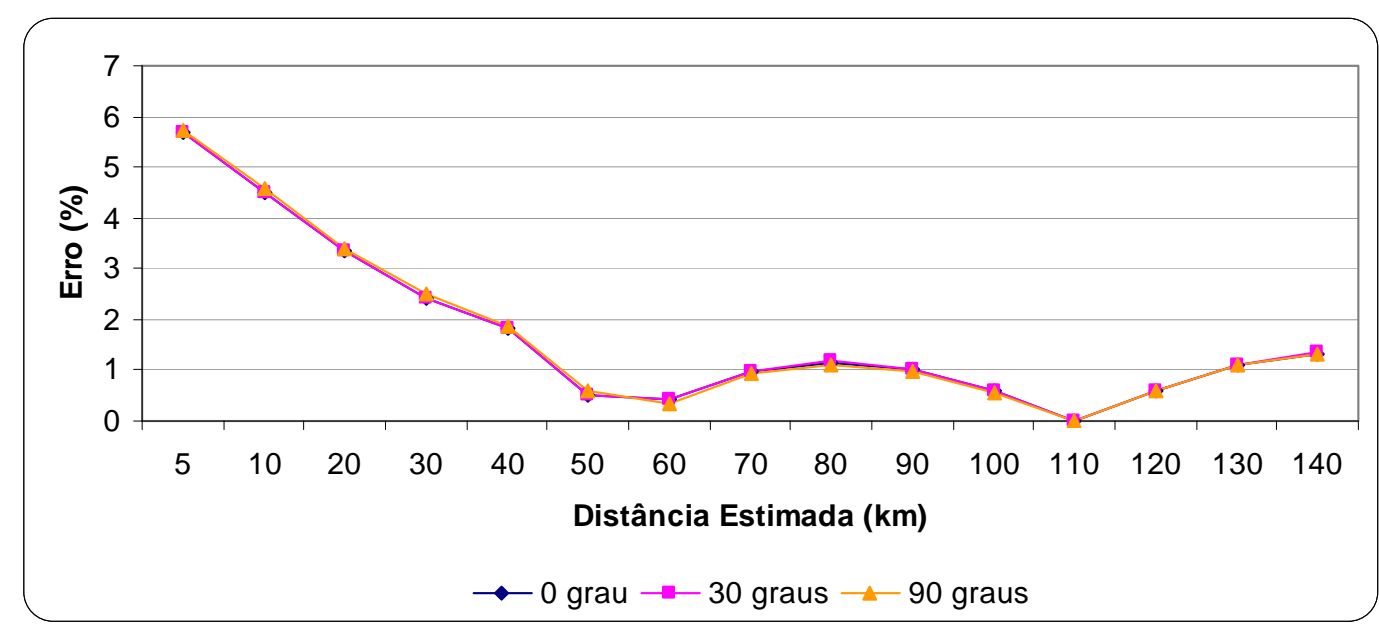

FIGURA 141 - Influência do ângulo de incidência sob o módulo de localização por componente fundamental utilizando dos sinais de aproximação para casos de falta fase-fase aplicadas no ramo 1.

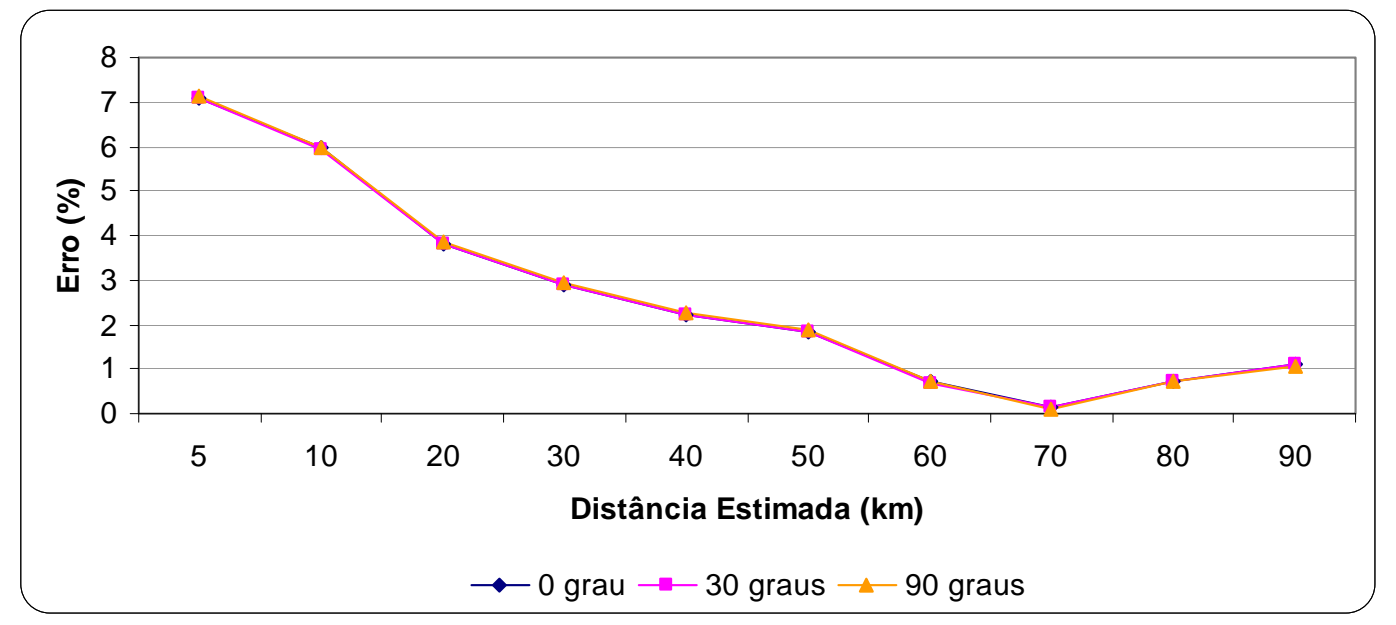

FIGURA 142 - Influência do ângulo de incidência sob o módulo de localização por componente fundamental utilizando dos sinais de aproximação para casos de falta fase-fase aplicadas no ramo 3.

\subsubsection{Influência da variação da resistência de falta}

Com o intuito de verificar a influência da resistência de falta no desempenho do módulo de localização por componentes fundamentais extraídos via TWE, foram realizados também testes variando-se a resistência de falta em: 0,1, 17, 30, 50, 100, 200, 400 e 800 ohms. Nas Figuras 143 e 144 demonstram-se os resultados onde se analisou os sinais de detalhe para localizar algumas situações de faltas fase-terra aplicadas sobre os diferentes ramos do sistema, considerando um ângulo de incidência próximo a zero grau. 
É notável pelas ilustrações apresentadas que o algoritmo se comportou bem, com um resultado satisfatório, para as variações de resistência de falta consideradas de 0 a 800 ohms, mesmo quando do ângulo de incidência da falta próximo de zero grau. Porém salienta-se que erros de má localização do ramo faltoso podem acontecer levando o algoritmo a grandes imprecisões na estimação da distância.

Ressalta-se que as mesmas observações feitas acima para o módulo de localização, utilizando dos sinais de detalhe, são válidas para testes com algoritmo tradicional dispondo da Transformada de Fourier.

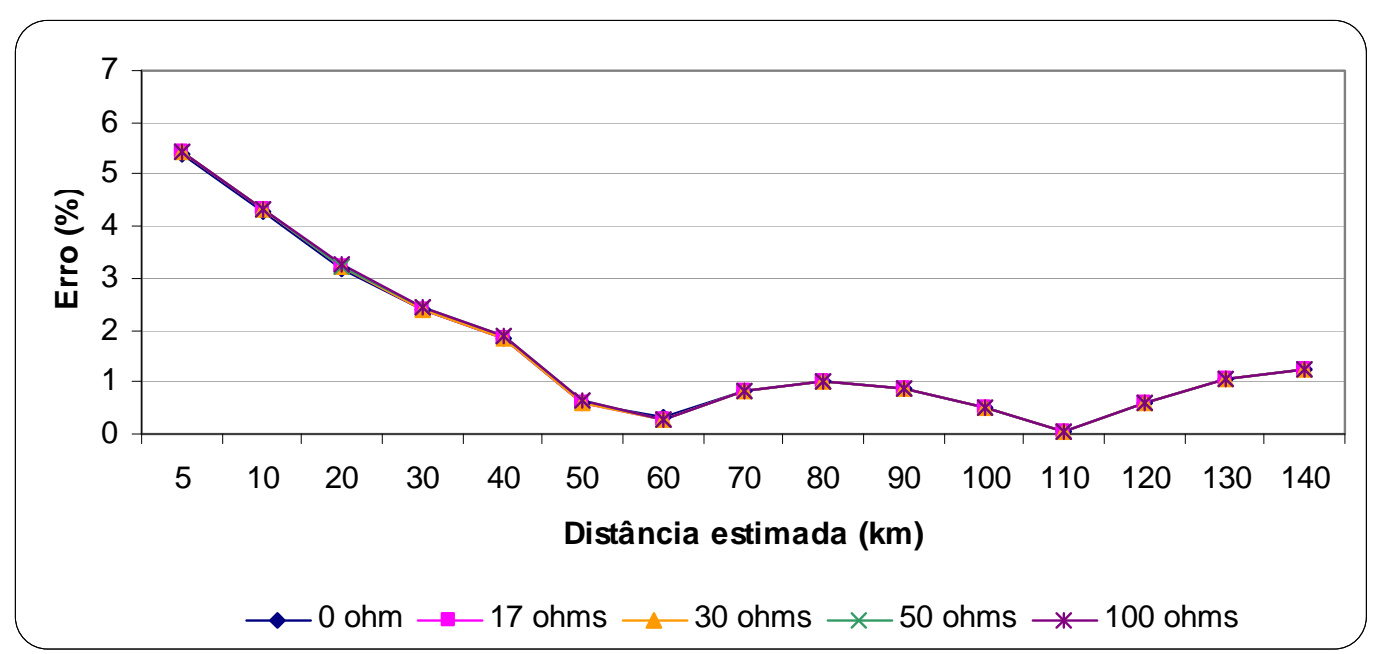

FIGURA 143 - Influência da resistência da falta sob o módulo de localização por componente fundamental utilizando dos sinais de detalhe para casos de falta fase-terra aplicadas no ramo 1.

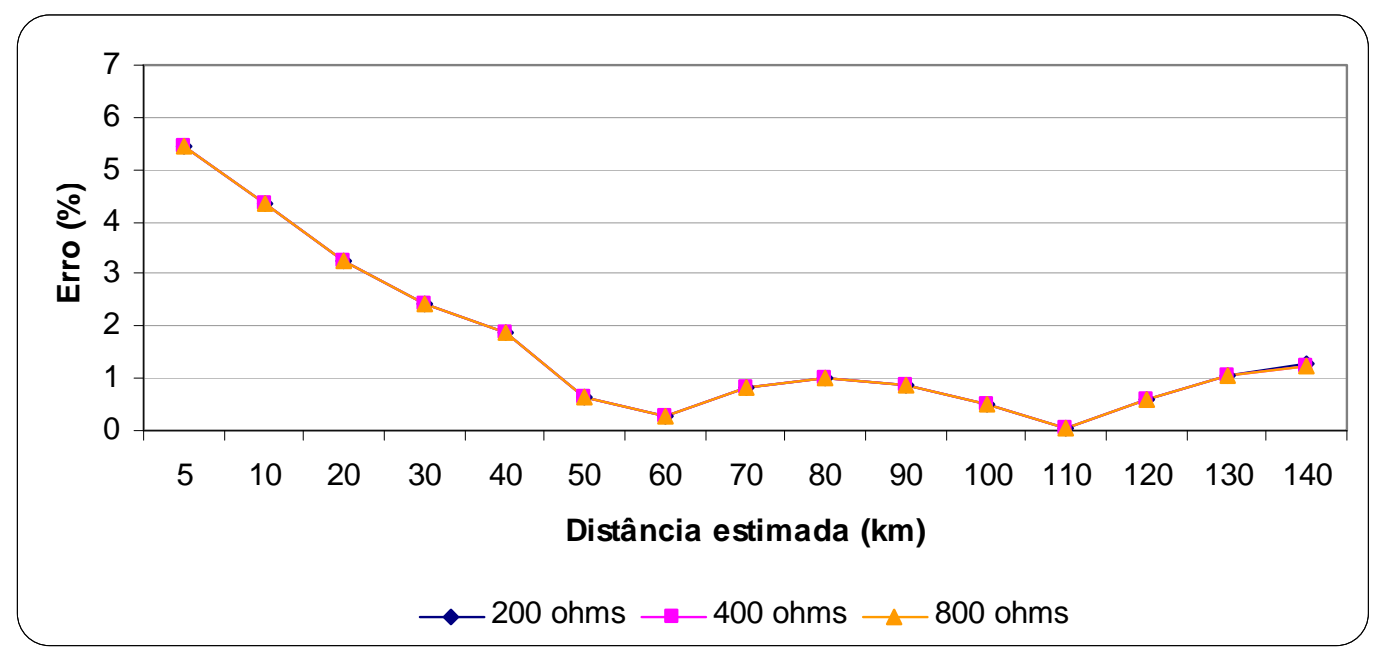

FIGURA 144 - Influência de elevadas resistências da falta sob o módulo de localização por componente fundamental utilizando dos sinais de detalhe para casos de falta fase-terra aplicadas no ramo 1. 
Utilizando-se dos sinais de aproximação (A3), de modo análogo aos sinais de detalhe, o algoritmo proposto também mostrou um ótimo desempenho na estimação da distância, o que pode ser constatado através das Figuras 145 e 146. Cabe destacar que o módulo baseado nos sinais de aproximação conseguiu localizar com uma precisão satisfatória, na grande maioria das vezes abaixo de 3\%, faltas com resistência de falta de até 800 ohms.

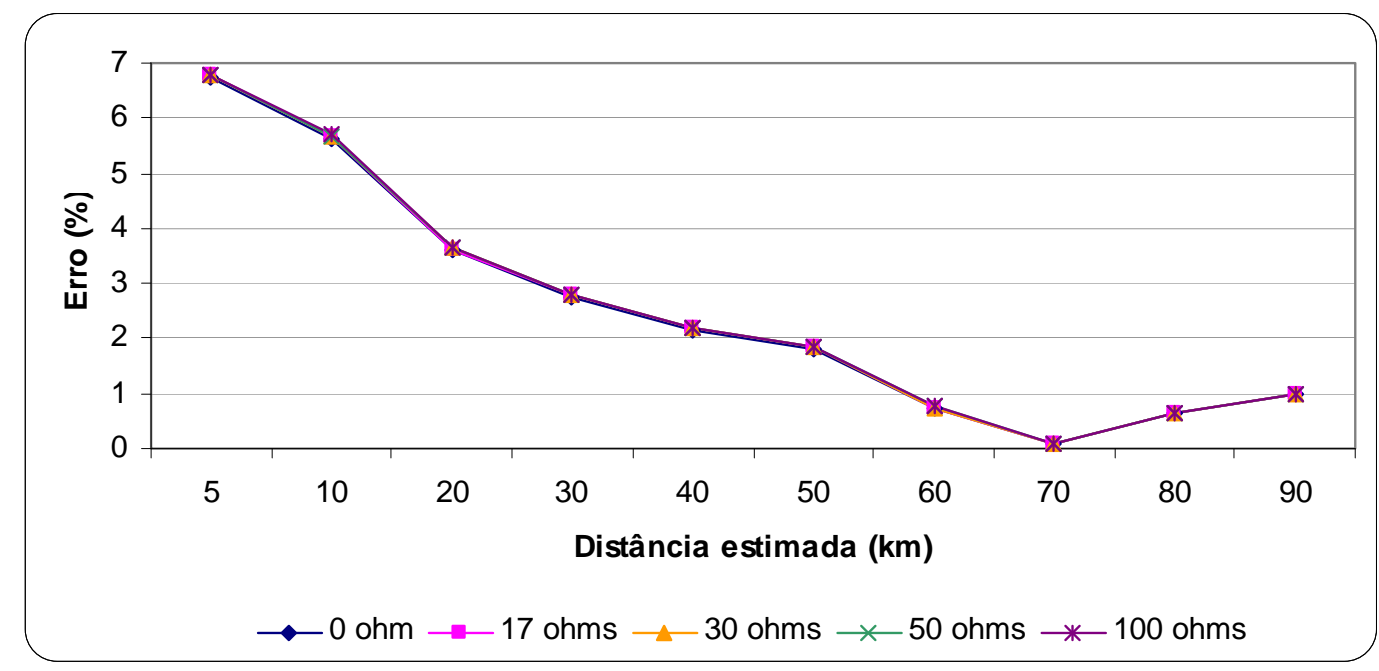

FIGURA 145 - Influência da resistência da falta sob o módulo de localização por componente fundamental utilizando dos sinais de aproximação para casos de falta fase-terra aplicadas no ramo 3.

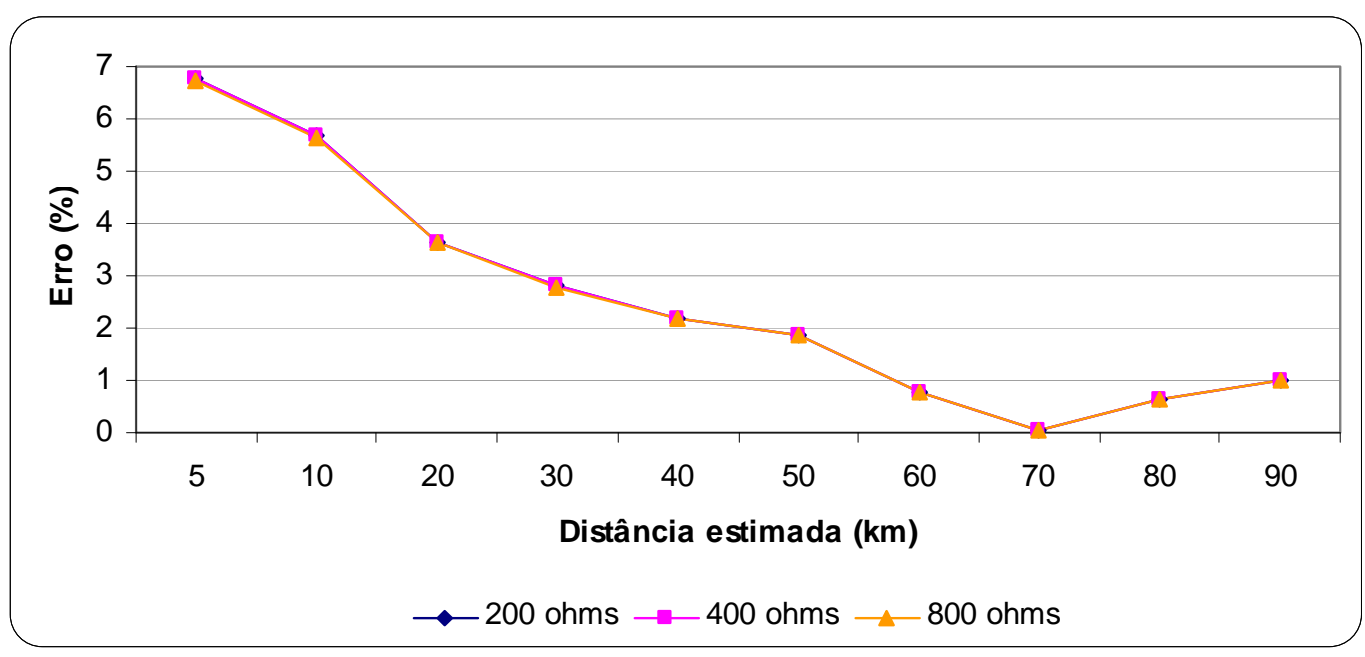

FIGURA 146 - Influência de elevadas resistências da falta sob o módulo de localização por componente fundamental utilizando dos sinais de aproximação para casos de falta fase-terra aplicadas no ramo 3. 


\subsubsection{Influência da distância da falta}

Durante a análise dos resultados obtidos observou-se que o módulo de localização por componente fundamental utilizando ou dos sinais de detalhe ou de aproximação, apresentava um desempenho inferior para faltas próximas aos barramentos do sistema de três terminais, vindo a melhorar ao passo que a distância aumentava. Além deste fato, algumas falhas de localização ocorreram para faltas muito próximas ao ponto de interligação das linhas devido a erros na identificação do ramo faltoso. Estas mesmas observações foram levantadas quando utilizado o algoritmo tradicional (TF).

\subsubsection{Influência do ruído correlacionado aos sinais analisados}

Analogamente a seção 6.1.5, buscou-se verificar a influência do ruído correlacionado ao sinal sobre o desempenho do módulo de localização.

O módulo em estudo foi exposto a sinais de corrente e tensão contendo níveis de ruído branco expresso em SNR da ordem de 80, 70, 60, 50 e 40 dB. Além do ruído, foram variados parâmetros como distância, ângulo de incidência e resistência de falta.

Nos testes, constatou-se que o desempenho e a precisão do módulo de localização não eram afetados pelo ruído branco adicionado ao sinal original. O que a princípio era esperado, uma vez que este módulo trabalha com os sinais de freqüência fundamental, sendo as componentes indesejáveis removidas ou atenuadas pelos filtros passa-baixa Butterworth e pela TWE.

As Figuras 147 e 148 demonstram alguns resultados referentes a situações de faltas fase-fase com ângulo de incidência de $30^{\circ}$ aplicadas sobre o ramo 2 , onde se buscou avaliar a influência do nível de ruído associado aos sinais de corrente e tensão sobre o módulo de localização em teste. 


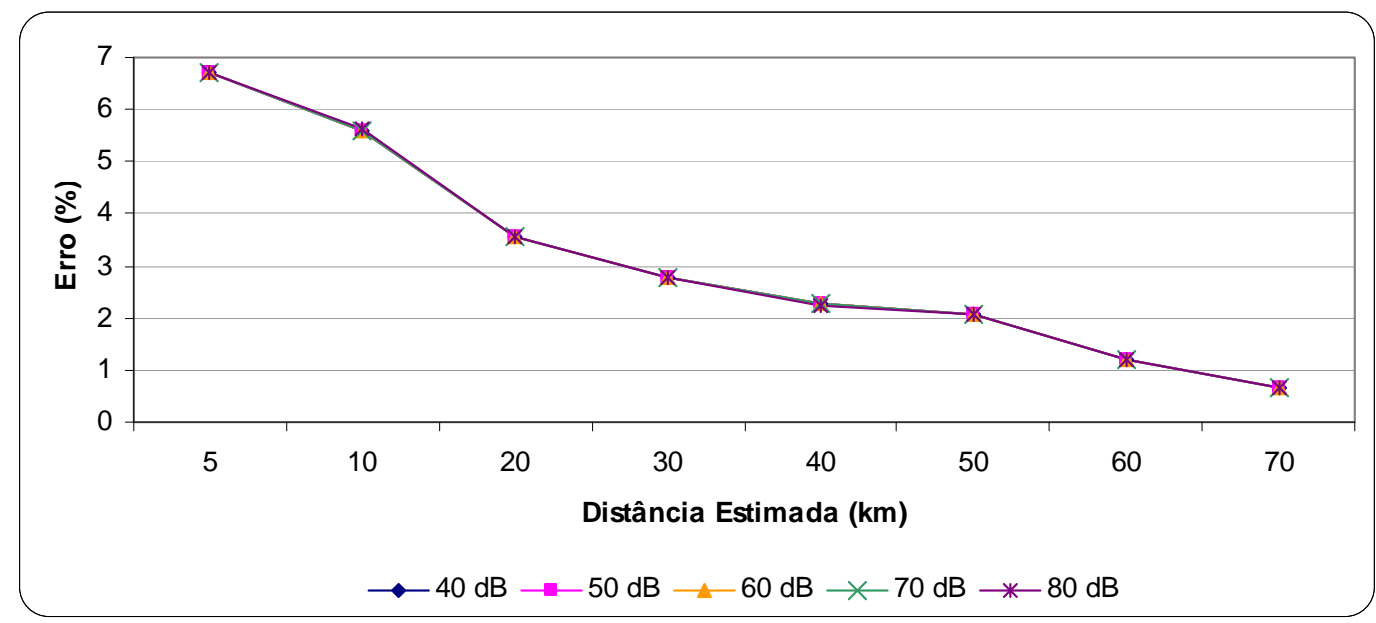

FIGURA 147 - Influência do ruído associado aos sinais no módulo de localização por componente fundamental utilizando dos sinais de detalhe para casos de falta fase-fase aplicadas no ramo 2.

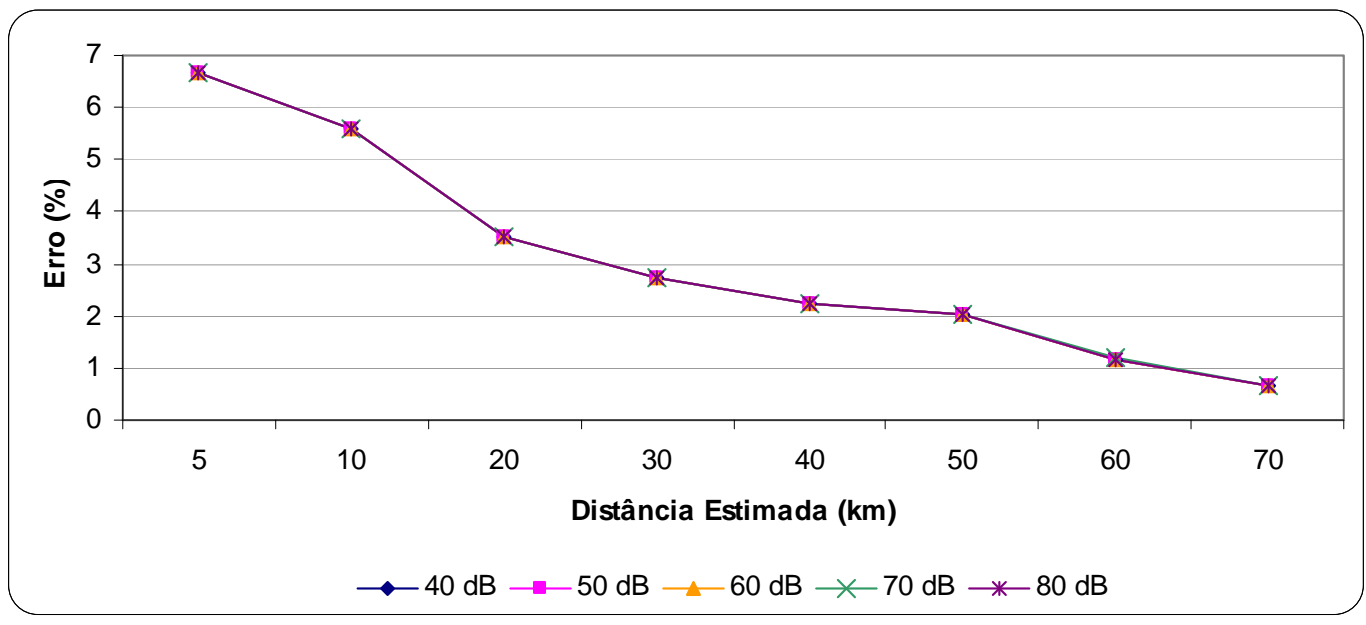

FIGURA 148 - Influência do ruído associado aos sinais no módulo de localização por componente fundamental utilizando dos sinais de aproximação para casos de falta fase-fase aplicadas no ramo 2.

\subsubsection{Comportamento da técnica frente ao acoplamento mútuo entre circuitos de uma linha de transmissão dupla}

Análogo a seção 6.1.6, verificou-se aqui o desempenho da aplicação do módulo de localização em questão quando utilizado em circuito duplo vertical de transmissão. $\mathrm{O}$ principal objetivo destes testes foi o de verificar a aplicabilidade dessa técnica a uma linha com circuito duplo, e uma possível influência na precisão do algoritmo devido ao efeito do acoplamento mútuo entre os circuitos.

Dentre os testes realizados, alguns são ilustrados pelas Figuras de 149 a 151, onde se analisou os sinais de detalhe, aproximação e os sinais extraídos via TWE, 
respectivamente, considerando situações de faltas fase-terra aplicadas sobre o ramo 1 $(150 \mathrm{~km})$ com ângulo de resistência de $90^{\circ}$ e variação da resistência de falta.

De um modo geral, percebeu-se que a precisão do algoritmo é influenciada, aumentado a margem de erro em torno de 1,0\% á 2,0\% em algumas situações. Quando analisado os sinais de detalhe, estes apresentaram resultados melhores para faltas próximas aos terminais quando comparado aos resultados utilizando-se os sinais de aproximação. Todavia, quando comparado os resultados do módulo baseado em TWE com o algoritmo tradicional baseado na $\mathrm{TF}$, foi notório que o algoritmo tradicional não conseguiu responder satisfatoriamente para faltas próximas aos terminais do sistema, como ilustram as figuras supracitadas. Constatou-se também que a variação da resistência e do ângulo da falta praticamente não influência o desempenho do módulo em questão. Salienta-se que podem ocorrer grandes imprecisões só quando da localização errônea do ramo faltoso, o que é passível de ocorrer principalmente para faltas nos finais do ramo com resistências de faltas elevadas.

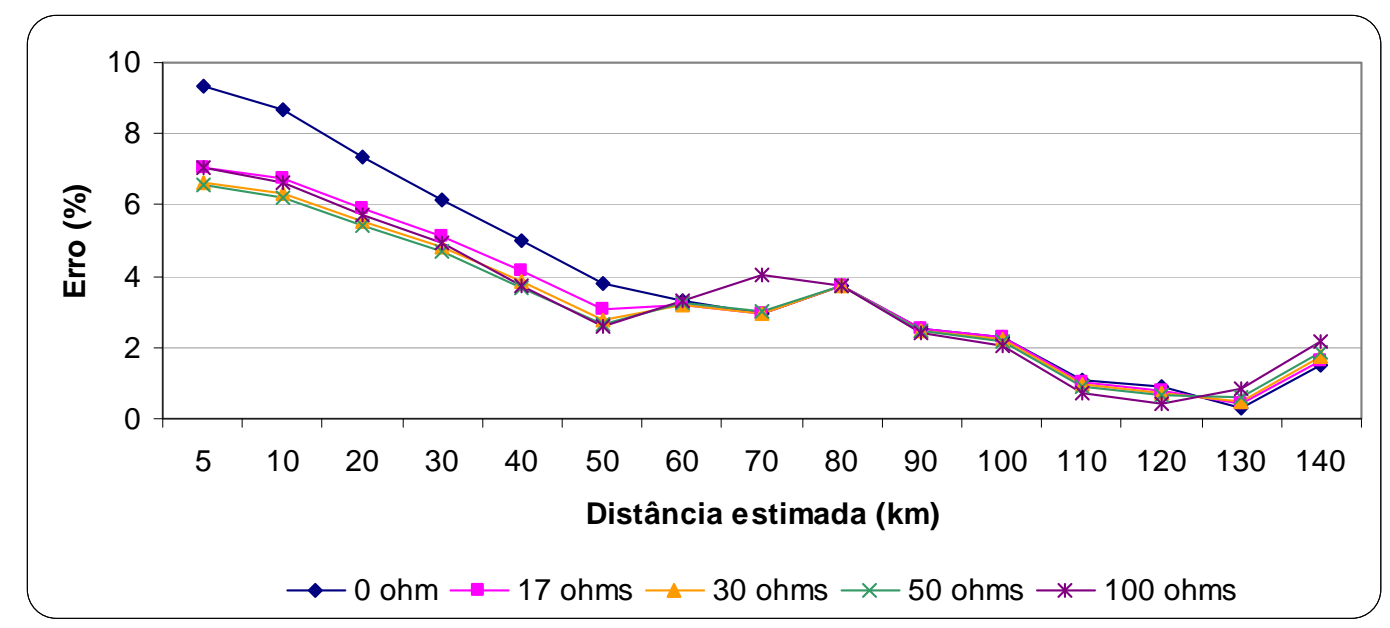

FIGURA 149 - Influência do acoplamento mútuo sobre o módulo de localização por componente fundamental utilizando dos sinais de detalhe para casos de falta fase-terra aplicadas no ramo 1. 


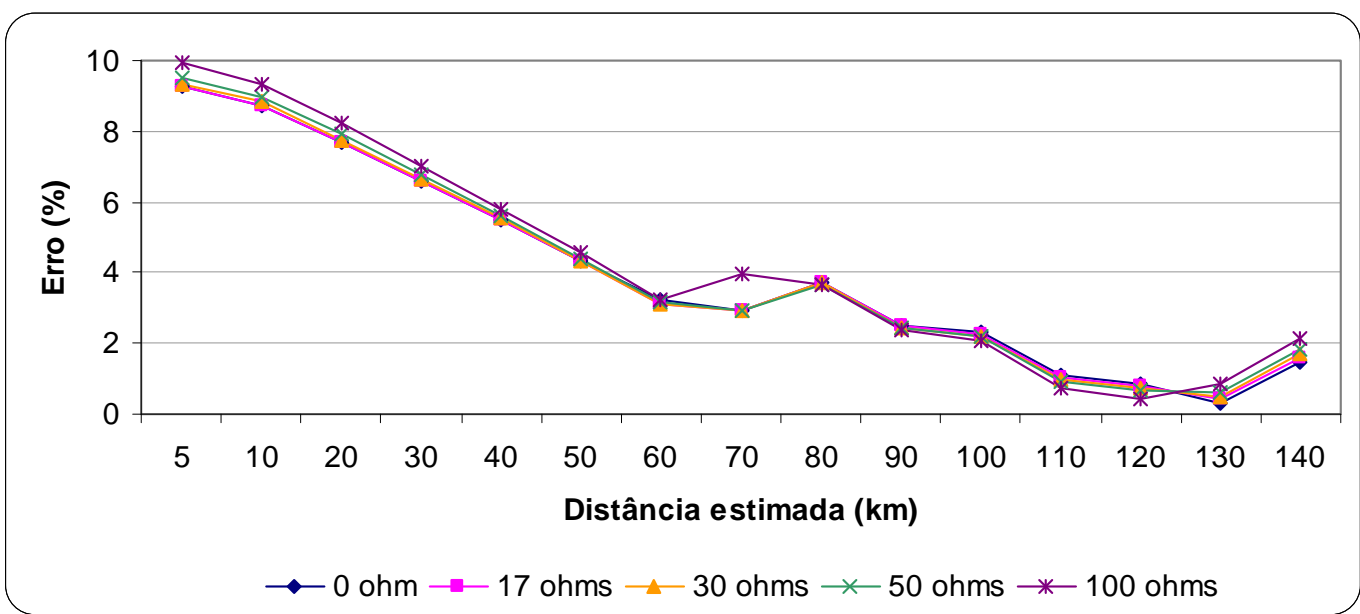

FIGURA 150 - Influência do acoplamento mútuo sobre o módulo de localização por componente fundamental utilizando dos sinais de aproximação para casos de falta fase-terra aplicadas no ramo 1.

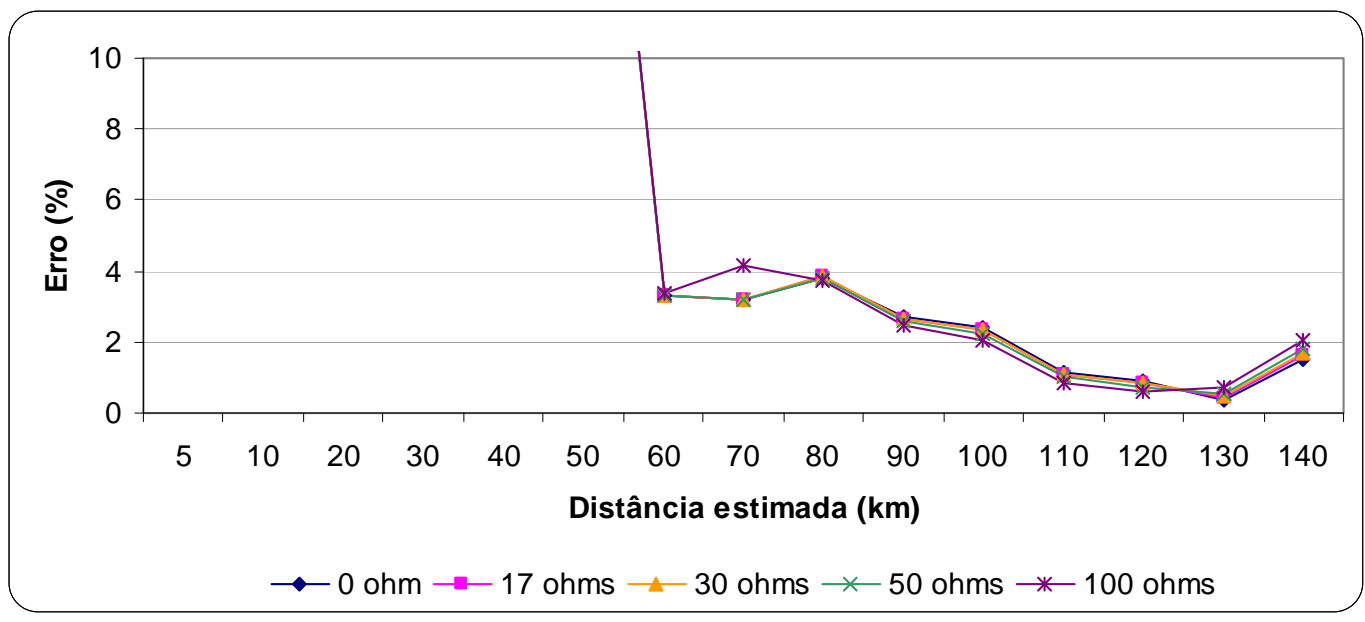

FIGURA 151 - Influência do acoplamento mútuo sobre o módulo de localização por componente fundamental tradicional via TF para casos de falta fase-terra aplicadas no ramo 1.

\subsubsection{Comportamento do módulo de localização quando utilizado linhas com parâmetros variantes com a freqüência}

Similarmente, foi testado o comportamento do módulo por componente fundamental extraídos via TWE quando da sua aplicação a sinais simulados via ATP onde se considerou linhas com parâmetros que variam com a freqüência do sistema.

Nos testes verificou-se que tanto utilizando os sinais de detalhe como os sinais de aproximação, o algoritmo apresentou resultados satisfatórios e melhores quando comparado aos resultados adquiridos utilizando-se sinais de simulações com parâmetros constantes com a freqüência. A melhoria na precisão foi de aproximadamente $1,0 \%$. 
Observou-se também que o aumento da resistência de falta influenciou modestamente a precisão do algoritmo.

Nas Figuras de 152 a 155, pode-se verificar o desempenho do módulo de localização testado sobre situações de faltas fase-terra aplicadas sobre o ramo 1 e 3, considerando um ângulo de incidência da falta de $30^{\circ}$ e variações da resistência da falta de 0 a 100 ohms. A maioria dos erros foram inferiores a 2,0\%.

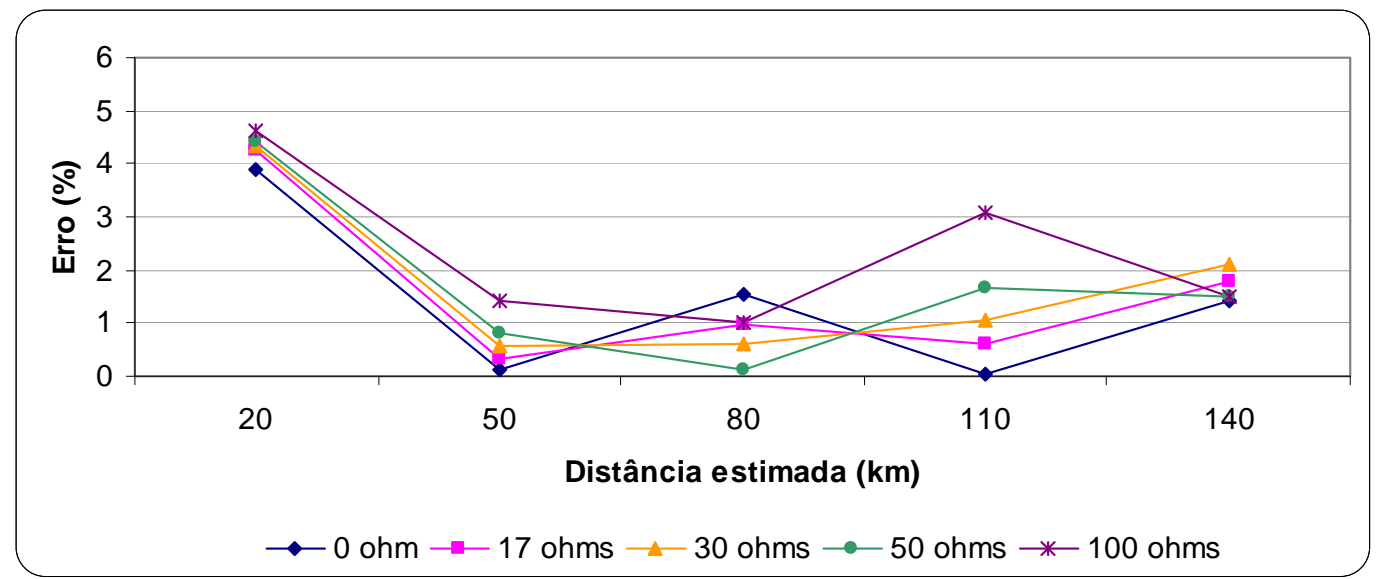

FIGURA 152 - Influência da variação dos parâmetros da linha com a freqüencia para falta fase-terra aplicadas sobre o ramo 1 ao analisar os sinais de detalhe.

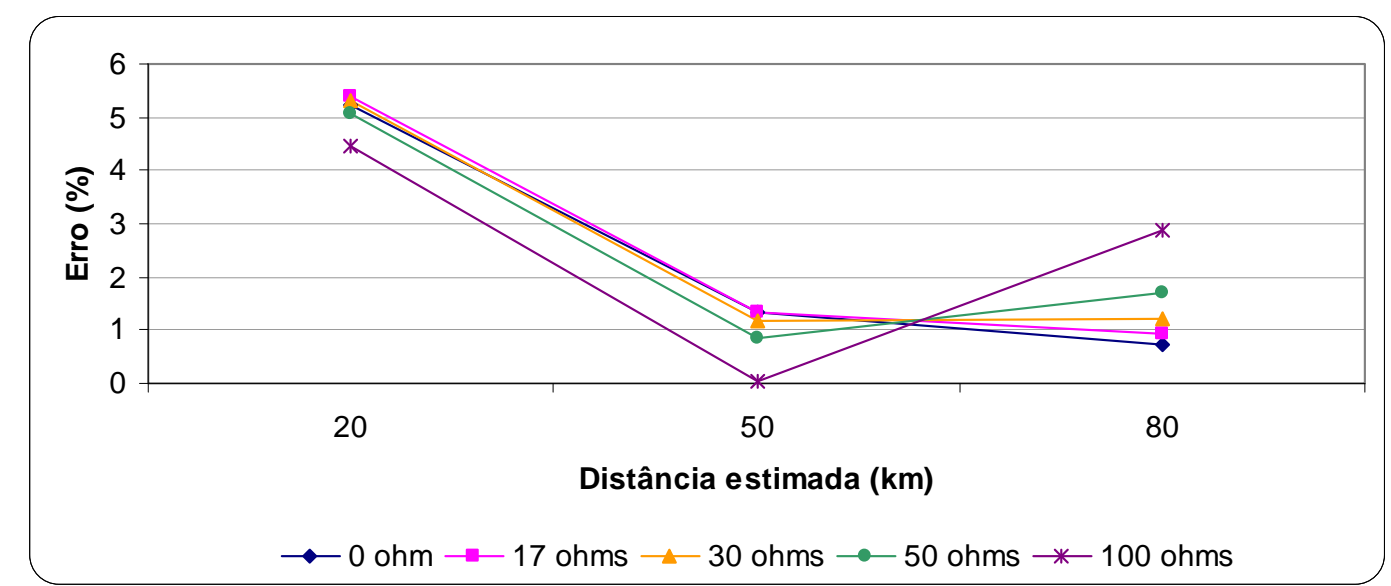

FIGURA 153 - Influência da variação dos parâmetros da linha com a freqüencia para falta fase-terra aplicadas sobre o ramo 3 a analisar os sinais de detalhe. 


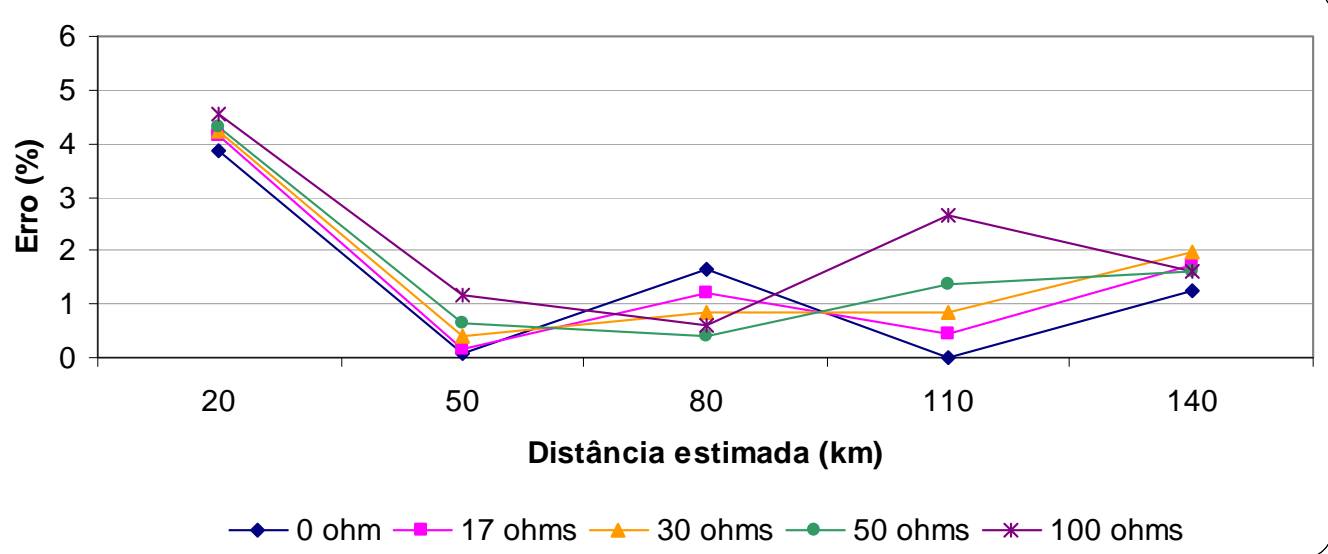

FIGURA 154 - Influência da variação dos parâmetros da linha com a freqüência para falta fase-terra aplicadas sobre o ramo 1 ao analisar os sinais de aproximação.

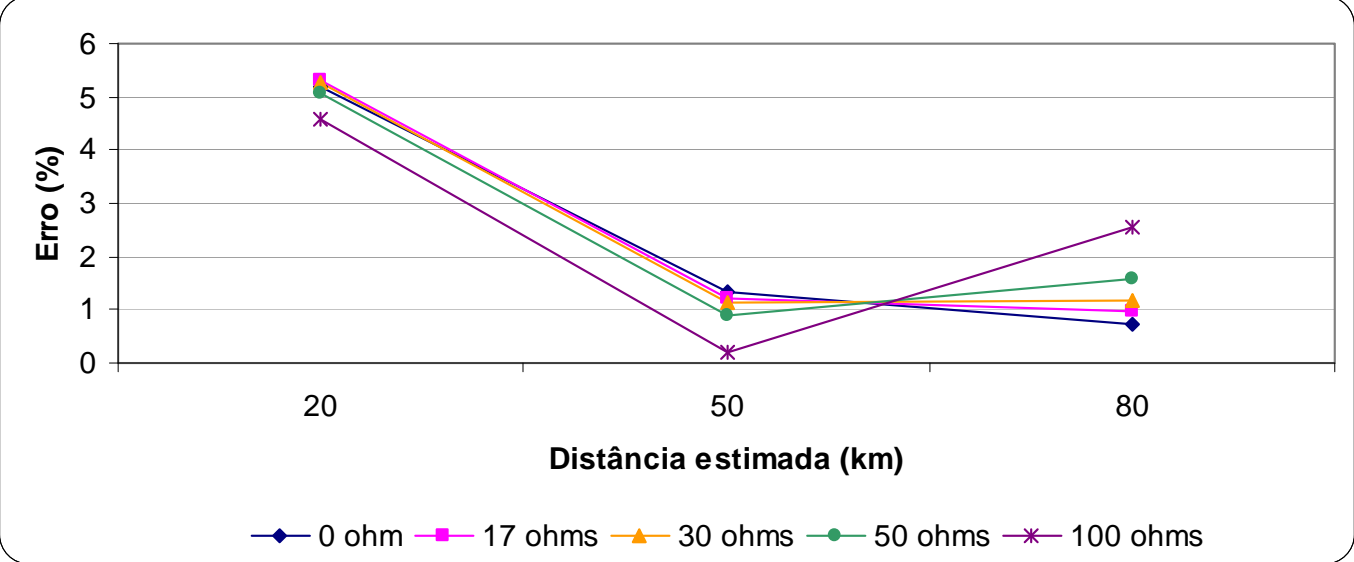

FIGURA 155 - Influência da variação dos parâmetros da linha com a freqüência para falta fase-terra aplicadas sobre o ramo 3 ao analisar os sinais de aproximação.

\subsubsection{Localização de distúrbios transitórios}

Os mesmos testes descritos na seção 6.1 .8 foram aplicados para avaliar a desempenho do módulo de localização por componente fundamental frente a distúrbios transitórios, tais como faltas de curtíssima duração e as decorrentes de descargas atmosféricas.

A Tabela 12 demonstra os resultados alcançados pelo algoritmo em teste frente às faltas fase-terra transitórias e descargas atmosféricas. Observa-se que o algoritmo apresentou resultados altamente satisfatórios, sendo o pior erro encontrado igual a 1,2\%, quando se utilizou dos sinais de aproximação. Nota-se também que o algoritmo 
apresentou um desempenho mais promissor quando da localização da falta dispondo dos sinais de detalhe.

No tocante a localização do ponto de incidência de descargas atmosféricas, o módulo de localização sob teste não foi eficiente, mostrando-se incapaz de localizar este tipo de distúrbio. A mesma observação é valida para o algoritmo original baseado na Transformada de Fourier.

TABELA 12 - Resultados obtidos pelo módulo de localização por componente fundamental frente à faltas transitórias.

\begin{tabular}{|c|c|c|c|c|c|c|c|c|c|}
\hline Tipo da Falta & $\begin{array}{c}\text { Distância } \\
\text { Real } \\
\text { (km) }\end{array}$ & $\begin{array}{c}\text { Ângulo de } \\
\text { incidência } \\
\text { (graus) }\end{array}$ & $\begin{array}{l}\text { Duração } \\
\text { (ciclos) }\end{array}$ & $\begin{array}{l}\text { Classificação } \\
\text { da Falta } \\
\text { (ABC/T) }\end{array}$ & $\begin{array}{c}\text { Ramo } \\
\text { Faltoso }\end{array}$ & $\begin{array}{l}\text { Localização } \\
\text { Média Absoluta } \\
\text { (TWE - A3) } \\
\text { (km) }\end{array}$ & $\begin{array}{l}\text { Erro } \\
(\%)\end{array}$ & $\begin{array}{l}\text { Localização } \\
\text { Média Absoluta } \\
\text { (TWE - D5) } \\
\text { (km) }\end{array}$ & $\begin{array}{l}\text { Erro } \\
\text { (\%) }\end{array}$ \\
\hline Faltas transitórias & 75 & 0 & $1 / 4$ & AT & AP & 77,83 & 1,13 & 73,60 & 0,56 \\
\hline Faltas transitórias & 75 & 0 & $1 / 2$ & AT & AP & 77,83 & 1,13 & 73,60 & 0,56 \\
\hline Faltas transitórias & 75 & 0 & 1 & AT & AP & 77,99 & 1,20 & 74,29 & 0,28 \\
\hline Faltas transitórias & 75 & 90 & $1 / 4$ & AT & AP & 77,77 & 1,11 & 72,70 & 0,92 \\
\hline Faltas transitórias & 75 & 90 & $1 / 2$ & AT & AP & 76,78 & 0,71 & 73,83 & 0,47 \\
\hline Faltas transitórias & 75 & 90 & 1 & AT & AP & 75,05 & 0,02 & 74,00 & 0,40 \\
\hline Desc. Atmosférica & 75 & 0 & - & AT & AP & "Não Localizada & - & "Não Localizada & - \\
\hline Desc. Atmosférica & 75 & 90 & - & AT & AP & Não Localizada & - & Não Localizada & - \\
\hline $\begin{array}{c}\text { Falta com } \\
\text { saturação do TC }\end{array}$ & 20 & 90 & - & $A B C$ & AP & Não Localizada & - & Não Localizada & - \\
\hline
\end{tabular}

\subsubsection{Influência da saturação dos TC's na localização por componentes fundamentais}

O comportamento do módulo de localização de faltas por componentes fundamentais também foi avaliado no que se refere à ocorrência de um possível distúrbio com a conseqüente saturação do TC mais próximo a este.

A execução deste teste foi feita de módulo análogo ao descrito na seção 6.1.9. Porém, os resultados obtidos não foram os mesmos, pois o módulo de localização em questão não foi capaz de localizar esse tipo de situação faltosa. Ressalta-se também que o mesmo comportamento foi encontrado utilizando-se do algoritmo original.

\subsubsection{Análise de sensibilidade do módulo por componente fundamental}

Nesta etapa buscou-se avaliar a sensibilidade do módulo baseado em componente fundamental frente a imprecisão de importantes variáveis de entrada que alimentam o algoritmo e que podem conter erros. Das variáveis de entrada, escolheramse a impedância de onda do sistema e a constante de propagação da linha, variáveis 
estas contidas nos equacionamentos para a estimação do ramo faltoso e da distância da falta.

Os testes foram executados inserindo erros de $\pm 5,0 \%$ nas duas variáveis escolhidas de forma simultânea e aplicado sinais de faltas fase-fase ao algoritmo. Os resultados demonstram que a imprecisão inserida nos parâmetros de entrada pode influenciar o algoritmo. Estas podem vir a melhorar a precisão quando do decréscimo das variáveis, ou a piorar quando do acréscimo das mesmas. Portanto a resposta do algoritmo mostrou-se indiretamente proporcional ao erro introduzido nas variáveis de entrada, nos moldes dos testes efetuados. Percebeu-se também o aumento da tendência do algoritmo em não identificar o ramo faltoso o que leva o mesmo a erros de estimação da distância da falta. As observações descritas sobre o teste de sensibilidade, assim como, o desempenho do módulo em questão podem ser constatadas pela análise dos resultados apresentados nas Figuras de 156 a 159.

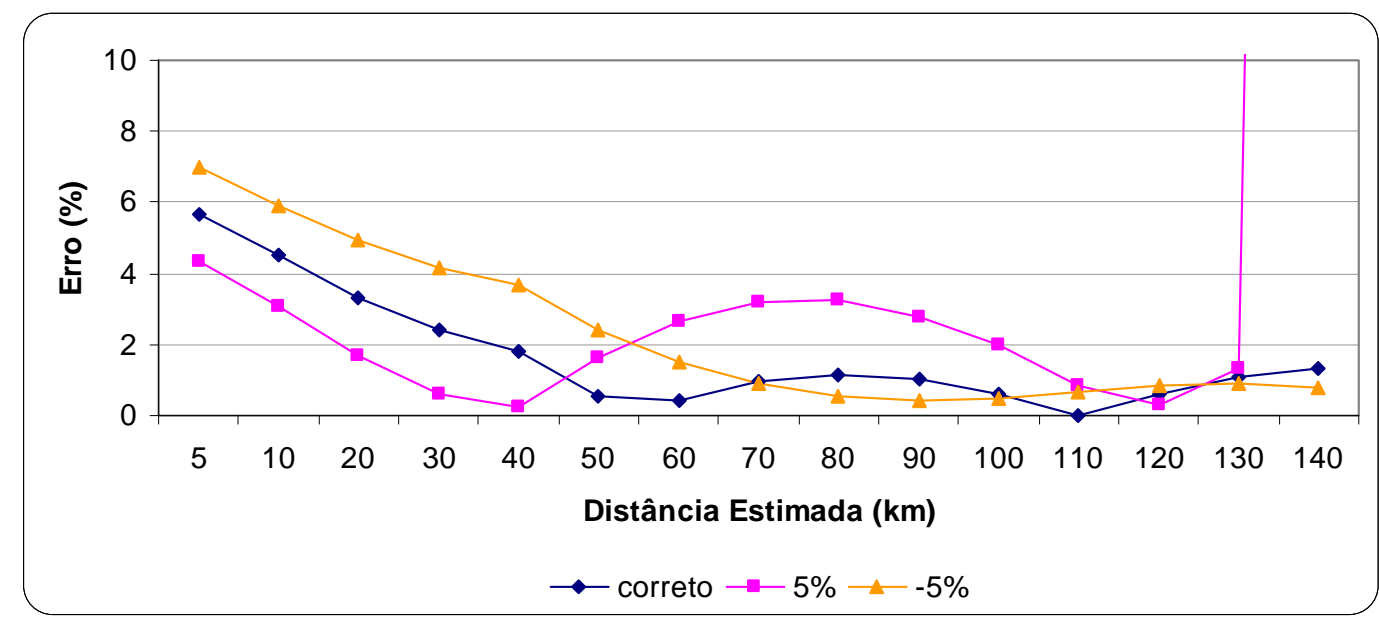

FIGURA 156 - Sensibilidade do módulo por componente fundamental utilizando os sinais de detalhe para variações da impedância de onda e da constante de propagação-ramo 1. 


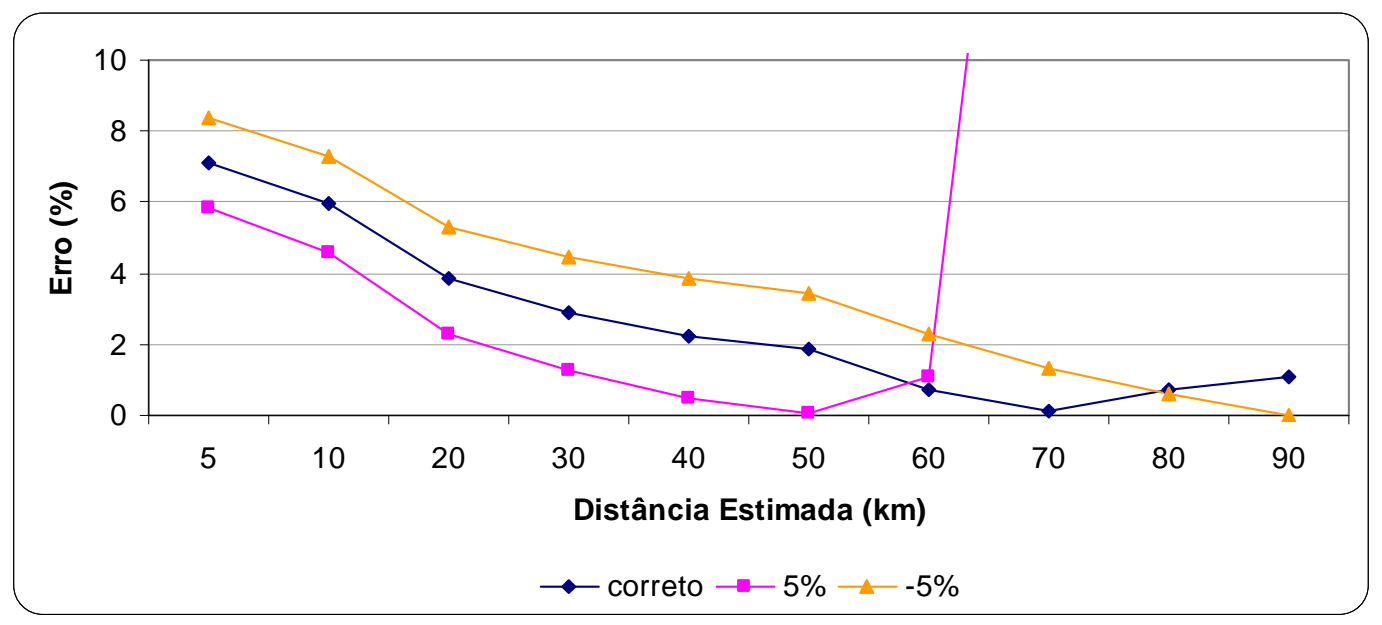

FIGURA 157 - Sensibilidade do módulo por componente fundamental utilizando os sinais de detalhe para variações da impedância de onda e da constante de propagação - ramo 3.

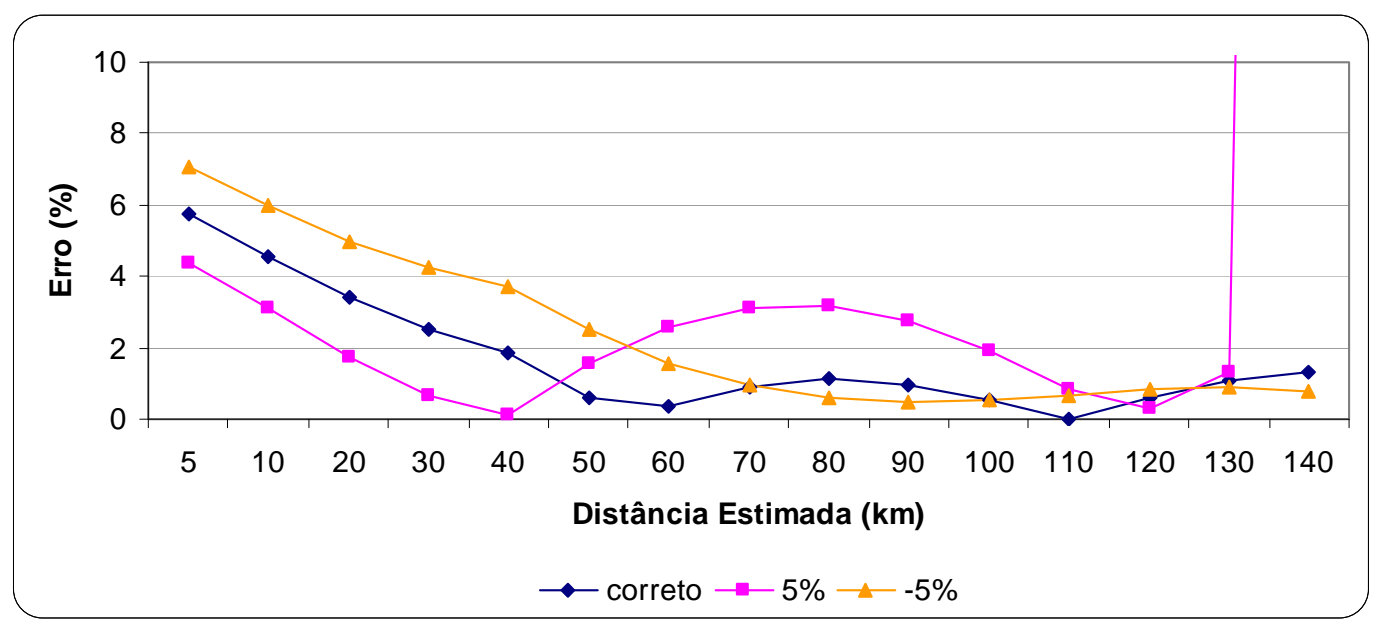

FIGURA 158 - Sensibilidade do módulo por componente fundamental utilizando os sinais de aproximação para variações da impedância de onda e da constante de propagação - ramo 1.

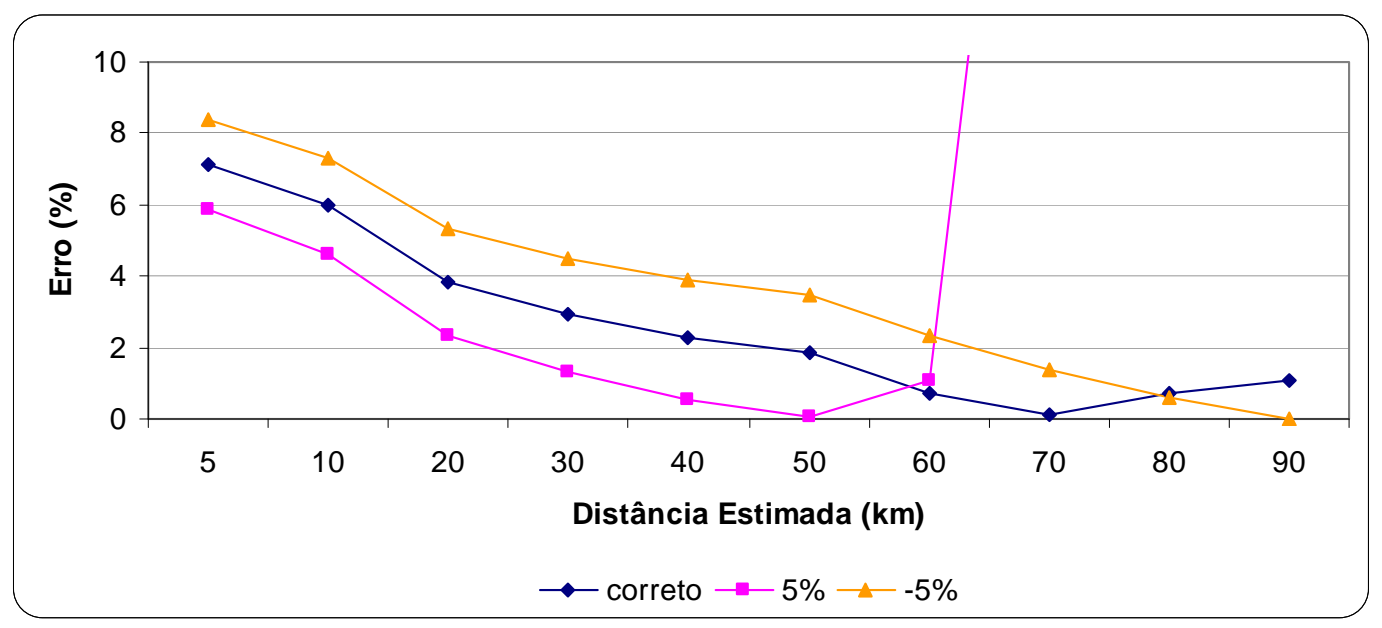

FIGURA 159 - Sensibilidade do módulo por componente fundamental utilizando os sinais de aproximação para variações da impedância de onda e da constante de propagação - ramo 3. 


\section{CONCLUSÕES}

Este trabalho apresentou a implementação de um algoritmo de localização de faltas híbrido fundamentado na teoria de ondas viajantes, cálculo da impedância aparente via componentes fundamentais e na utilização da Transformada Wavelet (análise multiresolução wavelet) em suas versões discreta (TWD) e estacionária (TWE).

$\mathrm{O}$ algoritmo apresentado pode fazer uso de dados provenientes dos três terminais, necessitando assim, que haja sincronização dos dados e um meio para transmissão destes entre os terminais, ou mesmo utilizar dados locais, apenas do terminal faltoso, para localizar a falta.

Todos os módulos de localização do algoritmo híbrido (LFHTW 1.01) foram testados utilizando-se de diversas situações de faltas simuladas através do software ATP.

Analisando os resultados alcançados, foi possível chegar a algumas conclusões que serão descritas a seguir.

\subsection{Considerações sobre a metodologia baseada em ondas viajantes}

O algoritmo proposto no tocante aos módulos de localização baseado em ondas viajantes (componentes de alta freqüência) via TWD, mostrou-se muito adequado e promissor quanto ao seu desempenho, precisão e confiabilidade. Destaca-se também que não só na etapa de localização, como nas demais etapas de detecção e classificação, onde o houve o emprego da $\mathrm{TW}$, as mesmas apresentaram resultados altamente satisfatórios, caracterizados por um excelente desempenho e confiabilidade.

Ressalta-se que ambos os módulos baseados em ondas viajantes, em seus estágios de detecção e localização do distúrbio, podem trabalhar tanto com os sinais de detalhe de corrente como de tensão, ou ainda, com os dois em paralelo, mantendo em geral um bom desempenho, independente do sinal utilizado. 
Testes demonstraram que algoritmo baseando em ondas viajantes requer um hardware equipado com conversores analógico-digitais (CAD's) superiores a 12 bits, para se garantir um perfeito desempenho e funcionalidade.

Os módulos dispondo de dados de um ou de três terminais se mostram praticamente insensíveis à variação da distância da falta, do tipo de falta, ângulo de incidência e resistência de falta, bem como pelo acoplamento mútuo caracterizado por um circuito duplo vertical.

Em específico, com relação à resistência de falta, o algoritmo como um todo foi capaz de localizar distúrbios com valores de até 800 ohms. Entretanto, em algumas ocasiões de faltas fase-terra, onde se aliou situações com elevadas resistências de faltas a baixos ângulos de incidência (próximos de zero grau), o algoritmo mostrou-se sensível, podendo até vir a deixar de localizar a falta, agravando-se quando se trata do módulo que trabalha com dados locais, devido a atenuação da segunda onda e de possíveis falhas na pré-localização da falta.

Em caso de faltas fase-fase-terra, os dois módulos apresentaram-se mais robustos, atenuando ou mesmo nem apresentado o problema delineado para faltas faseterra. Ao se verificar a influência da resistência de falta, percebeu-se também que o os resultados eram sutilmente melhores quando da análise dos sinais tensão.

Quanto à influência do ruído correlacionado aos sinais analisados, notou-se que o módulo que trabalha com dados dos três terminais é ineficiente caso a taxa sinal/ruído (SNR) presente nos sinais, seja menor que $60 \mathrm{~dB}$ para a corrente e, menor que $50 \mathrm{~dB}$ para a tensão. Já considerando o módulo que utiliza dados locais, o mesmo começa a sofrer influência para valores de SNR menores que $60 \mathrm{~dB}$. Notou-se também que, para os dois módulos, a influência do ruído torna-se marcante para faltas com ângulos de incidência próximos de zero.

Os módulos de ondas viajantes também se mostraram eficientes em localizar distúrbios transitórios como faltas de curta duração e descargas atmosféricas diretas sobre o condutor fase, tanto dispondo dos sinais de corrente como de tensão. Tal característica é de suma importância para se localizar pontos fracos no sistema e para a tomada de medidas a fim de se evitar problemas futuros de maior grandeza.

Não o bastante, constatou-se também que o algoritmo baseado em ondas viajantes é capaz de localizar distúrbios mesmo sob uma leve condição de saturação do TC, levando-se em conta a análise dos sinais de corrente, além de poder utilizar o sinais de tensão para tal, o que evitaria o problema. 
Ambos os módulos são sensibilizados por imprecisões contidas em dados de entrada, como por exemplo, a velocidade de propagação da onda na LT. Entretanto, caso o erro não seja tão expressivo, o algoritmo continua respondendo satisfatoriamente.

Por último, testaram-se os módulos que trabalham com dados locais e dos três terminais por meio de sinais simulados levando-se em conta linhas com parâmetros variando com a freqüência. Os testes revelaram que o algoritmo apresentou alterações nos seu desempenho (precisão), porém, estas alterações podem ser melhorar ou piorar a precisão do algoritmo. Constatou-se também que o módulo que trabalha com dados locais é mais sensível.

\subsection{Considerações sobre a metodologia baseada na extração do componente fundamental via TWE}

O módulo de localização proposto foi baseado no algoritmo apresentado por Coury [10]. Porém, ao invés de se utilizar a TF, foi sugerida a utilização da TWE para a extração do componente fundamental dos sinais de corrente e de tensão, visando o cálculo da localização da falta.

Tal modificação sobre o algoritmo original mostrou-se viável e promissora. O algoritmo modificado, ou módulo de localização por componente fundamental extraídos via TWE, tem apresentado, no geral, resultados satisfatórios quando comparado ao algoritmo original. A aplicação da TWE na filtragem dos sinais se mostrou eficiente e promissora, além de ser mais adequada que a TWD, dependendo do nível de decomposição analisado. Análogo ao módulo de ondas viajantes, o módulo de localização em questão, utiliza os sinais provenientes da decomposição wavelet para detectar, classificar e localizar os distúrbios. Tarefas estas que são executadas com um ótimo desempenho no geral. Ressalta-se que, diferentemente do algoritmo anterior, esta metodologia de localização pode utilizar tanto os sinais de detalhe como os de aproximação para localizar a falta.

Testes demonstraram que o algoritmo baseando na extração do componente fundamental pode trabalhar com um hardware equipado com conversores analógicodigitais (CAD's) iguais ou maiores que 8 bits, sem perda de funcionalidade e desempenho.

O algoritmo em discussão se apresenta menos preciso na ocorrência de faltas próximas aos terminais do sistema, podendo também vir a ocorrer falha quando da 
localização de faltas próximas ao ponto de interligação das linhas, o que se deve muitas das vezes, a identificação errônea do ramo faltoso por parte do algoritmo.

Observou-se no geral que o algoritmo não é significantemente influenciado pelo ângulo de incidência da falta em uma comparação isolada de outros parâmetros. De modo análogo, no tocante a resistência de falta, notou-se que o mesmo também não é influenciado para valores de resistência de até 800 ohms. Todavia, ao se unir condições de ângulos de falta próximos a zero com elevadas resistências, pode haver sim estimações com erros elevados da distância, assim como, do terminal faltoso.

Como era esperado, constatou-se que a metodologia em análise não foi influenciada pelo ruído superposto ao sinal, uma vez que apenas o componente de 60 $\mathrm{Hz}$ é utilizado, quando da filtragem dos outros componentes pela aplicação dos filtros analógico (Butterwoth) e digital (TWE).

Quanto ao efeito do acoplamento mútuo, nota-se pelos resultados que este tem alguma influência sobre o desempenho do algoritmo no sentido de prejudicar a precisão do algoritmo, além de aumentar a probabilidade de estimações errôneas do terminal faltoso para faltas próximas ao ponto de junção das linhas. Constatou-se também que o ângulo de incidência e a resistência de falta não influenciam significantemente a precisão do algoritmo. Entretanto, observou-se que o módulo proposto apresenta um desempenho superior quando comparado ao algoritmo tradicional utilizando a TF para esta mesma situação.

O módulo de localização por componente fundamental proposto também foi capaz de localizar situações faltosas com características transitórias, com uma precisão satisfatória. Entretanto, foi ineficiente na localização de descargas atmosféricas e situações onde houve saturação dos TCs.

No tocante a sensibilidade do algoritmo a entrada de dados imprecisos, como os valores da impedância de onda da linha e da constante de propagação, o algoritmo mostrou-se ser bastante influenciado, sendo a sua precisão indiretamente proporcional ao erro introduzido nas variáveis de entrada, considerando o molde de teste efetuado. Vale comentar que desde que os erros contidos nas variáveis de entrada não sejam tão expressivos, erros em torno de $\pm 5,0 \%$, o algoritmo responderá satisfatoriamente ou até mesmo melhor dependendo da situação.

Finalizando, o módulo em questão também foi submetido a sinais de corrente e tensão, simulados a partir de um sistema onde foi considerado o modelo de linhas com parâmetros variando com a freqüência. A resposta do algoritmo foi favorável, 
apresentando na maioria das vezes um desempenho igual ou superior se comparado aos testes onde se utilizou parâmetros constantes com a freqüência.

\subsection{Considerações gerais sobre o algoritmo de localização de faltas híbrido}

A estimação da localização da falta em uma linha de transmissão é muito importante, pois permite uma rápida determinação da natureza da falta, facilitando os reparos e a posterior restauração do sistema. Esta rapidez na determinação de uma situação de falta é de vital importância para uma operação econômica e confiável do sistema de potência como um todo, principalmente nos tempos atuais, onde um alto padrão de continuidade e conformidade do fornecimento de energia estão sendo exigidos.

Neste contexto, os resultados alcançados utilizando-se o LFHTW 1.01, apontam a uma aplicabilidade promissora, aliada a precisão e confiabilidade inerente. Tais características são obtidas graças ao desempenho e união das duas metodologias propostas, através de um algoritmo híbrido, de modo que uma metodologia complemente, amenize, ou mesmo, corrija pontos fracos da outra.

O LFHTW 1.01 pode ser utilizado priorizando o resultado da localização por ondas viajantes, uma vez que esta apresentou maior robustez e um melhor desempenho, principalmente no tocante a precisão e por apresentar até o término deste documento, os módulos local e sincronizado.

A aplicação da TW nas suas versões TWD e TWE ao problema delineado, mostrou-se bastante adequada e promissora.

Finalizando, temos sumarizado na Tabela 13, a aplicabilidade dos módulos de localização propostos e do LFHTW 1.01 como um todo, para todos os tipos de testes realizados nesta pesquisa. Pode-se notar que o LFHTW atende todas as situações em sua totalidade com excelente desempenho, salvo circunstâncias especiais descritas no corpo deste documento. 
TABELA 13 - Aplicabilidade geral do LFHTW 1.01

\begin{tabular}{|c|c|c|c|c|}
\hline & $\begin{array}{c}\text { Ondas Viajantes } \\
\text { Três Terminais } \\
\text { (TWD) }\end{array}$ & $\begin{array}{l}\text { Ondas Viajantes } \\
\text { Um Terminal } \\
\text { (TWD) }\end{array}$ & $\begin{array}{l}\text { Componente } \\
\text { Fundamental } \\
\text { Três Terminais } \\
\text { (TWE) }\end{array}$ & $\begin{array}{l}\text { LFHTW } 1.01 \\
\text { (TWD/TWE) }\end{array}$ \\
\hline Distância da Falta & $\bullet$ & $\sqrt{ }$ & $\sqrt{ }$ & $\bullet$ \\
\hline Tipo da Falta & $\bullet$ & $\bullet$ & $\bullet$ & $\bullet$ \\
\hline $\begin{array}{l}\text { Ângulo de Incidência da } \\
\text { Falta }\end{array}$ & $\bullet$ & $\bullet$ & $\bullet$ & $\bullet$ \\
\hline Resistência da Falta & $\bullet$ & $\sqrt{ }$ & $\bullet$ & $\bullet$ \\
\hline Acoplamento Mútuo & $\bullet$ & $\bullet$ & $\sqrt{ }$ & $\bullet$ \\
\hline Nível de Ruído & $\sqrt{ }$ & $\sqrt{ }$ & $\bullet$ & $\bullet$ \\
\hline $\begin{array}{l}\text { Parâmetros da LT } \\
\text { variando com a } \\
\text { frequência }\end{array}$ & $\bullet$ & $\sqrt{ }$ & $\bullet$ & $\bullet$ \\
\hline Faltas Transitórias & $\bullet$ & $\bullet$ & $\bullet$ & $\bullet$ \\
\hline Descargas Atmosféricas & $\bullet$ & $\bullet$ & - & $\bullet$ \\
\hline Saturação de TC & $\bullet$ & $\bullet$ & - & $\bullet$ \\
\hline Análise de Sensibilidade & $\sqrt{ }$ & $\sqrt{ }$ & $\sqrt{ }$ & $\sqrt{ }$ \\
\hline Número de bits do CAD & $\sqrt{ }$ & $\sqrt{ }$ & $\bullet$ & $\bullet$ \\
\hline & $\stackrel{\bullet}{\sqrt{ }}$ & \multicolumn{3}{|c|}{$\begin{array}{l}\text { Atende } \\
\text { Atende com ressalvas } \\
\text { Não atende }\end{array}$} \\
\hline
\end{tabular}

\subsection{Continuidade da pesquisa}

Tendo em vista o desenvolvimento continuado desta pesquisa, objetivando o aperfeiçoamento do algoritmo apresentado e possível aplicação prática do mesmo, sugere-se:

- Submissão do LFHTW 1.01 a testes com dados reais.

- Aprimoramento dos módulos de localização apresentados, assim como, implantação de um módulo baseado em componente fundamental que utilize apenas dados locais.

- Aplicação do LFHTW 1.01 em sua versão completa sobre um sistema com compensação série.

- Desenvolvimento de um protótipo do LFHTW 1.01. Aplicação de testes dispondo de dados reais via laboratório e instalação do protótipo em campo para conseqüente avaliação do seu desempenho. Projeção e produção do LFHTW a nível comercial. 


\section{REFERÊNCIAS BIBLIOGRÁFICAS}

[1] COURY, D. V. (1987). Um estimador ótimo aplicado à proteção dos sistemas elétricos de potência. Dissertação (Mestrado) - Escola de Engenharia de São Carlos, Universidade de São Paulo.

[2] STEVENSON JR., W. D. (1978). Elementos de análise de sistemas de potência. Rio de Janeiro, McGraw-Hill do Brasil.

[3] Filho, J. M. C.; OliveirA, T. C.; LEBORGNE, R. C.; ABREU, J. P. G. (2002). Análise comparativa de simulações e medições de afundamentos de tensão. XIV - Congresso Brasileiro de Automática, p. 2605-2610, setembro, Natal-RN.

[4] MAGAlhãeS, C. H. N.; GOUVÊA, M. R.; SilvA, F. A. T.; TAHAN, C. M. V.; ARAUJO FILHO, L. G. C. (2001). Avaliação do custo social de interrupção do fornecimento de energia elétrica do lado da demanda no estado de São Paulo. XVI - Seminário Nacional de Produção e Transmissão de Energia Elétrica, GPC/019, Campinas-SP, outubro.

[5] GIRGIS, A. A.; HART, D. G.; PETERSON, W. L. (1992). A new fault location technique for two and three terminal lines. IEEE Transactions on Power Delivery, v.7, n.1, p. 98-107, jan.

[6] GAUTIER, L. R. (1996). Localizadores digitais de faltas para linhas de transmissão de alta tensão. Dissertação (Mestrado) - - Escola de Engenharia de São Carlos, Universidade de São Paulo.

[7] LAIN, B. and SALAMA, M. M. A. (1996). An overview of the digital fault location algorithms for the power transmission line protection based on the steady-state fhasor approaches. Electric Machines and Power Systems, v.24, p. 83-115, Taylor \& Francis. 
[8] SCHWEITZER III, E. O. (1988). A review of impedance-based fault locating experience. Fifteenth Annual Western Protective Relay Conference, Spokane, Washington, Oct.

[9] IEEE STANDARDS C37.114 (2004). IEEE Guide for determining fault location on AC transmission and distribution lines. Sponsor Power System Relaying Committee of the IEEE Power Engineering Society, Dec.

[10] COURY, D. V. (1992). A practical approach to accurate fault location on extra high voltage teed feeders. Tese (Doutorado) - Universidade de Bath.

[11] SHENGFANG, L.; CHUNJU, F.; WEIYONG, Y.; HUARONG, C.; LI, K. K. (2004). A new phase measurement unit (PMU) based fault location algorithm for double circuit lines. Eighth IEE International Conference on Developments in Power System Protection, v. 1, p. 188-191, april.

[12] AMORIM, H. P. and HUAIS, L. (2004). Faults location I transmission lines through neural networks. IEEE/PES Transmission \& Distribution Conference \& Exposition: Latin America. p. 691-695, nov.

[13] EL-NAGGAR, K. M. (2001). A genetic based fault location algorithm for transmission lines. 16th International Conference and Exhibition on Electricity Distribution, v. 3, n. 482, june.

[14] SILVEIRA, P. M.; SEARA, R.; ZURN, H. H. (2001). Localização de faltas por ondas viajantes - Uma nova abordagem baseada em decomposição wavelet. XVI Seminário Nacional de Produção e Transmissão de Energia Elétrica, Campinas, GPC/027, 7 p. out.

[15] TAKAGI, T.; YAMAKOSHI, Y.; BABA, J.; UEMURA, K.; SAKAGUCHI, T. (1981). A new algorithm of an accurate fault location for EHV/UHV transmission lines: Part I - Fourier Transformation method. IEEE Transactions on Power Apparatus and Systems, v.PAS-100, n.3, p. 1316-1322, mar.

[16] TAKAGI, T.; YAMAKOSHI, Y.; BABA, J.; UEMURA, K.; SAKAGUCHI, T. (1982a). A new algorithm of an accurate fault location for EHV/UHV transmission lines: Part II - Laplace Transform method. IEEE Transactions on Power Apparatus and Systems, v.PAS-101, n.3, p. 564-573, mar. 
[17] TAKAGI, T.; YAMAKOSHI, Y.; YAMAURA, M.; KONDOW, R.; MATSUSHIMA, T. (1982b). Development of a new type fault locator using the one-terminal voltage and current data. IEEE Transactions on Power Apparatus and Systems, v.PAS-101, n.8, p. 2892-2898, aug.

[18] ERIKSSON, L.; SAHA, M. M.; ROCKEFELLER, G. D. (1985). An accurate fault location with compensation for apparent reactance in the fault resistance resulting from remote-end infeed. IEEE Transactions on Power Apparatus and Systems, v.PAS-104, n.2, p. 424-435, feb.

[19] RANJBAR, A. M.; SHIRANI, A. R.; FATHI, A. F. (1992). A new approach for fault location problem on power lines. IEEE Transmission on Power Delivery, v.7, n.1, p. 146-151, jan.

[20] GIRGIS, A. A.; FALLON, C. M. (1992). Fault location techniques for radial and loop transmission systems using digital fault recorded data. IEEE Transmission on Power Delivery, v.7, n.4, p. 1396-1945, out.

[21] JOHNS, A T.; MOORE, P. J.; WHITTARD, R. (1995). New technique for the accurate location of earth faults on transmission systems. IEE ProceedingGeneration, Transmission and Distribution, v.142, n.2, p. 119-127, mar.

[22] PURUSHOTHAMA, G. K.; NARENDRANATH, A U.; THUKARAM, D.; PARTHASARATHY, K. (2000). ANN applications in fault locators. ELSEVIER Electrical Power and Energy Systems, v.23, p. 491-506, jun.

[23] SAHA, M. M.; WIKSTROM, K.; IZYKOWSKI, J.; ROSOLOWSKI, E. (2001). New accurate fault location algorithm for parallel lines IEE Developments in Power System Protection, Conference Publication, n.479, p. 407-410.

[24] YIBIN, X.; WAI, D. C. T.; KEERThiPALA, W. W. L. (1997). A new technique using wavelet analysis for fault location. IEE Developments in Power System Protection, Conference Publication, n.434, p. 231-234, mar.

[25] SOARES, L. R.; CARVALHO JR., M. A.; OliveIRA, H. M. (2002). Localização de faltas em linhas de transmissão utilizando a representação wavelet multiresolução. XIV Congresso Brasileiro de Automática, Natal/RN, p. 2683-2688, set. 
[26] SENGER, E. C.; MANASSERO Jr, G.; REIS FILHO, F. A. e NAKAGOMI, R. M. (2003). Algoritmo para localização de faltas em linhas de transmissão. VII Seminário Técnico de Proteção e Controle, 22-27 de junho, Rio de Janeiro-RJ.

[27] PEREIRA, C. E. M. and ZANETTA Jr, L. C. (2004). Fault location in transmission lines using one-terminal posfault voltage data. IEEE Transactions on Power Delivery, v. 19, n. 2, april.

[28] SCHWEITZER, E. O.; JACHINOWSKI, J. K. (1981). A prototype microprocessor-based system for transmission line protection and monitoring. Eight Annual Western protective Relay Conference, Spokane, Washington, USA.

[29] SACHDEV, M. S.; AGGARWAL, R. (1985). Accurate fault location estimates from digital impedance relay measurements. IEE Conference Publication, n.249, p. 193-198.

[30] JEYASURYA, B.; RAHMAN, M. A. (1989). Accurate fault location of transmission lines using microprocessors. IEE Fourth International Conference, p. 13-17.

[31] JOHNS, A. T.; JAMALI, S. (1990). Accurate fault location technique for power transmission lines. IEE Proceedings, v.137, Pt. C, n.6, p. 395-402, nov.

[32] KALAM, A.; JOHNS, A. T. (1991). Accurate fault location technique for multi-terminal EHV lines. IEE International Conference on Advances in Power System Control, Operation and Management, Hong Kong, p. 420-424, nov.

[33] AGgarWAL, R. K.; COURY, D. V.; JOHNS, A. T.; KAlAM, A. (1993). A practical approach to accurate fault location on extra high voltage teed feeders. IEEE Transactions on Power Delivery, v.8, n.3, p. 874-883, jul.

[34] NOVOSEL, D.; HART, D. G.; UDREN, E.; SAHA, M. M. (1995). Fault location using digital relay data. IEEE Computer Applications in Power, v.8, n.3, p. 45-50, jul.

[35] ZAMORA, I.; MINAMBRES, J. F.; MAZON, A J.; ALVAREZ-ISASI, R.; LAZARO, J. (1996). Fault location on two-terminal transmission lines based on voltages. IEE Proceedings-Generation, Transmission and Distribution, v.143, n.1, p. 1-6, jan. 
[36] GONG, Q.; CHEN, Y.;ZHANG, C.; WANG, Z. (2000). A study of the accurate fault location system for transmission line using multi-terminal signals. IEEE Power Engineering Society Winter Meeting, v.4, p. 2533-2538.

[37] TZIOUVARAS, D. A.; ROBBERTS, J. and BENMOUYAL, G. (2001). New multi-ended fault location design for two-or three-terminal lines. Development in Power System Protection, Amsterdam, The Netherlands, april.

[38] SOllero, R. B.; BIANCO, J. C. N.; ASSIS, T. M. L.; RODRIGUES, M. A. M.; MIRANDA, A. L. L.; MANTUANO FILHO, S. (2001). Localização de faltas em sistemas de transmissão a partir de sinais oscilografados em ambas as extremidades da linha. XVI Seminário Nacional de Produção e Transmissão de Energia Elétrica, Campinas/SP, GPC/025, 6 p. out.

[39] SOUSA, W. M.; COSTA, C. A. B.; PEREIRA Jr, I. H. and FILHO, C. S. P. (2005). Sistema de localização automática de faltas em linhas de transmissão utilizando dados de dois terminais - Experiência da CEMIG. VIII - Seminário Técnico de Proteção e Controle, 28 de junho a 01 de junho, Rio de Janeiro-RJ.

[40] BEWLEY, L. V. (1963). Traveling waves on transmission systems. John Wiley \& Sons, New York.

[41] JOHNS, A. T. and SALMAN, S. K. (1995). Digital protection for power systems. Peter Peregrinus Ltd. on behalf of The Institution of Electrical Engineers (IEE), United Kingdom.

[42] CHRISTOPOULOS, C. and WRIGHT, A. (1999). Electrical power system protection. $2^{\text {nd }}$ Edition, Kluwer Academic Publishers, Dordrecht, The Netherlands.

[43] GAlE, P. F.; CROSSlEY, P. A.; BINGYIN, XU; YAOZHONG, GE; CORY, B. J.; BARKER, J. R.G. (1993). Fault localion based on traveling waves. Developments in Power System Protection, Fifth International Conference, p. 54-59.

[44] VITINS, M. (1978). A correlation method for transmission line protection. IEEE Transactions on Power Apparatus and Systems, v.PAS-97, n.5, p. 16071615 , sept/oct. 
[45] CROSSley, P. A.; MCLAREN, P. G. (1983). Distance protection based on travelling waves. IEEE Transactions on Power Apparatus and Systems, v.PAS102, n.9, p. 2971-2983, sept.

[46] RAJENDRA, S.; MCLAREN, P. G. (1985). Traveling wave techniques applied to the protection of teed circuits: Principle of traveling wave techniques. IEEE Transactions on Power Apparatus and Systems, v.PAS-104, n.12, p. 3544-3550, dec.

[47] SHEHAB-ELDIN, E. H.; MCLAREN, P. G. (1988). Traveling wave distance protection - Problem areas and solutions. IEEE Transactions on Power Delivery, v.3, n.3, p. 894-902, jul.

[48] ANCELL, G. B.; PAHALAWATHTHA, N. C. (1994). Maximum likelihood estimation of fault location on transmission lines using traveling waves. IEEE Transactions on Power Delivery, v.9, n.2, p. 680-686, apr.

[49] BO, Z. Q.; JOHNS, A. T.; AGGARWAL, R. K. (1997). A novel fault locator based on the detection of fault generated high frequency transients. IEE Developments in Power System Protection, Conference Publication, n.434, p. 197-200, mar.

[50] MAGNAGO, F. H.; ABUR, A. (1998). Fault location using wavelets. IEEE Transactions on Power Delivery, v.13, n.4, p. 1475-1480, oct.

[51] Liang, J.; ElanBOVAN, S.; DEVOtTA, J. B. X. (2000). Application of wavelet transform in traveling wave protection. ELSEVIER Electrical Power and Energy Systems, v.22, p. 537-542, apr.

[52] CHEN, Z.; BO, Z. Q.; JIANG, F.; DONG, X. Z.; WELLER, G.; CHIN, N. F. (2000). Wavelet transform based accurate fault location and protection technique pro cable circuits. IEE Proceedings of the Fifth International Conference on Advances in Power System Control, Operation and Management, Hong Kong, p. 59-63, oct.

[53] ABUR, A.; MAGNAGO, F. H. (2000). Use of time delays between modal components in wavelet based fault location. ELSEVIER Electrical Power and Energy Systems, v.22, p. 397-403. 
[54] SILVEIRA, P. M.; SEARA, R.; ZURN, H. H. (1999a). Fault type identification using wavelet transform. The International Conference on Intelligent Systems Application to Power Systems, p. 267-272, Rio de Janeiro, Brasil.

[55] SILVEIRA, P. M.; SEARA, R.; ZURN, H. H. (1999b). An approach using wavelet transform for fault type identification in digital relaying. IEEE Proceeding Summer Meeting, p. 937-942, Edmonton, Canadá.

[56] MUSTAFA, T. I. A. H.; THOMAS, D. W. P.; CHRISTOPOUlOS, C. and RAIZER, A. (2003). Comparison of simulated and recorded transients for traveling wave fault location. IEEE Bologna PowerTech Conference, June 2326, Bologna, Italy.

[57] SILVA, M.; OLESKOVICZ, M. and COURY, D. V. (2004). A fault locator for transmission lines using traveling waves and wavelet transform theory. Eighth IEE International Conference on Developments in Power System Protection, v.1, p. $212-215$, april.

[58] JIANG, L.; JI, Z.; LI, Q. and WU, Q. H. (2005). Fault location in power transmission lines using a second generation wavelet analysis. IEEE/PES Transmission and Distribution Conference \& Exhibition: Asia and Pacific, Dalian, China.

[59] IBE, A. O.; CORY, B. J. (1986). A traveling wave-based fault locator for twoand three-terminal networks. IEEE Transactions on Power Systems, v.PWRD-1, n.2, p. 283-288, apr.

[60] IBE, A. O.; CORY, B. J. (1987). Fault location algorithm for multiphase power lines. IEE Proceedings, v.134, Pt. C, n.1, p. 43-50, jan.

[61] LEE, H.; MOUSA, A. M. (1996). GPS Traveling wave fault locator systems: investigation into the anomalous measurements related to lightning strikes. IEEE Transactions on Power Systems, v.11, n.3, p.1214-1223, jul.

[62] JIAN, Q.; XIANGXUN, C.; JIANCHAO, Z. (1998). Traveling wave fault location of transmission line using wavelet transform. IEEE Proceedings International Conference on Power System Technology, v.1, p. 533-537, aug.

[63] GAle, P. F.; TAYlOR, P. V.; NAIDOO, P.; HITCHIN, C.; ClOWES, D. (2001). Traveling wave fault locator experience on eskom's transmission 
network. IEE Development in Power System Protection, Conference Publication n.479, p.327-330.

[64] KIM, G.; KIM, H.; CHOI, J. (2001). Wavelet transform based power transmission line fault location using GPS for accurate time synchronization. IEEE/IECON: The $27^{\text {th }}$ Annual Conference of the IEEE Industrial Electronics Society, p. 495-499.

[65] CHANDA, D.; KISHORE, N. K.; SINHA, A. K. (2003). A wavelet multiresolution analysis for location of faults on transmission lines. Electrical Power \& Energy Systems, v.25, p.59-69.

[66] PEREIRA, C.; SILVEIRA, E. G.; ABREU, S. S.; MELO, J. C. D.; BOLBA, R. C.; ANDRADE, A. D.; MARKIEWICZ, R. L. and RESENDE, D. B. (2003). Localizador de faltas para linhas de transmissão baseado no método das ondas viajantes. VII - Seminário Técnico de Proteção e Controle, 22-27 junho, Rio de Janeiro-RJ.

[67] SILVA, M.; OLESKOVICZ, M. and COURY, D. V. (2005). Um estudo de um localizador de faltas preciso para linhas de transmissão com multi-terminais usando wavelets. Sixth Latin-American: Electricity Generation and Transmission, november 13-17, Mar del Plata, Argentina.

[68] HEDMAN, D. E. (1978). Teoria das Linhas de Transmissão II. Tradução FARRET, F. A., Universidade Federal de Santa Maria, Santa Maria.

[69] GREENWOOD, A. (1971). Electrical transients in power systems. WileyInterscience, New York.

[70] NAIDU, S. R. (1985). Transitórios eletromagnéticos em sistemas de potência. Editora Grafset - Co-edição Eletrobrás/Universidade Federal do Paraíba.

[71] ZANETTA JR., L. C. (2003). Transitórios eletromagnéticos em sistemas de potência. EDUSP - Editora da Universidade de São Paulo, São Paulo-SP.

[72] LIMA, P. C. Wavelets: Teoria, Algoritmos e Aplicações. Belo Horizonte: Departamento de Matemática - ICEX - UFMG, p. 2002.

[73] GRAPS, A. (1995). An Introduction to wavelets. IEEE Computational Science and Engineering, v.2, p. 50-61, summer. 
[74] SCHIMIDT, R. F. (2000). Detecção e rastreamento de faces utilizando Gabor wavelet networks. Dissertação (Mestrado), Instituto de Matemática e Estatística, Universidade de São Paulo.

[75] KIM, C. H.; AGGARWAL, R. (2000). Wavelet transforms in power systems: Part 1 General introduction to the wavelet transforms. Power Engineering Journal, v.14, n.2, p. 81-87, Apr.

[76] DAUBECHIES, I. (1996). Where Do Wavelets Come From? - A Personal Point of View. Proceedings of the IEEE, v.84, n.4, p. 510-513, Apr.

[77] MISITI, M., MISITI, Y., OPPENHEIM, G. and POGGI, J.-M. (1997). Wavelet Toolbox: User`s Guide. Natick, MA: The MathWorks, 626 p.

[78] DAUBECHIES, I. (1992). Ten lectures on wavelets. Philadelphia, Pa.: Society for Industrial and Applied Mathematics, $357 \mathrm{p}$.

[79] MEYER, Y. (1992). Wavelets and operators. Cambridge: Cambridge University Press.

[80] CHUI, C. K. (1997). Wavelets: a tool for signal analysis. Philadelphia, Pa.: Society for Industrial and Applied Mathematics.

[81] STRANG, G. and NGUUEN, T. (1997). Wavelets and Filter Banks. WellesleyMA-USA: Wellesley-Cambridge Press.

[82] BURRUS, C. S., GOPINATH, R. A.; GUO, H. (1998). Introduction to wavelets and wavelet transforms : a primer. Upper Saddle River, NJ: Prentice Hall, 268 p.

[83] ADDISON, P. S. (2002). The Ilustrated Wavelet Transform Handbook: Introductory Theory and Applications in Science, Engineering, Medicine and Finance. Edinburg-UK: Institute of Physics Publishing.

[84] BURKE HUBBARD, B. (1998). The world according to wavelets. Wellesley, Massachusetts.: A. K. PETERS.

[85] KIM, C. H.; AGGARWAL, R. (2001). Wavelet transforms in power systems: Part 2 Examples of application to actual power system transients. Power Engineering Journal, p. 193-202, Aug. 
[86] PESQUET, J-C.; KRIM, H. e CARFANTAN, H. (1996). Time-Invariant Orthonormal Wavelet Representations. IEEE Transactions on Signal Processing, v.44, n.8, p. 1964-1970, Aug.

[87] SILVEIRA, P. M. (2001). Identificação e Localização de Faltas utilizando Análise por Decomposição Wavelet para Réles de Linhas de Transmissão. Tese (Doutorado) - Universidade Federal de Santa Catarina, Florianópolis.

[88] NASON, G. P. and SILVERMAN, B. W. (1995). The Stationary Wavelet Transform and some Statistical Applications. Lecture Notes in Statistics, Department of Mathematics of Bristol, Bristol, UK, pp.281-299.

[89] COIFMAN, R. R. and DONOHO, D. L. (1995). Translation-Invariant DeNoising. Lecture Notes in Statistics, Yale University and Stanford University, pp.125-150.

[90] SIMONCELli, E. P.; FREEMAN, W. T.; ADELSON, E. H. and HEEGER, D. J. (1992). Shiftable Multiscale Transforms. IEEE Transactions on Information Theory, v.38, n.2, p. 587-607, Mar.

[91] LANG, M.; GUO, H.; ODEGARD, J. E.; BURRUS, C. S. and WELLS Jr., R. O. (1996). Noise Reduction using an Undecimated Discrete Wavelet Trasnform. IEEE Signal Processing Letters, v.3, n.1, p. 10-12, Jan.

[92] MISITI, M.; MISITI, Y.; OPPENHEIM, G. and POGGI, J-M. (2005). Wavelet Toolbox User's Guide for use with Matlab ${ }^{\circledR}$, versão 3, The MathWorks, Inc.

[93] SANTOSO, S.; POWERS, E. J.; GRADY, W. M.; HOFMANN, P. (1996). Power Quality Assessment Via Wavelet Transform Analysis. IEEE Transactions on Power Delivery, v.11, n.2, p. 924-930, Apr.

[94] ALTERNATIVE TRANSIENTS PROGRAM - Rule Book. (1987). Leuven EMTP Center (LEC).

[95] PRIKLER, L. E HOIDALEN, H. K. (2002). ATPDRAW VERSION 3.5 FOR WINDOWS 9x/NT/2000/XP - USERS' MANUAL. Sintef Energy Research, Trondheim, Norway.

[96] OLESKOVICZ, M. (1997). Redes Neurais Artificiais: Uma Alternativa para proteção de Linhas de Transmissão. Dissertação (Mestrado) - Escola de Engenharia de São Carlos, Universidade de São Paulo. 
[97] TSIOUVARAS, D. A.; MACLAREN, P.; ALEXANDER, G.; DAWSON, D.; ESZTERGALYOS, J.; FROMEN, C.; GLINKOWSKI, M.; HASENWINKLE, M.; KEZUNOVIC, M.; KOJOVIC, L.; KOTHEIMER, B.; KUFFEL, R.; NORDSTROM, J. and ZOCHOLL, S. (2000). Mathematical models for current, voltage, and coupling capacitor voltage transformers. IEEE Transactions on Power Delivery, v.15, n.1, p.62-72, jan.

[98] KOJOVIC, L.; KEZUNOVIC, M. and FROMEN, C. W. (1994). A new method for the CCVT performance analysis using field measurements, signal processing and EMTP modeling. IEEE Transactions on Power Delivery, v.9, n.4, p.19071915 , oct.

[99] USHIKUBO, M. F. e ROMEIRO FILHO, J. N. R.. (1999). Simulação em tempo real de faltas utilizando ATP, simulador de sistemas de potência e GPS. XV SNTEE - Seminário Nacional de Produção e Transmissão de Energia Elétrica, 17 à 22 de Outubro de 1999, Foz do Iguaçu, Paraná, Brasil.

[100] OleSKOVICZ, M.; COURY, D. V.; SILVA, M.; BERNARDES, A. P. and ABBOUD, R. (2005). Um esquema completo de proteção diferencial de transformadores para testes em relés digitais. VIII STPC - Seminário Técnico de Proteção e Controle, 28 de junho a 01 de junho de 2005, Rio de Janeiro-RJ.

[101] KEZUNOVIC, M.; KOJOVIC, L. and PHILLIPS, F. (1994). Experimental evaluation of EMTP-Based current transformer models. IEEE Transactions on Power Delivery, v.9, n.1, p.405-413, jan.

[102] PHADKE, A. G. and THORP, J. S. (1988). Computer relaying for power systems. England, Research Studies Press Ltd.

[103] UNGRAD, H.; WINKLER, W. and WISZNIEWSKI, A. (1995). Protection techniques in electrical energy systems. Marcel Dekker, Inc. New York-Basel, Translated by HARRISON, P. G.

[104] IEE - POWER SYSTEM PROTECTION (1997). Volume 4: Digital protection and signaling. Edited by The Electricity Training Association, IEE Institution of Electrical Engineers, United Kingdom. 
[105] FRENCH, G. T. (1996). Understanding the GPS: An introduction to the Global Positioning System - What it is and How it works. First Edition, GeoResearch Inc.

[106] ZHAO, W.; SONG, Y. H.; CHEN, W. R. (2001). Improved GPS traveling wave fault locator for power cables by using wavelet analysis. ELSEVIER Electrical Power and Energy Systems, v.23, p. 403-411.

[107] BetTSTETTER, C.; VOGEL, H-J. and EBERSPACHER J. (1999). GSM Phase $2+$ General Packet Radio Service GPRS: Architecture, Protocols and Air Interface. IEEE Communications Surveys, v.2, n.3, Third Quarter 1999.

[108] EICHELBURG, W. K. (2005). Using GPRS to connect outlying distribution substations. XVII CIRED - International Conference on Electricity Distribution, 6-9 june 2005, Turin.

[109] URUSAWA, K.; KANEMARU, K.; TOYOTA, S.; SUGIYAMA, K. (1989). New fault location system for power transmission lines using composite fiberoptic overhead ground wire $(O P G W)$. IEEE Transactions on Power Delivery, v.4, n.4, p.2005-2011, oct.

[110] SILVA, M.; OLESKOVICZ, M. e COURY, D. V. (2004). Application of the Wavelet Transform on the Fault Location in Transmission Lines Problem. IEEE/PES T\&D 2004 Latin America, 08-11 novembro, São Paulo-SP.

[111] ARRUdA, E. F., DELMONT, O. F., COURY, D. V., CARNEIRO, A. A. F. M. (2002). Um Estudo das Famílias Wavelets Aplicadas à Qualidade da Energia Elétrica. CBA - Congresso Brasileiro de Automática, 14. Natal-RN. (CD).

[112] CAPOBIANCO, R. (2006). Transformada Wavelet-Packet: Compressão de Áudio - hard e soft threshold. Notas de Aula da disciplina SFI5871-1/2006 Introdução à Transformada Wavelet e Aplicações, Instituto de Física de São Carlos, Universidade de São Paulo, São Carlos/SP.

[113] CLARKE, E. (1943). Circuit analysis of A-C power systems. . John Wiley \& Sons, New York.

[114] WEDEPOHL, L. M. (1963). Application of matrix methods to the solution of traveling-wave phenomena in polyphase systems. PROC, IEE, v. 110, n. 12, dec. 
[115] ANCELL, G. B. and PAHALAWATHTHA, N. C. (1992). Effects of frequency dependence and line parameters on single ended traveling wave based fault location schemes. IEE Proceedings-C, v. 139, n. 4, july.

[116] IEEE standard C37_111_1991. (1991). “Common Format for Transient Data Exchange (COMTRADE) for Power Systems".

[117] Silva, M. (2003). Localização de faltas em linhas de transmissão utilizando a teoria de ondas viajantes e transformada wavelet. Dissertação (Mestrado) Escola de Engenharia de São Carlos, Universidade de São Paulo, São Carlos-SP.

[118] DUGAN, R. C.; MCGRANAGHAN, M. F. and BEATY, H. W. (1996). Electrical Power Systems Quality. McGraw-Hill Companies.

[119] SIDHU, T. S. (1999). Accurate measurement of power system frequency using a digital sinal processing technique. IEEE Transactions on Instrumentation and Measurement, v.48, n.1, p.75-81, feb.

[120] PEREIRA, C.; ABREU, S. S.; SILVEIRA, E. G.; MELO, J. C. D. e BOLDA, R. C. (2005). A influência de ruído e sinais espúrios na precisão e localização de faltas em linhas de transmissão utilizando o método das ondas viajantes. XVIII SNPTEE - Seminário Nacional de Produção e Transmissão de Energia Elétrica, 16-21 outubro 2005, Curitiba-Paraná.

[121] PEREIRA, C. E. M. (1999). Localizadores digitais de faltas em linhas de transmissão. Dissertação de Mestrado. Escola Politécnica da Universidade de São Paulo. 



\section{APÊNDICE A - Arquivos de entrada do ATP}

Neste apêndice é descrito o arquivo de entrada do ATP, o qual representa o sistema elétrico (três terminais - simples) em regime permanente utilizado para teste do localizador de faltas proposto.

\section{Sistema elétrico com três terminais disposto em circuito simples horizontal}

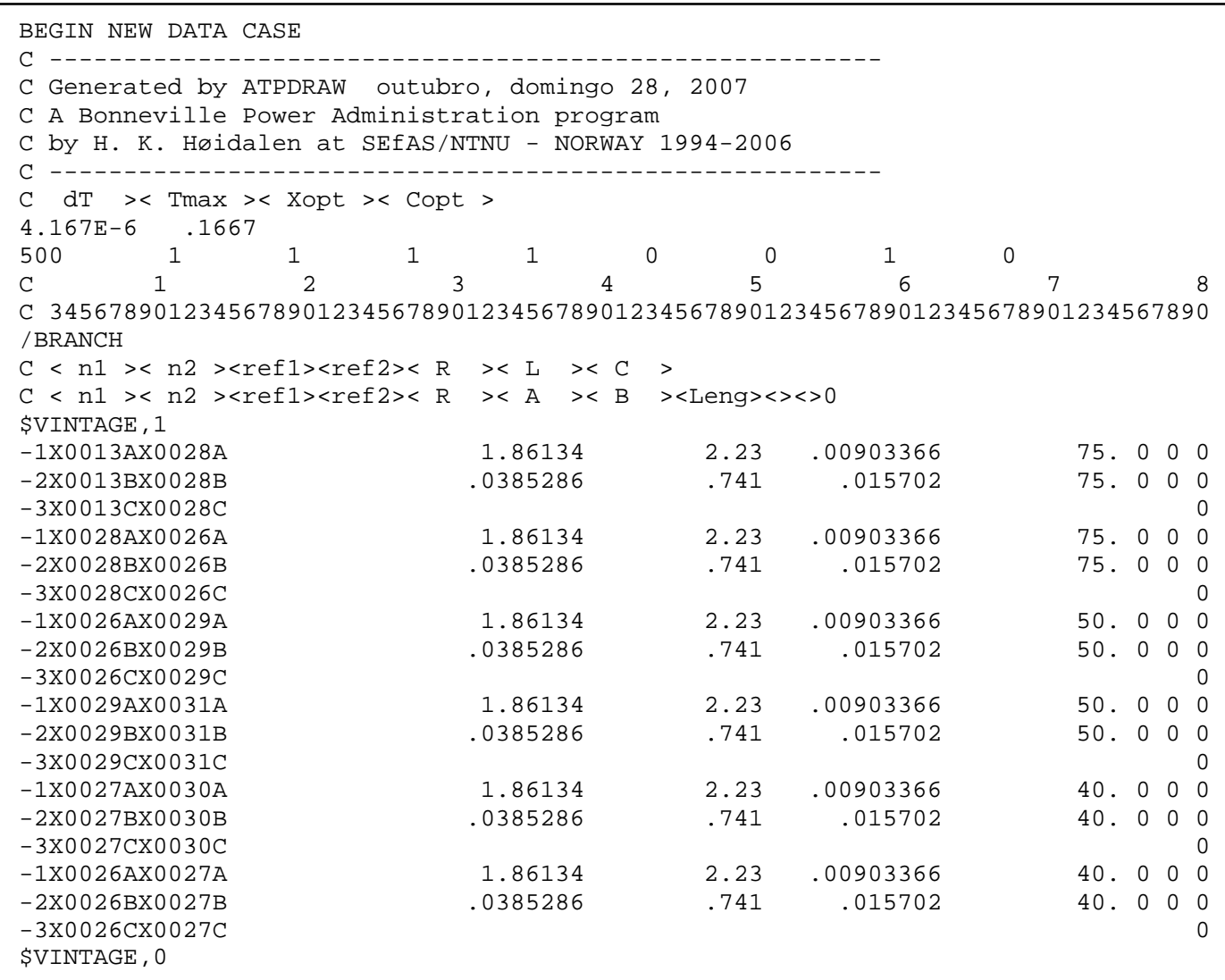


C RF1C

XX0014X0001C

C RF1A

X०००1AXX0014

C RF1B

XX००14X०००1B

C RF1C

$\mathrm{XX0015X00 \odot 2 \textrm {C }}$

C RF1A

$X X \odot \odot 15 X \odot \odot \odot 2 A$

C RF1B

XX0015X0००2B

C RF1C

XX००16X०००3C

C RF1A

XX0016X0००3A

C RF1B

XX0016X0००3B

\$VINTAGE, 1

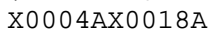

X०००4BX0018B

X०००4CX००18C

$\mathrm{X} 0018 \mathrm{~A}$

X०018B

X००18C

X००19AX००32A

X००19BX००32B

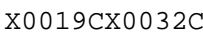

X००18AX0019A

X००18BX००19B

X००18CX००19C

X०019A

X०019B

X०019C

X००18AX0019A

X००18BХ००19B

Х००18CX००19C

$\mathrm{X} 0032 \mathrm{~A}$

$\mathrm{X} 0032 \mathrm{~B}$

$\mathrm{X} 0032 \mathrm{C}$

$\mathrm{X} 0032 \mathrm{~A}$

$\mathrm{X} 0032 \mathrm{~B}$

$X \odot 032 \mathrm{C}$

VBUS1A

VBUS1B

VBUS1C

VBUS1A

VBUS1B

VBUS1C

\$VINTAGE, $\odot$

51X0010AX00०4A

$52 X 0010 \mathrm{BX} 0004 \mathrm{~B}$

$53 \times 0010 \mathrm{CX} 0004 \mathrm{C}$

51X0012AX0००8A

$52 X 0012 \mathrm{BX} 0008 \mathrm{~B}$

53Х००12CX०००8C

51X०००6AX0011A

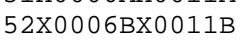

53X0006CX0011C

TRANSFORMER

๑. 00282842712

$\odot .00525107738$

๑. 00805200092

$\odot .00937604273$

๑. 0130507689

๑. 0269326991

$\odot .0363934345$

$\odot .062340771$

$\odot .0851843969$

0.178251034

$\odot .453547317$

9999
.001

.001

.001

.001

.001

.001

.001

.001

.001

$\odot$

$\odot$

$\odot$

$\odot$

$\odot$

$\odot$

$\odot$

.002546

.002546

.002546

.137376

.137376

360.

.137376

360 .

1890.

1890.

360.

1890.

95.

95.

95.

8. E-5

8. E-5

8.E-5

.00013

.00013

.00013

48500 .

48500 .

48500 .

1. 9E 7

1. $9 \mathrm{E} 7$

1. $9 \mathrm{E} 7$

$2.75 \mathrm{E} 6$

2. $75 \mathrm{E} 6$

2. $75 \mathrm{E} 6$

6.2

6.2

6.2

75.

75.

75 .

.31816

9.62105

1. 4035

42.4413

.33491

10.1274

1. 4774

44.6751

.35351

10.6901

1.5595

47.157

TX०००1

0

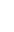

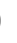

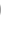

$\odot$

0

0

$\odot$

$\odot$

0

0

$\odot$

0

$\odot$

$\odot$

0

$\odot$

$\odot$

$\odot$

$\odot$

$\odot$

$\odot$

$\odot$

๑. 0262592259

$\odot .0750263597$

๑. 131296129

0.161306673

๑. 281348849

๑. 750263597

1. 27544811

1.61306673

1.76311945

1.87565899

2. 06322489 


\begin{tabular}{|c|c|c|c|}
\hline 1BUS1B & 1.2 & $.0013 . \mathrm{E3}$ & \\
\hline $2 X \odot \odot \odot 4 B X \odot \odot \odot 5 B$ & .0001 & .0155 & \\
\hline TRANSFORMER & & TX๑००2 & 0 \\
\hline 0.00282842712 & 0.0262592259 & & \\
\hline ๑. .0०525107738 & $\odot .0750263597$ & & \\
\hline$\odot .00805200092$ & 0.131296129 & & \\
\hline ๑. $009376 \odot 4273$ & $\odot .161306673$ & & \\
\hline$\odot .0130507689$ & 0.281348849 & & \\
\hline$\odot .0269326991$ & $\odot .750263597$ & & \\
\hline ๑.0363934345 & 1.27544811 & & \\
\hline$\odot .062340771$ & 1.61306673 & & \\
\hline ๑. 0851843969 & 1.76311945 & & \\
\hline$\odot .178251034$ & 1.87565899 & & \\
\hline$\odot .453547317$ & 2.06322489 & & \\
\hline \multicolumn{4}{|l|}{9999} \\
\hline 1BUS1A & 1.2 & $.001 \quad 3 . \mathrm{E3}$ & \\
\hline $2 X \odot \odot \odot 4 A X \odot \odot \odot 5 A$ & .0001 & .0155. & \\
\hline TRANSFORMER & & TX0003 & 0 \\
\hline ๑. 00282842712 & 0.0262592259 & & \\
\hline$\odot .0 \odot 525107738$ & $\odot .0750263597$ & & \\
\hline ๑. 00805200092 & 0.131296129 & & \\
\hline$\odot .00937604273$ & 0.161306673 & & \\
\hline$\odot .0130507689$ & 0.281348849 & & \\
\hline ๑. 0269326991 & 0.750263597 & & \\
\hline 0.0363934345 & 1.27544811 & & \\
\hline$\odot .062340771$ & 1.61306673 & & \\
\hline ๑. 0851843969 & 1.76311945 & & \\
\hline$\odot .178251034$ & 1.87565899 & & \\
\hline$\odot .453547317$ & 2.06322489 & & \\
\hline \multicolumn{4}{|l|}{9999} \\
\hline 1BUS1C & 1.2 & $.001 \quad 3 . \mathrm{E3}$ & \\
\hline $2 \times \odot \odot \odot 4 \mathrm{C} \times \odot \odot \odot 5 \mathrm{C}$ & .0001 & .0155 & \\
\hline BUS1A & 8. & & 1 \\
\hline BUS1B & 8. & & 1 \\
\hline BUS1C & 8. & & 1 \\
\hline TRANSFORMER & & TX0004 & 0 \\
\hline ๑. 00282842712 & 0.0262592259 & & \\
\hline ๑. 00525107738 & 0.0750263597 & & \\
\hline ๑. 00805200092 & $\odot .131296129$ & & \\
\hline$\odot .0 \odot 9376 \odot 4273$ & 0.161306673 & & \\
\hline ๑.0130507689 & 0.281348849 & & \\
\hline ๑. 0269326991 & 0.750263597 & & \\
\hline 0.0363934345 & 1.27544811 & & \\
\hline ๑.062340771 & 1.61306673 & & \\
\hline ๑. 0851843969 & 1.76311945 & & \\
\hline 0.178251034 & 1.87565899 & & \\
\hline$\odot .453547317$ & 2.06322489 & & \\
\hline \multicolumn{4}{|l|}{9999} \\
\hline 1BUS3B & 1.2 & $.001 \quad 3 . E 3$ & \\
\hline $2 \mathrm{X} \odot \odot \odot 6 \mathrm{BX} \odot \odot \odot 7 \mathrm{~B}$ & .0001 & .01 & \\
\hline TRANSFORMER & & TX0005 & 0 \\
\hline ๑. 00282842712 & $\odot .0262592259$ & & \\
\hline 0.00525107738 & 0.0750263597 & & \\
\hline ๑. 00805200092 & 0.131296129 & & \\
\hline 0.00937604273 & 0.161306673 & & \\
\hline ๑.0130507689 & 0.281348849 & & \\
\hline ๑.0269326991 & 0.750263597 & & \\
\hline 0.0363934345 & 1.27544811 & & \\
\hline$\odot .062340771$ & 1.61306673 & & \\
\hline ๑.0851843969 & 1.76311945 & & \\
\hline 0.178251034 & 1.87565899 & & \\
\hline$\odot .453547317$ & 2.06322489 & & \\
\hline \multicolumn{4}{|l|}{9999} \\
\hline 1BUS3C & 1.2 & $.001 \quad 3 . E 3$ & \\
\hline $2 \times \odot \odot \odot 6 C \times \odot \odot \odot 7 C$ & .0001 & .01 & \\
\hline TRANSFORMER & & TX๑००6 & 0 \\
\hline ๑. 00282842712 & 0.0262592259 & & \\
\hline ๑. 00525107738 & $\odot .0750263597$ & & \\
\hline$\odot .0 \odot 805200 \odot 92$ & 0.131296129 & & \\
\hline$\odot .00937604273$ & 0.161306673 & & \\
\hline ๑.0130507689 & 0.281348849 & & \\
\hline ๑.0269326991 & 0.750263597 & & \\
\hline ๑.0363934345 & 1.27544811 & & \\
\hline ๑.062340771 & 1.61306673 & & \\
\hline ๑. 0851843969 & 1.76311945 & & \\
\hline
\end{tabular}




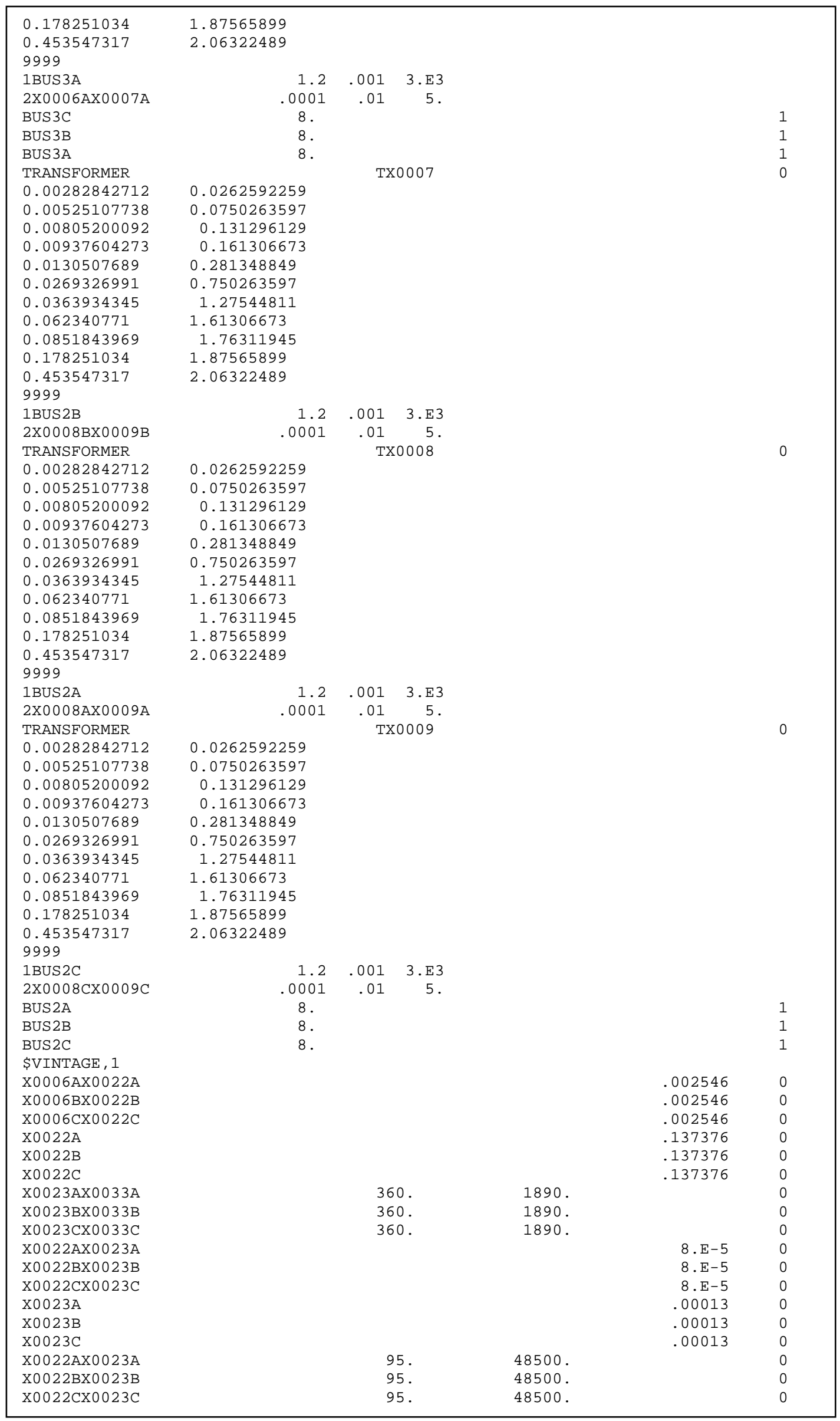




\begin{tabular}{|c|c|c|c|c|c|c|}
\hline \multicolumn{4}{|l|}{ X००3ЗА } & \multicolumn{2}{|l|}{$1.9 \mathrm{E} 7$} & 0 \\
\hline \multicolumn{4}{|l|}{ X๑०33B } & \multicolumn{2}{|l|}{ 1. $9 \mathrm{E} 7$} & 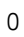 \\
\hline \multicolumn{6}{|l|}{$\mathrm{x} 0033 \mathrm{C}$} & $\Theta$ \\
\hline \multicolumn{6}{|l|}{$X 0033 \mathrm{~A}$} & $\odot$ \\
\hline \multicolumn{6}{|l|}{ X००33B } & $\odot$ \\
\hline \multicolumn{6}{|l|}{$\mathrm{x} \odot \odot 33 \mathrm{C}$} & 0 \\
\hline \multicolumn{3}{|l|}{ VBUS3A } & 6.2 & 38400 . & & $\Theta$ \\
\hline \multicolumn{3}{|l|}{ VBUS3B } & 6.2 & 38400 . & & 0 \\
\hline \multicolumn{3}{|l|}{ VBUS3C } & 6.2 & 38400. & & $\odot$ \\
\hline \multicolumn{3}{|l|}{ VBUS3A } & 75. & & & 0 \\
\hline VBUS3B & & & 75. & & & $\odot$ \\
\hline VBUS3C & & & 75 . & & & $\Theta$ \\
\hline $\mathrm{X} \odot \odot \odot 8 \mathrm{~A} X \odot \odot 24 \mathrm{~A}$ & & & & & .002546 & 0 \\
\hline $\mathrm{X} \odot \odot \odot 8 \mathrm{~B} \times \odot \odot 24 \mathrm{~B}$ & & & & & $.0 \odot 2546$ & $\odot$ \\
\hline $\mathrm{X} 0008 \mathrm{C} \times 0024 \mathrm{C}$ & & & & & .002546 & 0 \\
\hline$X 0024 A$ & & & & & .137376 & 0 \\
\hline$x \odot \odot 24 B$ & & & & & .137376 & 0 \\
\hline $\mathrm{X} 0024 \mathrm{C}$ & & & & & .137376 & 0 \\
\hline $\mathrm{X} 0025 \mathrm{~A} \times 0034 \mathrm{~A}$ & & & 360. & 1890. & & 0 \\
\hline $\mathrm{X} \odot \odot 25 \mathrm{~B} \times \odot \odot 34 \mathrm{~B}$ & & & 360. & 1890. & & $\odot$ \\
\hline $\mathrm{X} 0025 \mathrm{C} \times 0034 \mathrm{C}$ & & & 360. & 1890. & & 0 \\
\hline$X 0 \odot 24 A X \odot \odot 25 A$ & & & & & 8.E-5 & 0 \\
\hline$X \odot \odot 24 \mathrm{BX} \odot \odot 25 \mathrm{~B}$ & & & & & 8.E-5 & $\odot$ \\
\hline $\mathrm{X} \odot \odot 24 \mathrm{CX} \odot \odot 25 \mathrm{C}$ & & & & & 8.E-5 & $\Theta$ \\
\hline$X \odot \odot 25 A$ & & & & & .00013 & 0 \\
\hline$X \odot \odot 25 B$ & & & & & .00013 & $\odot$ \\
\hline$X \odot \odot 25 C$ & & & & & .00013 & $\Theta$ \\
\hline$X \odot \odot 24 A X \odot \odot 25 A$ & & & 95. & 48500. & & 0 \\
\hline $\mathrm{X} 0024 \mathrm{~B} X 0 \odot 25 \mathrm{~B}$ & & & 95. & 48500. & & 0 \\
\hline$X \odot \odot 24 C X \odot \odot 25 C$ & & & 95. & 48500. & & $\Theta$ \\
\hline $\mathrm{X} 0034 \mathrm{~A}$ & & & & 1. $9 \mathrm{E} 7$ & & 0 \\
\hline $\mathrm{x} \odot \odot 34 \mathrm{~B}$ & & & & 1. $9 \mathrm{E} 7$ & & 0 \\
\hline $\mathrm{X} \odot \odot 34 \mathrm{C}$ & & & & 1. $9 \mathrm{E} 7$ & & $\odot$ \\
\hline X0034A & & & $2.75 \mathrm{E} 6$ & & & 0 \\
\hline $\mathrm{X} \odot \odot 34 \mathrm{~B}$ & & & $2.75 \mathrm{E} 6$ & & & 0 \\
\hline $\mathrm{x} \odot \odot 34 \mathrm{C}$ & & & $2.75 \mathrm{E} 6$ & & & $\odot$ \\
\hline VBUS2A & & & 6.2 & 38400. & & 0 \\
\hline VBUS2B & & & 6.2 & 38400 . & & 0 \\
\hline VBUS2C & & & 6.2 & 38400 . & & $\Theta$ \\
\hline VBUS2A & & & 75. & & & $\odot$ \\
\hline VBUS2B & & & 75. & & & $\odot$ \\
\hline VBUS2C & & & 75. & & & $\odot$ \\
\hline \$VINTAGE, $\odot$ & & & & & & \\
\hline /SWITCH & & & & & & \\
\hline $\begin{array}{l}C<n \quad 1>n \\
C \text { Falta_F1 }\end{array}$ & Tclose & $\mathrm{p} /$ Tde $><$ & $\mathrm{Ie}$ & $><\mathrm{Vf} / \mathrm{CLOP}><$ type & & \\
\hline$X \odot \odot 01 \mathrm{~A} \times \odot \odot 28 \mathrm{~A}$ & 1.E3 & 1.E3 & & & & 0 \\
\hline$X \odot \odot \odot 1 B X \odot \odot 28 B$ & 1.E3 & 1.E3 & & & & $\odot$ \\
\hline $\mathrm{X} 0001 \mathrm{CX} \odot \odot 28 \mathrm{C}$ & 1.E3 & $1 . \mathrm{E3}$ & & & & $\odot$ \\
\hline C Falta_F1 & & & & & & \\
\hline$X \odot \odot \odot 2 A X \odot \odot \odot 29 A$ & 1.E3 & 1.E3 & & & & $\odot$ \\
\hline$X \odot \odot \odot 2 B X \odot \odot 29 B$ & $1 . \mathrm{E3}$ & 1.E3 & & & & 0 \\
\hline $\mathrm{X} \odot \odot \odot 2 \mathrm{CX} \odot \odot 29 \mathrm{C}$ & 1.E3 & 1.E3 & & & & $\odot$ \\
\hline C Falta_F1 & & & & & & \\
\hline$X \odot \odot \odot 3 A \times \odot-\odot 27 A$ & $1 . \mathrm{E3}$ & 1.E3 & & & & 0 \\
\hline $\mathrm{X} \odot \odot \odot 3 \mathrm{~B} X \odot \odot 27 \mathrm{~B}$ & $1 . \mathrm{E3}$ & 1.E3 & & & & 0 \\
\hline $\mathrm{x} \odot \odot \odot 3 \mathrm{C} \times \odot \odot 27 \mathrm{C}$ & 1.E3 & 1.E3 & & & & $\odot$ \\
\hline$X \odot \odot \odot 5 A X \odot \odot 13 A$ & & & & MEASURING & & $\odot$ \\
\hline$X 0005 \mathrm{~B} X 0013 \mathrm{~B}$ & & & & MEASURING & & 0 \\
\hline $\mathrm{X} \odot \odot \odot 5 \mathrm{C} \times \odot \odot 13 \mathrm{C}$ & & & & MEASURING & & $\odot$ \\
\hline$X 0007 \mathrm{AX} \odot \odot 31 \mathrm{~A}$ & & & & MEASURING & & $\odot$ \\
\hline $\mathrm{X} 0007 \mathrm{~B} X \odot 031 \mathrm{~B}$ & & & & MEASURING & & 0 \\
\hline $\mathrm{x} \odot \odot \odot 7 \mathrm{CX} \odot \odot 31 \mathrm{C}$ & & & & MEASURING & & 0 \\
\hline Х०००९AX००З०A & & & & MEASURING & & 0 \\
\hline $\mathrm{X} \odot \odot \bullet 9 B \times \odot \odot 30 \mathrm{~B}$ & & & & MEASURING & & 0 \\
\hline 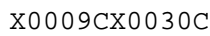 & & & & MEASURING & & $\odot$ \\
\hline XX०014 & -1 & 1.E3 & & & & 0 \\
\hline$X X 0016$ & -1 & 1.E3 & & & & $\odot$ \\
\hline XX0015 & -1 & $1 . \mathrm{E3}$ & & & & $\odot$ \\
\hline
\end{tabular}



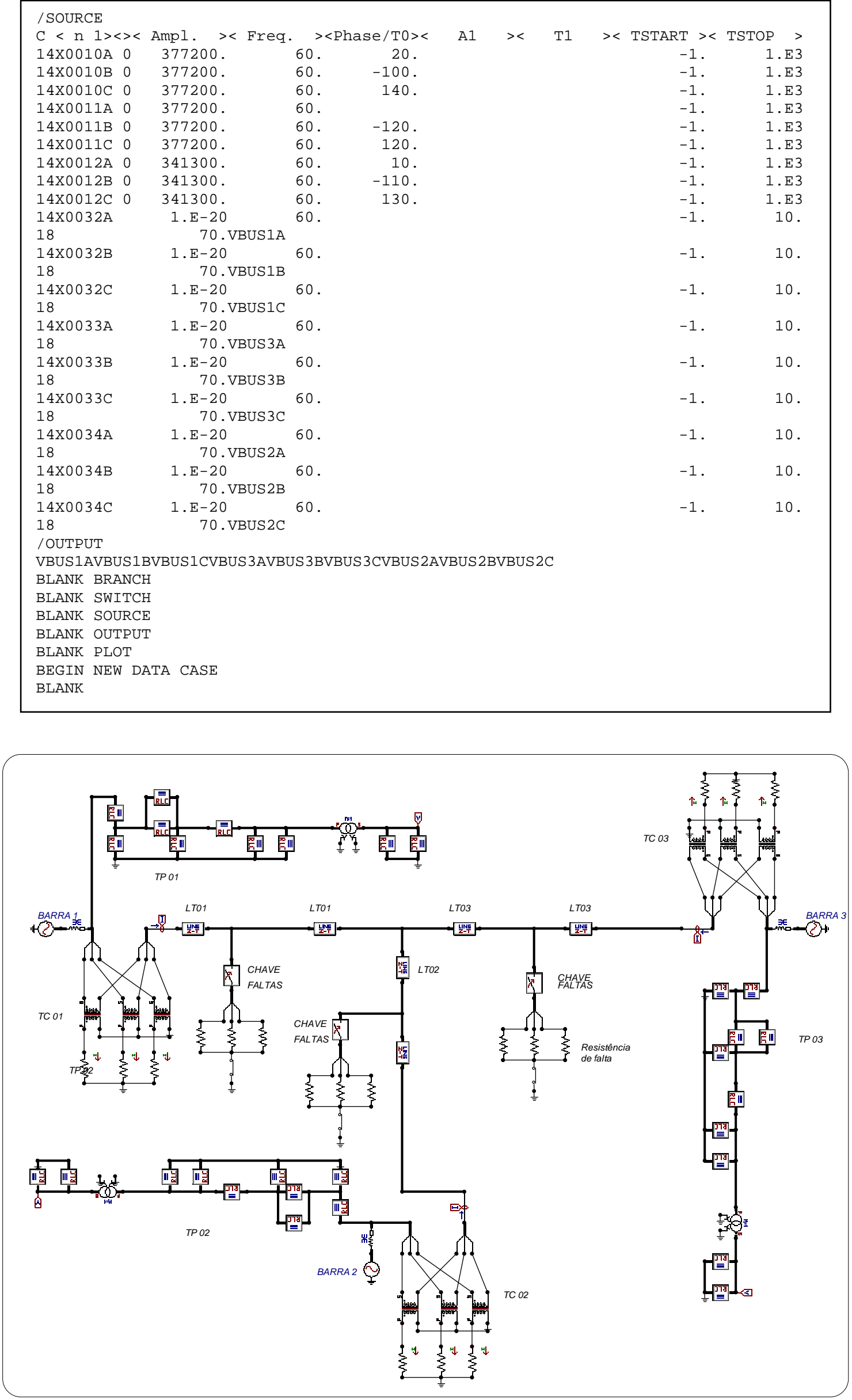